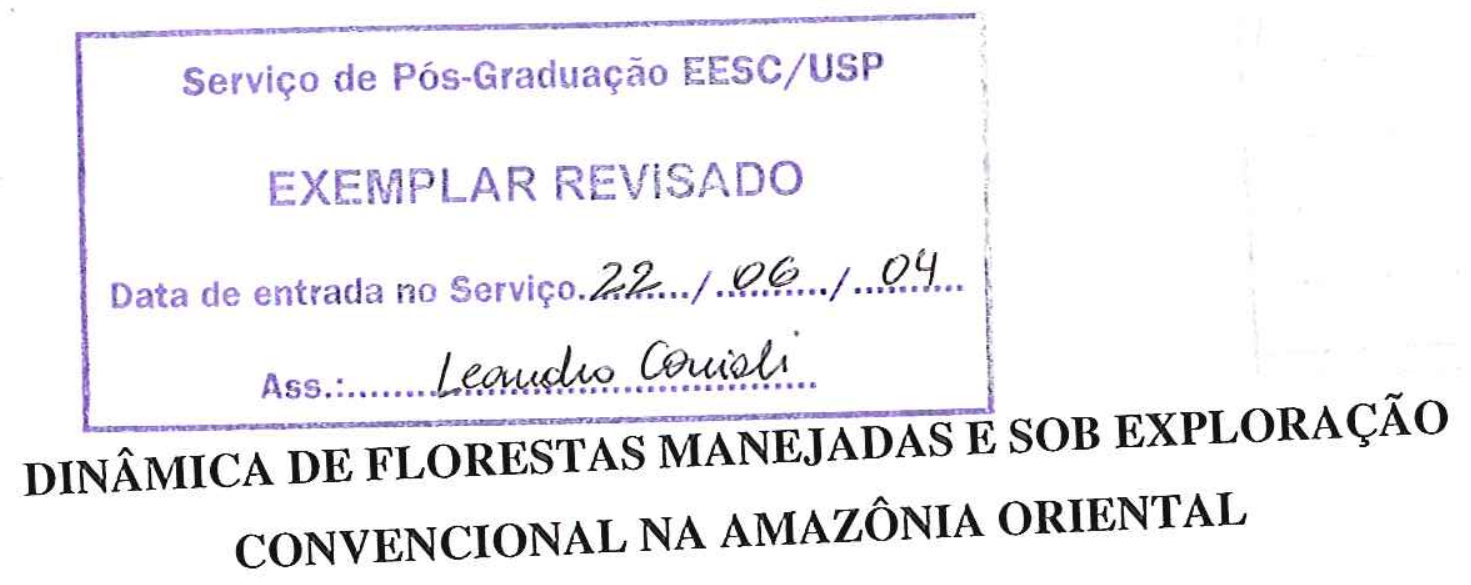

EDSON JOSÉ VIDAL DA SILVA

Orientador: Prof. Dr. Virgílio Maurício Viana

Tese apresentada à Escola de Engenharia de São Carlos, da Universidade de São Paulo, como parte dos requisitos para a obtenção do Título de Doutor em Ciências da Engenharia Ambiental.
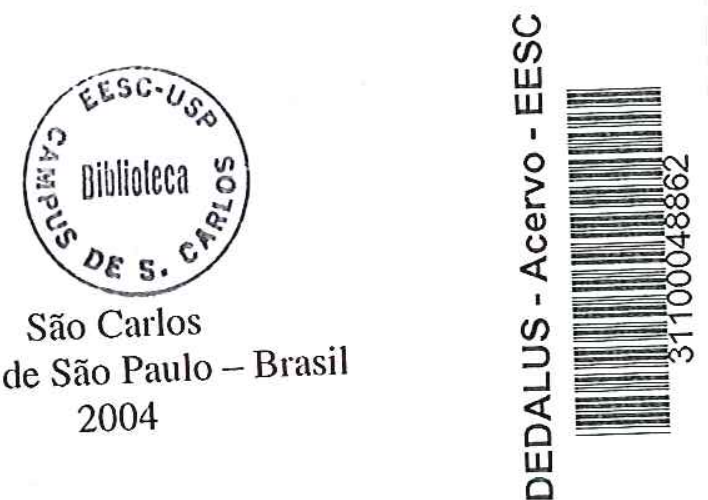
Class.

Cût.

It

5490

Temho

Sysme 1384104

Ficha catalográfica preparada pela Seção de Tratamento da Informação do Serviço de Biblioteca - EESC/USP

Silva, Edson José Vidal da

Dinâmica de florestas manejadas e sob exploração convencional na Amazônia oriental / Edson José Vidal da Silva. -- São Carlos, 2004.

Tese (Doutorado) -- Escola de Engenharia de São Carlos-Universidade de São Paulo, 2004.

Área: Ciências da Engenharia Ambiental.

Orientador: Prof. Dr. Virgílio Maurício Viana.

1. Floresta tropical. 2. Manejo Florestal.

3. Exploração de impacto reduzido. 4. Exploração convencional. 5. Crescimento. 6. Regeneração.

7. Diversidade. 8. Tratamentos silviculturais.

I. Título. 


\section{FOLHA DE JULGAMENTO}

Candidato: Engenheiro EDSON JOSÉ VIDAL DA SILVA

Tese defendida e julgada em 29-03-2004 perante a Comissão Julgadora:
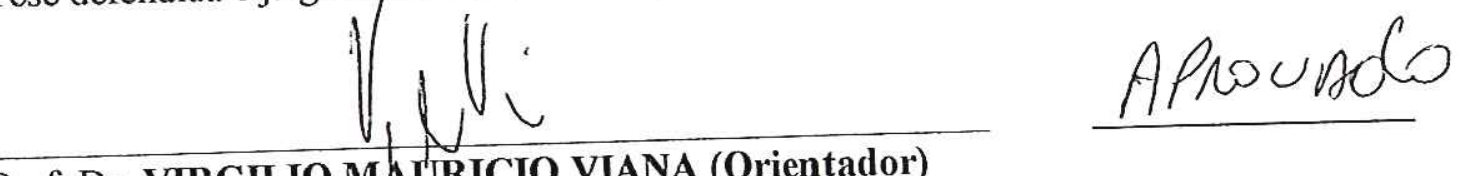

Prof. Dr. VIRGILIO MAURICIO VIANA (Orientador)

(Escola Superior de Agricultura "Luiz de Queiroz"/USP)
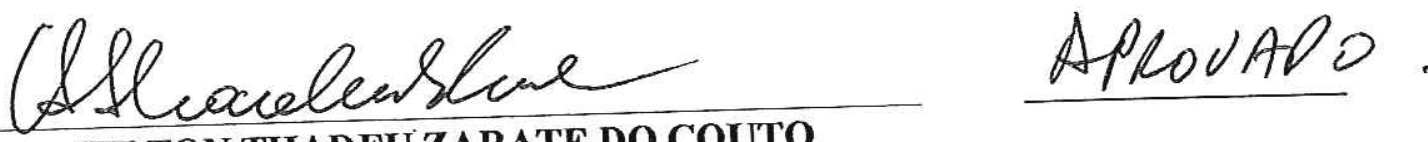

Prof. Dr. HILTON THADEU ZARATE DO COUTO

(Escola Superior de Agricultura "Luiz de Queiroz"/USP)

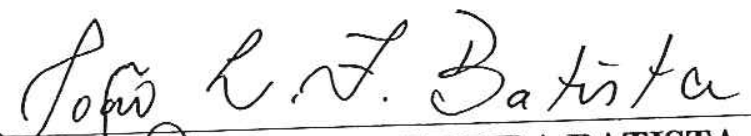

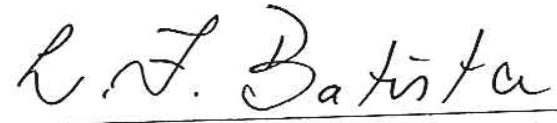

Prof. Dr. JOÃO LUIS FERREIRA BATISTA

(Escola Supeyior de Agricuftura "Luiz de Queiroz"/USP)

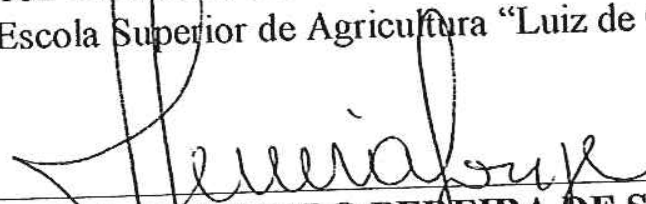

Prof. Tit MARCELO PEREIRA DE SOUZA

(Escola de kngenharia de Săd Carlos/USP)

Dr. JOSE NATALIN MACEDO SILVA

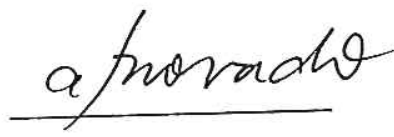

(Empresa.Brasileira de Pesquisa Agropecuária/EMBRAPA)

Prof. Associado EVALDO LUIZ GAgTTA ESPINDOLA

Coordenador do Programa de Pós-Graduação em Ciências da Engenharia Ambiental

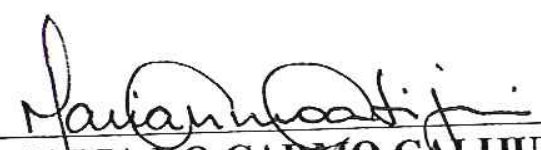

Presidente da Comissão de Pós-Graduação 


\section{DEDICATÓRIA}

Dedico:

A Minha Esposa Gerlane

Ao Meu Filhão Luiz Felipe

Ao Meu Pai Raimundo Ribeiro

A Minha Mãe Eunice Vidal (in memorian)

Aos Meus Irmãos:

Iomar

Rosiene

Edivam

Elson

Cláudia 


\section{AGRADECIMENTOS}

\section{Aos financiadores:}

WWF Brasil, USAID e Overbrook Foundation por disponibilizarem recursos para a pesquisa, e CNPq pela bolsa pessoal.

Aos colegas de trabalho:

James Grogan, Mark Schulze, Jeffrey Gerwing, Paulo Barreto, Adalberto Veríssimo, Paulo Amaral, Marco Lentini, Leonardo Sobral, Marco Sales, Rodney Salomão, Carlos Júnior e Eugênio Arima pelas discussões e sugestões durante o desenvolvimento desta tese.

\section{Aos Professores:}

João L. F. Batista e Luiz Carlos Estraviz Rodrigues pelas discussões valiosas sobre esta tese.

\section{Aos revisores:}

Natalino Silva, Plínio Sist e Carmen Garcia pela revisão dos manuscritos e pelos comentários relevantes ao trabalho. Gláucia Barreto pela revisão gramatical. E ao estatístico Márcio Sales pela imensa ajuda na análise dos dados.

Aos estagiários:

E hoje, grandes profissionais, Frank Pantoja, Rodney Salomão, Leonor Aguiar, Raniery e Catarina Amaral pela ajuda com a digitação dos dados.

Aos assistentes de campo:

Damião Farias, Manuel Farias, Miguel Lopes, Eliana Farias, sem os quais não seria possível coletar tantas informações nas florestas de Paragominas, no Pará. Agradeço sinceramente.

Aos proprietários da área de estudo:

Pérsio e Thales Lima, que ainda disponibilizam a área de sua Fazenda para a coleta de informações tão relevantes para a compreensão do comportamento das florestas exploradas.

Agradecimentos especiais:

A Christopher Uhl por ser o mentor do projeto que deu origem a este trabalho. A Virgílio Maurício Viana pelo apoio e confiança dispensados no processo de orientação.

\section{E finalmente:}

A minha família, que soube compreender a grande ausência, especialmente nestes dois últimos anos de trabalho. 


\section{SUMÁRIO}

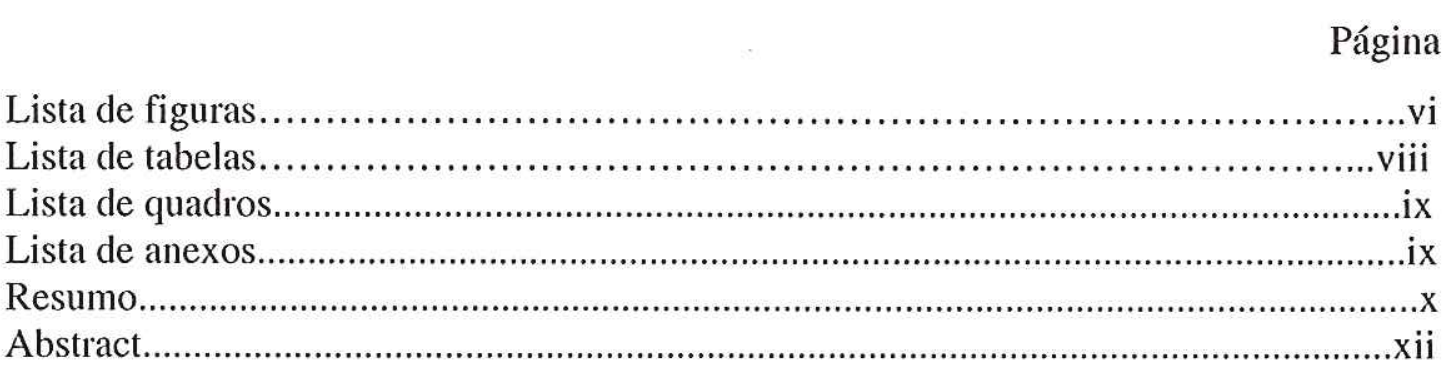

CAPÍTULO I: INTRODUÇÃO GERAL ...............................................................1

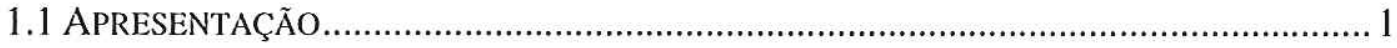

1.2 INTRODUÇÃO

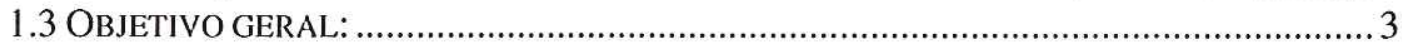

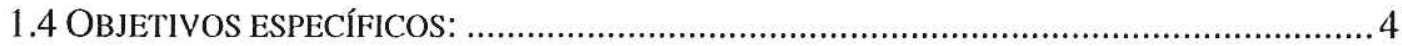

1.5 LOCALIZAÇÃO E CARACTERIZAÇÃO DA ÁREA DE ESTUDO......................................... 4

1.6 HIPÓTESES:

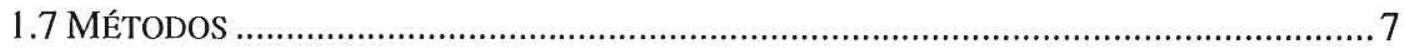

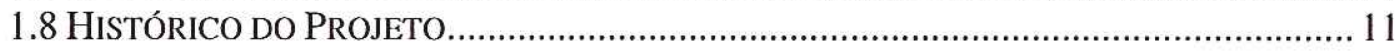

CAPÍTULO II: REVISÃO DA LITERATURA ...................................................15

2.1 Clareiras EM florestas tropicais - DinÂMICA DE REgENERAÇÃo EM

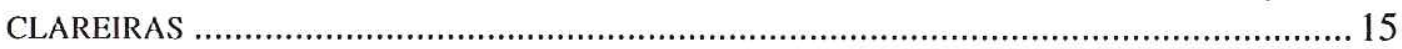

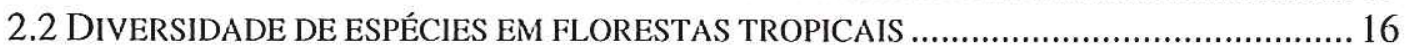

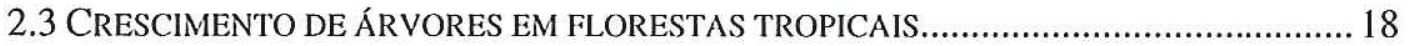

2.4 MANEJO X DESMATAMENTO - NECESSIDADE DE ESTIMULAR O MANEJO FLORESTAL

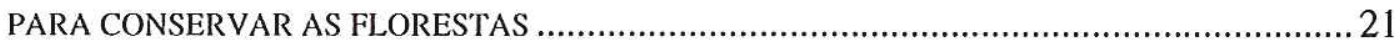

2.5 - BREVE HISTÓRICO DOS SISTEMAS SILVICULTURAIS NO MUNDO E NO BRASIL.........23

CAPÍTULO III: DINÂMICA DE ESPÉCIES ARBÓREAS EM CLAREIRAS FORMADAS PELA EXPLORAÇÃO DE IMPACTO REDUZIDO E EXPLORAÇÃO CONVENCIONAL EM PARAGOMINAS, PARÁ.......................28

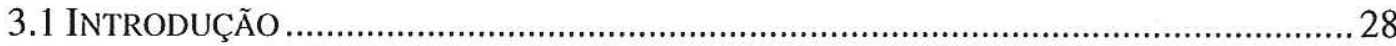

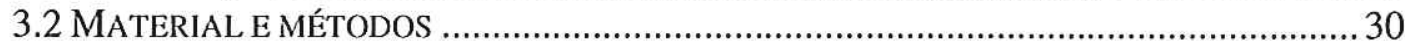

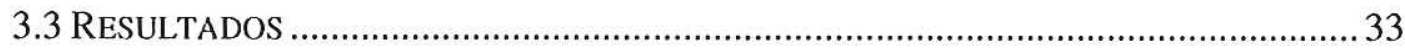

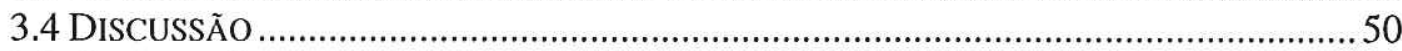

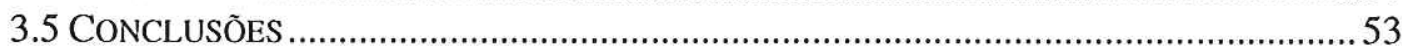

CAPÍTULO IV: TRATAMENTOS SILVICULTURAIS EM REGENERAÇÃO DE ESPÉCIES COMERCIAIS EM CLAREIRAS DE EXPLORAÇÃ̃O MADEIREIRA EM PARAGOMINAS, PARÁ...............................55

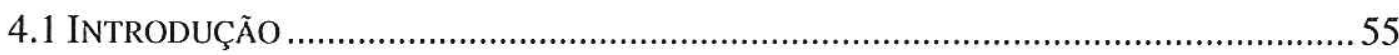




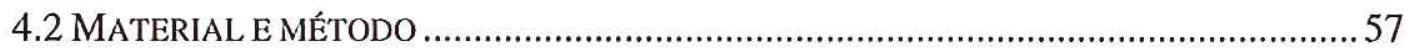

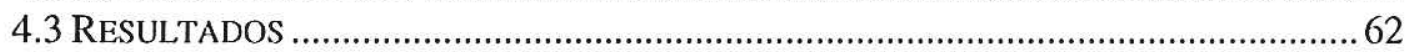

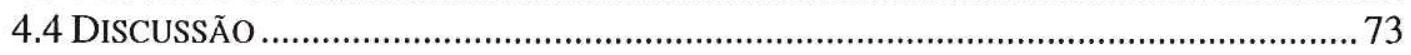

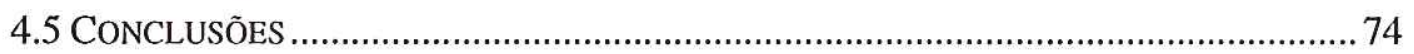

CAPÍTULO V: DIVERSIDADE DE ESPÉCIES EM FLORESTAS EXPLORADAS COM E SEM TÉCNICAS DE EXPLORAÇÃO DE IMPACTO REDUZIDO EM PARAGOMINAS, PARÁ............................................76

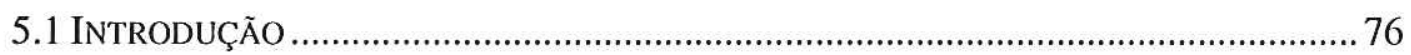

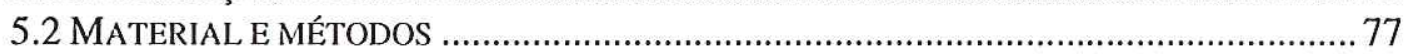

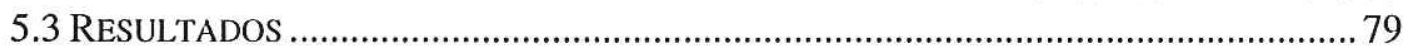

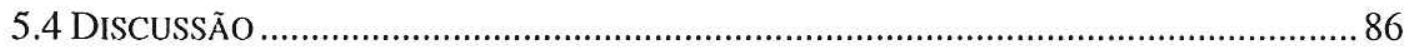

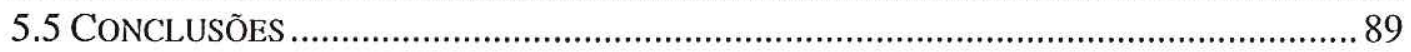

CAPÍTULO VI: DINÂMICA DA FLORESTA TROPICAL EXPLORADA COM E SEM EXPLORAÇÃO DE IMPACTO REDUZIDO SETE ANOS APÓS INTERVENÇÃO SILVICULTURAL EM PARAGOMINAS, PARÁ.........96

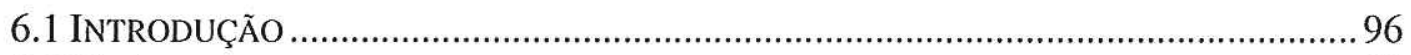

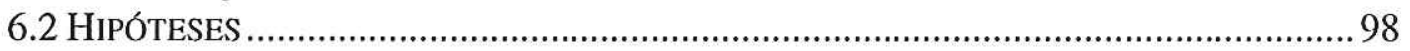

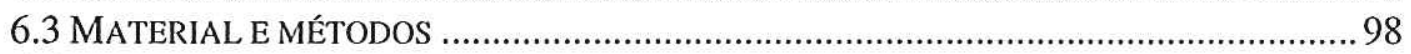

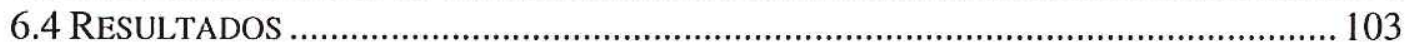

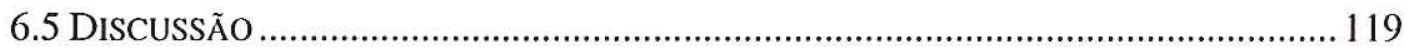

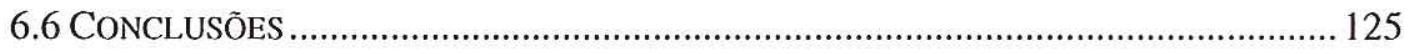

CAPÍTULO VII - CONCLUSÕES E RECOMENDAÇÕES................................... 128

REFERÊNCIAS BIBLIOGRÁFICAS ................................................................ 132 


\section{LISTA DE FIGURAS}

Página

Figura 1: Localização da área de estudo

Figura 2: Mapa com disposição dos tratamentos para acompanhamento do comportamento da floresta após a exploração.

Figura 3: Procedimentos de exploração de impacto reduzido no Projeto Piloto de Manejo Florestal em Paragominas,Pará,Brasil (Veríssimo e Amaral, 1996; Amaral et al, 1998).

Figura 4: Frequiência de tamanho de clareiras $\left(\mathrm{m}^{2}\right)$ clareiras de exploração de impacto reduzido (CEIR), clareiras de exploração convencional (CEC) e clareiras de florestas não submetidas à colheita de madeira - testemunha (CT)

Figura 5: Correlação de Spearman entre a área da clareira e o número de indivíduos em três tipos de clareira ((a) testemunha, (b) exploração de impacto reduzido e (c) exploração convencional). O Corr no canto inferior esquerdo se refere ao coeficiente de correlação de Spearman. ........35

Figura 6: Correlação de Spearman entre a área da clareira e o número de espécies em três tipos de clareira ((a) testemunha, (b) exploração de impacto reduzido e (c) exploração convencional). O corr no canto inferior esquerdo se refere ao coeficiente de correlação de Spearman.

Figura 7: Riqueza de espécies (a), riqueza relativa (b) e índice $\alpha$ de Fisher (c) por tipo de clareira e período de monitoramento (1999-2000).

Figura 8: Densidade média de indivíduos por hectare, por tratamento, no período de monitoramento (1996-2000).

Figura 9: Proporção da população de indivíduos presentes nas clareiras, por grupo ecológico e tipo de clareira, no final do monitoramento.

Figura 10: Relação entre mortalidade de indivíduos e tamanho da clareira. O Corr no canto superior esquerdo significa correlação de Spearman.

Figura 11: Relação entre tamanho da clareira e recrutamento: todas as clareiras. $\mathrm{O}$ Corr no canto superior esquerdo significa correlação de Spearman.

Figura 12: Acúmulo de área basal no período de monitoramento (1999-2000) por tipo de clareira (Clareiras testemunha, clareiras de exploração de impacto reduzido e clareiras de exploração de impacto reduzido) em Paragominas,Pará.

Figura 13: Imagem ykonos de 2000 mostrando a área do experimento e a localização das 60 clareiras de acordo com o tratamento aplicado.

Figura 14: Incremento corrente anual $\left(\mathrm{cm} \mathrm{ano}^{-1}\right)$ de regeneração de valor madeireiro em clareiras, em três tratamentos: clareiras submetidas a um desbaste, clareiras submetidas a dois desbastes e clareiras sem desbaste.

Figura 15: Incremento corrente anual (ICA) por tratamento e grupo ecológico: (a) pioneiras; (b) demandantes de luz; e (c) tolerantes à sombra.

Figura 16: Área basal média por hectare em cada tratamento ao longo do período monitorado. 
Figura 17: Área basal média por grupo ecológico ((a) pioneiras, (b) demandante de luz e (c) tolerantes à sombra) e por tratamento em Paragominas, Pará..

Figura 18: Número de espécies em 5,25 ha em cada tratamento (exploração convencional, exploração de impacto reduzido e testemunha) em Paragominas, Pará.

Figura 19: Número de indivíduos em 5,25 ha em cada tratamento (exploração convencional, exploração com técnicas de impacto reduzido e testemunha) em Paragominas, Pará.

Figura 20: Indices $\alpha$ de Fisher e Shannon em três tratamentos (Testemunha, exploração de impacto reduzido e Exploração Convencional) em três períodos (1993, 1996 e 2000) numa área de 5,25 ha em Paragominas,Pará.

Figura 21: A - Classes de dano de acordo com as condições físicas do fuste e da copa das árvores; B - Classes de incidência de cipó de acordo com a quantidade de cipó encontrada nas copas das árvores; e C - Classes de iluminação de acordo com as características de iluminação das copas das árvores.

Figura 22: Efeito do gradiente de cipós (a) e luz (b), danos físicos (copa (c) e fuste (d)), grupo ecológico (e) e tratamentos (f) sobre o crescimento das árvores individuais. A barra vertical representa o desvio-padrão.

Figura 23: Incremento corrente anual $\left(\mathrm{cm} \mathrm{ano}^{-1}\right)$ de espécies madeireiras $\mathrm{em}$ duas classes de DAP: a) $10 \mathrm{~cm}>$ DAP $<30 \mathrm{~cm} \mathrm{e} \mathrm{b)}>30 \mathrm{~cm}$ de DAP, em 3 tratamentos (testemunha, exploração convencional e exploração de impacto reduzido) em Paragominas,Pará.

Figura 24: Incremento Corrente Anual - ICA para árvores comerciais em 3 tratamentos (testemunha, exploração de impacto reduzido e exploração convencional), em duas classes de DAP: a) $>10<30 \mathrm{~cm} \mathrm{e} \mathrm{b)}>30 \mathrm{~cm}$ ), sete anos após exploração madeireira em Paragominas,Pará.

Figura 25: Incremento Períodico Anual (1993-2000) em (a) diâmetro (cm ano-1), (b) área basal $\left(\mathrm{m}^{2} \mathrm{ha}^{-1} \mathrm{ano}^{-1}\right)$ e (c) volume $\left(\mathrm{m}^{3} \mathrm{ha}^{-1}\right.$ ano $\left.^{-1}\right)$ por faixa diamétrica em cada tratamento, para o período de sete anos.

Figura 26: Taxa anual de mortalidade por tratamento e classe diamétrica. .................. 116

Figura 27: Sobrevivência de árvores com valor madeireiro em sete anos de monitoramento pós-exploração em três tratamentos (testemunha, exploração de impacto reduzido e exploração convencional)

Figura 28: Volume total por hectare em duas classes diamétricas: a) para árvores entre $10 \mathrm{~cm}>$ DAP $<30 \mathrm{~cm} \mathrm{e} \mathrm{b)}>30 \mathrm{~cm}$ de DAP em três tratamentos (testemunha, exploração de impacto reduzido e exploração convencional). 


\section{LISTA DE TABELAS}

Tabela 1: Nome científico, família, densidade (n/ha), \% de sobreviventes, taxa de mortalidade, indivíduos recrutados (n/ha) e incremento diamétrico das árvores (cm/ano) em clareiras de florestas não submetidas à colheita de madeira - testemunha (CT), clareiras de exploração de impacto reduzido (CEIR), e clareiras de exploração convencional (CEC), em Paragominas,Pará.

Tabela 2: Comparação da redução média da densidade em três tipos de clareira (testemunha-T, exploração de impacto reduzido-EIR e exploração convencional-EC) através de teste $t$ pareado.

Tabela 3: Taxa média de mortalidade anual por tratamento e por grupo ecológico. ....46

Tabela 4: Recrutamento por tratamento e por grupo ecológico.

Tabela 5: Comparação do crescimento através de incremento diamétrico médio entre clareiras da exploração de impacto reduzido, exploração convencional e testemunha em Paragominas/Pa.

Tabela 6: Comparação na redução média da densidade $\left(\mathrm{n}^{\circ} / \mathrm{ha}\right)$ em três tratamentos (sem desbaste, um desbaste e dois desbastes) através de teste $t$ pareado....63

Tabela 7: Nome científico, família, densidade (indivíduos/ha), \% de sobreviventes, taxa de mortalidade, indivíduos recrutados (indivíduos/ha) e crescimento $\left(\mathrm{cm} . \mathrm{ano}^{-1}\right.$ ) em cada tratamento considerado (um desbaste, dois desbastes e sem desbaste) em Paragominas,Pará.

Tabela 8: Incremento $\left(\mathrm{cm} \mathrm{ano}^{-1}\right)$ da regeneração de valor madeireiro em clareiras por tratamento e por grupo ecológico.

Tabela 9: Comparação estatística de incremento em área basal por tratamento e grupo ecológico.

Tabela 10: Proporção de mortos por grupo ecológico e por tratamento, uma média anual para os quatro anos de monitoramento (1996-2000) com resultado de estatística paramétrica e não- paramétrica em Paragominas,Pará.

Tabela 11: Balanço da porcentagem de espécies no período de monitoramento (1993-2000).

Tabela 12: Número de espécies, número de indivíduos, índice $\alpha$ de Fisher e índice de Shannon em três tratamentos (Testemunha-T, Exploração de impacto reduzido-EIR e Exploração Convencional-EC) numa área de 5,25 ha em Paragominas, Pará.

Tabela 13: Comparação estatística entre tratamentos através do índice de diversidade de Shannon em Paragominas-Pará.

Tabela 14: Valores das médias e desvio-padrão (em parênteses) e teste $t$ entre classes dentro de cada tratamento de incrementos em DAP, área basal e volume.

Tabela 15: Incrementos volumétricos em cinco faixas diamétricas em cada tratamento e respectivos resultados da Análise de variância. 
Tabela 16: Médias anuais de mortalidade e recrutamento sete anos após a exploração em três tratamentos (testemunha, exploração de impacto reduzido e exploração convencional).......................................................... 115

Tabela 17: Comparação de mortalidade dentro de cada tratamento por período de medição.

LISTA DE QUADROS

Página

Quadro 1: Resumo das atividades executadas em cada tratamento. 11

Quadro 2: Características da exploração no Projeto Piloto de Manejo Florestal em Paragominas, Pará.

\section{LISTA DE ANEXOS}

Página

Anexo 1: Espécies, famílias e densidade por espécie em cada tratamento, em Paragominas,Pará.

Anexo 2: Análise de Variância do incremento periódico anual (IPA) para DAP, área basal e volume em três classes de tamanho. Para o caso de incremento em DAP, como os dados não apresentaram distribuição normal foi realizada a transformação logarítma (Sokal e Rohlf, 1981)..... 127 


\title{
DINÂMICA DE FLORESTAS MANEJADAS E SOB EXPLORAÇÃO CONVENCIONAL NA AMAZÔNIA ORIENTAL
}

\author{
Autor: EDSON JOSÉ VIDAL DA SILVA \\ Orientador: Prof. Dr. VIRGILIO MAURICIO VIANA
}

\section{RESUMO}

Esta tese compara as dinâmicas de uma floresta explorada com exploração de impacto reduzido (EIR) com outra explorada convencionalmente (EC) numa propriedade denominada Fazenda Agrosete $\left(3^{\circ} \mathrm{S}, 50^{\circ} \mathrm{W}\right)$, em Paragominas, no nordeste do estado do Pará. Os estudos foram realizados numa área de 210 ha, dos quais 75 ha foram explorados convencionalmente, 105 ha foram explorados com exploração de impacto reduzido e 30 ha não explorados (testemunha). A área foi explorada em $1993 \mathrm{e}$ monitorada até 2000. A avaliação da dinâmica das espécies madeireiras nesses três tratamentos foi feita em 10 clareiras selecionadas em cada tratamento. A análise dos efeitos dos tratamentos silviculturais sobre a regeneração de valor madeireiro foi feita em 60 clareiras selecionadas aleatoriamente em cada tratamento. A análise da diversidade de espécies arbóreas foi feita numa área de 5,25 ha delimitada em cada tipo de exploração. E, finalmente, para analisar a dinâmica de espécies arbóreas estabeleceram-se 49 parcelas de 0,5 ha em cada tratamento. Os resultados demonstraram que: i) considerando a regeneração abaixo de $10 \mathrm{~cm}$ de DAP não existiram diferenças significativas na dinâmica da regeneração entre as clareiras de exploração de impacto reduzido e as de exploração convencional; ii) os tratamentos silviculturais causaram efeitos positivos sobre o crescimento de espécies de valor comercial presentes nas clareiras crescendo de $75 \%$ a $115 \%$ a mais do que as não tratadas; iii) considerando as espécies arbóreas acima de $10 \mathrm{~cm}$ de DAP, a diversidade de espécies reduziu com a colheita e tem apresentado uma boa recuperação, inclusive na área explorada de maneira convencional; iv) a mortalidade de árvores foi menor e o recrutamento foi maior no tratamento de exploração de impacto reduzido em comparação com os tratamentos de 
exploração convencional e com a testemunha; v) a taxa anual de mortalidade na área de exploração convencional foi $70 \%$ superior a da área com exploração de impacto reduzido; e vi) o crescimento das árvores no tratamento exploração de impacto reduzido foi 5,5 vezes maior do que o crescimento no tratamento de exploração convencional. Esses resultados demonstram que a exploração de impacto reduzido reduz bastante os efeitos negativos sobre a diversidade de espécies, além de promover o crescimento das árvores. Dessa maneira, as florestas exploradas com técnicas de exploração de impacto reduzido se recuperarão num período relativamente menor do que as florestas exploradas convencionalmente, ao mesmo tempo em que estarão mantendo a conservação da biodiversidade florestal. Nossa conclusão é que a exploração de impacto reduzido pode ser uma alternativa ao modelo de exploração atualmente praticado na Amazônia.

Palavras chaves: Floresta tropical, manejo florestal, exploração de impacto reduzido, exploração convencional, crescimento, regeneração, diversidade, tratamentos silviculturais. 


\title{
DYNAMICS OF MANAGED AND CONVENTIONAL LOGGING FORESTS IN THE EASTERN AMAZON
}

\author{
Author: EDSON JOSÉ VIDAL DA SILVA \\ Adviser: Prof. Dr. VIRGILIO MAURICIO VIANA
}

\begin{abstract}
\end{abstract}
This thesis compares the dynamics of forest harvested using reducing impact logging (RIL) and conventional logging forest (CL) at the property known as Fazenda Agrosete $\left(3^{\circ} \mathrm{S}, 50^{\circ} \mathrm{W}\right)$, in Paragominas, in the north-east of the State of Pará. The studies were carried out in an area of 210 ha, of which 75 ha were conventional logging, 105 ha were logged using reducing impact logging (RIL) and 30 ha was as an unlogged control. The area was harvested in 1993 and monitored until 2000. The evaluation of the dynamics of timber species in these three treatments was carried out in 10 gaps selected in each treatment. The analysis of the effect of silvicultural treatments on regeneration of timber value was done in 60 randomly selected gaps were for each species. The analysis of tree species diversity was done in an area of 5.25 ha delimited for each type of logging. And, finally, to analyse the dynamics of tree species 49 lots, each measuring 0.5 ha were established in each treatment. The results demonstrate that: i) considering regeneration below $10 \mathrm{~cm}$ DBH there were no significant differences in regeneration dynamics between the gaps in the reducing impact logging (RIL) area and those in the conventional logging area; ii) the silvicultural treatments caused positive effects on growth of commercially valuable species present in the gaps; grew $75 \%$ a $115 \%$ more than non-managed regeneration; iii) considering tree species above $10 \mathrm{~cm} \mathrm{DBH}$, species diversity was reduced with harvest and has shown good recovery, including in the conventional harvested area; iv) tree mortality was lower and recruitment was higher in the reducing impact logging (RIL) treatment in comparison with conventional logging and witness treatments; v) the annual mortality rate in the conventional logging area was $70 \%$ higher than that of the area under reducing impact logging (RIL); and vi) growth of 
trees in the management treatment was 5.5 times higher than growth under the conventional logging treatment. These results demonstrate that reducing impact logging (RIL) considerably reduces negative effects on species diversity, besides promoting tree growth. In this way, forests logged using reducing impact logging (RIL) techniques will recover in a relatively shorter period than forests that are conventional logging, while at the same time maintaining forest biodiversity. Our conclusion is that reducing impact logging (RIL) can be an alternative to the logging model currently practised in Amazon.

Keywords: Tropical forest, forest management, reducing impact logging, conventional logging, growth, regeneration, diversity, silvicultural treatments. 


\section{Capítulo I: Introdução Geral}

\subsection{Apresentação}

Esta tese foi realizada para fornecer informações sobre a dinâmica da floresta explorada com exploração de impacto reduzido e exploração convencional a fim de: i) melhorar a compreensão sobre o comportamento da floresta após a exploração no que se refere ao crescimento dos indivíduos e à diversidade de espécies; ii) conhecer a composição da floresta após a exploração e as técnicas silviculturais que podem aumentar o desenvolvimento da regeneração; e iii) determinar o ciclo de corte, o volume a ser explorado e as técnicas silviculturais para aumentar o desenvolvimento da regeneração. Assim, será possível fazer previsões de colheitas futuras na Amazônia.

Esta pesquisa foi conduzida na fazenda Agrosete no município de Paragominas, nordeste do estado do Pará, distante cerca de $300 \mathrm{~km}$ de Belém. A pesquisa foi iniciada em 1993 e faz parte de um projeto denominado Projeto Piloto de Manejo Florestal para Produção de Madeira, que o Imazon - Instituto do Homem e Meio Ambiente da Amazônia, com o apoio do Fundo Mundial para Natureza (WWF) e da Agência Norteamericana para o Desenvolvimento Internacional (USAID), conduz desde 1991. Nesta pesquisa comparam-se os custos e benefícios do emprego de técnicas de exploração de impacto reduzido com exploração convencional. Essas parcelas foram situadas em 210 hectares de floresta nativa, em uma área cedida pela Indústria Madeireira Santo Antonio. Em 1993, após a exploração, iniciou-se o monitoramento anual da floresta, que após o terceiro ano passou a ser bianual.

Esta tese está estruturada em sete capítulos: 
$1^{\circ}$ capítulo: introdução geral do tema, apresentação do método, dos objetivos e do histórico da área do projeto.

$2^{\circ}$ capítulo: discussão sobre o marco conceitual dos temas abordados na tese com base na literatura.

$3^{\circ}$ capítulo: análise da regeneração de espécies em clareiras formadas pela exploração de madeira convencional e com técnicas de exploração de impacto reduzido na Amazônia oriental.

$4^{\text {o }}$ capítulo: avaliação da regeneração natural e efeitos de tratamentos silviculturais em espécies comerciais em clareiras formadas pela exploração madeireira convencional na Amazônia oriental.

$5^{\circ}$ capítulo: avaliação da diversidade de espécies em florestas exploradas com exploração de impacto reduzido, exploração convencional e em floresta natural na Amazônia oriental.

$6^{\circ}$ capítulo: avaliação da dinâmica de floresta submetidas à exploração de impacto reduzido e exploração convencional na Amazônia oriental

$7^{\circ}$ capítulo: síntese da tese com conclusões e recomendações pertinentes.

\subsection{Introdução}

A exploração madeireira, quando realizada sem planejamento, pode transformar profundamente as florestas primárias, comprometendo sua regeneração e produtividade (Uhl e Vieira, 1989, Martini et al., 1994; Cochrane e Schulze, 1999). Dessa maneira, conhecer os impactos das intervenções de exploração sobre a regeneração e a estrutura da floresta é um requisito básico para desenvolver técnicas de manejo sustentável para essas florestas (Baur, 1964; Nicholson, 1979; Uhl e Vieira, 1989; Batista, 1984; Martini et al., 1994; Johns et al., 1996; Berthault e Sist, 1997; Vidal et al., 1998; Silva, 1998; Jennings et al., 2000; Rice et al., 2001; Sist e Nguyen-Thé, 2001). Além disso, é necessário entender a capacidade de regeneração e de desenvolvimento da floresta nas condições de floresta natural e explorada para fins madeireiros, para definir melhor o ciclo de corte, o volume a ser explorado e as técnicas de regeneração a serem utilizadas (Vidal et al., 2002). 
Na Amazônia brasileira, com exceção das pesquisas que enfocam a viabilidade econômica e a redução dos impactos ecológicos ao ecossistema das atividades antes e durante a exploração (Uhl et al., 1991; Uhl et al., 1997; Veríssimo et al., 1992; Barreto et al., 1998; Johns et al., 1996; Vidal et al., 1998; Holmes et al., 2002; Silva, 1998; Boltz et al., 2001), há poucas pesquisas de campo sobre desenvolvimento da floresta após a exploração madeireira para orientar tecnicamente os debates sobre manejo florestal (Silva, 1989; Lopes, 1993; Silva et al., 1995; Macedo, 1996; Higuchi et al., 1997; Vidal et al., 1998; Silva, 1998; Alder \& Silva, 2000; Vidal et al., 2002). Tais informações são importantes porque os métodos de exploração convencionais utilizados na Amazônia afetam drasticamente a produção futura de madeira, reduzindo as taxas de crescimento da floresta remanescente (Silva, 1998). Segundo Hutchinson (1986) e Panayotou \& Ashton (1992), o emprego de métodos de manejo florestal não-planejados contribuem para que os ciclos de corte sejam mais longos.

Além de afetar a produção futura de madeira, a exploração convencional afeta a composição florística, a diversidade e a estrutura da floresta (Silva, 1998, Vidal et al., 1998). Dessa maneira, o acompanhamento do desenvolvimento da floresta explorada é fundamental tanto para definir melhor o ciclo de corte como para entender a dinâmica da floresta manejada e definir os sistemas silviculturais mais adequados (Higuchi et al., 1997). Essas são informações básicas para determinar como seria a estrutura da floresta explorada no futuro.

\subsection{Objetivo geral:}

Avaliar a regeneração e o desenvolvimento da floresta submetida à exploração de impacto reduzido e exploração convencional ao longo de sete anos após a colheita. 


\subsection{Objetivos específicos:}

- analisar a regeneração natural de espécies em clareiras formadas pela exploração madeireira de impacto reduzido e exploração convencional e em clareiras naturais.

- avaliar a regeneração natural e os efeitos dos tratamentos silviculturais em espécies comerciais em clareiras formadas pela exploração madeireira convencional.

- avaliar a diversidade de espécies em florestas exploradas com técnicas de impacto reduzido, e convencionalmente e em floresta natural na Amazônia oriental.

- avaliar a dinâmica das espécies (crescimento, mortalidade e recrutamento) em florestas submetidas à exploração de impacto reduzido e exploração convencional na Amazônia oriental.

\subsection{Localização e caracterização da área de estudo}

A área de estudo localiza-se no município de Paragominas, no nordeste do estado do Pará, entre as coordenadas $2^{\circ} 25^{\prime}$ e $4^{\circ} 09^{\prime} \mathrm{S}$ e $46^{\circ} 25^{\prime}$ e $48^{\circ} 54^{\prime} \mathrm{W}$. O município é banhado pelas bacias do rio Capim e do rio Gurupi. O estudo foi realizado na Fazenda Agrosete, distante $30 \mathrm{~km}$ do centro de Paragominas (Figura 1). 
Figura 1: Localização da área de estudo.
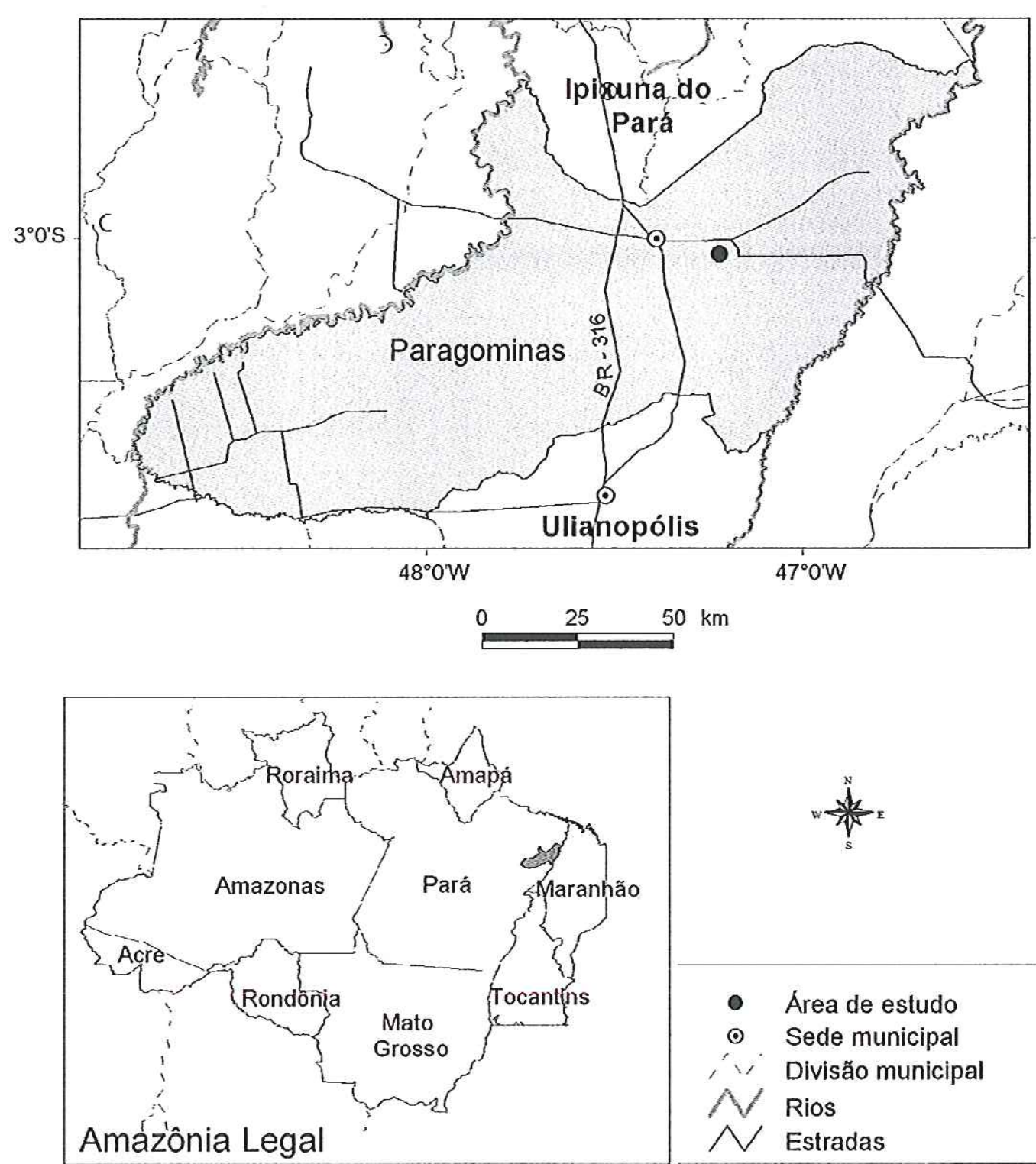

- Área de estudo

$\odot \quad$ Sede municipal

‘' Divisão municipal

$\triangle$ Rios

$\wedge$ Estradas 
Nessa região, o relevo varia de plano a suavemente ondulado. Os solos são predominantemente do grupo dos Latossolos Amarelos; pobres e bem profundos, e sua textura varia de média a muito argilosa (RadamBrasil, 1974).

O clima da região é quente e úmido, caracterizado por um período com muita chuva, de janeiro a maio (1700 mm/ano) (Nepstad et al., 1990), e um período com pouca chuva, de junho a novembro, quando ocorre a maior parte da exploração madeireira (Johns et al., 1996). A sazonalidade marcante de Paragominas é comum em outras regiões da Amazônia desde o noroeste até o sudoeste (Cattânio, 1996). Esta região é considerada o arco do desmatamento da região (Nepstad et al., 1994).

As florestas da região são perenifólias, com a altura do dossel variando entre 25 $\mathrm{m}$ e $40 \mathrm{~m}$ e uma biomassa acima do solo de aproximadamente 300 t/ha (Uhl et al., 1988). Nepstad (1989), em um levantamento realizado $7 \mathrm{~km}$ a noroeste de Paragominas ( $\left.2^{\circ} 59^{\prime} \mathrm{S} 47^{\circ} 31^{\prime} \mathrm{W}\right)$, encontrou 171 espécies de árvores e 40 famílias de árvores com DAP acima de $20 \mathrm{~cm}$. As espécies mais comuns eram Tetragastris altíssima (Aubl.) Swarts e Lecythis idatimon, Aubl. Silva (1998) e Vidal et al., (1998), em um levantamento realizado a $20 \mathrm{~km}$ do centro de Paragominas, em 24,5 ha na mesma área do projeto desta tese, encontraram 154 espécies, 85 gêneros e 37 famílias com DAP mínimo de $10 \mathrm{~cm}$. As espécies mais comuns encontradas foram Pouteria lasiocarpa Gomes, (33 indivíduos/ha), Lecythis paraensis (37 indivíduos/ha) e Ingá cf cilíndrica Mart. (35 indivíduos/ha).

\subsection{Hipóteses:}

Neste trabalho foram testadas as seguintes hipóteses:

Hipótese 1: a regeneração de espécies de valor madeireiro em clareiras formadas pela exploração de impacto reduzido é mais abundante do que nas clareiras formadas pela exploração convencional. Isto porque, nas primeiras, o recrutamento é maior por causa da existência de maior quantidade de árvores matrizes, e a mortalidade é menor pelo fato de as mudas pré-existentes terem sofrido menos danos. 
Hipótese 2: A regeneração de espécies de valor madeireiro submetidas a tratamentos silviculturais de desbaste cresce mais do que a regeneração não submetida a desbaste. Isto porque a competição principalmente por luz é reduzida.

Hipótese 3: A diversidade de espécies nas clareiras de florestas exploradas é maior do que nas clareiras testemunha da floresta nativa. Isto porque, nas primeiras, a densidade de indivíduos por hectare e o recrutamento são maiores e a predominância de espécies pioneiras é menor.

Hipótese 4: A diversidade de espécies (Índice de Shannon e $\alpha$ Fisher) nas áreas com exploração de impacto reduzido é menos afetada do que nas áreas exploradas sem o uso dessas técnicas. Isto porque na primeira, o planejamento da exploração diminui os impactos sobre ela.

Hipótese 5: O crescimento (volumétrico, em área basal e em DAP) das árvores na floresta com exploração de impacto reduzido é maior do que na floresta explorada de maneira convencional. Isto porque, na primeira, há maior proporção de árvores sãs (isto é, sem danos na copa e no tronco, etc.), menor presença de cipós nas árvores e menor mortalidade de árvores.

Hipótese 6: O crescimento das árvores nas florestas com exploração de impacto reduzido e exploração convencional é maior do que na floresta nativa, pois a incidência de luz sobre as copas das árvores é maior por causa da abertura no dossel causada pela exploração.

\subsection{Métodos}

Aqui se descreve o método utilizado em todos os capítulos. Os métodos mais especificamente relacionados com o tema de cada capítulo são descritos posteriormente. 


\subsubsection{Descrição dos tratamentos}

\subsubsection{Exploração madeireira convencional}

Este é o sistema utilizado atualmente na maior parte da Amazônia brasileira. Neste modelo de exploração, uma equipe de motosserristas entra na floresta em busca das árvores a serem derrubadas sem o conhecimento prévio de sua localização. Após a derrubada, a equipe de tratoristas constrói as estradas para o transporte das toras e, próximo a um aglomerado de árvores derrubadas, abre os pátios para estocá-las. Desses pátios, as toras são posteriormente transportadas para as serrarias. Utilizando tratores de esteira sem guincho, a equipe de operadores sai à procura das árvores derrubadas para arrastá-las até os pátios. Essas operações causam grandes desperdícios e danos florestais, por causa principalmente da não realização do mapeamento das árvores e do planejamento do arraste (Vidal et al., 1998; Vidal et al., 2002) (Figura 2).

\subsubsection{Exploração de impacto reduzido}

A exploração de impacto reduzido segue os procedimentos de manejo desenvolvidos pelo Instituto do Homem e Meio Ambiente da Amazônia (IMAZON) na região da Amazônia oriental. Esses procedimentos são atualmente replicados com adequações pela Fundação Floresta Tropical (FFT). Eles compreendem etapas executadas antes, durante e após a exploração (Amaral et al., 1998).

- Atividades anteriores à exploração de impacto reduzido - Dois anos antes da colheita, a equipe de planejamento entra na floresta e delimita o talhão. Em seguida, abrem-se trilhas para realizar o censo dos indivíduos com DAP superior a $25 \mathrm{~cm}$. Um ano e meio antes da colheita, a equipe responsável corta os cipós com diâmetro superior a $2 \mathrm{~cm}$ presentes nas árvores a serem derrubadas. Três meses antes da colheita, a equipe de planejamento de infra-estrutura da exploração faz o planejamento: com base no mapeamento feito anteriormente, ela delimita as estradas principais e os pátios de estocagem de toras, e seleciona as árvores a serem derrubadas.

- Atividades durante a exploração de impacto reduzido - Poucos dias antes da colheita, uma equipe planeja, no campo, a extração. Ela marca trilhas com balizas e fitas 
plásticas coloridas e faz um mapa para orientar a equipe de derrubada e de arraste durante a colheita. Além disso, essa equipe demarca os locais onde serão abertas as estradas principais para o tráfego dos caminhões, os pátios de estocagem e os ramais de arraste. A derrubada direcional das árvores, que é uma técnica de exploração de impacto reduzido, é então realizada.

- Atividades após a colheita - Após a colheita realizaram-se medições anuais do crescimento das árvores, que, após o terceiro ano, passaram a ser bianuais (Figura 2).

\subsubsection{3 Área não submetida à colheita de madeira (testemunha ou controle)}

Neste tratamento não se realizou exploração madeireira. Entretanto, mapearamse as árvores e realizaram-se inventários contínuos (Figura 2). 
Figura 2: Mapa com disposição dos tratamentos para acompanhamento do comportamento da floresta após a exploração.
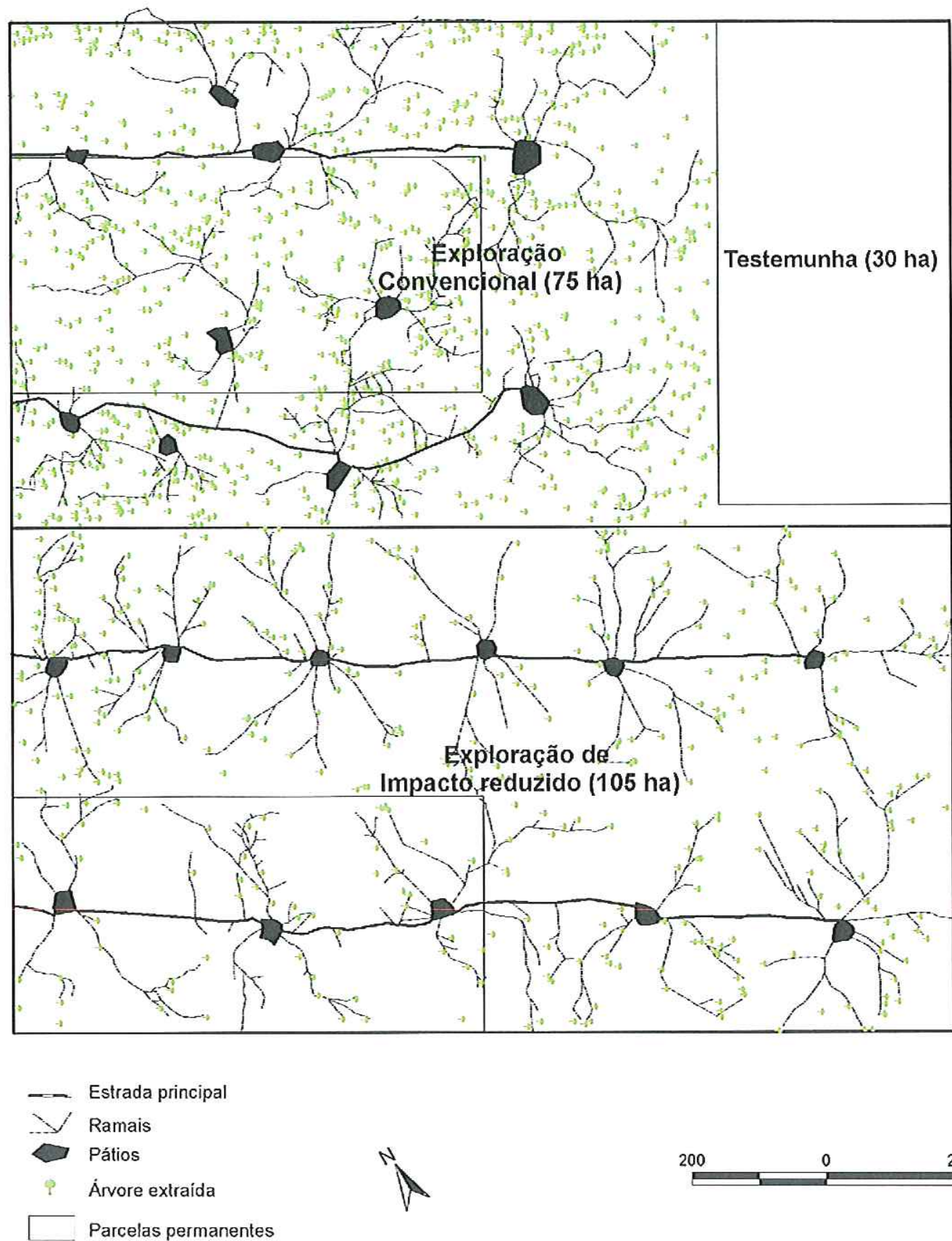

200 
Quadro 1: Resumo das atividades executadas em cada tratamento.

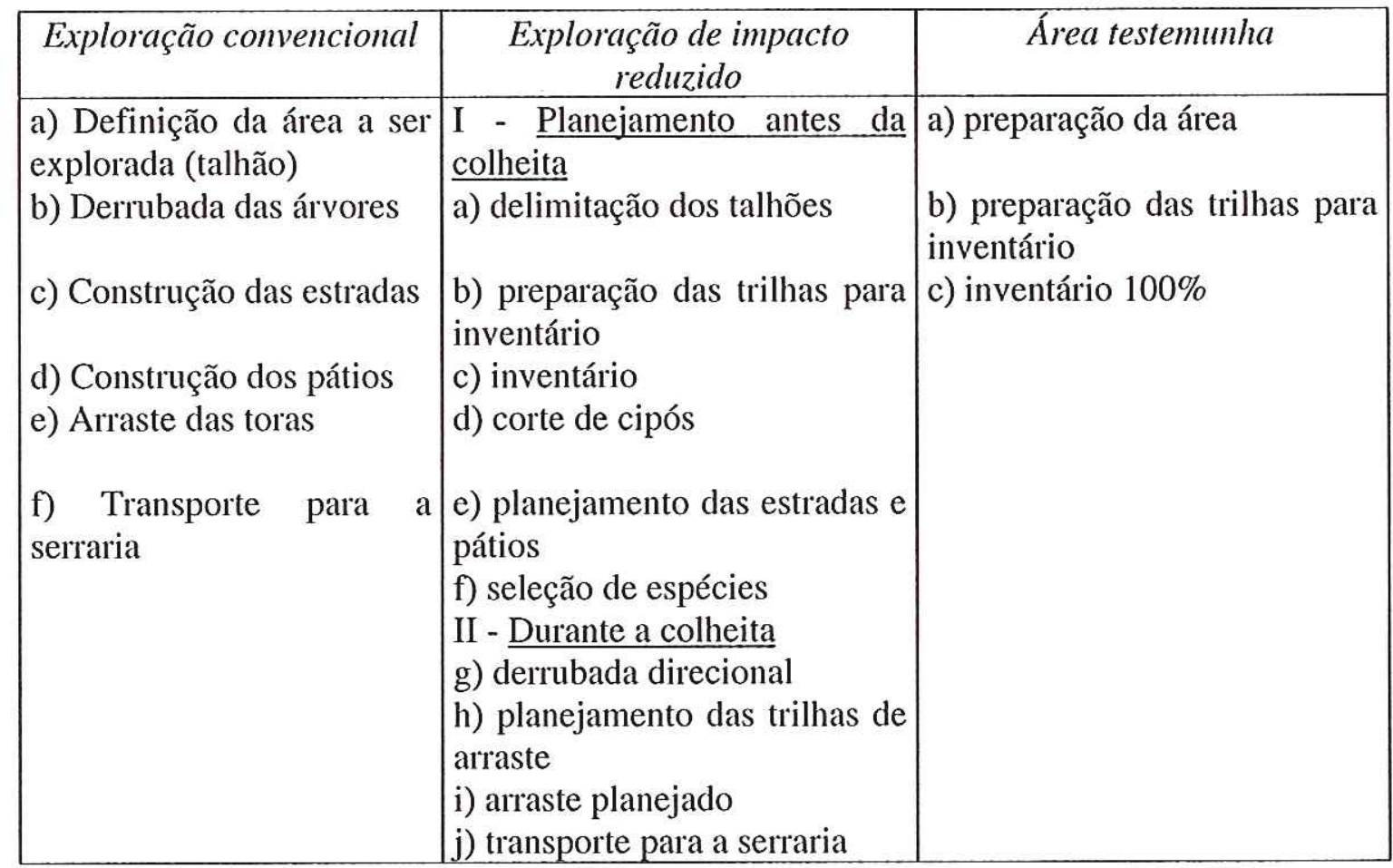

\subsection{Histórico do Projeto}

Em 1991, o Instituto do Homem e Meio Ambiente da Amazônia (Imazon) iniciou um projeto de pesquisa com manejo florestal em Paragominas, na Amazônia oriental. Este projeto foi inicialmente realizado para comparar custos e benefícios do manejo florestal entre dois modelos de exploração: exploração convencional (predatória); o modelo predominante na região, e exploração de impacto reduzido; um modelo com intervenções planejadas. Neste estudo, utilizaram-se duas áreas vizinhas, que foram exploradas em 1993. A seguir, enumeram-se as características da exploração: 
Quadro 2: Características da exploração no Projeto Piloto de Manejo Florestal em Paragominas, Pará.

\begin{tabular}{lcc}
\hline \multicolumn{1}{c}{ Características da exploração } & $\begin{array}{c}\text { Exploração de } \\
\text { impacto } \\
\text { reduzido }\end{array}$ & $\begin{array}{c}\text { Exploração } \\
\text { Convencional }\end{array}$ \\
\hline Volume médio extraído $\left(\mathrm{m}^{3} \mathrm{ha}^{-1}\right)$ & 38,6 & 29,7 \\
Número de árvores extraídas/ha & 4,5 & 5,6 \\
Área basal das árvores extraídas $\left(\mathrm{m}^{2} \mathrm{ha}^{-1}\right)$ & 2,2 & 2,3 \\
Volume médio por árvore extraída & 8,16 & 5,3 \\
DAP médio das árvores extraídas & 79,0 & 71,8 \\
\hline
\end{tabular}

Fonte: Barreto et al., 1998.

No experimento, a intensidade volumétrica de colheita por hectare foi maior na colheita com exploração de impacto reduzido em relação à exploração convencional. Coincidentemente, as árvores eram maiores e o volume por árvore extraída também foi maior na exploração de impacto reduzido. A colheita de árvores maiores implica em clareiras maiores.

Os resultados da análise comparativa de custos e benefícios entre as áreas exploradas com técnicas de impacto reduzido e convencionalmente indicam que há ganhos na redução dos impactos ecológicos. Estes incluem: (i) redução da abertura do dossel em $47,4 \%$; (ii) redução de $25,5 \%$ por árvore extraída dos danos às espécies de valor comercial com DAP superior a $10 \mathrm{~cm}$; (iii) redução de $24,2 \%$ da área de solo afetada ( $\mathrm{m}^{2} /$ árvore extraída); (iv) redução dos desperdícios de madeira em até 26,5\%; (v) redução do tamanho das clareiras à metade; (vi) densidade de estradas (metro/m $\mathrm{m}^{3}$ ) $33 \%$ menor e; (vii) densidade de abertura de pátios de estocagem de toras $\left(\mathrm{m}^{2} / \mathrm{m}^{3}\right) 70 \%$ menor (Barreto et al., 1998; Amaral et al., 1998).

$\mathrm{Na}$ parte operacional, os principais ganhos incluem: (i) produtividade $\left(\mathrm{m}^{3} /\right.$ hora homem) 14,7\% superior; (ii) tempo gasto para abrir estradas (minuto/máquina $/ \mathrm{m}^{3}$ ) $16 \%$ menor; (iii) tempo gasto para abertura de pátios de estocagem de toras (minuto/máquina $/ \mathrm{m}^{3}$ ) $66 \%$ menor; e (iv) produtividade do arraste de toras $\left(\mathrm{m}^{3} / \mathrm{hora}\right.$ ) 
$48,5 \%$ maior. O aumento da produtividade permitiu recuperar $13 \%$ dos custos totais da exploração de impacto reduzido quando se usou o trator florestal skidder e $8 \%$ quando se usou o trator de esteira (Barreto et al., 1998).

Outro benefício gerado no médio prazo pela exploração de impacto reduzido é a redução dos riscos de acidentes. Neste estudo, o número de situações de risco nessas operações foi 18 vezes menor, o que reflete o bem-estar dos operários, o qual pode reduzir os custos com assistência médica e social (Barreto et al., 1998).

Em síntese, a análise de custos e benefícios entre as áreas exploradas com e sem técnicas de exploração de impacto reduzido indicou que o planejamento contribuiu para que a exploração de impacto reduzido fosse tecnicamente fácil e economicamente viável. Esse planejamento inclui: (i) planejamento da exploração com execução de inventário $100 \%$, corte de cipós, planejamento de corte, de arraste e de estradas; (ii) troca de informações entre as equipes de derrubada e as de arraste de toras; (iii) utilização de equipamento adequado (skidder), e (iv) utilização de mão-de-obra treinada (Figura 2).

Finalizando, esta análise comparativa de custos e benefícios demonstrou que os benefícios da exploração de impacto reduzido são maiores do que os da exploração convencional. Prosseguindo o estudo nessa área, nosso objetivo agora é analisar a dinâmica da floresta ao longo de sete anos após exploração madeireira com exploração de impacto reduzido e exploração convencional. 
Figura 3: Procedimentos de exploração de impacto reduzido no Projeto Piloto de Manejo Florestal em Paragominas,Pará,Brasil (Veríssimo e Amaral, 1996; Amaral et al, 1998).

\section{PROCEDIMENTOS ANTES DA COLHEITA}

Inventário e mapeamento

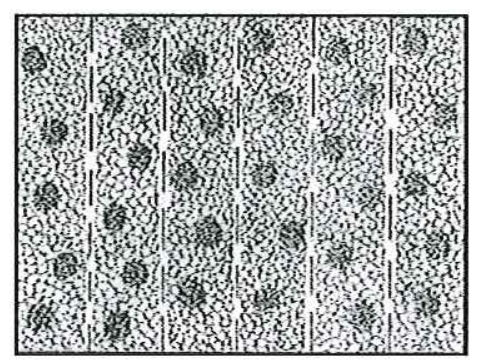

Menor desperdício durante a colheita
Corte de cipós

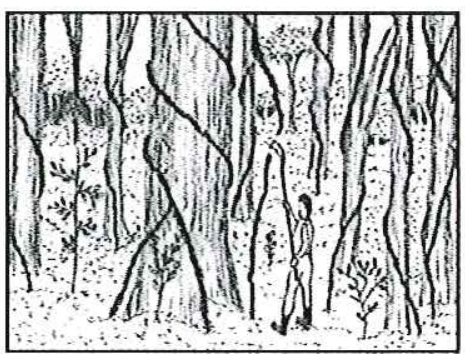

Menores danos na copa e menores riscos de acidente
Planejamento das estradas e ramais de arraste

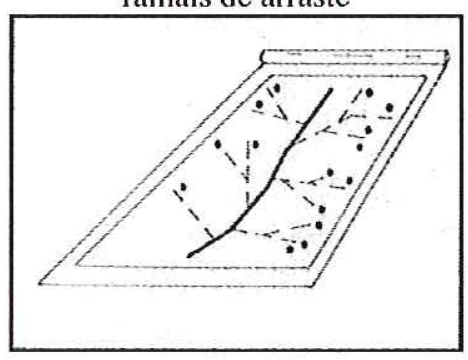

Menores danos às árvores

PROCEDIMENTOS DURANTE A COLHEITA

Exploração de impacto reduzido

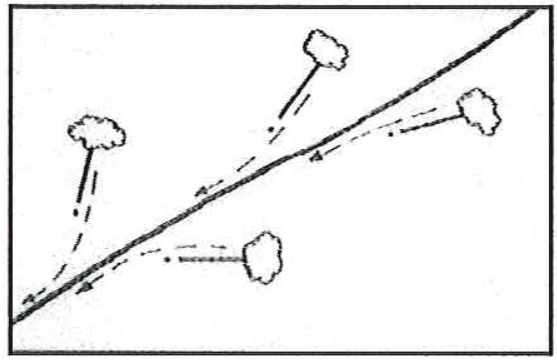

Menor uso do maquinário durante o arraste
Utilização de equipamento adequado

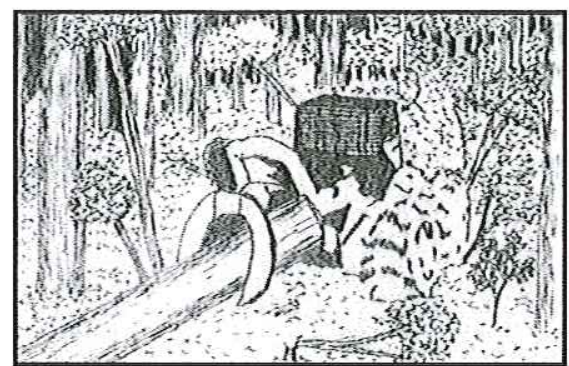

Menor distúrbio no solo e maior produtividade na colheita

\section{PROCEDIMENTOS APÓS A COLHEITA}

Tratamentos silviculturais

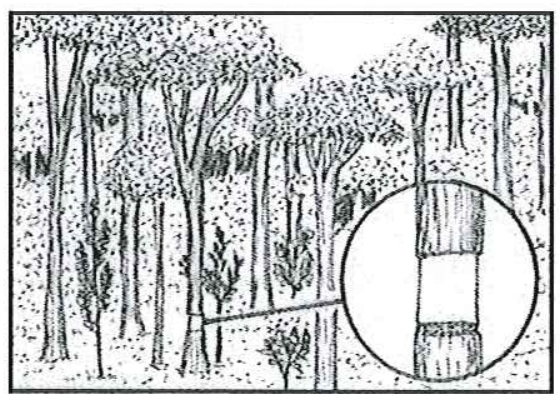

Menor competição entre as árvores remanescentes
Monitoramento do crescimento

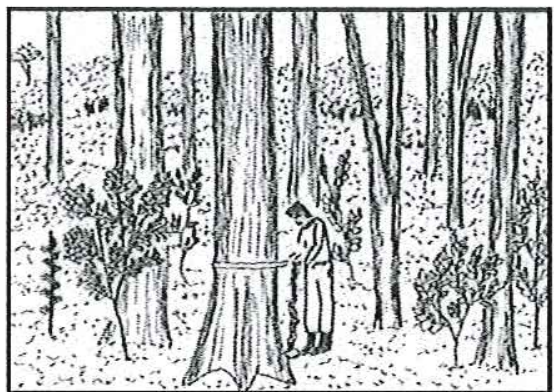

Ajuda a prever produção futura 


\section{Capítulo II: Revisão da Literatura}

\subsection{Clareiras em florestas tropicais - Dinâmica de regeneração em clareiras}

Os distúrbios naturais, principalmente a queda de árvores, representam um papel importante na manutenção da diversidade de espécies nas florestas tropicais úmidas neotropicais (Denslow, 1995).

A queda de árvores formando clareiras é o principal agente de distúrbio natural nas florestas tropicais, e essas aberturas no dossel beneficiam principalmente plântulas pré-estabelecidas (Uhl et al., 1988). A luz é o fator mais imediato e, talvez, o mais importante efeito da abertura de clareiras (Denslow, 1987). O fenômeno de clareiras em florestas tropicais naturais estimula o crescimento de todas as espécies (Fox, 1976).

A determinação da presença ou ausência de uma espécie na clareira está relacionada com o seu tempo de ocorrência, proximidade do centro de dispersão de sementes, tamanho da clareira, condições de substrato e interações planta-herbívoro (Lopes, 1993). O tamanho da clareira tem pouco efeito sobre a densidade, estabelecimento e mortalidade das plantas (Uhl et al., 1988). O tamanho e o tipo de clareira tem efeito sobre a composição de espécies e o arranjo espacial da floresta (Spies \& Franklin, 1989; Denslow, 1980).

É importante salientar que, em virtude do avanço desordenado da exploração dos recursos florestais na região amazônica, a floresta tem sofrido grandes alterações em sua estrutura natural. Um exemplo, são as grandes e inúmeras aberturas no dossel da floresta, as quais podem provocar: (i) o aumento da frequiência de queda de árvores maduras pela ação do vento (Uhl \& Vieira, 1989); (ii) a ocorrência de fogo ocasionada pelo aumento da radiação solar que atinge o solo, secando os resíduos (Holdsworth \& 
Uhl, 1997; Nepstad et al., 1999); e (iii) a proliferação de cipós e outras plantas pioneiras (Fox, 1968; Appanah \& Putz, 1984; Johns et al., 1996). Portanto, é importante entender a dinâmica de espécies madeireiras em clareiras formadas pela exploração madeireira para fazer prognósticos mais corretos da flora futura e identificar os tratamentos necessários para diminuir a competição em áreas perturbadas pela exploração madeireira.

\subsection{Diversidade de espécies em florestas tropicais}

Berry (2002) fez uma revisão ampla dos estudos sobre diversidade de espécies nas florestas neotropicais. Para ele, uma das razões de as florestas neotropicais serem consideradas de baixa diversidade de espécies é a carência de pesquisas sobre composição florística nessas florestas. Berry (2002) relata que as florestas do sudeste asiático sempre foram consideradas as mais diversas. No entanto, nas últimas duas décadas, cientistas têm demonstrado que as florestas com maior diversidade no planeta se encontram nos neotrópicos (Gentry 1982; Berry 2002; Gentry 1988; Gentry 1988 Phillips et al., 1994; Valencia et al., 1994).

Entende-se por diversidade, a riqueza de espécies de uma dada área (floresta). Existem diversas maneiras de medi-la: i) delimitando uma parcela (tamanho e forma variável) na qual são coletadas informações sobre identificação de espécies, sua forma de crescimento e seu diâmetro (Berry, 2002); e ii) tradicionalmente, através do número de espécies por área, curva de espécies-área e cálculo de índices de diversidade. Ao longo das últimas décadas, os índices de diversidade (Shannon-Weaver, Simpson, Morisita, Similaridade, etc.) são as formas de aferir diversidade mais amplamente usadas. $\mathrm{O}$ forma de analisar diversidade através de curvas de espécies-área não têm sido muito usada ultimamente (para um melhor embasamento sobre índices de diversidade ver Magurran, 1987). Condit et al. (1996) contestam o uso da curva de espécies-área afirmando que as espécies se acumulam de maneira sensível e previsível em função do número de indivíduos amostrados e não em função da área. Na realidade, o número cumulativo de espécies versus área tem sido deixado para segundo plano por ser 
definível (Condit et al., 1996; Oliveira, 1997). Por isso, é importante usar número de indivíduos ao invés de área. Um índice que tem se mostrado eficiente por não permitir que a abundância influencie a diversidade é o índice de Fisher. Neste índice, a diversidade depende do número de indivíduos amostrados. Ele permite realizar comparações entre parcelas de diferentes áreas e parcelas com diferentes números de indivíduos e também extrapolar o número de espécies obtido em diferentes amostras até um número comum de indivíduos. Do ponto de vista matemático, o índice $\alpha$ de Fisher controla e elimina o efeito positivo que a abundância tem sobre a diversidade. Isso permite determinar se uma parcela na floresta é mais diversa do que a outra (Berry, 2002). Apesar das vantagens do índice $\alpha$ de Fisher em relação às demais maneiras de estimar a diversidade de espécies, ele não é perfeito. Não se recomenda, por exemplo, aplicá-lo em amostras que contenham menos do que 500 indivíduos.

Condit et al. (1998) fazem recomendações básicas para obter as melhores comparações possíveis de riquezas de espécies: (i) comparar amostras que tenham um número similar de indivíduos independentemente da área; (ii) empregar a mesma metodologia de coleta de dados; (iii) usar o índice $\alpha$ de Fisher para amostras com menos de 3.000 indivíduos ao invés do número (riqueza) de espécies; (iv) estar ciente do erro amostral que oscila em torno de $30 \%$.

Conhecem-se basicamente três tipos de diversidade: alfa (diversidade local), beta (diversidade regional) e gama (diversidade global). Nas florestas neotropicais existem padrões distintos de diversidade beta. É o caso das florestas de várzea e das de terrafirme da Amazônia (Campbell et al., 1986; Prance 1989; Berry, 2002).

É muito importante conhecer a diversidade da floresta e os efeitos que intervenções específicas têm sobre ela para avaliar se estes efeitos são negativos ou positivos. Segundo Aguilar (1999) e Jólon (1999) citado por Louman et al. (2001), as intervenções humanas nas florestas não necessariamente têm efeitos negativos na flora e fauna. De fato, em algumas situações como nos arredores de Manaus/AM por exemplo, Magnussom et al. (1999) observaram, entre o terceiro e o oitavo ano após a exploração, uma riqueza de espécies nas áreas exploradas superior a das áreas não exploradas,. Nesta mesma região, Costa \& Magnusson (2003), investigando o efeito da exploração 
madeireira sobre a diversidade e abundância de espécies não-madeireiras florindo e frutificando, em intensidades de corte de $14 \mathrm{~m}^{3} \mathrm{ha}^{-1}$ a $45 \mathrm{~m}^{3} \mathrm{ha}^{-1}$, não notaram nenhuma redução na produção de flores e frutos. Portanto, a sobrevivência da comunidade do subbosque nas áreas de exploração madeireira aparentemente não sofre redução com a exploração madeireira. Analisando o efeito da exploração de madeira sobre a diversidade, Vidal et al. (1998) perceberam que, na exploração convencional, a diversidade de espécies é alterada logo após a exploração, e que três anos depois, esta alteração ainda persiste. Enquanto que nas áreas exploradas com técnicas de exploração de impacto reduzido não se notou diferenças em relação à diversidade de espécies quando comparada com a diversidade antes da exploração.

\subsection{Crescimento de árvores em florestas tropicais}

Há vários estudos sobre crescimento da floresta após exploração madeireira nas florestas tropicais. Em um deles, realizado em Ghana/África, Osafo (1970) observou que as árvores comerciais cresceram em diâmetro o equivalente a $0,6 \mathrm{~cm} / \mathrm{ano}$, em um período de seis anos de acompanhamento. O sistema testado foi o "shelterwood" modificado, no qual foi realizado o mapeamento, em compartimentos de 128 ha, de todas as espécies comerciais com CAP (Circunferência à Altura do Peito) acima de 65 $\mathrm{cm}$. Os cipós e árvores sem valor comercial eram eliminados após a exploração para liberar as espécies comerciais com CAP entre $10 \mathrm{~cm}$ e $45 \mathrm{~cm}$. Essa intervenção resultou na remoção média de $53 \mathrm{~m}^{3} / \mathrm{ha}$.

Na Nigéria, Mevart (1974) testou o sistema tropical "shelterwood", que consistiu na exploração de cinco árvores por hectare com DAP acima de $80 \mathrm{~cm}$, resultando em uma remoção média de $20 \mathrm{~m}^{3} /$ ha. Após essa exploração na Nigéria, foram realizados tratamentos silviculturais de envenenamento e corte de cipós durante um período de 8 anos (Lowe, 1978). O crescimento diamétrico das árvores comerciais verificado foi de $0,6 \mathrm{~cm} / \mathrm{ano}$, para um período de cinco anos de monitoramento.

Nas florestas pantanosas de Sarawak, onde foi aplicado o sistema malaio modificado, Bryan (1981) verificou que nas florestas exploradas sem tratamentos 
silviculturais, o incremento diamétrico de todas as árvores foi de $0,6 \mathrm{~cm} / \mathrm{ano}$, enquanto que nas florestas que sofreram extração de madeira comercial e desbaste, o crescimento diamétrico foi de $0,7 \mathrm{~cm} / \mathrm{ano}$.

Na Malásia Peninsular, o crescimento diamétrico das espécies de valor comercial no sistema de manejo seletivo foi bem superior ao encontrado nos outros estudos citados acima. Este crescimento chegou a $0,8-1,0 \mathrm{~cm}$ ao ano ou 2,0-2,5 $\mathrm{m}^{3} /$ ano durante operíodo de 4 anos. Neste sistema, o limite mínimo de corte ficou entre $45 \mathrm{~cm}$ e $50 \mathrm{~cm}$ de diâmetro, deixando-se em torno de 32 árvores com DAP entre $30-45 \mathrm{~cm}$ por hectare com boas características. Os tratamentos silviculturais eram decididos mediante resultado do inventário pós-exploratório. (Abdul Rashid, 1983 citado por Silva, 1989; Tang, 1987).

No Suriname, com o emprego do Sistema Silvicultural CELOS, o crescimento das árvores em diâmetro nas áreas manejadas com o emprego de tratamentos silviculturais, foi de 0,6 cm/ano a 1,0 cm/ano (De Graaf, 1986 e Jonkers, 1987). Esses autores observaram que quando foi realizado um tratamento silvicultural através de refinamento, o incremento médio anual no DAP das árvores comerciais com DAP acima de $5 \mathrm{~cm}$ aumentou entre $4 \%$ a $42 \%$. O incremento em área basal foi de $0,6 \mathrm{~m}^{2} / \mathrm{ha}$.

Na década de 1970, na Floresta Nacional do Tapajós, município de Belterra/PA $\left(55^{\circ} 18^{\prime} \mathrm{W}\right.$ e $\left.2^{\circ} 50^{\prime} \mathrm{S}\right)$, o antigo Instituto Brasileiro de Desenvolvimento Florestal IBDF iniciou uma pesquisa com intervenção da floresta tropical, que foi ampliada pela Embrapa - Amazônia oriental. Esta intervenção consistiu na retirada de $75 \mathrm{~m}^{3} / \mathrm{ha}$ de madeira, seguindo os procedimentos de mapeamento das árvores, de derrubada direcional e de desbaste das espécies sem valor comercial realizado antes da exploração. O crescimento das espécies comerciais e de todas as espécies com DAP acima de $5 \mathrm{~cm}$ após 6 anos foi de 0,5 cm/ano (Silva, (1989); Silva, (1993)). Foi observada uma grande variação no crescimento em DAP das espécies.

Após 13 anos, Silva et al. (1995) observaram uma taxa de crescimento volumétrico das árvores com DAP acima de $20 \mathrm{~cm}$ de $1,8 \mathrm{~m}^{3} \mathrm{ha}^{-1} \mathrm{ano}^{-1}$ para as espécies comerciais e de $5,2 \mathrm{~m}^{3} \mathrm{ha}^{-1} \mathrm{ano}^{-1}$ para todas as espécies. Esses autores observaram que na floresta explorada com algumas técnicas de manejo, o crescimento das árvores em DAP foi superior aos obtidos na área não explorada, e que os benefícios da abertura do dossel 
duraram apenas cerca de três anos. Após esse período, o crescimento é reduzido até tornar-se semelhante à floresta não explorada. Este comportamento está de acordo com as descobertas de Primack et al. (1985), no leste da Malásia.

A partir de 1987, o Instituto Nacional de Pesquisas da Amazônia (INPA), através do Projeto Bionte, iniciou vários estudos na Amazônia central sobre as implicações da exploração madeireira sem planejamento florestal sobre a ecologia do ecossistema florestal. Esses estudos consistiram na retirada de percentuais de área basal da floresta, em 4 tratamentos distintos: (i) sem remoção de área basal (testemunha), (ii) remoção de $25 \%$ de área basal, (iii) remoção de $50 \%$ de área basal e (iv) remoção de $75 \%$ de área basal. O crescimento das espécies comerciais com DAP acima de $10 \mathrm{~cm}$ nesses estudos foi: para a testemunha, $0,17 \mathrm{~cm} / \mathrm{ano}$; com remoção de $25 \%$ de área basal, $0,31 \mathrm{~cm} / \mathrm{ano}$; com remoção de $50 \%$ de área basal, 0,29 cm/ano; e com remoção de $75 \%$ de área basal, $0,30 \mathrm{~cm} /$ ano (Higuchi et al., 1997). O incremento volumétrico para a testemunha foi $2,82 \mathrm{~m}^{3} \mathrm{ha}^{-1} \mathrm{ano}^{-1}$; com remoção de $25 \%$ de área basal, $1,3 \mathrm{~m}^{3} \mathrm{ha}^{-1} \mathrm{ano}^{-1}$; com remoção de $50 \%$ de área basal, $0,93 \mathrm{~m}^{3} \mathrm{ha}^{-1} \mathrm{ano}^{-1}$; e com remoção de $75 \%$ de área basal, $0,10 \mathrm{~m}^{3} \mathrm{ha}^{-}$ ${ }^{1}$ ano $^{-1}$ (Higuchi et al., 1997).

Alder \& Silva (2000) desenvolveram um modelo de crescimento (CAFOGROM) para duas regiões da Amazônia: Jari e Flona Tapajós em Santarém. Considerando indivíduos de valor comercial com DAP acima de $45 \mathrm{~cm}$, foi encontrada uma taxa de crescimento variando de $0,39 \mathrm{~m}^{3}$ a $1,0 \mathrm{~m}^{3} \mathrm{ha}^{-1} \mathrm{ano}^{-1}$ para um período de 12-17 anos. Segundo esses autores, essa diferença pode ser explicada pela estrutura da floresta, composição de espécies e recrutamento após o corte. Se houver uma normalização na diversidade de composição das espécies, esta taxa pode ser em torno de 0,6 a $0,7 \mathrm{~m}^{3} \mathrm{ha}^{-}$ ${ }^{1} \mathrm{ano}^{-1}$. Baseados nas informações destes dois experimentos, os autores concluem que o segundo corte deve ser em torno de 30 a 35 anos.

Uma pesquisa recente de Alder e Silva (2001), na qual foram retirados $2 \mathrm{~m}^{3} \mathrm{ha}^{-1}$ de área basal ou cerca de 27-28 $\mathrm{m}^{3} \mathrm{ha}^{-1}$, o modelo de crescimento CAFOGROM mostrou que o ciclo de corte pode ser sustentável por um período de 200 anos, considerando um ciclo de corte de 30 anos. 
A grande maioria dos estudos realizados em florestas tropicais pós-exploração não compara exploração de impacto reduzido com exploração convencional. Para a Amazônia, essas informações são particularmente interessantes, pois a maior parte da exploração madeireira é realizada sem a utilização de técnicas de exploração de impacto reduzido e também, há poucas informações sobre o crescimento da floresta após exploração madeireira. Essas informações são igualmente importantes para a melhoria dos debates sobre manejo florestal na região.

A grande maioria dos estudos pioneiros que enfocam crescimento em florestas tropicais tem avaliado o crescimento através do diâmetro. Este parâmetro é importante, todavia, ele não mostra o crescimento real da floresta. Isto porque quando as árvores menores têm o mesmo crescimento das árvores maiores, elas necessariamente não crescem igualmente do ponto de vista de área basal.

\subsection{Manejo x desmatamento - necessidade de estimular o manejo florestal para conservar as florestas}

A exploração madeireira na Amazônia começou historicamente há cerca de 300 anos com a exploração de poucas espécies nas regiões de várzea. A intensidade de exploração era baixa, retirando-se apenas poucos metros cúbicos de madeira por hectare. Juntamente com a exploração de madeira acontecia a extração de produtos nãomadeireiros, principalmente borracha, castanha e cacau (Barros \& Uhl. 1995). A partir da década de 1970, a atividade madeireira teve um impulso ocasionado principalmente pela valorização da floresta. Isto ocorreu por causa da chegada de imigrantes para a região, vindos principalmente das regiões sul e sudeste do país, e também por causa da exaustão das florestas tropicais de Mata Atlântica do Brasil (Viana et al., 2002; Viana, 2002; Lentini et al., 2003).

As florestas primárias da Amazônia desaparecem em ritmo alarmante a uma taxa de quase dois milhões de hectares por ano (INPE, 2000). Se o desmatamento continuar neste ritmo, a Amazônia perderá praticamente toda a sua cobertura florestal em aproximadamente 200 anos (The Economist, 2001). Estima-se que a Amazônia já perdeu 
$15 \%$ de sua cobertura florestal original. Todavia, o desmatamento foi mais acentuado nos últimos 30 anos. Na área desmatada, o uso do solo predominante é a pecuária $(77,5 \%)$, seguida da agricultura $(7,1 \%)$, plantação florestal $(0,5 \%)$, áreas em descanso $(3,6 \%)$ e áreas produtivas não-utilizadas $(9,9 \%)$. Dos $15 \%$ de área desmatados na Amazônia, $165 \mathrm{~km}^{2}$ estão abandonados (IBGE, 1996).

Em geral, as taxas de desmatamento têm diminuído ao longo dos últimos anos. Todavia, ainda não está numa taxa considerada aceitável. Já existe base política suficiente para que o desmatamento diminua, mesmo que os governos Federal e Estadual não criem alternativas mais sustentáveis de uso dos recursos florestais, como o ordenamento territorial e o incentivo a usos mais sustentáveis. Os madeireiros e demais comunidades amazônicas já conseguem ver o valor econômico da floresta em pé. Isso é uma realidade mesmo em uma das regiões mais desmatadas da Amazônia; Paragominas, no nordeste do Pará. Esta percepção é consequiência dos resultados da aplicação de técnicas de exploração de impacto reduzido (EIR) de madeira, que apresenta as seguintes características: é fácil de praticar, gera lucros, é legal, tem maior credibilidade no mercado e é mais barata do que a exploração predatória (Barreto et al., 1998; Holmes et al., 2002; De Graaf et al., 2003).

O desmatamento é causado por inúmeras variáveis e fatores que se combinam sofisticadamente. Essas variáveis são: (i) proximidade de estradas, (ii) preço dos produtos agropecuários, (iii) disponibilidade de crédito, e (iv) crescimento populacional (Margulis, 2003). Os principais responsáveis pelo desmatamento a partir da década de 1990 são a exploração madeireira predatória, a pecuária extensiva e os assentamentos de reforma agrária. Os investimentos maciços em infra-estrutura, planejados no Programa “Avança Brasil", implementado pelo Governo Brasileiro passado (até 2002) na Amazônia, poderiam ter impactos catastróficos na paisagem regional. O Programa poderia aumentar muito a oferta de recursos naturais em madeira e terras para a agropecuária, o que, além de provocar perdas ambientais, poderia provocar perdas econômicas significativas (Arima \& Veríssimo, 2001; Margulis, 2003). No entanto, existem alternativas viáveis através de políticas públicas no âmbito do Ministério do Meio Ambiente, que poderão assegurar um desenvolvimento sustentável com base nos 
recursos florestais manejados e na intensificação da agropecuária em áreas desmatadas (Arima \& Veríssimo, 2001).

\section{5 - Breve histórico dos sistemas silviculturais no mundo e no Brasil}

\section{a. Experiências no mundo}

Durante o último século foram realizadas muitas pesquisas silviculturais nas florestas tropicais. Uma das mais antigas experiências que se tem conhecimento aconteceu na Índia, na metade do século XIX. Esta experiência serviu como base para o desenvolvimento de sistemas silviculturais na Malásia e em outras partes do mundo como o Brasil (Baur, 1964; Whitmore, 1984).

Os sistemas silviculturais testados nas florestas tropicais do mundo podem ser divididos em: (i) sistemas silviculturais voltados à produção sustentada em florestas naturais; (ii) sistemas de transformação; e (iii) sistemas de substituição (Lamprecht, 1990).

Os sistemas voltados à produção sustentada em florestas naturais originalmente se resumiam na determinação do diâmetro mínimo de corte (DMC) e desbastes de beneficiamento (improvement thinings).

Os sistemas de transformação podem ser entendidos como os que convertem a composição e estrutura de uma floresta de forma gradual e lenta, sem a total destruição. Eles podem ser divididos em sistemas de melhoramento, sistemas de enriquecimento e transformação através de regeneração avançada combinada com exploração. Os sistemas de substituição têm uma característica peculiar que é substituir drasticamente a floresta original por uma floresta com predominância de poucas espécies. Os sistemas de substituição testados nas florestas tropicais foram o Limba, Okoumé e o Taungya.

No século passado, o sistema seletivo (policíclico) e o shelterwood com variações foram testados amplamente na América latina. Muitas experiências não foram muito bem-sucedidas. A principal dificuldade era promover a regeneração natural e o baixo crescimento. Além disso, as experiências iniciais parecem ter sofrido influência da alta seletividade do mercado - geralmente voltado para produção de espécies de alto 
valor para exportação. Isso implicava numa baixa produção e numa alta intensidade e frequiência de tratamentos silviculturais - limpeza, desbastes, corte de cipós - para favorecer poucas espécies (Wadsworth, 1997).

No sistema seletivo, a adoção de diâmetro mínimo não foi suficiente para garantir a regeneração e a obtenção de espécies de rápido crescimento (Lamprecht, 1990).

O sistema Shelterwood foi bem sucedido onde existia regeneração avançada. E manipulações do dossel falharam apenas em promover regeneração onde inexistia regeneração avançada. Em regiões onde o Método Tropical de Regeneração sob Cobertura - TSS foi bem sucedido, o sistema Shelterwood foi abandonado, sobretudo devido aos custos iniciais elevados, à insuficiência administrativa e organizacional e a grande pressão demográfica (Lamprecht, 1990).

Existem informações insuficientes sobre ciclos de corte. Nas experiências mais antigas, realizadas na Ásia, África e Índia, não houve continuidade da coleta de informações do monitoramento ou então a floresta remanescente, devido à forte pressão demográfica, foi convertida em outros usos do solo. Dessa forma, foram criados os modelos de predição para estimar os ciclos de corte em florestas tropicais (Synnott, 1976; Vanclay, 1994 e 1995; Alder, 1980; Alder \& Synnott, 1992). Hoje, as estimativas de ciclo de corte para a Amazônia ficam em torno de 25-35 anos para manejo empresarial e 15-20 anos para manejo florestal comunitário (Silva et al., 1995; Alder \& Silva, 2001).

Uma revisão mais detalhada sobre o tema "sistemas silviculturais predominantemente usados nas florestas tropicais mundiais" pode ser encontrada em Lamprecht (1990), Buschbacher (1990), Wadsworth (1997), Dawkins \& Philip (1998) e Louman et al., (2001). Uma revisão extensa da literatura sobre impactos da colheita de madeira em florestas tropicais úmidas feito pela FAO demonstrou que as determinações da intensidade de corte, a análise do nível de impacto na floresta e no ecossistema, e a minimização de desperdícios na colheita e no posterior processamento da madeira são questões relevantes para pesquisa. A minimização dos danos às árvores residuais e a garantia dos processos de regeneração após colheita são essenciais para o sucesso de 
qualquer sistema silvicultural policíclico. Na prática, entretanto, pouca consideração tem sido dada a essas questões (Pulkki, et al. 2001).

\section{b. Experiências na Amazônia brasileira}

As experiências silviculturais mais antigas que se têm registro na Amazônia datam de 1958, na Estação Experimental de Curuá-Una, Santarém-Pará (Não se está considerando o manejo etnoecológico feito por populações tradicionais indígenas (senso Posey, 1982 e 1983). O sistema empregado nessa área foi o Método Tropical de Regeneração sob Cobertura (TSS) (Pitt, 1969; Dubois, 1991). Após 36 anos, houve uma redução na diversidade geral da floresta com um aumento na densidade e dominância de Vochysia maxima Ducke, Simarouba amara Aubl., Tachigali myrmecophila (Ducke) Ducke, Dipterix odorata (Aubl.) Willd., Trichilia lecointei Ducke, Manilkara huberi (Ducke) A. Chev. e Virola sp. Infelizmente houve descontinuidade nas atividades programadas e o abandono das áreas experimentais (Dubois, 1991).

No Amazonas, a primeira experiência que se tem registro foi no ano de 1964 na Reserva Ducke, em Manaus. Nessa área, foram testados ensaios de plantação em linhas de plantio envolvendo as espécies: Cedrela odorata L., Clarisia racemosa Ruiz \& Pav., Callophylum brasiliensis Cambess., Dipterix odorata (Aubl.) Willd., Carapa guianensis Aubl., Gloupia glabra, Cedrelinga cateniformes (Ducke) Ducke, Tabebuia sp entre outras. O crescimento geral das espécies foi baixo, com exceção das espécies Carapa guianensis, Gloupia glabra e Cedrelinga cateniformis (Ducke) Ducke, que apresentaram ótimo crescimento em altura. Um dos motivos desses baixos índices de crescimento foi o espaçamento muito pequeno entre linhas não permitindo a entrada de luz para as plântulas (Volpato et al., 1973).

Em 1983, na Reserva Florestal de Buriticupu da Companhia Florestas Rio Doce S. A. (Maranhão), foram feitos ensaios de diferentes intensidades em 20 blocos de $50 \mathrm{~m}$ x 100 m, com dois modelos de colheita: (i) corte de todas as árvores de exploração do povoamento com exceção das espécies comerciais com DAP entre $20 \mathrm{~cm}-40 \mathrm{~cm}$; e (ii) corte de todas as árvores com exceção das espécies comerciais com DAP entre $15 \mathrm{~cm}-20$ $\mathrm{cm}$. Depois de 6 anos, observou-se que nas maiores intensidades de exploração houve 
menor potencial de espécies comerciais para produção de madeira ou lenha bem como grande infestação de cipós (Schmidt, 1972).

Outra experiência interessante da Companhia Florestas Rio Doce foi realizada em Linhares (ES), em 1986. Nesta experiência, foi testado o efeito da redução de área basal sobre a dinâmica de crescimento e produção; todas as áreas onde ocorreu intervenção, o incremento periódico anual em diâmetro aumentou substancialmente (Jesus \& Souza, 1995). A reposição da biomassa inicial para os tratamentos de corte raso, de corte seletivo sem restrição quanto à classe diamétrica, e de corte de todos os indivíduos menores que $10 \mathrm{~cm}$ de DAP, recuperou em 18 anos a área basal no tratamento 1, 14 anos no tratamento 2, e 17 anos no tratamento 3 (Jesus \& Souza, 1995).

As experiências iniciais de manejo florestal na Amazônia se basearam no sistema tropical de cobertura (Tropical Shelterwood System). Em todo o mundo, este sistema foi considerado muito intensivo e inviável economicamente (Silva, 2000). As pesquisas iniciadas na década de 1970 não são consideradas muito diferentes do modelo conhecido como exploração de impacto reduzido (EIR). Os resultados no passado (1970) já eram positivos tanto tecnicamente como economicamente, contudo, técnicas de manejo florestal até meados da década de 1990 não tinham sido adotadas devido à ausência de: (i) projetos demonstrativos; (ii) transferência de tecnologia e capacitação; (iii) treinamento; e (iv) análise de custos e benefícios do manejo florestal (Barreto et al., 1998; Silva, 2000).

Nos últimos 20 anos, houve grandes avanços em pesquisa sobre manejo de florestas tropicais. Todavia, muitas dessas pesquisas foram realizadas com o objetivo de avaliar as ações que são degradantes ou não sustentáveis. Ou seja, para diminuir os impactos ecológicos da exploração madeireira sobre a estrutura e a regeneração natural da floresta. O uso da engenharia do manejo florestal, através das técnicas de exploração de impacto reduzido contribuiu para a redução dos impactos biológicos, aumentou a produtividade do trabalho, diminuiu os riscos de acidentes, resultou no aumento do crescimento das árvores e causou menor impacto sobre a diversidade de espécies. Entende-se hoje que já existem técnicas que promovam a conservação florestal. Acredita-se que o próximo desafio será entender quais são os outros obstáculos para a 
adoção do manejo florestal e quais são os refinamentos necessários para tornar o manejo mais sustentável do ponto de vista econômico, social e ambiental.

\subsection{Monitoramento de florestas tropicais}

Historicamente, a questão do monitoramento das florestas exploradas nas florestas tropicais não tem sido muito tratada. Dentre as razões para isso está o fato de as florestas serem transformadas em outros usos do solo e haver descontinuidade na coleta de informação de monitoramento da floresta. O monitoramento do crescimento é geralmente realizado com o estabelecimento de parcelas antes da exploração e medições subseqüientes. Essas informações são usadas para definir melhor o ciclo de corte.

Existe um grupo criado recentemente pelo ProManejo/IBAMA - do qual fazem parte a Embrapa Amazônia Oriental, Amazonas e Acre, o Imazon, INPA, FUA, UFRA, Ecoflorestal - que visa criar uma rede de parcelas permanentes na Amazônia brasileira (Jornal O Liberal, 07/06/2003).

Para definir o padrão de crescimento da floresta, é necessário desenvolver modelos de crescimento. Para Alder \& Silva (2001), a pesquisa com desenvolvimento de modelos de crescimento nas florestas tropicais é recente. Todavia, contou com avanços significativos nas últimas duas décadas. Na Amazônia, este tema tem sido tratado por vários pesquisadores (Higuchi, 1987; Silva, 1989; Biot et al., 1997; Alder, 1995; Alder \& Silva, 2000; Alder \& Silva, 2001). 


\section{Capítulo III: Dinâmica de Espécies Arbóreas em Clareiras Formadas pela Exploração de Impacto Reduzido e Exploração Convencional em Paragominas, Pará.}

\subsection{Introdução}

A maioria dos trabalhos sobre regeneração de florestas tropicais na Amazônia tem enfocado regeneração em clareiras naturais, clareiras artificiais, clareiras de agricultura itinerante, pastagens abandonadas e fragmentos florestais. Estudos que enfocam a regeneração em florestas exploradas são raros, apesar de serem importantes para a implantação de modelos de manejo baseados na regeneração natural (Leal Filho, 2000). Um dos grandes obstáculos operacionais para o sucesso do manejo florestal é a regeneração lenta e imprevisível das espécies de valor comercial após a exploração (Leal Filho, 2000). Por isso, é necessário conhecer sobre a regeneração após exploração madeireira, pois a grande maioria dessas áreas depende da regeneração natural para se recuperar (Poorter, 1998). Alguns dos raros estudos regionais que procurou enfocar a regeneração após intervenção de exploração madeireira foram realizados na Amazônia central. Em um deses estudos, foi observado que o número de espécies aumenta significativamente nos quatro anos iniciais após a exploração, entre o quarto e o sexto ano, e que havia pouca variação no número de espécies nas clareiras (Vieira, 1996). Outro estudo mostrou que a riqueza de espécies era significativamente maior nas áreas exploradas do que nas áreas não exploradas (Magnusson et al., 1999). Um princípio básico do manejo florestal baseado em regeneração natural é assegurar um estoque

suficiente de espécies de árvores comerciais nas áreas exploradas visando sua sustentabilidade. Dessa maneira, torna-se extremamente importante entender a dinâmica 
das clareiras formadas pela colheita de madeira para que possam ser desenvolvidos planos adequados de manejo florestal. Visto que as clareiras são responsáveis pela composição de espécies da floresta futura, também é necessário entender a diversidade de espécies madeireiras neste ambiente. Os distúrbios naturais são um elemento importante para a manutenção da diversidade de espécies e outras comunidades (Watt,1923). Autores de trabalhos clássicos que pioneiramente trataram sobre este tema foram Aubréville (1938), Richards (1952) e Van Steenis (1956).

Muitos estudos demonstram que os distúrbios responsáveis pela formação das clareiras têm efeito na estrutura, funcionalidade, dinâmica e composição de espécies (Grubb, 1977; Pickett \& White, 1985; Uhl et al., 1988; Spies \& Franklin, 1989; Denslow, 1980). Há estudos que afirmam que o tamanho da clareira é um fator importante na composição e no número de espécies (Uhl et al., 1988; Lopes, 1993). Outros identificam a luz como o fator mais imediato e, talvez, o mais importante efeito da abertura de clareiras (Denslow, 1987). Outros estudos, entretanto, relatam que o fenômeno de clareiras em florestas tropicais naturais estimula o crescimento de todas as espécies (Fox, 1976) e que algumas delas têm preferência por determinado tamanho de clareira (Bongers \& Popma, 1988; Hartshorn, 1980). Neste capítulo analisa-se a dinâmica de crescimento, mortalidade, recrutamento e diversidade de espécies em clareiras formadas pela exploração madeireira convencional e pela exploração de impacto reduzido e em clareiras naturais na Amazônia oriental. Procura-se especificamente responder as seguintes perguntas:

i) Como se comportam as espécies comerciais, por grupo ecológico, em clareiras criadas pela exploração?

ii) Como as espécies madeireiras sobrevivem nas clareiras de exploração de impacto reduzido (CEIR), nas clareiras de exploração convencional (CEC) e nas clareiras de florestas não submetidas à colheita de madeira - testemunha (CT)?

iii) Como é a diversidade, a dinâmica de crescimento, a mortalidade e o recrutamento da regeneração das espécies de valor madeireiro nas clareiras de exploração de impacto reduzido (CEIR), nas clareiras de exploração 
convencional (CEC) e nas clareiras de florestas não submetidas à colheita de madeira - testemunha (CT)?

\subsection{Material e métodos}

\subsubsection{Procedimentos amostrais e estatísticos}

Para analisar o comportamento da regeneração das espécies de valor madeireiro mapearam-se 10 clareiras em cada tratamento: exploração de impacto reduzido, exploração convencional e testemunha (Figura 2). Selecionou-se aleatoriamente clareiras de diferentes tamanhos, três anos após a exploração na área. Pela dificuldade de se encontrar clareiras testemunhas com a mesma idade das encontradas nos demais tratamentos, escolheram-se aquelas que apresentavam a mesma estrutura das demais clareiras, ou seja, vegetação dominante com a mesma altura (cerca de 3 metros). Em seguida, mapeou-se a área de abertura de cada clareira. O mapeamento das clareiras seguiu o modelo de Bongers \& Popma, (1988) com algumas adaptações. Por exemplo, não foi utilizado um número fixo de linhas partindo do centro da clareira. Ao invés disso, se utilizou o número necessário de linhas para formar figuras geométricas. $\mathrm{O}$ procedimento para delimitar o local exato da projeção da clareira seguiu o método de Brokaw (1982). Isto é, era considerada clareira toda a vegetação que tivesse uma altura de no máximo 3 metros. Os indivíduos amostrados dentro dessas clareiras foram espécies de valor madeireiro com altura igual ou superior a 1 metro.

Baseado em consultas na literatura e a especialistas e levando-se em conta seus requerimentos de germinação e estabelecimento, classificaram-se as espécies da regeneração de valor madeireiro presentes nas clareiras em três grupos ecológicos: (i); pioneiras (espécies que necessitam de altos níveis de iluminação para germinação e estabelecimento, de tal maneira que seu recrutamento se restringe a etapas sucessionais muito juvens e a grandes clareiras; (ii) demandantes de luz (espécies que se estabelecem nas etapas sucessionais jovens, porém, com uma longevidade maior do que as espécies pioneiras); e (iii) tolerantes à sombra (espécies que podem se estabelecer em baixos níveis de iluminação) (Uhl (1987) e Richards (1996) citado por Peña-Claros, 2001). Essa classificação foi baseada nos trabalhos de Martinez-Ramos (1985), Whitmore, (1989), 
Viana (1989), Louman et al., 2000 e observações pessoais dos pesquisadores José do Carmo Lopes (Embrapa Belém), Mark Schulze e James Grogan (Imazon) e do Sr. Nelson Rosa (Museu Paraense Emilio Goeldi).

\subsubsection{Identificação botânica}

A identificação botânica foi realizada por Nelson de Araújo Rosa do Museu Paraense Emílio Goeldi, um botânico prático com mais de 20 anos de experiência na Amazônia.

\subsubsection{Coleta de dados e monitoramento}

Para cada indivíduo, coletou-se informação sobre a espécie botânica, localização (mapeamento das árvores nas clareiras), DAP, altura e condições de iluminação da copa. As clareiras foram formadas em 1993 e, em julho de 1996, realizou-se a primeira medida. A última medida foi feita em julho de 2000. No total, foram 4 anos de monitoramento das espécies de valor madeireiro nas clareiras formadas pela exploração madeireira. No quarto ano (2000), realizou-se a coleta de dados sobre as espécies de valor madeireiro que haviam ultrapassado 1 metro de altura, isto é, as espécies recrutadas no período.

\subsubsection{Análise de dados}

Tamanho das clareiras: Para analisar se havia diferenças no tamanho das clareiras entre os tratamentos testados - clareiras de exploração de impacto reduzido (CEIR), clareiras de exploração convencional (CEC) e clareiras naturais de florestas não submetidas à colheita de madeira (testemunha) (CT) - utilizou-se a análise de variância de um fator para realizar as comparações. Foram feitos testes de normalidade e homocedasticidade. Quando essas suposições não foram aceitas, foi aplicado transformação logarítmica (T = log (área)) (Sokal and Rohlf, 1981).

Correlação de Spearman: Para avaliar se o tamanho da clareira tinha algum efeito sobre o número de espécies e o número de indivíduos, utilizou-se a correlação de Spearman. Quanto mais próximo de 1 (um) for o coeficiente de correlação de Sperman, 
mais satisfatória será a correlação. E quanto mais próximo de 0 (zero), menos satisfatória será a correlação. Este modelo foi usado por ele aceitar correlações com escalas bastante diferentes.

Percentagem de indivíduos em 2000: Para avaliar o comportamento dos grupos ecológicos no período de monitoramento, realizou-se uma análise gráfica da evolução temporal do percentual do número de indivíduos em relação ao início do monitoramento.

Densidade e riqueza de espécies: Comparou-se a densidade de indivíduos de valor madeireiro por hectare presentes nos três tratamentos: clareiras de exploração de impacto reduzido (CEIR), clareiras de exploração convencional (CEC) e clareiras de florestas não submetidas à colheita de madeira - testemunha (CT). Avaliou-se se a densidade de indivíduos nas clareiras mudou em cada tratamento após o período de monitoramento (1996-2000). Compararam-se estatisticamente as densidades médias no início e no fim do monitoramento. Para isso, utilizou-se o teste $t$ pareado após a verificação de aceitação das suposições de normalidade e homocedasticidade (Sokal e Rohlf, 1981). Para analisar a diversidade de espécies, conferiram-se as espécies no início de todos os anos de monitoramento. Para o cálculo da riqueza relativa, considerou-se a riqueza no início do monitoramento igual a $100 \%$ para todos os tratamentos (clareiras) e a percentagem da riqueza nos demais anos foi calculada em relação ao número de espécie no início do monitoramento. Para calcular a diversidade utilizou-se o índice $\alpha$ de Fisher no período - 1996 a 2000.

Crescimento diamétrico: foi obtido subtraindo-se o valor do DAP final (2000) do valor do DAP inicial (1996). Em seguida, dividiu-se o resultado pelos anos de monitoramento (4 anos).

Taxa de Mortalidade: a taxa de mortalidade média anual foi calculada de acordo com o modelo abaixo (Primack et al. 1985): 
$m=1-\left(\mathrm{N}_{1} / \mathrm{N}_{0}\right)^{1 / 1}$, onde: $\mathrm{m}$ é a taxa anual de mortalidade; $\mathrm{N}_{0}$ é o número de indivíduos na amostra inicial (1996); $N_{1}$ é o número de indivíduos na amostra final (2000) e t é o tempo de observações em ano (4).

\subsection{Resultados}

\subsubsection{Tamanho das clareiras}

As clareiras entre os tratamentos tinham tamanhos médios diferentes. Neste estudo, a área média das clareiras da área com exploração de impacto reduzido $\left(238 \mathrm{~m}^{2}\right)$ eram maiores do que as áreas médias das clareiras da exploração convencional $\left(206 \mathrm{~m}^{2}\right)$ e das clareiras testemunha $\left(168 \mathrm{~m}^{2}\right)$. Isto pode ser explicado por uma das duas razões a seguir: (i) problema experimental - as 10 clareiras em cada tratamento não foram suficientes para mostrar as diferenças; (ii) na área com exploração de impacto reduzido, as árvores eram maiores do que na exploração convencional. Árvores maiores contribuem para clareiras maiores. Na área com exploração de impacto reduzido, o tamanho médio das árvores era $79 \mathrm{~cm}$ de DAP, enquanto que na exploração convencional, o tamanho médio foi $71,8 \mathrm{~cm}$ de DAP.

Não houve diferenças estatísticas entre as áreas das clareiras nos três tratamentos considerados neste estudo $(F=1,90 ; \mathrm{p}=0,168)$. Estes dados diferem dos encontrados por Johns et al. (1996), que registrou clareiras de exploração convencional maiores (355 $\left.\mathrm{m}^{2}\right)$ do que clareiras de exploração de impacto reduzido $\left(166 \mathrm{~m}^{2}\right)$ na mesma área de estudo. Nas áreas exploradas (exploração de impacto reduzido e exploração convencional), não se encontraram clareiras pequenas com menos de $100 \mathrm{~m}^{2}$. Nesta faixa de tamanho foram encontradas apenas clareiras naturais. Os tamanhos das clareiras concentraram-se na faixa entre $100 \mathrm{~m}^{2}$ e $400 \mathrm{~m}^{2}$. A maior clareira foi encontrada na exploração de impacto reduzido (Figura 4). 
Figura 4: Frequiência de tamanho de clareiras $\left(\mathrm{m}^{2}\right)$ clareiras de exploração de impacto reduzido (CEIR), clareiras de exploração convencional (CEC) e clareiras de florestas não submetidas à colheita de madeira - testemunha (CT).

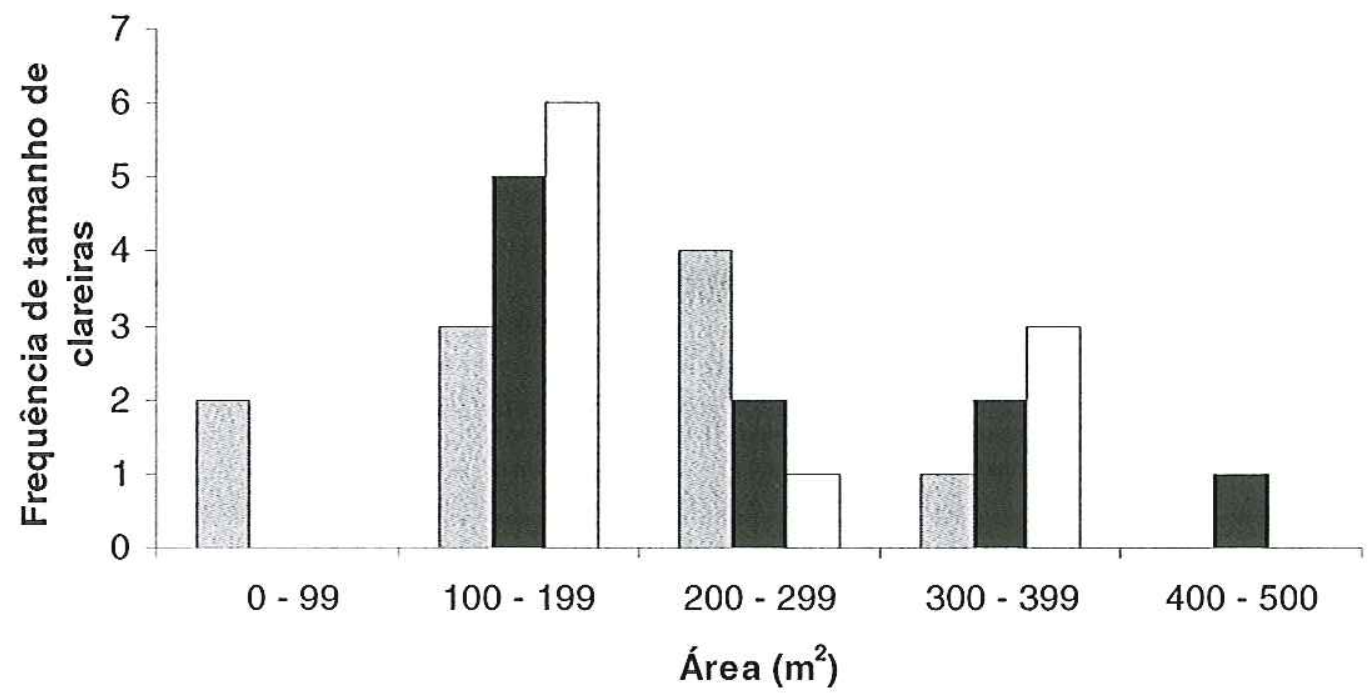

$\square$ clareiras testemunha $\mathbf{\square}$ clareiras de exploração de impacto reduzido $\square$ clareiras de exploração convencional

\subsubsection{Número de indivíduos por área da clareira}

Na correlação de Spearman entre os números de indivíduos por área da clareira, as clareiras testemunha apresentaram uma correlação alta $(r=0,88)$, enquanto que as clareiras da exploração convencional apresentaram correlação média $(\mathrm{r}=0,56)$ e as clareiras da exploração de impacto reduzido apresentaram correlação baixa $(r=0,38)$ (Figura 5). Isso significa que nas clareiras da área testemunha existe evidência de que o número de indivíduos aumenta à medida que aumenta a área da clareira. Existe pouca evidência de que isso ocorre nas clareiras da exploração de impacto reduzido. 
Figura 5: Correlação de Spearman entre a área da clareira e o número de indivíduos em três tipos de clareira ((a) testemunha, (b) exploração de impacto reduzido e (c) exploração convencional). O Corr no canto inferior esquerdo se refere ao coeficiente de correlação de Spearman.
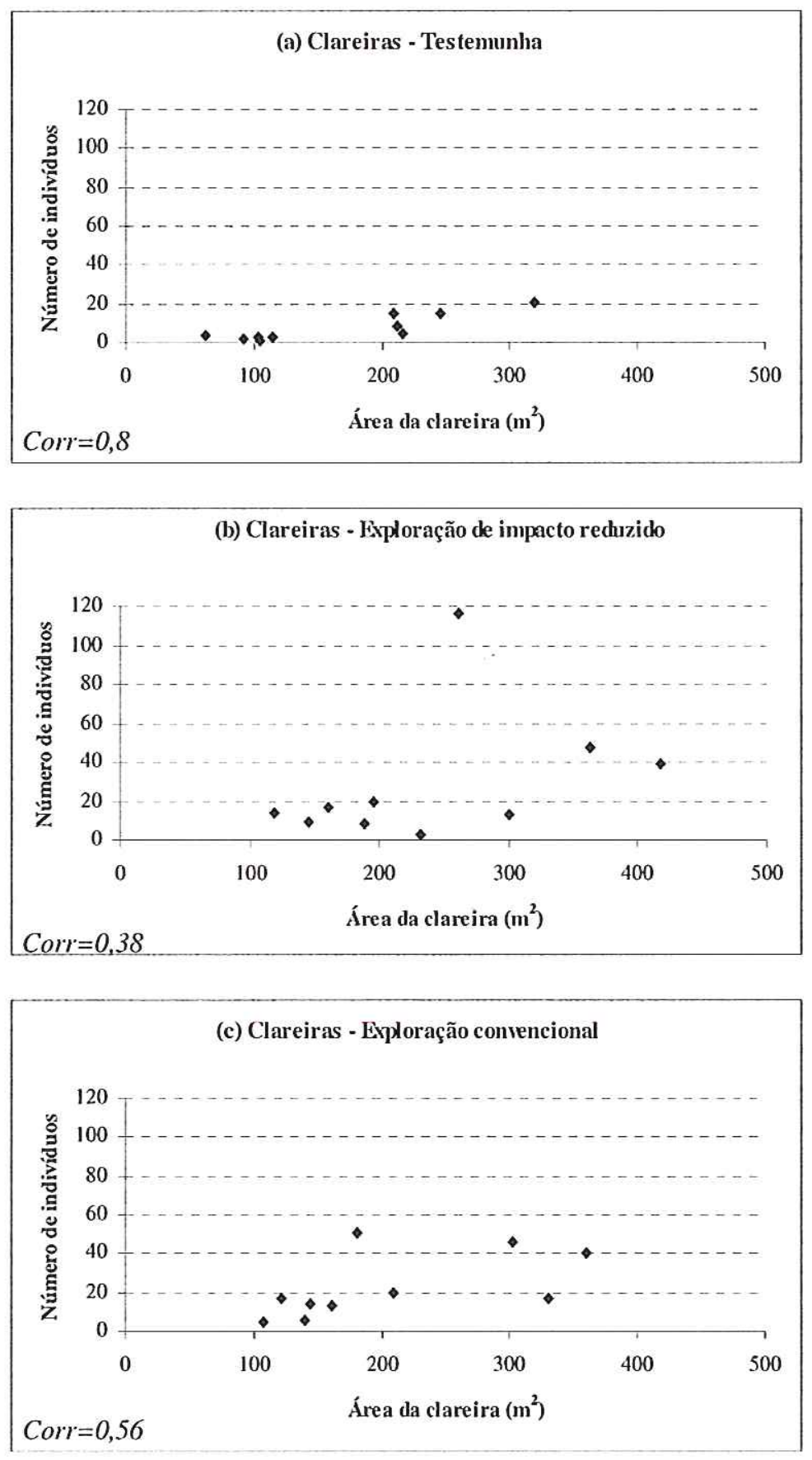


\subsubsection{Número de espécies por área da clareira}

A correlação do número de espécies por área da clareira mostrou-se alta ( $\mathrm{r}=$ $0,85)$ nas clareiras testemunha, média $(\mathrm{r}=0,55)$, nas clareiras de exploração de impacto reduzido e baixa $(\mathrm{r}=0,23)$ nas clareiras de exploração convencional (Figura 6). Isso significa que somente na área testemunha existe evidência de que o número de espécies aumenta à medida que aumenta a área da clareira. 
Figura 6: Correlação de Spearman entre a área da clareira e o número de espécies em três tipos de clareira ((a) testemunha, (b) exploração de impacto reduzido e (c) exploração convencional). O corr no canto inferior esquerdo se refere ao coeficiente de correlação de Spearman.
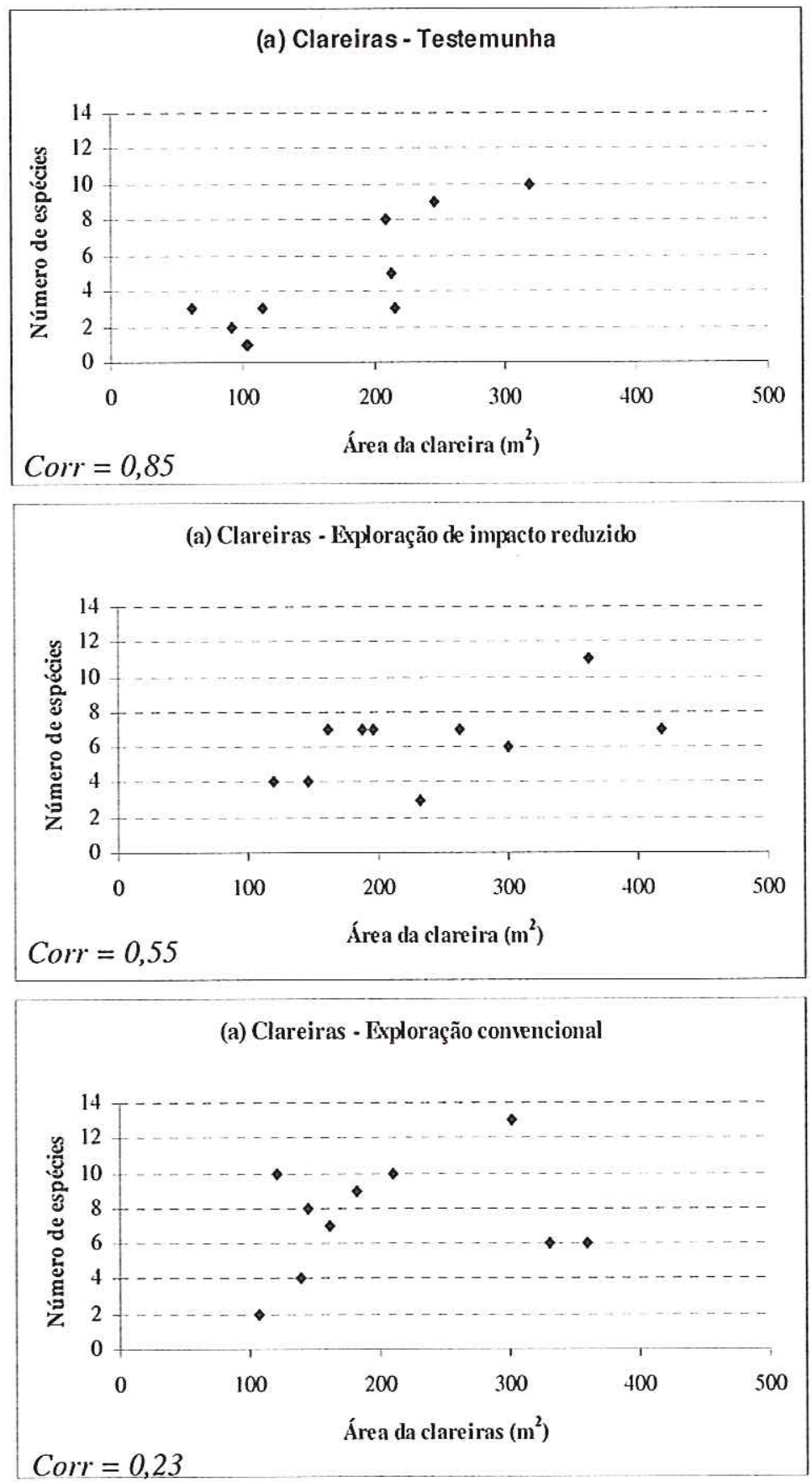


\subsubsection{Composição florística}

Identificaram-se 30 espécies madeireiras de 16 famílias em todas as clareiras juntas (testemunha, exploração de impacto reduzido e exploração convencional). As famílias mais representativas foram a Caesalpiniacea com cinco espécies, seguida da Mimosaseae com quatro espécies, e a Burseraceae com três espécies (Tabela 1). A maioria das espécies foi classificada como demandante de luz. As espécies pioneiras eram as menos numerosas pelo fato de existirem poucas espécies pioneiras de valor madeireiro (Tabela 1). Das espécies encontradas nas clareiras, 4 eram pioneiras, 15 eram demandantes de luz e 11 eram tolerantes à sombra (Tabela 1). 
Tabela 1: Nome científico, família, densidade (n/ha), \% de sobreviventes, taxa de mortalidade, indivíduos recrutados (n/ha) e incremento diamétrico das árvores ( $\mathrm{cm} / \mathrm{ano}$ ) em clareiras de florestas não submetidas à colheita de madeira - testemunha (CT), clareiras de exploração de impacto reduzido (CEIR), e clareiras de exploração convencional (CEC), em Paragominas,Pará.

\begin{tabular}{|c|c|c|c|c|c|c|c|c|c|c|c|c|c|c|c|c|c|c|c|c|}
\hline \multirow[t]{3}{*}{ Nome Científico } & \multirow[t]{3}{*}{ FAMILIA } & \multicolumn{6}{|c|}{ Densidade (n/ha) } & \multicolumn{3}{|c|}{$\begin{array}{l}\text { Percentagem de } \\
\text { sobreviventes }\end{array}$} & \multicolumn{3}{|c|}{ Mortalidade (\%) } & \multicolumn{3}{|c|}{$\begin{array}{l}\text { Recrutamento } \\
\text { (indivíduos/ha) }\end{array}$} & \multicolumn{3}{|c|}{$\begin{array}{c}\text { Incremento } \\
\text { diamétrico 1996- } \\
2000(\mathrm{~cm} / \mathrm{ano})\end{array}$} & \multirow{3}{*}{$\begin{array}{c}\text { Grupo } \\
\text { Ecologico }\end{array}$} \\
\hline & & \multicolumn{2}{|c|}{$\mathrm{CT}$} & \multicolumn{2}{|c|}{ CEIR } & \multicolumn{2}{|c|}{ CEC } & \multirow{2}{*}{ CT } & \multirow{2}{*}{ CEIR } & \multirow{2}{*}{ CEC } & \multirow{2}{*}{$\mathrm{CT}$} & \multirow{2}{*}{ CEIR } & \multirow{2}{*}{ CEC } & \multirow{2}{*}{ CT } & \multirow{2}{*}{ CEIR } & \multirow{2}{*}{ CEC } & \multirow{2}{*}{$\mathrm{CT}$} & \multirow{2}{*}{ CEIR } & $\mathrm{CFC}$ & \\
\hline & & 1996 & 2000 & 1996 & 2000 & 1996 & 2000 & & & & & & & & & & & & $\mathrm{CEC}$ & \\
\hline Astronium lecointei Ducke & Anacardiaceae & 23.8 & 29.8 & 138,4 & 100.7 & 9.7 & 14,6 & $100 \%$ & $61 \%$ & $100 \%$ & $0 \%$ & $39 \%$ & $0 \%$ & 6,0 & 16.8 & 4.9 & 0.16 & 0,08 & 0.06 & I \\
\hline Bagassa guianensis Aublet & Moraceae & 23.8 & 11.9 & 260.1 & 41.9 & 272 & 58.4 & $50 \%$ & $16 \%$ & $20 \%$ & $50 \%$ & $84 \%$ & $80 \%$ & 0 & 0 & 4.9 & 0.07 & 0,17 & 0,12 & $\dot{p}$ \\
\hline Caryocar glabum (Aublet) Pers.spp glabrum & Caryocaraceae & 11.9 & 0.0 & 4.2 & 4.2 & & & $0 \%$ & $100 \%$ & & $100 \%$ & $0 \%$ & & 0 & 0 & 0 & & 0,23 & & I \\
\hline Cordia bicolor D.C & Boraginaceae & 6.0 & 0.0 & & & 9,7 & 0.0 & $0 \%$ & & $0 \%$ & $100 \%$ & & $100 \%$ & 0 & 0 & 0 & & & & I \\
\hline Cordia goeldana Huber & Boraginaceae & 11.9 & 17.9 & 0.0 & 8.4 & & & $50 \%$ & & & $50 \%$ & & & 11.9 & 8.4 & & 0.09 & & & I \\
\hline Couratari oblongfolia Ducke et Knuth. & Lecythedacea & & & & & 14,6 & 9.7 & & & $67 \%$ & & & $33 \%$ & 0 & 0 & 0 & & & 0.36 & TS \\
\hline Dipteryx odorata Willd & Leg: Papilionoideae & 0.0 & 6.0 & 4,2 & 4,2 & 4,9 & 4,9 & & $100 \%$ & $100 \%$ & & $0 \%$ & $0 \%$ & 6.0 & 0 & 0 & & 0.15 & 0.20 & I \\
\hline Guateria schomburgkiana Mart. & Annonaceae & 6.0 & 6.0 & & & 102,14 & 48,6 & $100 \%$ & & $48 \%$ & $0 \%$ & & $52 \%$ & 0 & 0 & 0 & 0.36 & & 0.27 & TS \\
\hline Hymenaea courbaril L. & Leg: Caesalpinioideae & & & & & 14,6 & 24,3 & & & $100 \%$ & & & $0 \%$ & 0 & 0 & 9,7 & & & 0,11 & Ts \\
\hline Jacaranda copaia (Aublet) D. Don & Bignoniaceae & 23.8 & 23.8 & 289,4 & 117.5 & 170.2 & 34,0 & $100 \%$ & $41 \%$ & $20 \%$ & $0 \%$ & $59 \%$ & $80 \%$ & 0 & 0 & 0 & 0.51 & 0.26 & 0.12 & $\mathrm{P}$ \\
\hline Lecyrhis lurida (Miers) Mori & Lecythidaceae & & & 4.2 & 4,2 & 4.9 & 4.9 & & $100 \%$ & $100 \%$ & & $0 \%$ & $0 \%$ & 0 & 0 & 0 & & 0.08 & 0,03 & TS \\
\hline Manilkara bidentada (DC.)A. Chev. & Sapotaceae & 6.0 & 6.0 & & & & & $100 \%$ & & & $0 \%$ & & & 0 & 0 & 0 & 0.14 & & & TS \\
\hline Manilkara huberi (Huber) Stanley & Sapotaceae & 35,8 & 35.8 & 12.6 & 12,6 & 9.7 & 9.7 & $100 \%$ & $100 \%$ & $100 \%$ & $0 \%$ & $0 \%$ & $0 \%$ & 0 & 0 & 0 & 0.11 & 0.07 & 0,15 & TS \\
\hline Nectandra pichurim (H.B.K.) Mez & Lauraceae & 23.8 & 17.9 & 121,6 & 8.4 & 38.9 & 29.2 & $75 \%$ & $7 \%$ & $75 \%$ & $25 \%$ & $93 \%$ & $25 \%$ & 0 & 0 & 0 & 0.25 & 0.16 & 0.14 & Ts \\
\hline Ocotea glomerata (Nees) Mez & Lauraceae & & & 8.4 & 8.4 & & & & $100 \%$ & & & $0 \%$ & & 0 & 0 & 0 & & 0,79 & & TS \\
\hline Parkia gigantocarpa Ducke & Leg: Mimosoideae & 6.0 & 6,0 & 0.0 & 8.4 & 0.0 & 4.9 & $100 \%$ & & & $0 \%$ & & & 0 & 8.4 & 4.9 & 0.63 & & & $\mathrm{I}$ \\
\hline Parkia nitida Miq & Leg: Mimosoideae & 47.7 & 53.6 & 62.9 & 46.1 & 141.1 & $\$ 7.5$ & $100 \%$ & $73 \%$ & $62 \%$ & $0 \%$ & $27 \%$ & $38 \%$ & 6,0 & 0 & 0 & 0.39 & 0.71 & 0.48 & 1 \\
\hline Protium sagotianum March. & Burseraceae & & & 4.2 & 4.2 & 4.9 & 4.9 & & $100 \%$ & $100 \%$ & & $0 \%$ & $0 \%$ & 0 & 0 & 0 & & 0.18 & 0.40 & TS \\
\hline Pseudopiptadenia suaveolens (Miq.) J.W.Grimes & Leg: Mimosoideae & 65.6 & 53.6 & 75.5 & 67.1 & 43.8 & 73.0 & $82 \%$ & $78 \%$ & $89 \%$ & $18 \%$ & $22 \%$ & $11 \%$ & 0 & 8.4 & 34 & 0.13 & 0.06 & 0.08 & I \\
\hline Scheffera morototoni (Aubl.) Mag.. Steyer \& Frodin & Araliacene & & & 25.2 & 12.6 & 58,4 & 4,9 & & $17 \%$ & $0 \%$ & & $83 \%$ & $100 \%$ & 0 & 8.4 & 4.9 & & 1,85 & & $\mathrm{P}$ \\
\hline Schizolobium parahyba (Vell.) Blake & Leg: Caesalpinioideae & & & 12.6 & 4.2 & & & & $33 \%$ & & & $67 \%$ & & 0 & 0 & 0 & & 0.58 & & $\mathrm{p}$ \\
\hline Sclerolobium goeldianum Huber & Leg: Caesalpinioideae & 113.2 & 113.2 & 96.5 & 75.5 & 97,3 & 92.4 & $100 \%$ & $78 \%$ & $95 \%$ & $0 \%$ & $22 \%$ & $5 \%$ & 0 & 0 & 0 & 0.29 & 0.28 & 0.27 & i \\
\hline Sterculia speciosa K.Schum. & Sterculiaceae & 17.9 & 17.9 & 12,6 & 12.6 & 43,8 & 34,0 & $100 \%$ & $100 \%$ & $78 \%$ & $0 \%$ & $0 \%$ & $22 \%$ & 0 & 0 & 0 & 0.28 & 0.45 & 0.36 & I \\
\hline Striphnodendron paniculata Poepp. \& EnI. & Leg: Mimosoideae & & & 0.0 & 4.2 & 0.0 & 9.7 & & & & & & & 0 & 4,2 & 9.7 & & & & I \\
\hline Tabebuia serratifolia (Vanl.) Nichols. & Bignoniaceae & 6.0 & 6,0 & 4,2 & 4.2 & & & $100 \%$ & $100 \%$ & & $0 \%$ & $0 \%$ & & 0 & 0 & 0 & 0,30 & 0.10 & & I \\
\hline Tachigali paniculata (Ducke) Dwyer & Leg: Caesalpinioideae & & & & & 14,6 & 14.6 & & & $100 \%$ & & & $0 \%$ & 0 & 0 & 0 & & & 0,23 & I \\
\hline Tachigalia alba Ducke & Leg: Caesalpinioideae & & & & & 9.7 & 9.7 & & & $100 \%$ & & & $0 \%$ & 0 & 0 & 0 & & & 0.14 & 1 \\
\hline Tetragastris altissima Willd. & Burseraceae & 0.0 & 11.9 & & & 9.7 & 9.7 & & & $100 \%$ & & & $0 \%$ & 11,9 & 0 & 0 & & & 0,15 & TS \\
\hline Trattinickia rhoifolia Willd & Burseraceae & & & 12.6 & 4.2 & 29.2 & 14,6 & & $33 \%$ & $50 \%$ & & $67 \%$ & $50 \%$ & 0 & 0 & 0 & & 0.13 & 0.20 & I \\
\hline Virola cuspidata Warb. & Myristicaceae & 29,8 & 35.8 & 16.8 & 16.8 & 9.7 & 19.5 & $100 \%$ & $75 \%$ & $100 \%$ & $0 \%$ & $25 \%$ & $0 \%$ & 6.0 & 4.2 & 9.7 & 0.25 & 0.25 & 0.30 & TS \\
\hline
\end{tabular}

convencional; (b) Espaços em branco significam que a espécie näo ocorreu e zero (0) quando a espécie näo foi recrutada; (c) $P \rightarrow$ Grupo ecológico pioneiras; $l \rightarrow$ Grupo ecolósico demandantes de luz e TS $\rightarrow$ grupo ecológico tolerantes à sombra. 


\subsubsection{Riqueza e diversidade de espécies nas clareiras}

As clareiras da exploração convencional apresentaram maior riqueza de espécies ao longo dos quatro anos de monitoramento em comparação às clareiras dos demais tratamentos (Figura 7a). No entanto, considerando a riqueza relativa de espécies, as clareiras de exploração de impacto reduzido tiveram sua riqueza aumentada em $16 \%$, enquanto que nas clareiras da exploração convencional e nas clareiras testemunha essa riqueza se manteve inalterada (Figura $7 b$ ).

$\mathrm{Na}$ diversidade de espécies medida pelo índice $\alpha$ de Fisher, as clareiras da exploração de impacto reduzido e as da exploração convencional tiveram diversidades maiores do que as clareiras testemunha, sendo que o índice das clareiras da exploração convencional foi levemente superior ao das clareiras da exploração de impacto reduzido (Figura 7c).

Figura 7: Riqueza de espécies (a), riqueza relativa (b) e índice $\alpha$ de Fisher (c) por tipo de clareira e período de monitoramento (1999-2000).

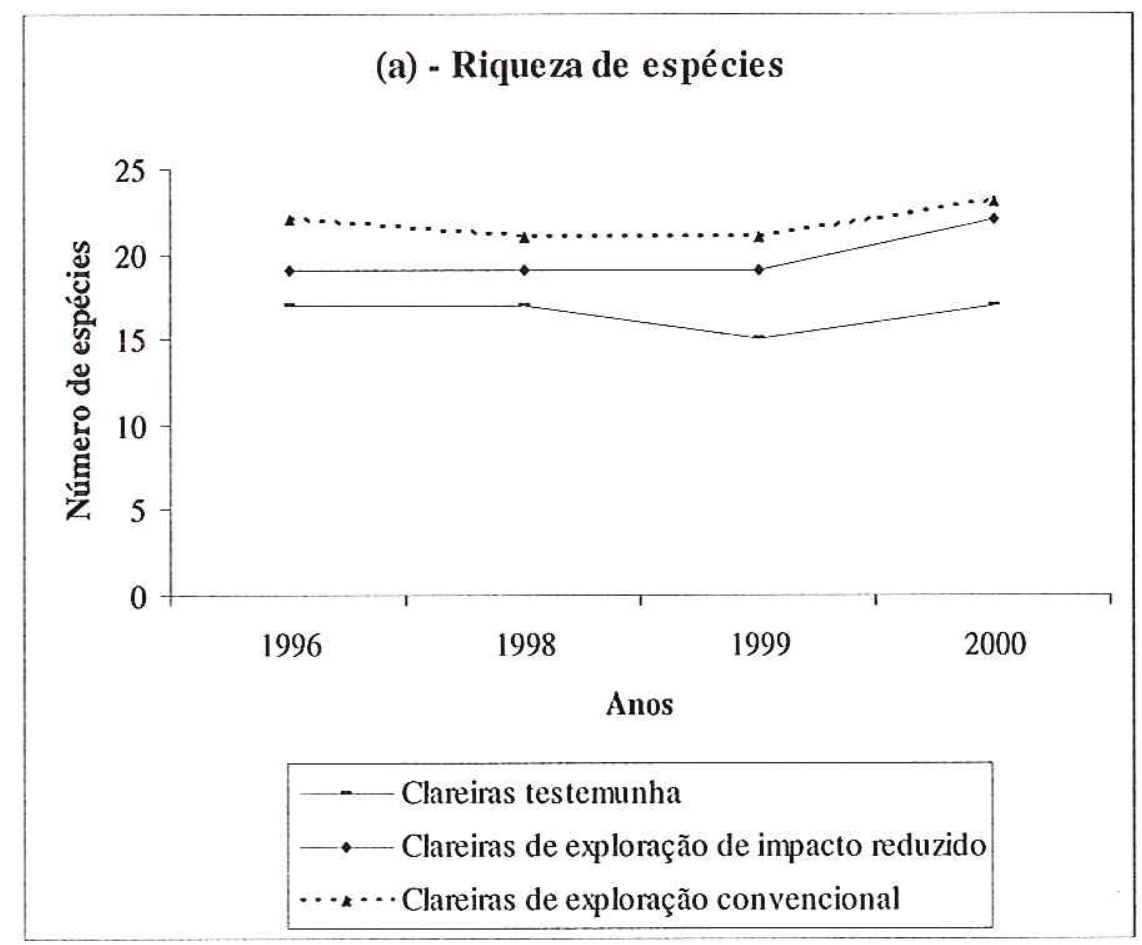



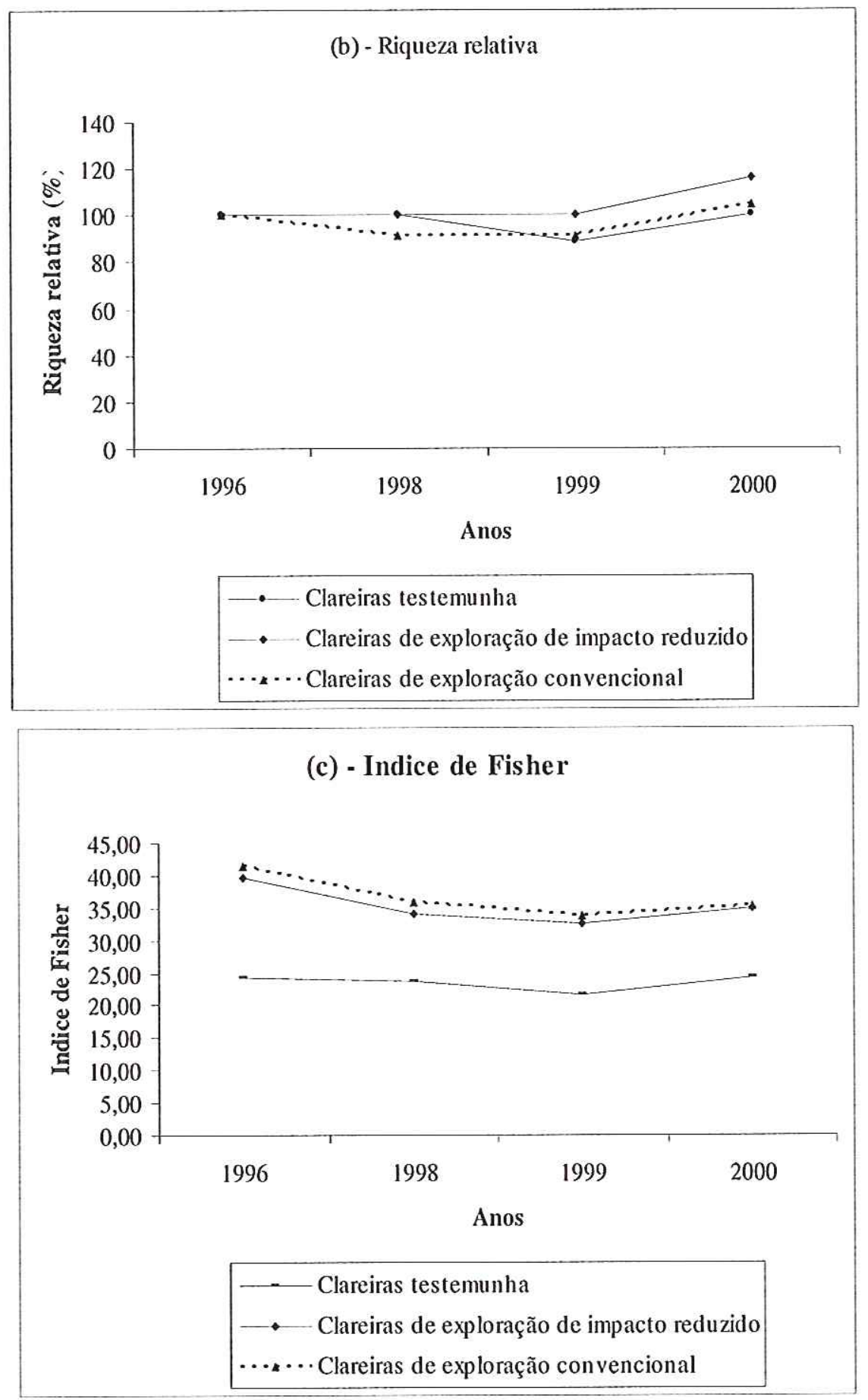


\subsubsection{Densidade (indivíduos/ha) nas clareiras}

A densidade de indivíduos por hectare foi muito semelhante entre as clareiras da exploração madeireira com exploração de impacto reduzido e as clareiras da exploração convencional, ou seja, muitos indivíduos nos períodos iniciais e uma grande mortalidade nos primeiros anos de regeneração natural. Este é um padrão clássico encontrado em clareiras recentemente abertas. As clareiras testemunha não apresentaram diferenças substanciais em densidade para o mesmo período (1996-2000), indicando que estas clareiras selecionadas para o estudo já estavam estabilizadas. A densidade média por tipo de clareira em 1996 foi de 410,5 ind/ha nas clareiras testemunha, $1.145 \mathrm{ind} / \mathrm{ha}$ nas clareiras de exploração de impacto reduzido e 1.100 ind/ha nas clareiras de exploração convencional (Figura 8).

Figura 8: Densidade média de indivíduos por hectare, por tratamento, no período de monitoramento (1996-2000).

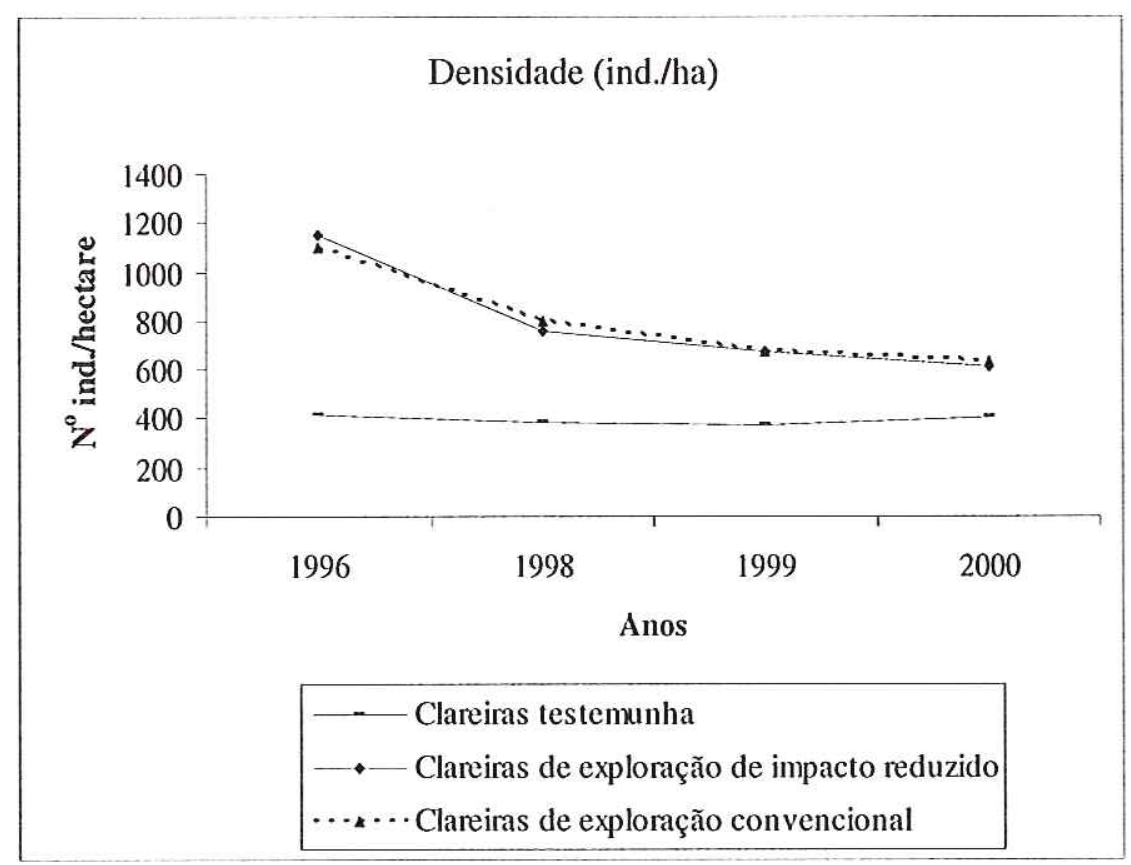




\subsubsection{Redução na densidade de indivíduos}

Somente as clareiras testemunha não apresentaram reduções significativas na densidade média de árvores, indicando padrão de estabilidade. Comparando os dois tratamentos (exploração de impacto reduzido e exploração convencional) através do teste $t$ para duas amostras independentes, com variância não combinada, obteve-se $t=-$ 0,19 , com $p=0,86$. A conclusão é que as diferenças na redução da densidade de indivíduos nas clareiras não foram significativas entre os tratamentos que ocorreu exploração em relação às clareiras onde não ocorreu exploração - testemunha (Tabela 2).

A redução no número de indivíduos foi maior nas clareiras de exploração de impacto reduzido $(46,8 \%)$ em comparação com as da exploração convencional $(42,8 \%)$ e as clareiras testemunha $(0,4 \%)$. Em 2000, as clareiras testemunha detinham 99,6\% dos indivíduos sobreviventes, as clareiras da exploração convencional detinham $57 \%$ e as clareiras de exploração de impacto reduzido, $57 \%$.

Tabela 2: Comparação da redução média da densidade em três tipos de clareira (testemunha-T, exploração de impacto reduzido-EIR e exploração convencional-EC) através de teste $t$ pareado.

\begin{tabular}{lcccc}
\hline & $\begin{array}{c}\text { Densidade média em } \\
\text { Tratamento }\end{array}$ & $\begin{array}{c}\text { Densidade média em } \\
\text { 1996 (indivíduos/ha) }\end{array}$ & $\mathrm{t}$ & $\mathrm{p}$ \\
\hline $\mathrm{T}$ & 41000 (indivíduos/ha) & & \\
EIR & 1145 & 408,7 & $-0,10$ & 0,46 \\
$\mathrm{EC}$ & 1100 & 613 & $-1,93$ & 0,043 \\
\hline
\end{tabular}

\subsubsection{Balanço do número de espécies}

No início do estudo (1996) foram encontradas 17 espécies madeireiras nas clareiras testemunha, 19 espécies nas clareiras de exploração de impacto reduzido e 22 nas clareiras de exploração convencional. Encontraram-se 10 espécies comuns nos três tipos de clareiras, três espécies que ocorriam apenas nas clareiras testemunha, duas que ocorriam apenas nas clareiras de exploração de impacto reduzido e cinco espécies que ocorriam apenas nas clareiras de exploração convencional (Tabela 2). Houve reduções 
no número de espécies nas clareiras testemunha (12\%) e nas de exploração convencional (9\%). As espécies que desapareceram nas clareiras testemunha foram Caryocar glabum (Aublet) Pers. spp glabrum e Cordia bicolor D.C. Nas clareiras de exploração convencional desapareceram a Cordia bicolor A. DC. e Scheffera morototoni (Aubl) Maguirre (Tabela 1).

Analisando o histórico da área, observou-se que todas as espécies exploradas na área apresentaram regeneração nas clareiras.

\subsubsection{Sobrevivência por tratamento e por grupo ecológico}

As menores proporções de indivíduos sobreviventes nas clareiras eram de espécies pioneiras, exceto nas clareiras testemunha, onde as menores proporções de sobreviventes eram de espécies demandantes de luz. No período de monitoramento, observaram-se poucas mudanças nessas clareiras, uma evidência de que elas estão em equilíbrio. Para o grupo de espécies demandante de luz não houve diferenças de indivíduos sobreviventes entre os tratamentos. Em relação aos indivíduos sobreviventes das espécies tolerantes à sombra, as clareiras de exploração de impacto reduzido foram as que apresentaram a menor proporção desses indivíduos (Figura 9). 
Figura 9: Proporção da população de indivíduos presentes nas clareiras, por grupo ecológico e tipo de clareira, no final do monitoramento.

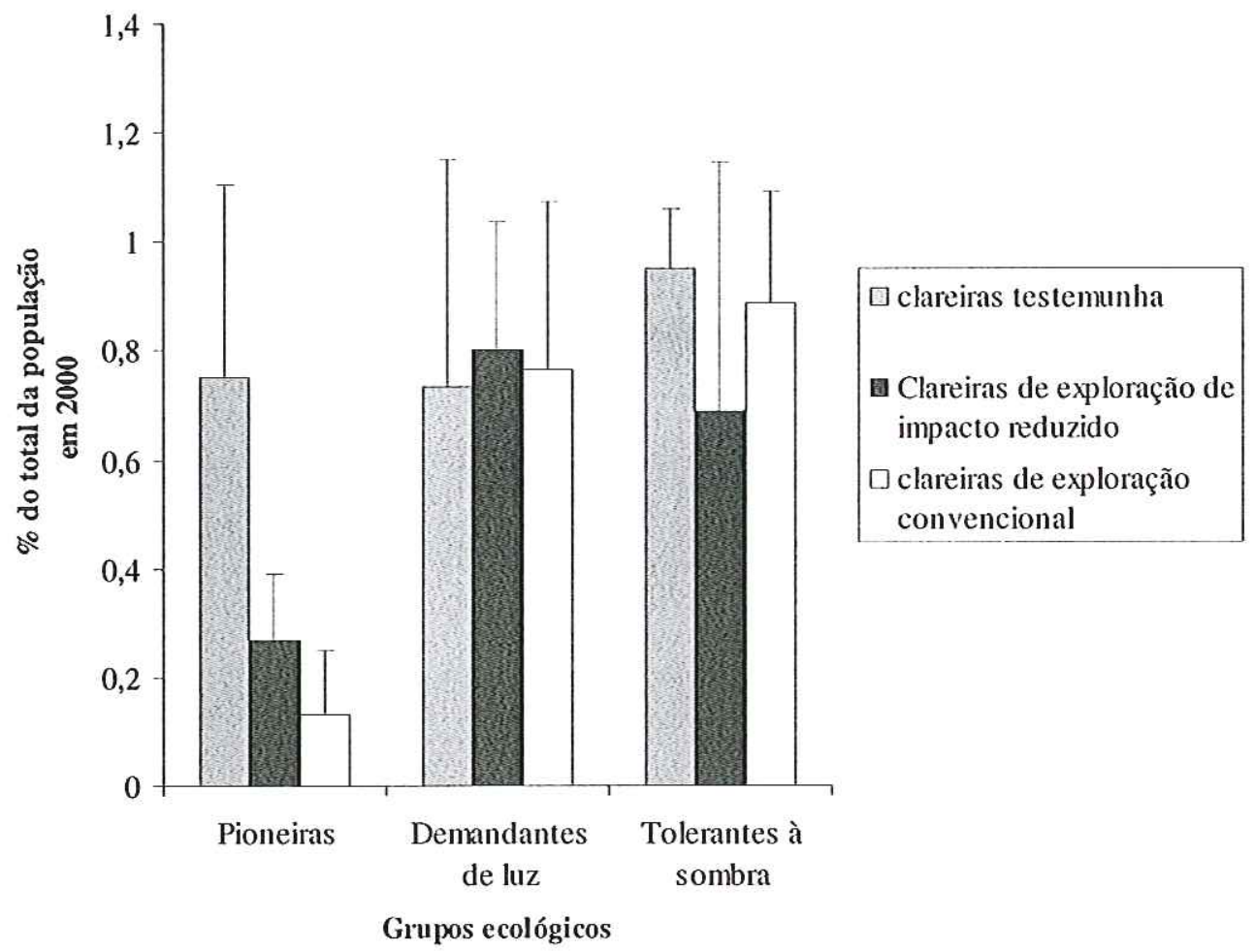

\subsubsection{Mortalidade}

\subsubsection{Relação entre mortalidade de indivíduos e área da clareira}

Considerando todas as clareiras juntas, observou-se que a mortalidade de indivíduos está fortemente relacionada com o tamanho da área; quanto maior a área da clareira mais alta é a densidade e mortalidade devido à alta competição entre as plantas (Figura 10). Isto é explicado pela alta predominância de espécies pioneiras nas clareiras grandes. Este grupo de espécies tem evolutivamente uma característica de povoar as clareiras na fase inicial e morrerem em seguida deixando o lugar para outros grupos de espécies como as demandantes de luz e as tolerantes à sombra. A ecologia destes grupos de espécies tem sido relatada por muitos pesquisadores como Uhl (1987), Uhl et al. (1988), Kyereh et al. (1999), Tabarelli \& Mantovani (2000) e Pena-Claros (2001). 
Figura 10: Relação entre mortalidade de indivíduos e tamanho da clareira. O Corr no canto superior esquerdo significa correlação de Spearman.

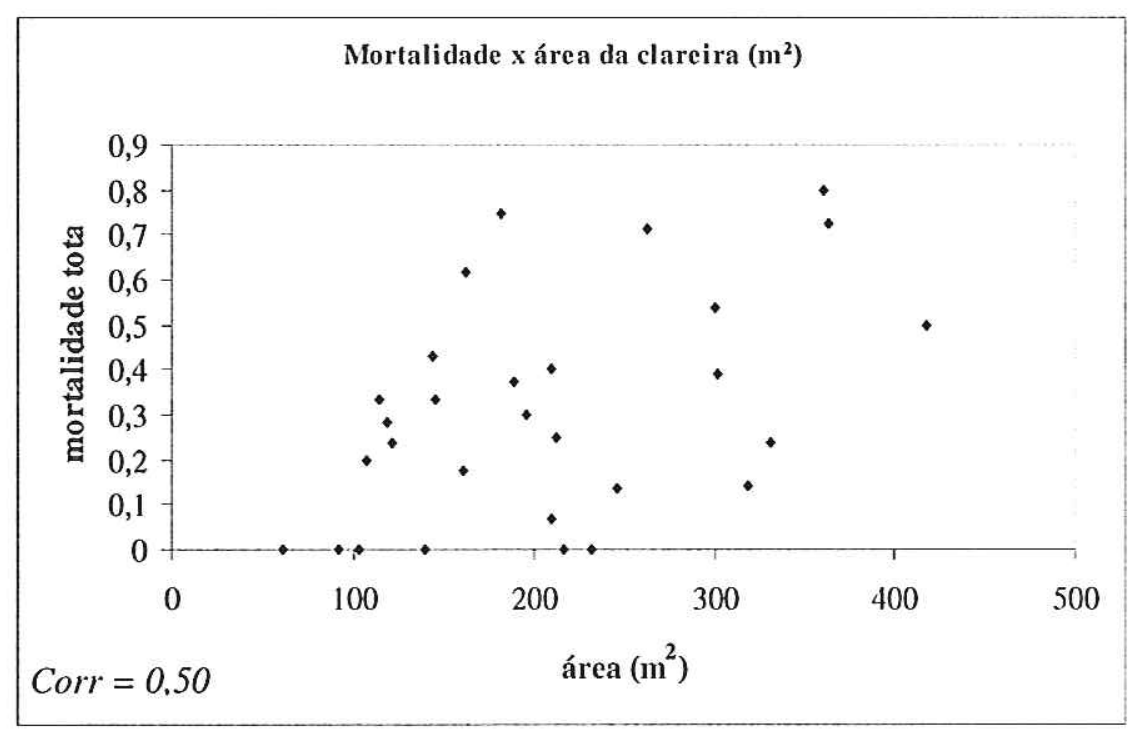

\subsubsection{Mortalidade por tratamento e por grupo ecológico}

Não houve diferenças estatísticas na taxa média de mortalidade anual entre as clareiras de exploração de impacto reduzido (0,39\%/ano) e as clareiras de exploração convencional $(0,41 \% / a n o)$. Entretanto, observaram-se diferenças altamente significativas na taxa de mortalidade entre as clareiras testemunha (0,09\%/ano) e os demais tipos de clareira (Tabela 3). Na comparação entre grupos ecológicos, encontraram-se diferenças significativas na taxa de mortalidade entre os três grupos considerados neste trabalho (Tabela 3).

Tabela 3: Taxa média de mortalidade anual por tratamento e por grupo ecológico.

\begin{tabular}{l|ccc|c}
\hline \multicolumn{1}{c|}{ Grupos ecológicos } & $\begin{array}{c}\text { Clareiras } \\
\text { Testemunha }\end{array}$ & $\begin{array}{c}\text { Clareiras } \\
\text { EIR }\end{array}$ & $\begin{array}{c}\text { Clareiras } \\
\text { EC }\end{array}$ & Média geral \\
\hline Pioneiras & 0,25 & 0,65 & 0,74 & $0,64^{\mathrm{a}}$ \\
Demandantes de luz & 0,10 & 0,20 & 0,19 & $0,17^{\mathrm{b}}$ \\
Tolerantes à sombra & 0,07 & 0,35 & 0,35 & $0,29^{\mathrm{c}}$ \\
Média geral & $0,09^{\mathrm{a}}$ & $0,39^{\mathrm{b}}$ & $0,41^{\mathrm{b}}$ & \\
\hline & $F=7,20 ; \mathrm{p}=0,03$ & & $F=15,38 ; \mathrm{p}<0,001$ \\
\hline
\end{tabular}


Notas: Mortalidade e homocedasticidade aceitáveis; números que repartem letras diferentes foram diferentes estatisticamente pelo teste de Tukey para o nível de significância global de $5 \%$ de probabilidade.

\subsubsection{Recrutamento}

Considerando todas as clareiras juntas, o tamanho da clareira (área em $\mathrm{m}^{2}$ ) não influenciou o recrutamento das plantas (Figura 11). Não se encontraram diferenças estatísticas significativas na taxa de recrutamento entre os tratamentos $(F=0,59 ; \mathrm{p}=$ $0,559)$, havendo, porém, entre os grupos ecológicos $(F=12,34 ; \mathrm{p}=0,001)$ (Tabela 4). Observaram-se seis espécies recrutadas nas clareiras testemunhas, sete nas clareiras de exploração de impacto reduzido, e oito nas clareiras de exploração convencional. Encontrou-se recrutamento de espécies novas nas clareiras, sendo duas nas clareiras testemunha (Tetragastris altissima (Aubl.) Swart. E Dipteryx odorata (Aubl.) Willd), três nas clareiras de exploração de impacto reduzido (Parkia gigantocarpa Ducke, Cordia goeldiana Huber e Striphnodendron paniculata Poepp. \& Engl.) e duas nas clareiras de exploração convencional (Parkia gigantocarpa Ducke e Striphnodendron paniculata Poepp. \& EnI.) (Tabela 1).

Figura 11: Relação entre tamanho da clareira e recrutamento: todas as clareiras. O Corr no canto superior esquerdo significa correlação de Spearman.

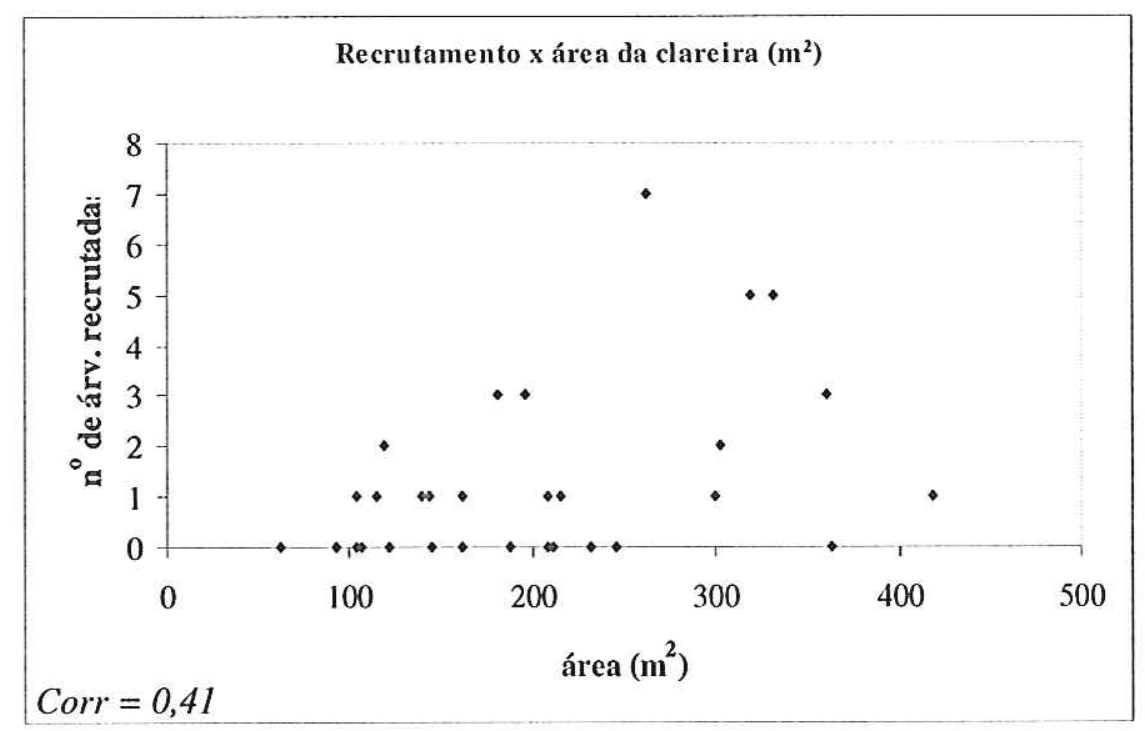


Tabela 4: Recrutamento por tratamento e por grupo ecológico.

\begin{tabular}{l|ccc|c}
\hline Grupos ecológicos & $\begin{array}{c}\text { Clareiras } \\
\text { Testemunha }\end{array}$ & $\begin{array}{c}\text { Clareiras } \\
\text { exploração } \\
\text { de impacto } \\
\text { reduzido }\end{array}$ & $\begin{array}{c}\text { Clareiras } \\
\text { exploração } \\
\text { convencional }\end{array}$ & Média geral \\
\hline Pioneiras & 0,0 & 7,63 & 5,56 & $4,4^{\mathrm{a}}$ \\
Demandantes de luz & 27,7 & 51,8 & 57,6 & $44,8^{\mathrm{b}}$ \\
Tolerantes à sombra & 10,9 & 5,1 & 8,55 & $8,18^{\mathrm{a}}$ \\
Média geral & $38,6^{\mathrm{a}}$ & $64,6^{\mathrm{b}}$ & $71,7^{\mathrm{c}}$ & $F=12,34 ; \mathrm{p}$ \\
& \multicolumn{3}{|c}{$F=0,59 ; \mathrm{p}=0,559$} & $<, 001$ \\
\hline
\end{tabular}

Notas: suposições estatísticas de normalidade e homocedasticidade razoáveis.

\subsubsection{Crescimento diamétrico por tratamento}

Não houve diferenças estatísticas na taxa de incremento diamétrico entre as clareiras dos três tratamentos. No teste estatístico normal de análise de variância, os parâmetros de normalidade e homocedasticidade não foram aceitáveis. Dessa forma, realizou-se a análise através do teste de Kruskal Wallis que também não foi significativo (Tabela 5).

Tabela 5: Comparação do crescimento através de incremento diamétrico médio entre clareiras da exploração de impacto reduzido, exploração convencional e testemunha em Paragominas/Pa.

\begin{tabular}{lcc}
\hline \multicolumn{1}{c}{ Tratamento } & N & $\begin{array}{c}\text { Média de incremento em } \\
\text { diâmetro (cm/ano) }\end{array}$ \\
\hline Clareiras testemunha & 10 & 0,26 \\
Clareiras de exploração de impacto reduzido & 10 & 0,26 \\
Clareiras de exploração convencional & 10 & 0,25 \\
\hline Fanava $_{\text {panava }}$ & $\mathbf{0 , 0 3}$ \\
H $_{\text {Kruskal Wallis }}$ & $\mathbf{0 , 9 7 5}$ \\
p $_{\text {Kruskal Wallis }}$ & $\mathbf{0 , 6 0 0}$ \\
\hline
\end{tabular}


Notas: Número de indivíduos por tratamento $(N)$, considerando 10 clareiras de tamanhos diferentes por tratamento.

As espécies que mais cresceram no período de monitoramento foram Schefflera morototoni (Aubl.) Maguire, Steyerm. \& Frodin (1,85 cm/ano), Ocotea glomerata (Nees) Mez (0,79 cm/ano) e Parkia nitida Miq $(0,71 \mathrm{~cm} / \mathrm{ano})$ nas clareiras de exploração de impacto reduzido e a Parkia gigantocarpa Ducke $(0,63 \mathrm{~cm} / \mathrm{ano})$ nas clareiras testemunha (Tabela 1).

\subsubsection{Crescimento em área basal}

A área basal média por hectare tem se mantido maior nas clareiras de exploração de impacto reduzido em relação às demais clareiras consideradas neste estudo. As clareiras testemunha $\mathrm{e}$ as da exploração convencional apresentaram um crescimento semelhante no início do monitoramento. No entanto, a partir do segundo ano, o crescimento em área basal nas clareiras de exploração convencional se tornou superior. Na comparação estatística de incremento periódico em área basal através de anava entre os tratamentos, não se observaram diferenças entre os tipos de clareira $(F=0,91 ; \mathrm{p}=$ 0,415). Na comparação de incremento médio em área basal por grupo ecológico observou-se uma diferença estatística entre o grupo tolerantes à sombra e os demais grupos. Todavia, não foram observadas diferenças estatísticas entre pioneiras e demandantes de luz $(F=9,96 ; \mathrm{p}=<0,0001)$ (Figura 12). 
Figura 12: Acúmulo de área basal no período de monitoramento (1999-2000) por tipo de clareira (Clareiras testemunha, clareiras de exploração de impacto reduzido e clareiras de exploração de impacto reduzido) em Paragominas, Pará.

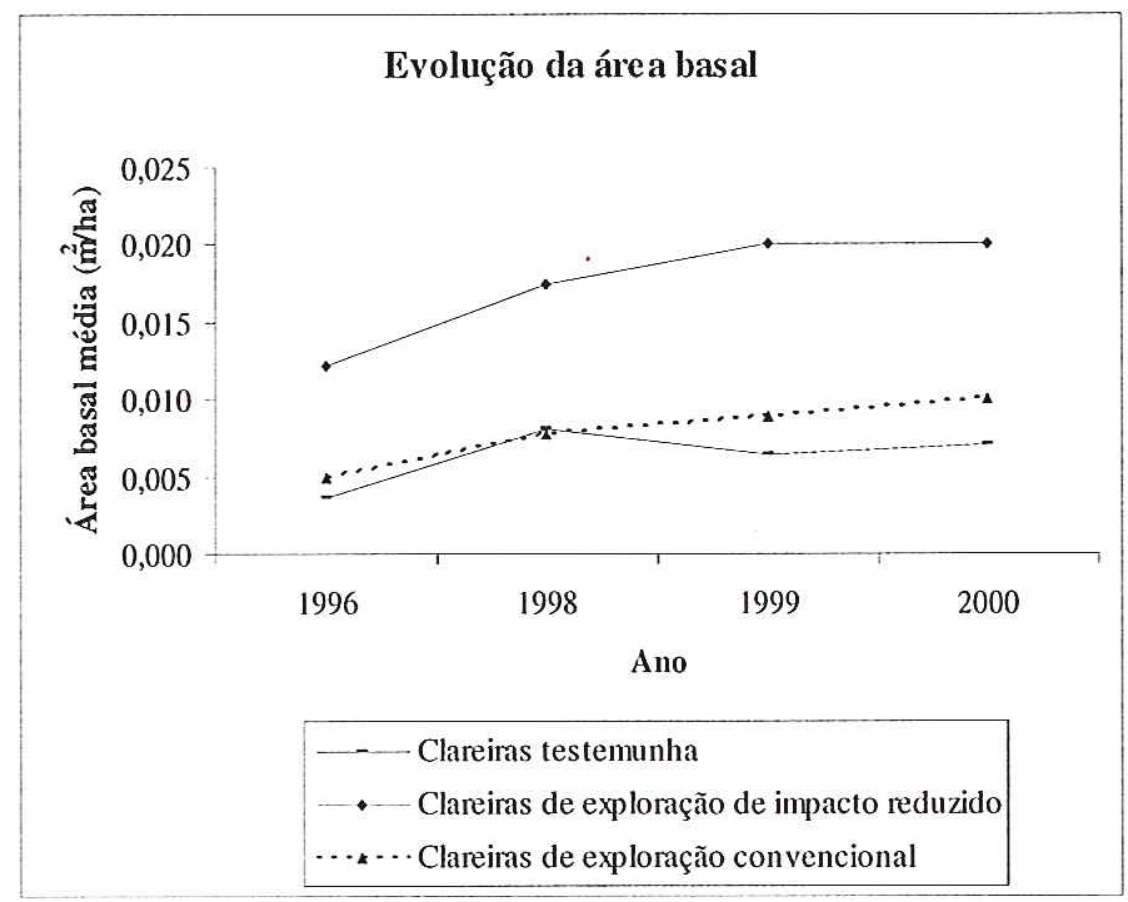

\subsection{Discussão}

\subsubsection{Tamanho das clareiras}

Em geral, as clareiras encontradas neste estudo eram bem menores do que as encontradas em outras regiões do mundo e da Amazônia brasileira. Bullock (1980) encontrou um tamanho médio de clareiras de $400 \mathrm{~m}^{2} \quad(n=100)$ em Camarões; $58 \%$ superior às encontradas na área testemunha, $40 \%$ superior às da área de exploração de impacto reduzido e 49\% superior às da exploração convencional. Agyeman et al., (1995) encontrou uma abertura de clareiras por árvore derrubada entre $350 \mathrm{~m}^{2}$ e $1.800 \mathrm{~m}^{2} \mathrm{em}$ Bura Forest Reserve na Uganda, enquanto que neste estudo, as aberturas das clareiras das áreas exploradas (exploração de impacto reduzido e exploração convencional) ficaram entre $107 \mathrm{~m}^{2} \mathrm{e} 415 \mathrm{~m}^{2}$. 
Neste estudo, o tamanho das clareiras na exploração de impacto reduzido foi um pouco maior do que as da exploração convencional. Jonhs et al., 1996 e Holdsworth \& Uhl (1997), neste mesmo local de estudo, utilizando outra metodologia, encontraram uma redução de $53 \%$ no tamanho médio das clareiras de exploração de impacto reduzido em relação às da exploração convencional. Costa \& Magnusson (2003) encontraram clareiras de exploração cujo tamanho variava entre $90 \mathrm{~m}^{2}$ e $2.500 \mathrm{~m}^{2}$ próximo de Manaus, na Amazônia Central. Cinqüenta e nove por cento dessas clareiras encontradas por Costa \& Magnusson mediam mais de $200 \mathrm{~m}^{2}$ (Vieira e Higuchi, 1990). A maioria das clareiras nesta área de estudo era menor do que $2.000 \mathrm{~m}^{2}$ (Almeida, 1989).

Correlação entre número de espécies e de indivíduos pela área da clareira: É importante salientar aqui que nas clareiras testemunhas não se conhecia a idade exata das clareiras. As clareiras testemunha foram selecionadas levando-se em conta a semelhança na altura do estrato superior predominante em relação às clareiras da área com exploração florestal. Os resultados de relacionamento de espécies e indivíduos pela área da clareira, densidade ao longo do período de monitoramento, diversidade, mortalidade e recrutamento apresentados pelas clareiras testemunha nos levam a crer que essas clareiras podem ter idade superior às clareiras de exploração de impacto reduzido e de exploração convencional, pois suas características parecem as de uma clareira de floresta estável.

Padrão de colonização das espécies nas clareiras: Neste estudo, as espécies Bagassa guianensis Aubl., Guatteria schomburgkiana Mart. e Schefflera morototoni (Aubl.) Maguire, Steyerm. \& Frodin dominaram as clareiras grandes. Nas clareiras menores, as espécies mais freqüentes foram Sterculia speciosa K. Schum. e Couratari oblongifolia Ducke \& Knuth. Algumas espécies como Astronium lecointei Ducke, pseudopiptadenia suaveolens (Miq.) J.W.Grimes, e Sclerolobium goeldianum Huber não aparentaram preferência por tamanho de clareira no período de monitoramento; sendo encontradas em vários tamanhos de clareira. Outros estudos com este enfoque confirmam a preferência de algumas espécies por algum tamanho de clareira. Hartshorn (1980), em seu estudo, observou espécies com tendência de povoar clareiras grandes como a Ceiba, cavanillesia, Fícus e Swietenia, e espécies com tendência de povoar 
clareiras não muito grandes como a Cecropia, Jacaranda, Ochroma e Trema. Já no Panamá, Brokaw (1985) observou que a abertura da clareira favorecia o estabelecimento de espécies clímax e Brandani et al. (1988), observaram variação na composição de espécies dentro da clareira. Este estudo confirma que a composição pode variar de clareira para clareira e dentro da própria clareira.

Na correlação de Spearman, tanto o número de indivíduos como o número de espécies apresentou correlação positiva com o tamanho da clareira $\left(\mathrm{m}^{2}\right)$ em todos os tratamentos. Como observado neste estudo e já comprovado por Ter Steege et al. (1996) na Guiana e por Spies \& Franklin (1989) e Denslow (1980) em outras regiões, o tamanho da clareira pode influenciar a composição futura de espécies e o arranjo espacial da floresta. No entanto, essas informações diferem dos resultados de Uhl et al. (1988), que observaram que o tamanho da clareira tem pouco efeito sobre a densidade, estabelecimento e mortalidade das plantas. Como discutido acima, o aparecimento de uma dada espécie em uma clareira pode estar relacionada a diversos fatores, porém, se não tiverem espécies matrizes para dispersar sementes, nenhum arranjo espacial será capaz de promover o aparecimento da espécie na clareira.

\subsubsection{Riqueza e diversidade de espécies}

A riqueza e a diversidade de espécies foram maiores nas áreas onde houve exploração. Esses resultados combinam com os de Magnussom et al. (1999) na Amazônia Central. Quando se mediu a diversidade de espécies através da riqueza relativa, notou-se que as clareiras de exploração de impacto reduzido apresentaram um crescimento relativo da diversidade nos últimos anos superior ao das demais clareiras consideradas neste estudo. Este aumento é resultado principalmente das espécies recrutadas no último período de medição. Todavia, nos resultados deste estudo, não houve diferenças substanciais entre as clareiras de exploração de impacto reduzido e as clareiras de exploração convencional em relação à dinâmica e à composição. 


\subsection{Conclusões}

Apesar de a intensidade de amostragem ser considerada baixa, principalmente para clareiras da exploração de impacto reduzido e da exploração convencional, foi possível analisar estatisticamente as principais diferenças referentes à dinâmica desses tipos de clareiras em relação às clareiras testemunha. Ao longo do período de monitoramento, nenhuma espécie desapareceu nas clareiras de exploração de impacto reduzido, enquanto que nas clareiras testemunhas e nas da exploração convencional houve perda de espécies (12\% nas clareiras testemunha e 9\% nas clareiras de exploração convencional, respectivamente). A riqueza de espécies foi levemente maior nas clareiras da exploração convencional comparando com as clareiras da exploração de impacto reduzido. No entanto, a riqueza relativa (percentagem da riqueza em relação à riqueza inicial) foi superior nas clareiras da exploração de impacto reduzido em relação às demais clareiras. A diversidade de espécies através do índice $\alpha$ de Fisher foi semelhante entre as clareiras de exploração de impacto reduzido e da exploração convencional. Já o acúmulo em área basal no período foi maior nas clareiras de exploração de impacto reduzido. Não houve diferenças nas taxas de crescimento, taxa de mortalidade e taxas de redução de densidade entre os tipos de clareira.

Não houve diferenças significativas no tamanho médio das clareiras da exploração convencional e da exploração de impacto reduzido. Entretanto, encontraramse diferenças de tamanho entre as clareiras criadas pela exploração (exploração de impacto reduzido e exploração convencional) e as clareiras testemunha. Além disso, quanto maior área da clareira, maior foi à taxa de mortalidade. As clareiras de exploração de impacto reduzido foram maiores do que as da exploração convencional; provavelmente por terem sido derrubadas árvores maiores na exploração de impacto reduzido.

Os resultados indicam que as clareiras formadas pela exploração madeireira apresentam diversidade, densidade e crescimento em área basal maiores do que as clareiras da área não submetida à exploração, considerando apenas as espécies de valor madeireiro. Portanto, os distúrbios provocados pela queda de árvores na exploração são importantes para o estabelecimento e o crescimento também de espécies madeireiras 
devido aos vários tipos de mudanças no ambiente onde se localizam as clareiras. Estudos futuros de longo prazo sobre dinâmica de clareiras são importantes para acompanhar o comportamento de espécies madeireiras nas clareiras exploradas, pois as espécies presentes nestas clareiras deverão compor as colheitas futuras. Um resultado importante deste estudo é que a intervenção para a colheita de madeira aumenta a diversidade de espécies. No entanto, mesmo aumentando a diversidade de espécies, algumas espécies apresentaram regeneração insuficiente necessitando de plantios de enriquecimento. Como o crescimento da regeneração é relativamente baixo, é importante que sejam realizados tratamentos silviculturais nessas clareiras para promover um crescimento maior da regeneração. 


\section{Capítulo IV: Tratamentos Silviculturais em Regeneração de Espécies Comerciais em Clareiras de Exploração Madeireira em Paragominas, Pará.}

\subsection{Introdução}

A floresta amazônica abrange uma área de aproximadamente 280 milhões de hectares, constituindo-se na mais extensa floresta tropical úmida contínua do mundo. Essa região compreende $57,4 \%$ do território nacional e tem como principal característica uma grande diversidade de espécies representantes da fauna e flora. Estima-se que a Amazônia tenha cerca de 60 bilhões de metros cúbicos de madeira em tora de valor comercial (Veríssimo \& Amaral, 1996 e 1998) e 53\% das florestas em pé do mundo (John, 2002). Isto a torna a maior detentora de madeira tropical do mundo (Veríssimo \& Amaral, 1996 e 1998).

O setor madeireiro tem um papel importante na economia regional. Nos estados do Pará, Mato Grosso e Rondônia, o setor contribui com 15\% do PIB (Schneider et al., 2000). Até meados dos anos 1970, o volume extraído era modesto. Entretanto, nos anos 1990, a região assumiu a liderança na produção de madeira no país. Atualmente, a Amazônia produz cerca de 28 milhões de metros cúbicos de madeira em tora, o que equivale a 86\% da produção do país (Smeraldi \& Veríssimo, 1999; Arima \& Veríssimo, 2001). Porém, a importância econômica dessa atividade contrasta com os grandes impactos que ela causa à floresta (Uhl \& Vieira, 1989; Jonhs et al., 1996; Veríssimo \& Amaral, 1996 e 1998; Barreto et al.,1998). As práticas atuais de exploração na região se comparam a uma "garimpagem florestal" (Veríssimo \& Amaral, 1996 e 1998). Neste modelo de exploração, os madeireiros retiram inicialmente da floresta apenas as espécies 
de alto valor comercial. Sem darem um tempo para que a floresta se regenere, eles retornam a essas áreas para retirar as novas espécies que adquiririam valor comercial. Em função do avanço da exploração dos recursos florestais na região amazônica, a floresta vem sofrendo grandes alterações em sua estrutura natural. Um dos distúrbios mais impactantes são as grandes e inúmeras aberturas no dossel da floresta, as quais podem causar: (i) aumento da frequiência de quedas de árvores maduras pela ação do vento; (ii) ocorrência de fogo ocasionado pelo aumento da radiação solar que atinge o solo, secando os resíduos (Holdsworth \& Uhl, 1997); e (iii) proliferação de cipós e outras plantas pioneiras (Putz, 1984; Vidal et al., 1997; Uhl, et al., 1997). A proliferação dessas plantas nas áreas exploradas é indesejável do ponto de vista madeireiro. Isto porque as espécies pioneiras competem por luz e nutrientes com as espécies de valor comercial, impedindo-as de se desenvolverem. Esta situação obriga o madeireiro a esperar mais tempo para poder fazer um novo corte de madeira naquela área.

Para analisar a viabilidade produtiva futura dessas áreas exploradas, é necessário que se realizem estudos que avaliem as condições das clareiras em termos de dinâmica, composição florística e técnicas de tratamentos silviculturais. Do contrário, essas áreas serão abandonadas ou mesmo convertidas em outros usos do solo. Além disso, para que se desenvolvam práticas silviculturais que visem requisitos econômicos e conservacionistas necessários à sustentabilidade, é necessário conhecer detalhadamente o processo de regeneração das espécies em áreas de exploração de impacto reduzido. (Leal Filho, 2000).

A hipótese deste estudo é de que a regeneração de espécies de valor madeireiro submetidas a tratamentos silviculturais de desbaste cresce mais do que a regeneração não submetida a desbaste. Isto porque a competição, principalmente por luz, é reduzida.

Os objetivos desta pesquisa incluem: (i) identificar a composição da regeneração de espécies de valor em clareiras formadas pela exploração madeireira convencional (EC); (ii) conhecer a dinâmica dessas clareiras; (iii) avaliar o efeito de tratamentos silviculturais no desenvolvimento da regeneração nessas clareiras; e (iii) avaliar os custos da aplicação da técnica silvicultural de desbaste. 


\subsection{Material e método}

\subsubsection{Procedimentos amostrais e estatísticos}

Na área de 75 hectares explorada convencionalmente no PPMF do Imazon (Figura 13), três anos após ter ocorrido exploração predatória (1996), mapeou-se aleatoriamente 60 clareiras de tamanhos diferentes. A intensidade amostral para o número de clareiras foi de $14 \%$ do número de clareiras existentes na área. 
Figura 13: Imagem ykonos de 2000 mostrando a área do experimento e a localização das 60 clareiras de acordo com o tratamento aplicado.

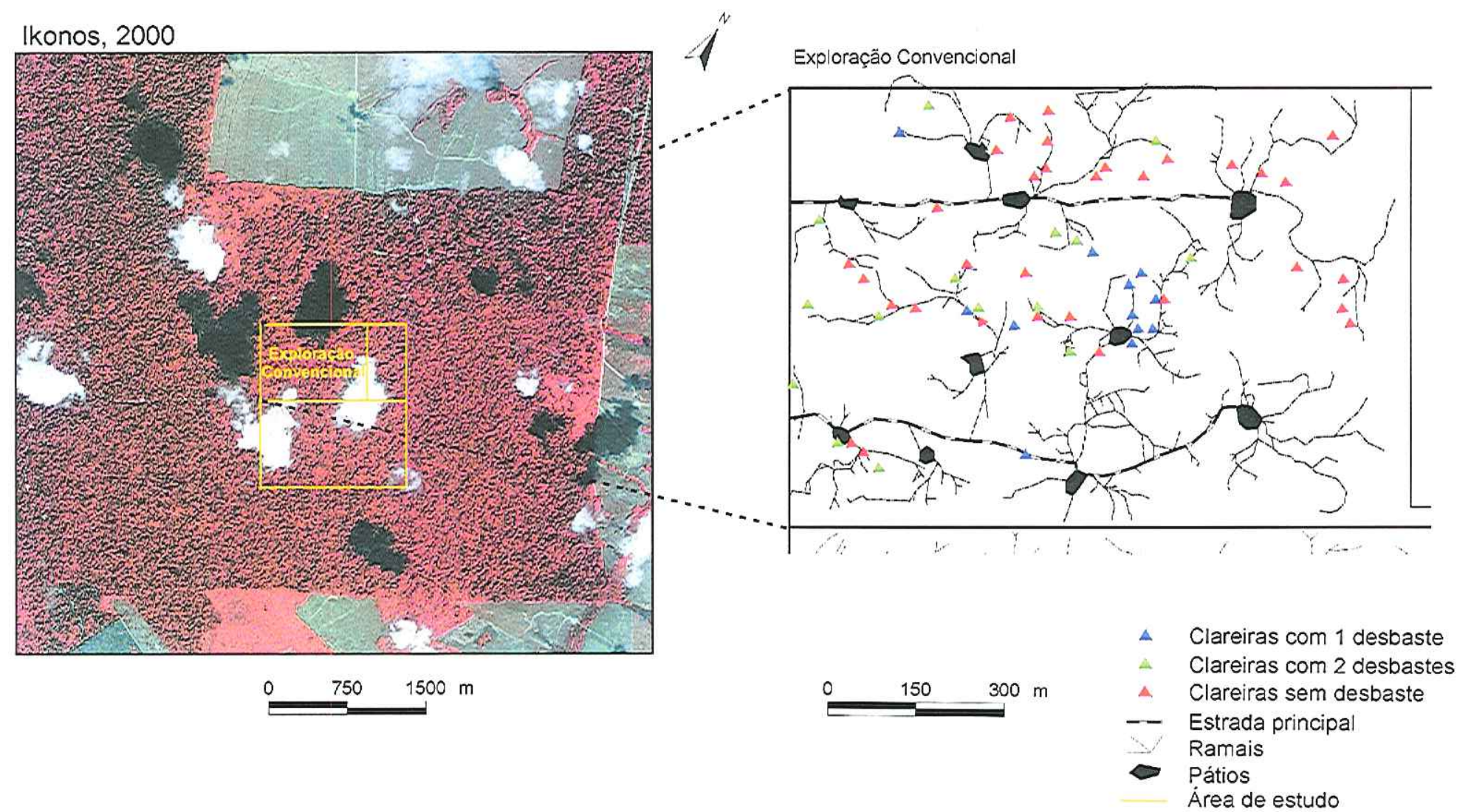




\subsubsection{Coleta dos dados}

Em cada clareira, identificaram-se e mediram-se todos os indivíduos de espécies de valor comercial com altura acima de 1 metro. Eles foram mapeados e marcados com uma placa de alumínio numerada. As áreas das clareiras foram medidas para facilitar o cálculo da densidade de indivíduos. Para avaliar o efeito de tratamentos silviculturais nas clareiras testaram-se 3 tratamentos: clareira testemunha, clareira com realização de um desbaste e clareira com realização de dois desbastes. Em 15 clareiras realizou-se um desbaste, em outras 15 clareiras realizaram-se dois desbastes e em 30 clareiras não se realizou nenhum tratamento. Estas clareiras foram reservadas como testemunha. Para estimar o custo da aplicação dos tratamentos, foi cronometrado o tempo gasto em cada atividade nos diferentes tratamentos. Os tempos registrados e que foram incluídos na estimativa de custos são: tempo para encontrar arvoretas, tempo para se deslocar de uma clareira para outra e tempo para realizar o tratamento (desbaste).

\subsubsection{Monitoramento da coleta de dados}

Os dados foram coletados anualmente, sempre no mês de julho. A exploração ocorreu em 1993. A primeira medição (inventário de espécies de valor nas clareiras) foi feita em julho de 1996 e a última, em julho de 2000, totalizando quatro anos de acompanhamento. A idade da clareira em 2000, portanto, era de sete anos. Como as espécies inventariadas eram indivíduos acima de 1 metro de altura, assumiu-se que as espécies presentes nas clareiras eram de regeneração de espécies madeireiras já estabelecidas.

\subsubsection{Desbaste}

O desbaste consistiu na remoção da vegetação competidora num raio de até 2 metros a partir do pé da planta de valor comercial madeireiro de interesse. Esse procedimento foi realizado no início do experimento (1996), três anos após a colheita, nas clareiras submetidas a um desbaste. Para as clareiras submetidas a dois desbastes, 
realizou-se o primeiro no início do experimento (1996) e o segundo, dois anos depois (1998).

As plantas beneficiadas com o desbaste foram aquelas que apresentavam as melhores condições de crescimento (boa forma do tronco e da copa). Observou-se também a distribuição das plantas escolhidas dentro das clareiras, e selecionaram-se preferencialmente as bem-distribuídas. Se houvesse abundância de espécies de valor, selecionavam-se as melhores, localizadas em espaçamentos adequados, pois se as plantas beneficiadas estivessem muito próximas, logo elas estariam competindo entre si.

\subsubsection{Grupos ecológicos}

As regenerações de valor madeireiro encontradas nas clareiras foram divididas em três grupos ecológicos (funcionais): (i) pioneiras, (ii) demandantes de luz e (iii) tolerantes à sombra. Mais detalhes da classificação das espécies estão no capítulo 3.

\subsubsection{Densidade}

Realizou-se teste $t$ pareado para comparar as densidades antes e após o período do estudo (1996-2000) (no início e no final do monitoramento). Os testes foram realizados após a verificação das suposições de normalidade e homocedasticidade.

\subsubsection{Dinâmica de crescimento da regeneração nos tratamentos}

Para analisar o crescimento, coletaram-se informações de DAP da regeneração com DAP abaixo de $10 \mathrm{~cm}$ e com altura até 1 metro, por um período de quatro anos. Para isso, em 1996, estabeleceram-se as parcelas nas áreas das clareiras mapeadas e registraram-se os indivíduos de valor comercial e o ponto de medição em seus fustes (local determinado para fazer as outras medições). Os dados de crescimento foram coletados em cada tratamento. As análises foram realizadas através de análise de variância. Para comparar estatisticamente os dados através de análise de variância, foi necessário aplicar a transformação logarítmica sobre a variável dependente. As 
transformações logarítmicas foram realizadas quando as suposições de normalidade ou homocedasticidade não eram aceitáveis (Sokal and Rohlf, 1981).

\subsubsection{Cálculo dos incrementos:}

O incremento periódico anual (IPA) foi calculado subtraindo-se a medida final (2000) da medida inicial (1996). Em seguida, dividiu-se o resultado pelos anos de monitoramento (4 anos). O incremento corrente anual (ICA) foi calculado subtraindo o ano posterior do anterior.

\subsubsection{Mortalidade e recrutamento}

Taxa de Mortalidade: a taxa de mortalidade média anual para cada tratamento (sem desbaste, 1 desbaste e 2 desbastes) foi calculada de acordo com o modelo abaixo (Primack et al. 1985):

$m=1-\left(N_{1} / N_{0}\right)^{1 / 2}$, onde: $m$ é a taxa anual de mortalidade; $N_{0}$ é o número de indivíduos na amostra inicial (1996); $\mathrm{N}_{1}$ é o número de indivíduos na amostra final (2000) e t é o tempo de observações em ano (4).

Análises: A proporção de mortos por tratamento e por grupo ecológico inicialmente foi analisada através de análise de variância. Como as suposições de normalidade se apresentaram razoáveis (isto é, observações apenas gráficas), fez-se o teste também através de estatística não-paramétrica de Kruskal Wallis. Para o teste de comparação de medianas usou-se o teste de Dunn (1964). Como o recrutamento também não preencheu requisitos de normalidade e homocedasticidade da análise de variância, foi realizado o teste não-paramétrico de Kruskal Wallis. 


\subsection{Resultados}

\subsubsection{Tamanho das clareiras.}

As áreas das clareiras variaram de $89 \mathrm{~m}^{2}$ a $746 \mathrm{~m}^{2}$. A média geral do tamanho da clareira foi $259 \mathrm{~m}^{2}$ (limite de confiança $= \pm 35,1$ ). As áreas das clareiras se concentraram entre $100 \mathrm{~m}^{2}$ e $400 \mathrm{~m}^{2}$.

Foram encontradas apenas quatro clareiras acima de $500 \mathrm{~m}^{2}$. Na Bolívia, Myers et al., 2000, encontraram resultados semelhantes. Esses resultados não diferem muito também dos registrados por Elias (1996) na Indonésia, que encontrou uma média de 396 $\mathrm{m}^{2}$ por clareira, variando de $285 \mathrm{~m}^{2}$ a $512 \mathrm{~m}^{2}$. No entanto, esses dados são bem inferiores aos encontrados por Stokes et al. (1997) nas florestas de várzeas da Amazônia e por Agyeman et al. (1995) em Ghana. Eles encontraram áreas de clareiras variando de $350 \mathrm{~m}^{2}$ a $1.800 \mathrm{~m}^{2}$. A área média das clareiras com um desbaste foi de $294 \mathrm{~m}^{2}$ (limite de confiança $= \pm 52$ ), da com dois desbastes, $317 \mathrm{~m}^{2}$ (limite de confiança $= \pm 95,26$ ) e das clareiras sem desbastes, $213 \mathrm{~m}^{2}$ (limite de confiança $= \pm 38,04$ ). Cinquienta por cento das clareiras sem desbaste estavam no intervalo de 100 a 199 metros quadrados.

\subsubsection{Densidade de regeneração nas clareiras}

O primeiro inventário nas clareiras registrou 750 indivíduos/ha na clareira natural, 1.174 indivíduos/ha na clareira submetida a um desbaste e 745 indivíduos/ha nas submetidas a dois desbastes. Quatro anos após o primeiro levantamento (2000), a densidade média de indivíduos foi reduzida em $36 \%$ nas clareiras submetidas a um desbaste, em $34 \%$ nas clareiras submetidas a dois desbastes e em $35 \%$ nas clareiras sem o tratamento de desbaste. Os resultados do teste $t$ pareado para os três tratamentos independentes mostraram que não houve diferença significativa na redução de densidade nos tratamentos. Isso significa que o tratamento não afetou negativamente a redução de densidade entre os tratamentos (Tabela 6). 
Tabela 6: Comparação na redução média da densidade $\left(\mathrm{n}^{\circ} / \mathrm{ha}\right)$ em três tratamentos (sem desbaste, um desbaste e dois desbastes) através de teste $t$ pareado.

\begin{tabular}{lcccc}
\hline \multicolumn{1}{c}{ Trat/GE } & $\begin{array}{c}\text { Dens. média } \\
\text { em 1996 }\end{array}$ & $\begin{array}{c}\text { Dens. média } \\
\text { em 2000 }\end{array}$ & $t$ & $\mathrm{p}$ \\
\hline Um desbaste & 745 & 476 & $-4,04$ & $<0,001$ \\
Dois desbastes & 1.174 & 778 & $-4,10$ & $<0,001$ \\
Sem desbaste & 750 & 487 & $-3,47$ & $<0,001$ \\
\hline
\end{tabular}

\subsubsection{Diversidade de espécies}

Identificaram-se 38 espécies de valor madeireiro de 21 famílias nas 60 clareiras. As famílias com maior número de espécies foram Mimosaceae e Caesalpinaceae, ambas com cinco espécies e, Burseraceae, com quatro espécies. Neste estudo, as espécies que predominaram nas clareiras foram: Bagassa guianensis Aubl., presente em 47 clareiras, Jacaranda copaia (Aubl.) D. Don em 36 clareiras, Parkia multijuga Benth em 33 clareiras e pseudopiptadenia suaveolens (Miq.) J.W.Grimes em 31 clareiras. As espécies Bagassa guianensis (33,4\% ), Jacaranda copaia (Aubl.) D. Don (21,7\% ), Parkia nitida Miq. - (8,5\%), Guatteria schomburgkiana Mart (6\%), Pseudopiptadenia suaveolens (Miq.) J.W.Grimes (4,3\%), Nectandra pichurim (H.B.K.) Mez (4\%) e Scheffera morototoni (Aubl.) Maguire $(4,2 \%)$ eram as mais abundantes. Elas foram responsáveis por $82,7 \%$ do número total de indivíduos. A quantidade de espécies por clareira no primeiro levantamento variou de 1 a 14, e de indivíduos, de 1 a 467.

A quantidade de espécies por tratamento foi: 27 nas clareiras sem tratamento, 21 nas clareiras com um desbaste e 28 nas clareiras com dois desbastes. Vinte e quatro espécies eram comuns em todos os tratamentos. Apenas 5 espécies foram classificadas como pioneiras, 20 como demandantes de luz e 13 como tolerantes à sombra (Tabela 7).

Após quatro anos de monitoramento, algumas espécies tiveram uma queda brusca em suas populações, enquanto que outras aumentaram. Desapareceu uma espécie nas clareiras com um desbaste e uma nas clareiras sem desbaste. Foram recrutadas seis espécies nas clareiras sem tratamento, sete nas clareiras com um tratamento e cinco nas clareiras com dois desbastes (Tabela 7). 
Tabela 7: Nome científico, família, densidade (indivíduos/ha), \% de sobreviventes, taxa de mortalidade, indivíduos recrutados (indivíduos/ha) e crescimento $\left(\mathrm{cm}^{\mathrm{ann}} \mathrm{o}^{-1}\right.$ ) em cada tratamento considerado (um desbaste, dois desbastes e sem desbaste) em Paragominas,Pará.

\begin{tabular}{|c|c|c|c|c|c|c|c|c|c|c|c|c|c|c|c|c|c|c|c|c|}
\hline \multirow{3}{*}{ Espécic } & \multirow{3}{*}{ Família } & \multicolumn{6}{|c|}{ Densidade (individuos/ha) } & \multirow{2}{*}{\multicolumn{3}{|c|}{$\begin{array}{l}\text { \% da populacăo } \\
\text { original }\end{array}$}} & \multirow{2}{*}{\multicolumn{3}{|c|}{ Mortalidade }} & \multirow{2}{*}{\multicolumn{3}{|c|}{ Recrutadas }} & \multirow{2}{*}{\multicolumn{3}{|c|}{$\begin{array}{l}\text { taxa crescimento } \\
(\mathrm{cm} / \mathrm{ano})\end{array}$}} & \multirow{3}{*}{$\begin{array}{c}\text { Grupo } \\
\text { ecologico }\end{array}$} \\
\hline & & \multicolumn{2}{|c|}{$1 \mathrm{D}$} & \multicolumn{2}{|c|}{ 2D } & \multicolumn{2}{|c|}{ SD } & & & & & & & & & & & & & \\
\hline & & 1996 & 2000 & 1996 & 2000 & 1996 & 2000 & 1D & $2 \mathrm{D}$ & SD & 10 & $2 \mathrm{D}$ & SD & $1 \mathrm{D}$ & 2D & SD & 1D & $2 \mathrm{D}$ & SD & \\
\hline Apeiba echinata Gaern & Tiliaceac & & & 2.1 & 2.1 & & & & $100 \%$ & & & $0 \%$ & & 0.0 & 0.0 & 0.0 & & 1.35 & & $\mathrm{P}$ \\
\hline Astronium lecointei Ducke & Anacardiaceac & 4.5 & 6.8 & 8.4 & 14.7 & 21.1 & 27.5 & $100 \%$ & $100 \%$ & $100 \%$ & $0 \%$ & $0 \%$ & $0 \%$ & 2.3 & 6.3 & 6.5 & 0.19 & 0.19 & 0.09 & I \\
\hline Bagassa guianensis nubb. & Moraceae & 353.7 & 77.1 & 307.4 & 46.3 & 260.7 & 68.0 & $19 \%$ & $13 \%$ & $24 \%$ & $81 \%$ & $87 \%$ & $76 \%$ & 9.1 & 6.3 & 4.9 & 0.12 & 0.44 & 0.16 & $\mathrm{p}$ \\
\hline Bombax longipedicellatum Ducke & Bombacaceac & & & 0.0 & 2.1 & & & & & & & & & 0.0 & 2.1 & 0.0 & & & & I \\
\hline Caraipa richardiana Camb. & Guttiferac & 0.0 & 4.5 & 0.0 & 6.3 & 0.0 & 11.3 & & & & & & & 4.5 & 6.3 & 11.3 & & & & I \\
\hline Caryocar glabrum (Aubl.) Pers. Spp glabrum & Caryocaraceac & 0,0 & 2.3 & 4.2 & 4.2 & 0.0 & 1.6 & & $100 \%$ & & & $0 \%$ & & 2.3 & 0.0 & 1.6 & & 0.71 & & I \\
\hline Caryocar villosum (Aubl.) Pers & Caryocaraceas & 56.7 & 22.7 & 14.7 & 8.4 & & & $40 \%$ & $57 \%$ & & $60 \%$ & $43 \%$ & & 0.0 & 0.0 & 0.0 & 0.18 & 0.38 & & 1 \\
\hline Cordia bicolor DC. & Boraginaceac & 11.3 & 11.3 & 8.4 & 6.3 & 3.2 & 0,0 & $100 \%$ & $75 \%$ & $0 \%$ & $0 \%$ & $25 \%$ & $100 \%$ & 0.0 & 0.0 & 0.0 & 0.72 & 0.37 & & I \\
\hline Cordia goeldana Huber & Boraginaceac & 0.0 & 2.3 & 2.1 & 6.3 & 11.3 & 13.0 & & $100 \%$ & $100 \%$ & & $0 \%$ & $0 \%$ & 2.3 & 4.2 & 1.6 & & 0.75 & 0.40 & 1 \\
\hline Couratari obliongfolia Ducke \& Knuth. & Lecythedacea & 2.3 & 4.5 & 0.0 & 2.1 & 4.9 & 6.5 & $100 \%$ & & $67 \%$ & $0 \%$ & & $33 \%$ & 2.3 & 2.1 & 3.2 & 0.33 & & 0.36 & TS \\
\hline Dipteryx odorata (Aubl.) Willd. & Leg: Papilionoideace & 2.3 & 2.3 & 2.1 & 2.1 & 4.9 & 4.9 & $100 \%$ & $100 \%$ & $100 \%$ & $0 \%$ & $0 \%$ & $0 \%$ & 0.0 & 0.0 & 0.0 & 0.33 & 0.65 & 0.26 & I \\
\hline Guateria schomburgkiana Mart. & Annonaceac & 13.6 & 2.3 & 99.0 & 52.6 & 51.8 & 25.9 & $17 \%$ & $49 \%$ & $50 \%$ & $83 \%$ & $51 \%$ & $50 \%$ & 0.0 & 4.2 & 0.0 & 0.63 & 0.55 & 0.26 & TS \\
\hline Hymenaea courbaril L. & Leg:Caesalpinioideace & 4.5 & 4.5 & 8.4 & 23.2 & 6.5 & 16.2 & $100 \%$ & $75 \%$ & $100 \%$ & $0 \%$ & $25 \%$ & $0 \%$ & 0.0 & 16.8 & 9.7 & 0.28 & 0.53 & 0.12 & TS \\
\hline Hymenaea oblongfolia Huber & Leg:Cacsalpinioideace & 2.3 & 2.3 & & & & & $100 \%$ & & & $0 \%$ & & & 0.0 & 0.0 & 0.0 & 0.58 & & & Ts \\
\hline Jacaranda copaia (Aubl.) D. Don & Bignoniaceac & 52.1 & 31.7 & 448.5 & 290.6 & 103.6 & 27.5 & $57 \%$ & $62 \%$ & $22 \%$ & $43 \%$ & $38 \%$ & $78 \%$ & 2.3 & 14.7 & 4,9 & 0.34 & 0.59 & 0.19 & $\mathrm{P}$ \\
\hline Lecythis Lurida (Miers) S.A.Mori & Lecythidaceac & & & 2.1 & 2.1 & 3.2 & 3.2 & & $100 \%$ & $100 \%$ & & $0 \%$ & $0 \%$ & 0.0 & 0.0 & 0.0 & & 0.20 & 0.15 & 1 \\
\hline Manilkara huberi (Ducke) A.Chev. & Sapotaceace & 11.3 & 18.1 & 12.6 & 25.3 & 6.5 & 6.5 & $100 \%$ & $100 \%$ & $100 \%$ & $0 \%$ & $0 \%$ & $0 \%$ & 6.8 & 12.6 & 0.0 & 0.32 & 0.24 & 0.09 & TS \\
\hline Nectandra pichurim (H.B.K.) Mez & Lauraceac & 15.9 & 9.1 & 50.5 & 23.2 & 45.3 & 35.6 & $57 \%$ & $46 \%$ & $79 \%$ & $43 \%$ & $54 \%$ & $21 \%$ & 0.0 & 0.0 & 0.0 & 0.58 & 0.36 & 0.28 & Ts \\
\hline Ocotea glomerata (Nees) Mez. & Liaraceace & 2.3 & 2.3 & 8.4 & 4.2 & 1.6 & 1.6 & $100 \%$ & $50 \%$ & $100 \%$ & $0 \%$ & $50 \%$ & $0 \%$ & 0.0 & 0.0 & 0.0 & 0.50 & 0.44 & 0.35 & TS \\
\hline Parkia gigantocarpa Ducke & Leg: Mimosoideae & & & 0.0 & 2.1 & 0.0 & 1.6 & & & & & & & 0.0 & 2.1 & 1.6 & & & & I \\
\hline Parkia multijuga Benth & Leg: Mimosoideae & 115.6 & 97.5 & 52,6 & 48.4 & 68.0 & 50.2 & $84 \%$ & $88 \%$ & $71 \%$ & $16 \%$ & $12 \%$ & $29 \%$ & 0,0 & 2.1 & 1.6 & 0.64 & 0.85 & 0.53 & I \\
\hline Parkia nitida Miq & Leg: Mimosoideac & 11.3 & 11.3 & & & 0.0 & 0.0 & $80 \%$ & & & $20 \%$ & & & 2.3 & 0.0 & 0.0 & 0.97 & & & I \\
\hline Parkia pendula Benth Ex. Walp & Leg: Mimosoideate & 0.0 & 36.3 & 2.1 & 2.1 & 3.2 & 6.5 & & $100 \%$ & $100 \%$ & & $0 \%$ & $0 \%$ & 36.3 & 0.0 & 3.2 & & 0.35 & 0.41 & I \\
\hline Protium sagotianum March. & Burseraceac & & & 2.1 & 0.0 & & & & $0 \%$ & & & $100 \%$ & & 0.0 & 0.0 & 0.0 & & & & Ts \\
\hline Protium temifolium Engl. & Burseraceac & & & 19.0 & 14.7 & 3.2 & 1.6 & & $78 \%$ & $50 \%$ & & $22 \%$ & $50 \%$ & 0.0 & 0.0 & 0.0 & & 0.44 & 0.40 & TS \\
\hline $\begin{array}{l}\text { Pseudopiptadenia suaveolens (Miq.) J.W.Grimes } \\
\text { Schefflera morototoni (Aubl.) Mavuire, Steyerm. \& }\end{array}$ & Leg: Mimosoideac & 29.5 & 36,3 & 42.1 & 86.3 & 43.7 & 53.4 & $69 \%$ & $90 \%$ & $78 \%$ & $31 \%$ & $10 \%$ & $22 \%$ & 15.9 & 48.4 & 19.4 & 0.38 & 0.34 & 0.14 & $\mathrm{I}$ \\
\hline Frodin & Araliaceac & 43.1 & 29.5 & 35.8 & 12.6 & 35.6 & 4.9 & $53 \%$ & $35 \%$ & $9 \%$ & $47 \%$ & $65 \%$ & $91 \%$ & 6.8 & 0.0 & 1.6 & 0.73 & 1.24 & 0.06 & $\mathrm{p}$ \\
\hline Sclizolobitum paralyba (Vell.) Blake & Leg:Caesalpinioideac & 0.0 & 2.3 & & & 4.9 & 4.9 & & & & & & $100 \%$ & 2.3 & 0.0 & 0.0 & & & 0.28 & $\mathrm{p}$ \\
\hline Simaruba amara Aubl. & Simarubaceac & & & & & 1.6 & 1.6 & & & $100 \%$ & & & $0 \%$ & 0.0 & 0.0 & 0.0 & & & 0.28 & I \\
\hline Sterculia speciosa K.Schum. & Sterculiaceac & 4.5 & 4.5 & 2.1 & 2.1 & 22.7 & 17.8 & $100 \%$ & $100 \%$ & $79 \%$ & $0 \%$ & $0 \%$ & $21 \%$ & 0.0 & 0.0 & 0.0 & 0.45 & 0.70 & 0.44 & I \\
\hline Tabebuta impetiginosa (Mart. Ex DC.) Standl. & Bignoniaceae & & & 0,0 & 16.8 & 0.0 & 4.9 & & & & & & & 0,0 & 16.8 & 4.9 & & & & I \\
\hline Taleebuia serratifolia (Vahl.) Nichols & Bignoniaceac & & & & & 0.0 & 1.6 & & & & & & & 0.0 & 0.0 & 1.6 & & & & I \\
\hline Talebhuia sp & Bignoniaceac & & & & & 19.4 & 17.8 & & & $92 \%$ & & & $8 \%$ & 0.0 & 0.0 & 0.0 & & & 0.06 & I \\
\hline Tachigali paniculata Aubl. & Leg:Caesalpinioideac & 2.3 & 2.3 & 4.2 & 4.2 & 6.5 & 6.5 & $100 \%$ & $100 \%$ & $100 \%$ & $0 \%$ & $0 \%$ & $0 \%$ & 0.0 & 0.0 & 0.0 & 0.65 & 0.99 & 0.41 & I \\
\hline Tachigalia myrmecoplyylla Ducke & Leg:Caesalpinioideac & 0.0 & 9.1 & 4.2 & 8.4 & 3.2 & 4.9 & & $100 \%$ & $100 \%$ & & $0 \%$ & $0 \%$ & 9.1 & 4.2 & 1.6 & & 0.46 & 0.14 & I \\
\hline Tetragrastris atisssima (Aubl.) Swart & Burseraceae & 0.0 & 4.5 & 2.1 & 2.1 & 4.9 & 8.1 & & $100 \%$ & $100 \%$ & & $0 \%$ & $0 \%$ & 4.5 & 0.0 & 3.2 & & 0.35 & 0.22 & TS \\
\hline Trattinickia rhoifolia Willd & Burseraceae & 13,6 & 24.9 & 29.5 & 16.8 & 29.2 & 19.4 & $83 \%$ & $57 \%$ & $56 \%$ & $17 \%$ & $43 \%$ & $44 \%$ & 13.6 & 0.0 & 3.2 & 0.44 & 0.29 & 0.24 & Ts \\
\hline Virola cuspidatat Warb. & Myristicaceae & 2.3 & 29.5 & 6.3 & 27.4 & 16.2 & 30.8 & $100 \%$ & $67 \%$ & $80 \%$ & $0 \%$ & $33 \%$ & $20 \%$ & 27.2 & 23.2 & 17.8 & 0.78 & 1.01 & 0.37 & TS \\
\hline
\end{tabular}




\subsubsection{Crescimento por espécie}

A espécie que mais cresceu no tratamento com dois desbastes foi a Apeiba echinata Gaertn (1,35 cm ano $\left.{ }^{-1}\right)$, seguida da Scheffera morototoni (Aubl.) Maguire (1,24 $\left.\mathrm{cm} \mathrm{ano}^{-1}\right)$. No tratamento com um desbaste, a espécie que se destacou em crescimento foi a Parkia nitida Miq., atingindo $0,97 \mathrm{~cm}^{2} \mathrm{ano}^{-1}$. No tratamento sem desbaste, a espécie que apresentou maior crescimento foi a Parkia multijuga Benth, atingindo $0,53 \mathrm{~cm}^{2}$ ano $^{-1}$ (Tabela 7). Acompanhando isoladamente apenas espécies comuns nos três tratamentos, que estavam presentes no final do monitoramento, se notou que o crescimento foi maior no tratamento de dois desbastes, e que no tratamento de um desbaste, o crescimento foi superior ao do sem desbaste.

\subsubsection{Crescimento diamétrico em cada tratamento}

Análise estatística do incremento periódico anual (IPA): Após a transformação dos dados, quando as suposições se tornaram aceitáveis, as análises foram estatisticamente diferentes entre os tratamentos. $\mathrm{O}$ incremento médio anual $\mathrm{em} \mathrm{cm}$ de DAP das espécies de valor madeireiro em clareira natural, após 4 anos, foi $0,26 \mathrm{~cm}^{2}$ ano ${ }^{1}$. Nas clareiras com um desbaste, esse incremento foi $0,45 \mathrm{~cm} \mathrm{ano}^{-1}$, e nas clareiras com dois desbastes, $0,56 \mathrm{~cm} \mathrm{ano}^{-1}(F=52,19 ; P<0,001)$ (Tabela 8). Nas clareiras submetidas a um desbaste, os indivíduos de espécies madeireiras cresceram $73 \%$ mais do que os das clareiras sem desbaste. E, nas clareiras com dois desbastes, esses indivíduos cresceram $115 \%$ mais do que os das sem desbaste. Os indivíduos das clareiras com dois desbastes cresceram $20 \%$ mais do que os das com um desbaste. Não houve diferença estatística entre os grupos ecológicos $(F=0,11 ; p=0,892)$. 
Tabela 8: Incremento $\left(\mathrm{cm} \mathrm{ano}^{-1}\right)$ da regeneração de valor madeireiro em clareiras por tratamento e por grupo ecológico.

\begin{tabular}{l|ccc|c}
\hline \multicolumn{1}{c|}{ Tratamentos } & Pioneiras & $\begin{array}{c}\text { Demandantes } \\
\text { de luz }\end{array}$ & $\begin{array}{c}\text { Tolerantes } \\
\text { à sombra }\end{array}$ & Média geral \\
\hline Um desbaste & 0,29 & 0,52 & 0,43 & $0,45^{\mathrm{a}}$ \\
Dois desbastes & 0,60 & 0,52 & 0,50 & $0,56^{\mathrm{b}}$ \\
Sem desbastes & 0,17 & 0,29 & 0,26 & $0,26^{\mathrm{c}}$ \\
\hline Média geral & $0,45^{\mathrm{a}}$ & $0,41^{\mathrm{a}}$ & $0,39^{\mathrm{a}}$ & $\mathrm{F}=8,18$ \\
& & $\mathrm{~F}=0,11 ;$ & & $\mathrm{p}=<0,001$ \\
& & $\mathrm{p}=0,892$ & & \\
\hline
\end{tabular}

Notas: Números que repartem letras diferentes foram diferentes estatisticamente pelo teste Tukey para o nível de significância global de $5 \%$ de probabilidade.

Incremento corrente anual: as arvoretas de valor madeireiro nas clareiras responderam bem ao tratamento silvicultural. A resposta dessas arvoretas ao tratamento foi imediata, sendo que nas clareiras com dois desbastes, se observou uma inclinação bem acentuada da reta (Figura 14). Do ponto de vista ecológico, os resultados dos tratamentos são positivos.

Figura 14: Incremento corrente anual $\left(\mathrm{cm} \mathrm{ano}^{-1}\right)$ de regeneração de valor madeireiro em clareiras, em três tratamentos: clareiras submetidas a um desbaste, clareiras submetidas a dois desbastes e clareiras sem desbaste. 


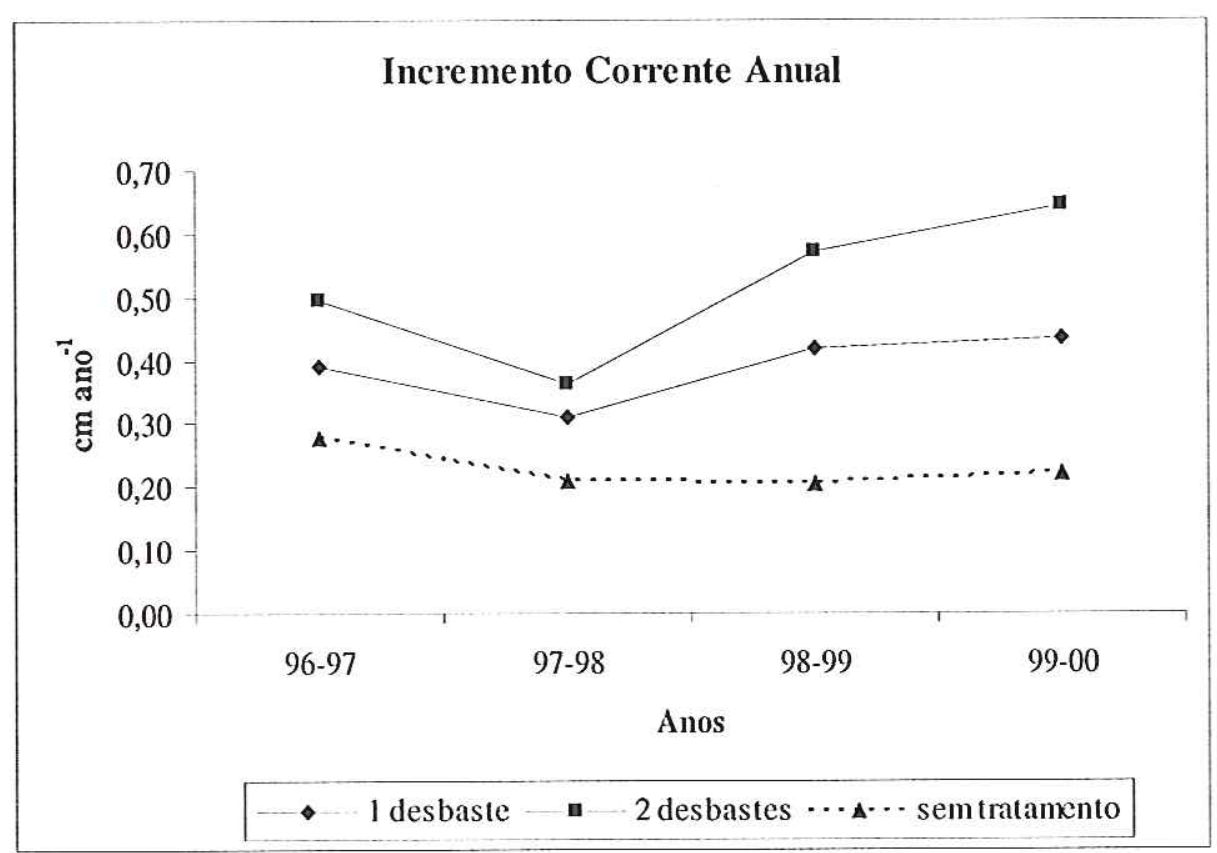

Dos três grupos ecológicos considerados, a taxa de crescimento diamétrico foi menor nas clareiras sem desbaste. As espécies demandantes de luz cresceram bem no tratamento de dois desbastes, enquanto que nos tratamentos com um e no sem desbaste as espécies pioneiras e tolerantes à sombra tiveram crescimento semelhante (Figura 15). Em todos os grupos ecológicos e tratamentos houve uma queda na taxa de crescimento em 1998, provavelmente por causa do fenômeno El Niño, pois as quedas foram semelhantes em todos os tratamentos. 
Figura 15: Incremento corrente anual (ICA) por tratamento e grupo ecológico: (a) pioneiras; (b) demandantes de luz; e (c) tolerantes à sombra.
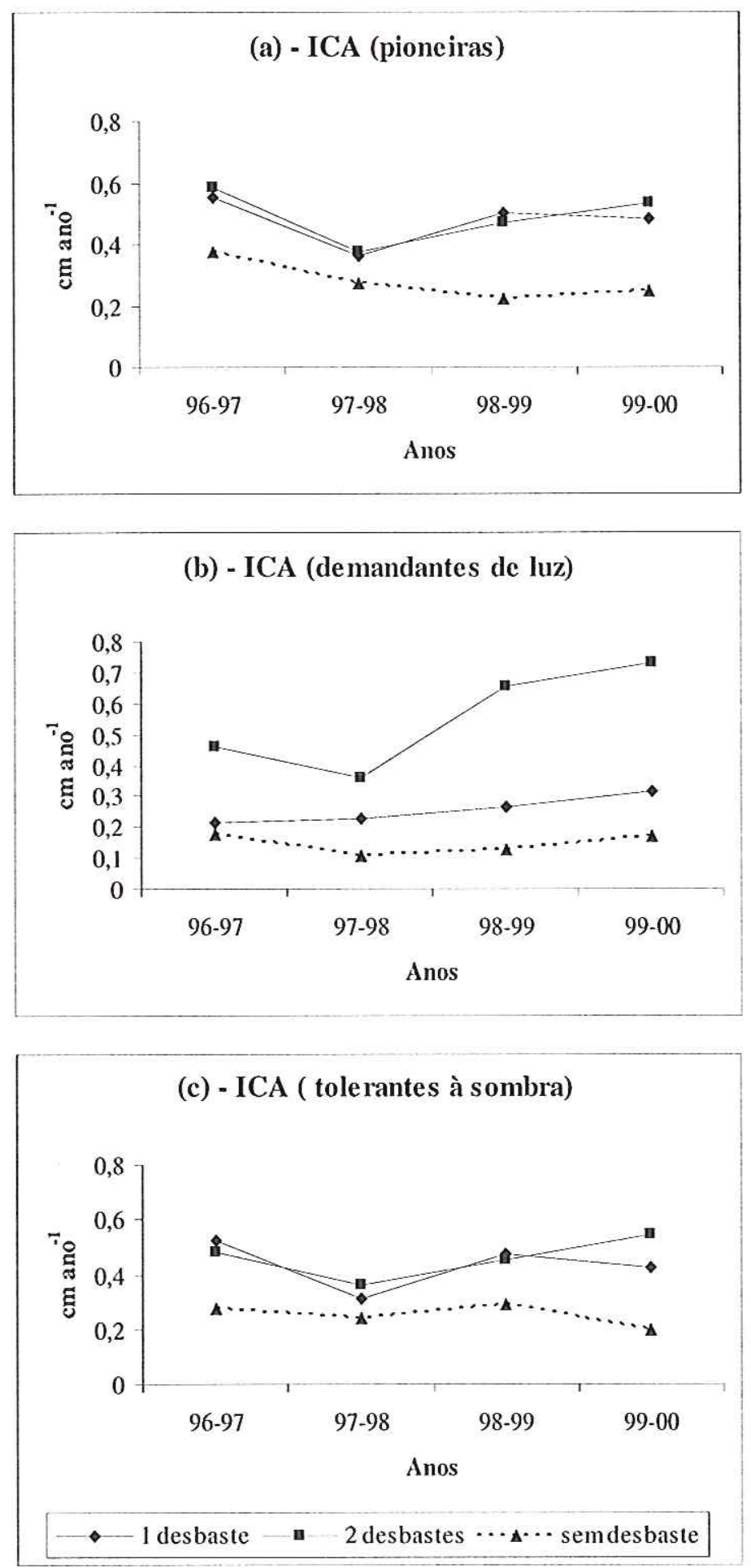
Crescimento em função do tamanho da clareira: Os resultados $\left(r^{2}=0,38 ; p=\right.$ $0,908)$ demonstraram que a área da clareira tem pouco efeito sobre o crescimento em DAP das plantas. Esses resultados combinam com os de Brokaw (1985), que estudando o crescimento em altura da regeneração, notou que não havia correlação do crescimento da regeneração com a área da clareira. Porém, as espécies tolerantes à sombra parecem ter seu crescimento favorecido nas clareiras pequenas e não apresentam um crescimento maior nas clareiras grandes (Brokaw, 1985).

Acúmulo de área basal ao longo do período monitorado: A taxa média de incremento em área basal foi de $0,01802 \mathrm{~m}^{2} \cdot \mathrm{ha}^{-1}$ nas clareiras com dois desbastes, de $0,00781 \mathrm{~m}^{2}$.ha ${ }^{-1}$ nas com um desbaste e de $0,00224 \mathrm{~m}^{2}$.hat ${ }^{-1}$ nas sem desbaste. Houve diferença estatística de incremento em área basal entre as clareiras com dois desbastes e as demais clareiras. Porém, não se observou diferença estatística entre as clareiras com um desbaste e as sem desbaste $(F=52,19 ; \mathrm{p}=0,001)$ (Tabela 9).

Tabela 9: Comparação estatística de incremento em área basal por tratamento e grupo ecológico.

\begin{tabular}{|c|c|c|c|c|}
\hline Tratamentos & Pioneiras & $\begin{array}{c}\text { Demandantes } \\
\text { de luz }\end{array}$ & $\begin{array}{l}\text { Tolerantes } \\
\text { à sombra }\end{array}$ & Média geral \\
\hline Um desbaste & $-0,0034$ & 0,0087 & 0,0010 & $0,00781^{\mathrm{ab}}$ \\
\hline Dois desbastes & 0,0037 & 0,0098 & 0,0037 & $0,01802^{\mathrm{a}}$ \\
\hline Sem desbaste & $-0,0037$ & 0,0051 & 0,0005 & $0,00224^{\mathrm{b}}$ \\
\hline Média geral & $-0,0017^{\mathrm{a}}$ & $\begin{array}{c}0,0072^{\mathrm{b}} \\
F=25,93 ; \\
\mathrm{p}<0,001\end{array}$ & $0,0015^{c}$ & $\begin{array}{l}F=52,19 \\
p<0,001\end{array}$ \\
\hline
\end{tabular}

Analisando o acúmulo em área basal ao longo do período, notou-se que a área basal das clareiras com dois desbastes têm crescido mais do que a das clareiras com um desbaste e das sem desbaste. A área basal média nas clareiras com dois desbastes aumentou em $59 \%$ em relação ao início do monitoramento, enquanto que as clareiras com um desbaste aumentaram em $31 \%$ e as clareiras sem desbaste aumentaram apenas $7 \%$ (Figura 16). 
Figura 16: Área basal média por hectare em cada tratamento ao longo do período monitorado.

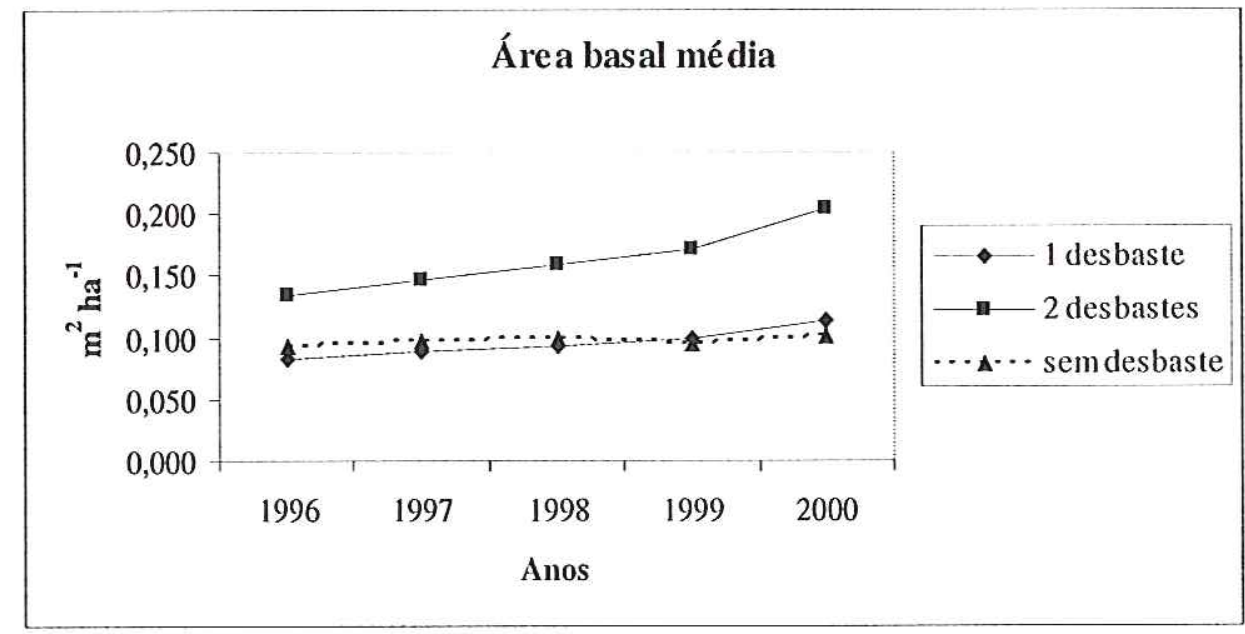

Área basal por tratamento e grupo ecológico: As espécies pioneiras têm contribuído substancialmente para o aumento da área basal no tratamento de dois desbastes em relação às espécies demandantes de luz e às tolerantes à sombra, que apresentam uma redução no tratamento de um desbaste e no testemunha. Isso significa que as aberturas promovidas pelos desbastes de liberação tem contribuído para o crescimento das espécies pioneiras presentes nas clareiras de dois desbastes. O padrão de crescimento em área basal para as espécies demandantes de luz foi semelhante entre os tratamentos. $\mathrm{E}$ os tartamentos parecem não ter estimulado o crescimento das espécies tolerantes a sombra, mostrando que nossa classificação de espécies em grupos ecológicos está correta (Figura 17). 
Figura 17: Área basal média por grupo ecológico ((a) pioneiras, (b) demandante de luz e (c) tolerantes à sombra) e por tratamento em Paragominas, Pará.
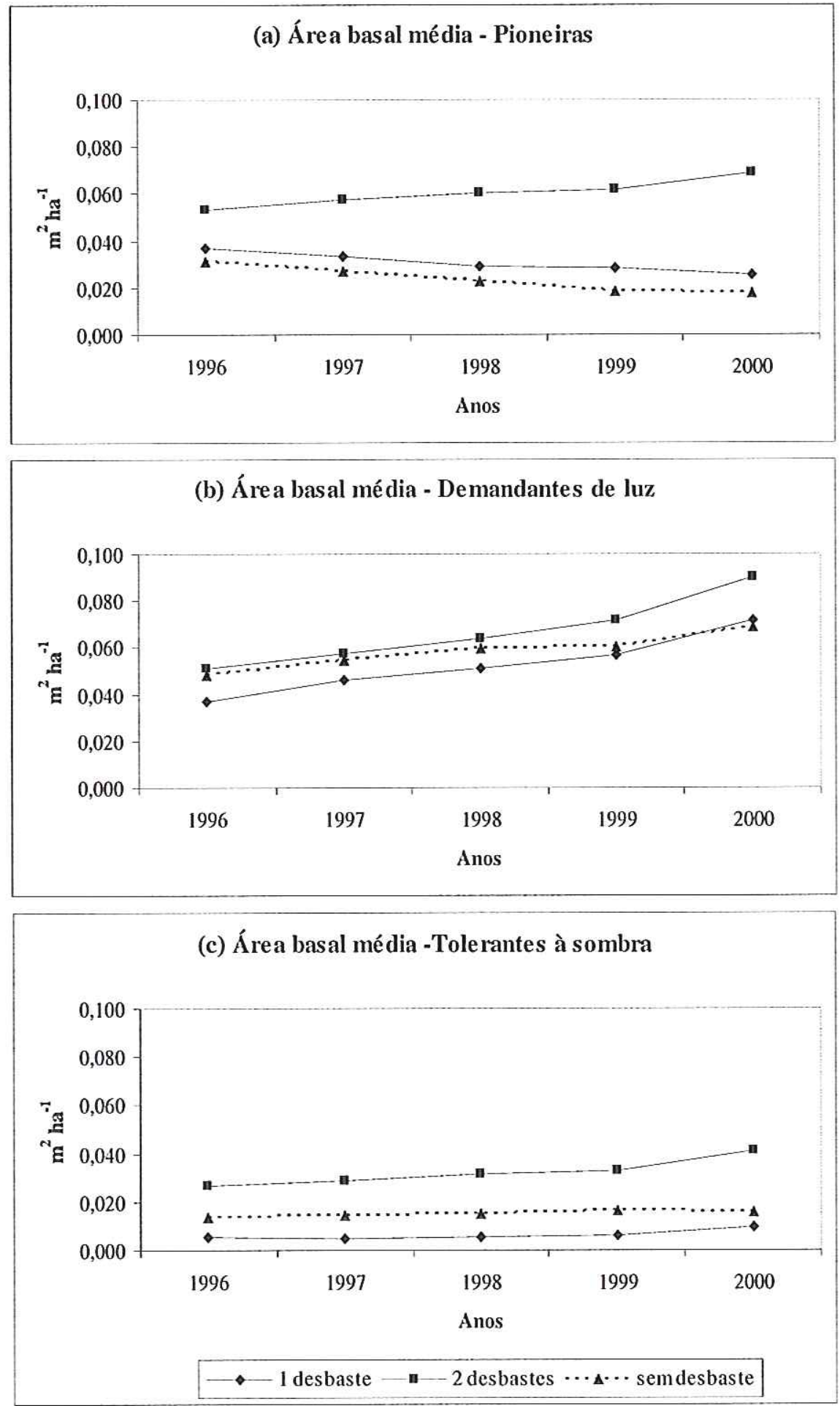


\subsubsection{Custos para realizar desbaste}

Os custos para realizar o desbaste, incluindo tempo para deslocamento, tempo para marcação da regeneração de valor madeireiro e tempo efetivo de desbaste, foi de $\mathrm{R} \$ 6,69$ para cada clareira $(\mathrm{n}=10)$ submetida a um desbaste. $O$ custo por indivíduo ficou em $\mathrm{R} \$ 0,09$. O custo para a aplicação de dois desbastes, por clareira, foi $\mathrm{R} \$ 12,80$ $(n=13)$. Nessas clareiras, o custo por arvoreta remanescente ficou em $R \$ 0,12$. Nas clareiras submetidas a desbaste, os custos variaram principalmente em função do número de plantas beneficiadas e do tamanho da clareira. Os custos do desbaste por planta beneficiada com dois desbastes foi $33 \%$ superior ao custo das beneficiadas com um desbaste.

\subsubsection{Mortalidade entre tratamentos e entre grupos ecológicos}

O teste de análise de variância indicou haver diferenças nas porcentagens de mortalidade entre os três tratamentos apenas no nível de $10 \%$ pelo teste de Tukey $(F=$ 2,66; $p=0,079)$. A comparação entre grupos ecológicos foi altamente significativa. $O$ teste de Kruskal Wallis também apresentou o mesmo resultado para grupo ecológico (H $=50,41 ; \mathrm{p}<0,001)$, todavia, diferiu no teste entre tratamentos $(\mathrm{H}=3,55 ; \mathrm{p}=0,169)$ (Tabela 10).

Tabela 10: Proporção de mortos por grupo ecológico e por tratamento, uma média anual para os quatro anos de monitoramento (1996-2000) com resultado de estatística paramétrica e não- paramétrica em Paragominas,Pará.

\begin{tabular}{l|ccc|c}
\hline $\begin{array}{c}\text { Trat/Grupo } \\
\text { ecológico }\end{array}$ & Pioneiras & $\begin{array}{c}\text { Demandantes } \\
\text { de luz }\end{array}$ & $\begin{array}{c}\text { Tolerantes } \\
\text { à sombra }\end{array}$ & Total \\
\hline Um desbaste & 0,72 & 0,26 & 0,22 & $0,51^{\mathrm{a}}$ \\
Dois desbastes & 0,73 & 0,22 & 0,36 & $0,50^{\mathrm{a}}$ \\
Sem desbaste & 0,67 & 0,18 & 0,29 & $0,36^{\mathrm{a}}$ \\
\hline & $0,70^{\mathrm{a}}$ & $0,21^{\mathrm{b}}$ & $0,31^{\mathrm{c}}$ & \\
\hline $\mathrm{F}_{\text {anava }}$ & \multicolumn{3}{|c}{} & 2,66 \\
$\mathrm{p}_{\text {anava }}$ & $<2,69$ & 0,079 \\
\hline $\mathrm{H}_{\text {Kruskal Wallis }}$ & \multicolumn{3}{|c}{} & 3,55 \\
$\mathrm{p}_{\text {Kruskal Wallis }}$ & \multicolumn{3}{|c}{0,41} & 0,169 \\
\hline
\end{tabular}


Notas: Nas comparações foi usado o teste de Tukey (teste paramétrico) para comparações múltiplas entre médias e o proposto por Dunn (1964) (teste nãoparamétrico), para comparações múltiplas de medianas.

\subsubsection{Recrutamento}

Não houve diferenças estatísticas nas taxas médias de recrutamento por hectare no período monitorado (1996-2000) entre os tratamentos $(F=2,16 ; p=0,125)$. As clareiras tratadas com dois desbastes tiveram em média 190 indivíduos/ha recrutados, as tratadas com um desbaste, 42 indivíduos/ha e as clareiras naturais, 94 indivíduos/ha.

\subsection{Discussão}

\subsubsection{Implicações para o manejo florestal}

Muitas pesquisas demonstram o papel dos tratamentos silviculturais dentro dos sistemas silviculturais pelo mundo. Eles são considerados eficientes para aumentar a taxa de crescimento das plantas em vários experimentos (Lamprecht, citado por De Graaf, 1999). Ao longo das últimas três décadas, De Graaf vem desenvolvendo uma dessas raras pesquisas nas florestas neotropicais do Suriname,.

Os resultados do nosso estudo demonstram que a exploração de impacto reduzido é positiva para a produção de madeira. Isto porque a redução da competição através do tratamento de desbaste proporcionou um grande aumento de crescimento das espécies (cerca de $115 \%$ em relação às não tratadas) com potencial para colheita no futuro. Nicholson (1979), no sudoeste da Ásia, também encontrou resultados semelhantes; aumento de crescimento de $1 \mathrm{~cm} /$ ano para 1,25 cm/ano. Para De Graaf (1999), a taxa de crescimento em área basal pode ser aumentada inicialmente em 4,1\% e, com o passar dos anos, reduzida em até $1 \%$.

Em nosso estudo, o tratamento de desbaste não influenciou substancialmente nas taxas de mortalidade e de recrutamento. Em um estudo desenvolvido por De Graaf (1999), a taxa de recrutamento de espécies potenciais foi aumentada e a mortalidade tem tendência a aumentar conforme a severidade do tratamento. 
Um dos argumentos mais fortes para a aplicação de tratamentos silviculturais especificamente em clareiras de exploração convencional sem ocorrência de reentradas é que eles melhoram o crescimento individual de espécies potenciais e não influenciam a mortalidade. Ao invés disso, eles podem até, em alguns casos, aumentar a taxa de recrutamento de espécies potenciais para a colheita. É necessário encontrar alternativas para evitar que essas áreas sejam transformadas em outros usos do solo.

Um ponto chave e pouco tratado até o momento por silvicultores no tema tratamentos silviculturais é o aspecto econômico. Para verificar a viabilidade econômica da aplicação dessas técnicas, é necessário se realizarem pesquisas de análise de custos e benefícios. De Graaf (1999) menciona que pelo fato de esses tratamentos melhorarem o recrutamento e o crescimento individual de espécies potenciais eles podem ser considerados economicamente atrativos; isto porque há uma redução do acesso a grandes reservas florestais. No entanto, é necessário fazer avaliações econômicas (custos e benefícios) sob o ponto de vista do empresário, para que a justificativa do uso dessas técnicas sejam baseadas em parâmetros conclusivos.

\subsection{Conclusões}

O tratamento silvicultural de desbaste nas clareiras influencia positivamente o crescimento da regeneração; um resultado importante para a exploração de impacto reduzido. Contudo, é necessário se realizarem análises de custos e benefícios para avaliar se o tratamento é economicamente viável e se poderá ser estimulado. A idéia central de se buscar alternativas para clareiras de exploração convencional é evitar que essas áreas sejam convertidas em outros usos do solo.

A densidade de espécies madeireiras nas clareiras da exploração madeireira convencional é predominantemente formada por poucas espécies. Desta forma, é necessário aumentar a diversidade de espécies plantando-as nessas clareiras tornando, assim, a floresta explorada economicamente mais valiosa. É importante que no plantio as características ecológicas das espécies sejam respeitadas para que não haja resultados desastrosos. O plantio em clareiras pode ser uma alternativa de rendimento sustentável 
para espécies que apresentam problemas de regeneração. Este é o caso da madeira mais valiosa da Amazônia, o mogno, (Swietenia macrophilla King). Portanto, mesmo que o tratamento silvicultural de desbaste na regeneração de clareiras promova um bom crescimento, poucas são as espécies que serão beneficiadas. Entretanto, são raras as experiências de pesquisa com plantio em clareiras e a aplicação do plantio, de forma operacional, em clareiras. 


\section{Capítulo V: Diversidade de Espécies em Florestas Exploradas com e sem Técnicas de Exploração de Impacto Reduzido em Paragominas, Pará.}

\subsection{Introdução}

Entender o que acontece com a diversidade de espécies nas áreas de exploração madeireira é primordial para conhecer o real valor de conservação da floresta manejada para a produção de madeira em florestas tropicais. A diversidade de árvores é fundamental para a biodiversidade total da floresta, por providenciar recursos e estrutura para habitat para a grande maioria das espécies do ecossistema (Cannon et al., 1998; Huang et al., 2003). O efeito da exploração madeireira sobre a diversidade de espécies nas florestas tropicais é largamente desconhecido (Cannon et al, 1998, Whitmore, 1997). Assim, é necessário conhecer a diversidade da floresta e os efeitos que intervenções específicas têm sobre ela para melhor se analisar os impactos das atividades econômicas sobre a biodiversidade (Delgado et al. (1997) e Jólon (1999) citado por Louman et al., 2001).

Estudos em Queensland (Austrália) (Nicholson et al., citado por Cannon et al., 1998) e nos arredores de Manaus (Brasil) (Magnussom et al., 1999) sugerem que a diversidade após a exploração é mantida. Em Manaus, foi observada uma riqueza de espécies maior nas áreas exploradas do que nas áreas não exploradas entre o terceiro e oitavo ano após a exploração. Outros estudos mostram que ocorre uma redução na densidade e no número de espécies, tanto para árvores grandes ( $>50 \mathrm{~cm}$ de DAP) como para árvores intermediárias (20 cm-30 cm de DAP) (Cannon et al., 1998). 
Na maioria dos sistemas silviculturais usados em Porto Rico até a década de 1970 ocorria uma redução considerável de espécies (Wadsworth, 1974). Silva (1989) e Carvalho (1992), na região do Tapajós, em Belterra, no Pará, mostraram que a diversidade aumenta. Na exploração, a retirada de indivíduos adultos nas florestas tropicais pode promover a redução no número de espécies. Na legislação brasileira existem três critérios para assegurar a conservação das espécies: manutenção de dez por cento dos indivíduos adultos, limite de corte de $45 \mathrm{~cm}$ de DAP e intensidade máxima permitida por hectare (Instrução Normativa $\mathrm{N}^{0} 4$, de 4 de março de 2002, MMA http://www.mma.gov.br). A exploração de impacto reduzido pode conservar as espécies porque respeita os critérios acima e ainda usa outros critérios como não cortar espécies raras (espécies que tenham número inferior a 5 indivíduos por cem hectares). Nas florestas tropicais, o Diâmetro Mínimo de Corte (DMC) das árvores é usualmente usado para garantir a sustentabilidade da população das espécies florestais madeireiras (Lamprecht, 1990; Pariona \& Fredericksen, 2000; Sokpon \& Bioau, 2002). Nas florestas tropicais da Indonésia foram recomendados três limites de diâmetro mínimo de corte, de acordo com a estrutura diamétrica das espécies da família Dipterocarpáceae (Sist, 2001; Sist et al., 2003 ${ }^{\mathrm{a}}$ ).

Neste capítulo, avaliar-se-á a diversidade de espécies em uma área submetida à exploração madeireira de impacto reduzido (MF), à exploração convencional (EC) e em uma área não submetida à exploração (testemunha) em Paragominas, Pará.

\subsection{Material e métodos}

\subsubsection{Procedimentos amostrais e estatísticos}

Para analisar os efeitos da exploração madeireira de impacto reduzido e da exploração convencional sobre a diversidade de espécies, em 1993, antes da exploração, estabeleceu-se uma parcela de 5,25 ha $(75 \mathrm{~m} \times 700 \mathrm{~m})$ em cada tratamento. Os tratamentos aplicados foram: exploração com técnicas de impacto reduzido, exploração convencional e testemunha (mais detalhes no item 1.7 do capítulo 1). 


\subsubsection{Coleta dos dados}

Utilizando fita diamétrica, mediram-se inicialmente os DAPs das árvores em 1993 e, posteriormente, em 1996 e 2000. Somente em 2000 coletaram-se dados de recrutamento. Todas as espécies de valor madeireiro com DAP acima de $10 \mathrm{~cm}$ foram identificadas pelo nome vulgar e pelo nome científico. As árvores foram então mapeadas através de um sistema de coordenadas e marcadas com uma placa de alumínio.

\subsubsection{Análise dos dados}

\subsubsection{Balanço do número de indivíduos e espécies antes e após a exploração}

Antes e após intervenção na floresta, registrou-se o número de espécies e de indivíduos, a mortalidade e o recrutamento das espécies.

\subsubsection{2 Índice de diversidade $\alpha$ de Fisher e de Shannon.}

Para medir a diversidade de espécies foram aplicados os dois índices mais utilizados na literatura mundial, o $\alpha$ de Fisher e o de Shannon. O primeiro foi usado porque é pouco afetado pelo tamanho da amostra (Berry, 2002), e o segundo, porque permite comparações estatísticas sem a necessidade de repetições, sendo, assim, mais sensível a reduções no número de indivíduos (Magurran, 1987; Martins, 1999). Neste caso, para medir o efeito da exploração na diversidade de espécies, foi interessante efetuar comparações estatísticas dentro de cada tratamento, em dois períodos: antes (1993) e três anos após (1996) a exploração, e antes e sete anos após (2000) a exploração. Também coletaram-se dados numa área de floresta natural (testemunha).

\subsubsection{Composição florística}

Para analisar os efeitos dos tratamentos sobre a composição florística das espécies, identificou-se todas as espécies, pelo seu nome vulgar e botanicamente. As espécies foram monitoradas num período total de sete anos. 


\subsection{Resultados}

\subsubsection{Composição florística}

Considerando todos os tratamentos, foram identificadas 171 espécies de 45 famílias. As famílias mais representativas foram Mimosaceae com 22 espécies, Sapotaceae com 19 espécies, Caesalpiniaceae com 13 espécies, Lauraceae com 13 e Lecythidaceae com 10 espécies. Dezoito famílias apresentaram apenas uma espécie e 13 não foram identificadas. A distribuição de famílias por tratamento no início do experimento era de 44 (7 não identificadas) na testemunha, 40 (12 não identificadas) na área com exploração de impacto reduzido e 38 (10 não identificadas) na explorada convencionalmente (Anexo 1).

$\mathrm{Na}$ exploração de impacto reduzido, a família Celastraceae foi localmente extinta. Na área explorada convencionalmente, foram extintas as famílias Celastraceae e Meliaceae. E na área testemunha, nenhuma família foi extinta localmente (Anexo 1).

\subsubsection{Efeito da exploração madeireira sobre o número de espécies e o número de indivíduos}

Número de espécies. Na área de 5,25 ha do tratamento com exploração de impacto reduzido foram encontradas 157 espécies antes da exploração. Destas, 12 foram identificadas somente até o nome vulgar e uma não foi identificada (Figura 18, Anexo 1).

No tratamento exploração de impacto reduzido desapareceram 9 espécies (Aioea sp., Bowdichia nitida Spruce ex Benth, Guatteria olivaceae R. E. Fries, Maytenos guianensis K1., Ocotea guianensis Aubl., Ingá pezizifera Benth, Pouteria cuspidata (DC.) Baehni, pepino (NI i). Pouteria oppositifolia (Ducke) Baehni). Duas espécies desaparecidas nos primeiros três anos de monitoramento foram recrutadas (Byrsonima aerugo Sagot. e Inga capitata Desv.). Cinco espécies novas também foram recrutadas (Apeiba sp, Bombax longipedicellatum (Ducke) A. Robyns, Nectandra pichurim (H.B.K.) Mez., Sclerobium melanocaroum Ducke e Sterculia speciosa K. Schum). 
Trinta e nove por cento não sofreram nenhuma redução populacional, $5 \%$ aumentaram e $57 \%$ reduziram suas populações (Tabela 11 ).

Na área de exploração convencional foram encontradas 117 espécies antes da exploração. Destas, nove foram identificadas apenas até o nome vulgar e uma não foi identificada (Figura 18, Anexo 1).

$\mathrm{Na}$ exploração convencional desapareceram 9 espécies (Carapa guianensis Aubl., Caryocar villosum (Aublt.) Pers, Copaifera duckei Dwyer, Dipteryx odorata (Aubl.) Willd, Calophyllum brasiliense Cambess., Maytenos guyanensis Klotzsch., Niporana (NI g), Parahancornia falciculata (Poir.) Benoist, Terminalia guyanensis Eichler. Onze espécies novas foram recrutadas (Bagassa guianensis Aubl., Diploon venezuelana Aubl., Drypetes variabilis Uittien, Inga capitata Desv., Nectandra pichurim (H.B.K.) Mez., Ocotea cernua (Nees) Mez., Apeiba sp, Zygia racema (Ducke) Barneby \& J.W. Grimes, Sclerobium melanocaroum Ducke, Sterculia speciosa Schum e Tabebuia impetiginosa (Math ex DC.) Standl.). Dezesseis por cento não sofreram nenhuma redução populacional, $19 \%$ aumentaram e $66 \%$ reduziram suas populações (Tabela 11, Anexo 1).

$\mathrm{Na}$ área testemunha foram identificadas 138 espécies. Destas, seis foram identificadas até o nome vulgar e uma não foi identificada (Tabela 11, Anexo 1). Nesta área desapareceram 3 espécies (Zygia racema (Ducke) Barneby \& J.W. Grimes, Bowdichia nitida Spruce ex Benth, Schichozolobium parahyba (Vell.) Blake. Uma das espécies que havia desaparecido nos primeiros três anos de monitoramento (Drypetes variabilis Uittien) e cinco espécies novas foram recrutadas (Apeiba sp, Diploon cuspidatum (Hoehne) Cronquist., Duguetia echynophora R.E. Fr., Lecythis pisonis Cambess e Tavomita umbellata Benth). Quarenta e sete por cento das espécies não sofreram nenhuma redução populacional, $27 \%$ aumentaram e $28 \%$ reduziram suas populações (Tabela 11, Anexo 1). 
Figura 18: Número de espécies em 5,25 ha em cada tratamento (exploração convencional, exploração de impacto reduzido e testemunha) em Paragominas, Pará.

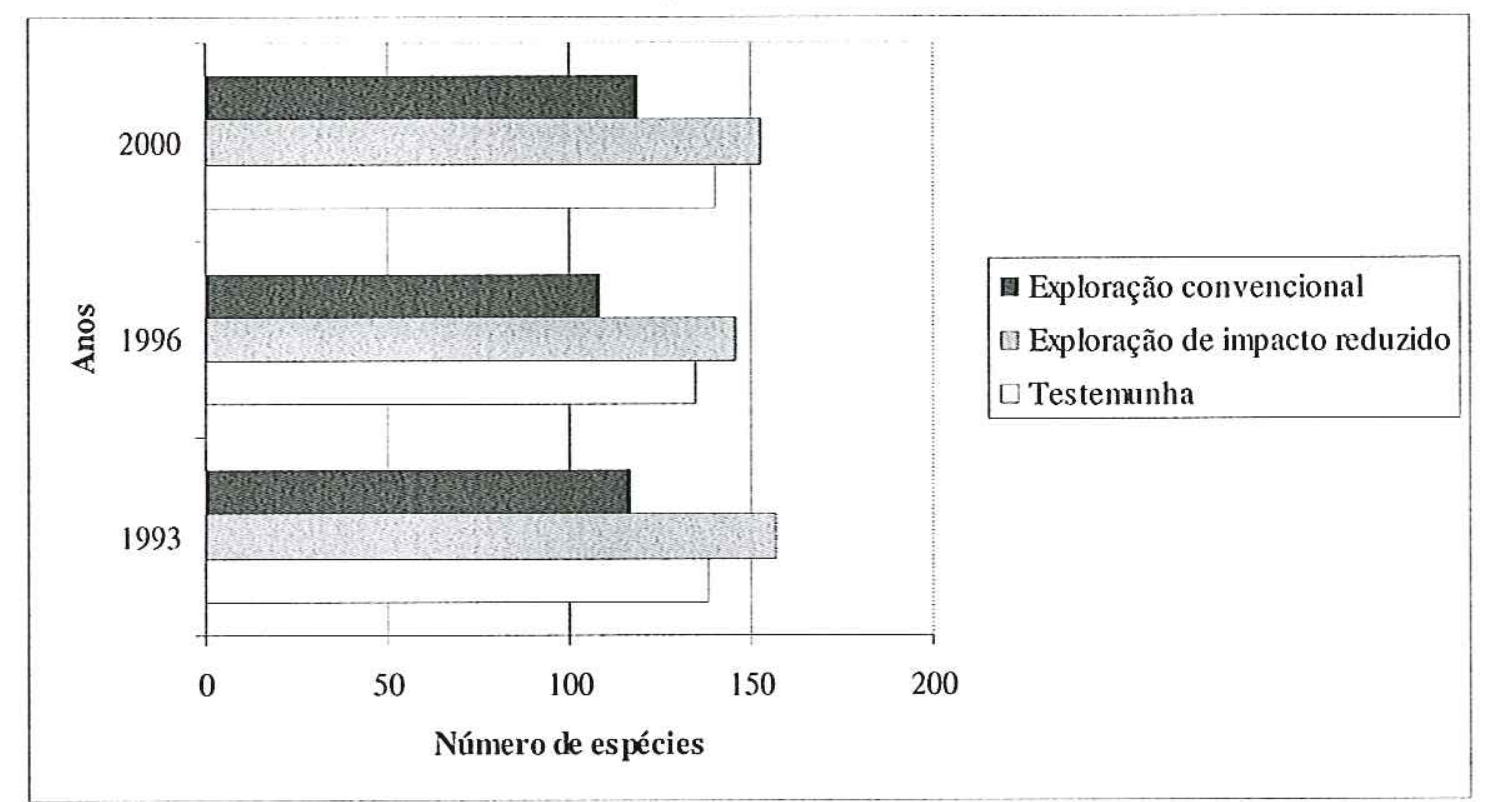

Tabela 11: Balanço da porcentagem de espécies no período de monitoramento (19932000).

\begin{tabular}{lcccc}
\hline & $\begin{array}{c}\text { Desapareceram } \\
(\%)\end{array}$ & $\begin{array}{c}\text { Reduziram } \\
\text { população } \\
(\%)\end{array}$ & $\begin{array}{c}\text { Aumentaram } \\
\text { população } \\
(\%)\end{array}$ & $\begin{array}{c}\text { Não } \\
\text { alteraram } \\
(\%)\end{array}$ \\
\hline $\begin{array}{l}\text { Testemunha } \\
\begin{array}{l}\text { Exploração de impacto } \\
\text { reduzido }\end{array}\end{array}$ & $2(3)$ & $28(39)$ & $27(37)$ & $47(65)$ \\
Exploração Convencional & $8(9)$ & $57(89)$ & $5(8)$ & $39(61)$ \\
\hline
\end{tabular}

Nota: números entre parênteses referem-se ao número de espécies.

Número de indivíduos. Na exploração de impacto reduzido houve uma redução de $21 \%$ no número de indivíduos causada pela exploração. Sete anos depois, este número reduziu para $20 \%$. Isso significa que está havendo uma recuperação lenta no número de indivíduos. Na exploração convencional, o número de indivíduos foi reduzido em $25 \%$ pela exploração e, sete anos depois, este número foi reduzido para 
22\%. Na área testemunha, em 3 anos de monitoramento, observou-se uma pequena redução de $4 \%$ no número de indivíduos. Em sete anos, este número era $3 \%$. Portanto, o estoque de árvores existente hoje comparado com o que existia originalmente, é de $80 \%$ na área de exploração de impacto reduzido, de $78 \%$ na de exploração convencional e de 97\% na área testemunha (Figura 19).

Figura 19: Número de indivíduos em 5,25 ha em cada tratamento (exploração convencional, exploração com técnicas de impacto reduzido e testemunha) em Paragominas, Pará.

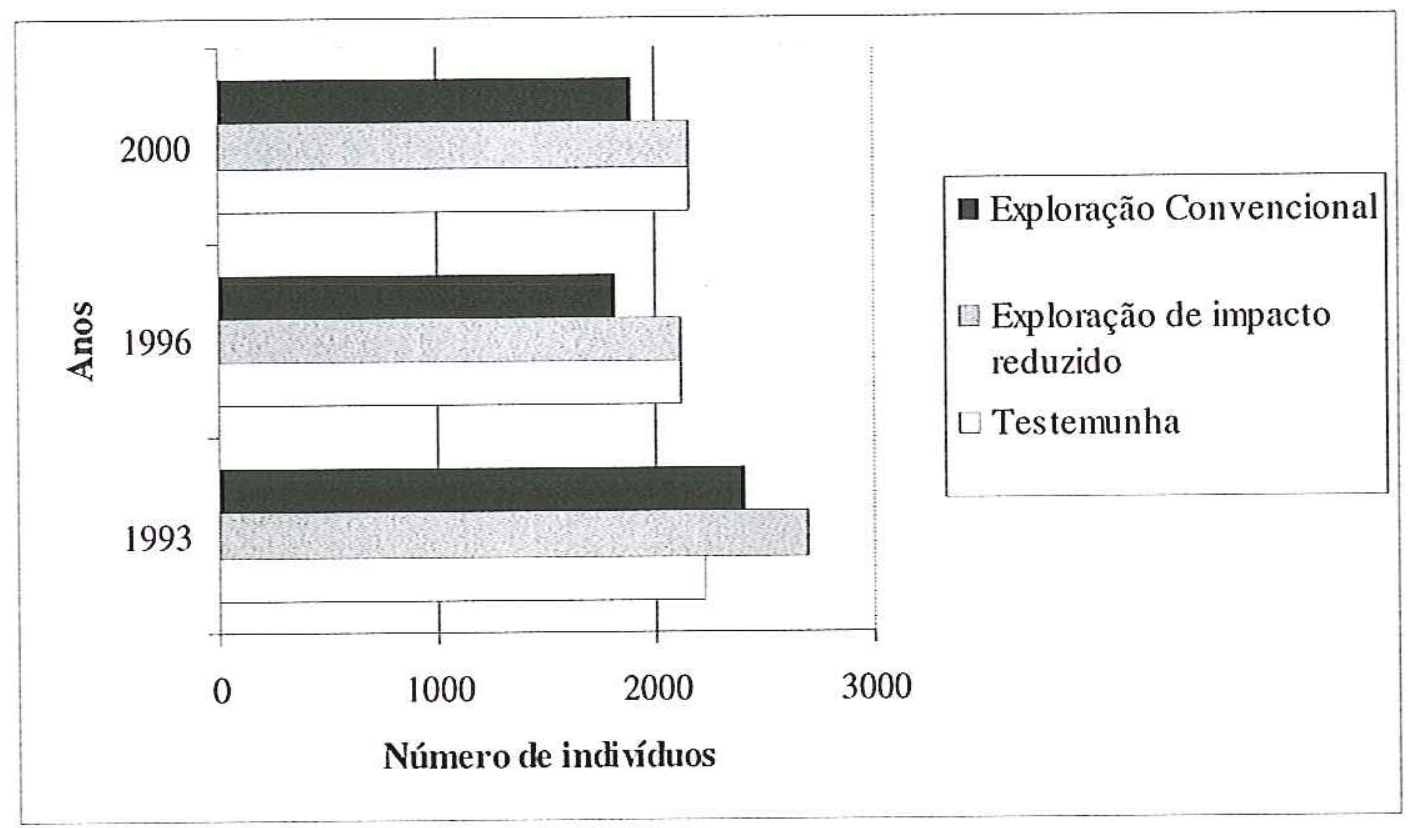

\subsubsection{Diversidade de espécies através dos índices de diversidade $\alpha$ de Fisher e de Shannon-Weiner}

A diversidade de espécies analisada através do índice $\alpha$ de Fisher demonstrou, nos três períodos avaliados, um padrão evolutivo bastante semelhante entre os três tratamentos. A diversidade avaliada por este índice não foi afetada pela exploração, ao invés disso, aumentou ao longo do período monitorado logo após a exploração. No 


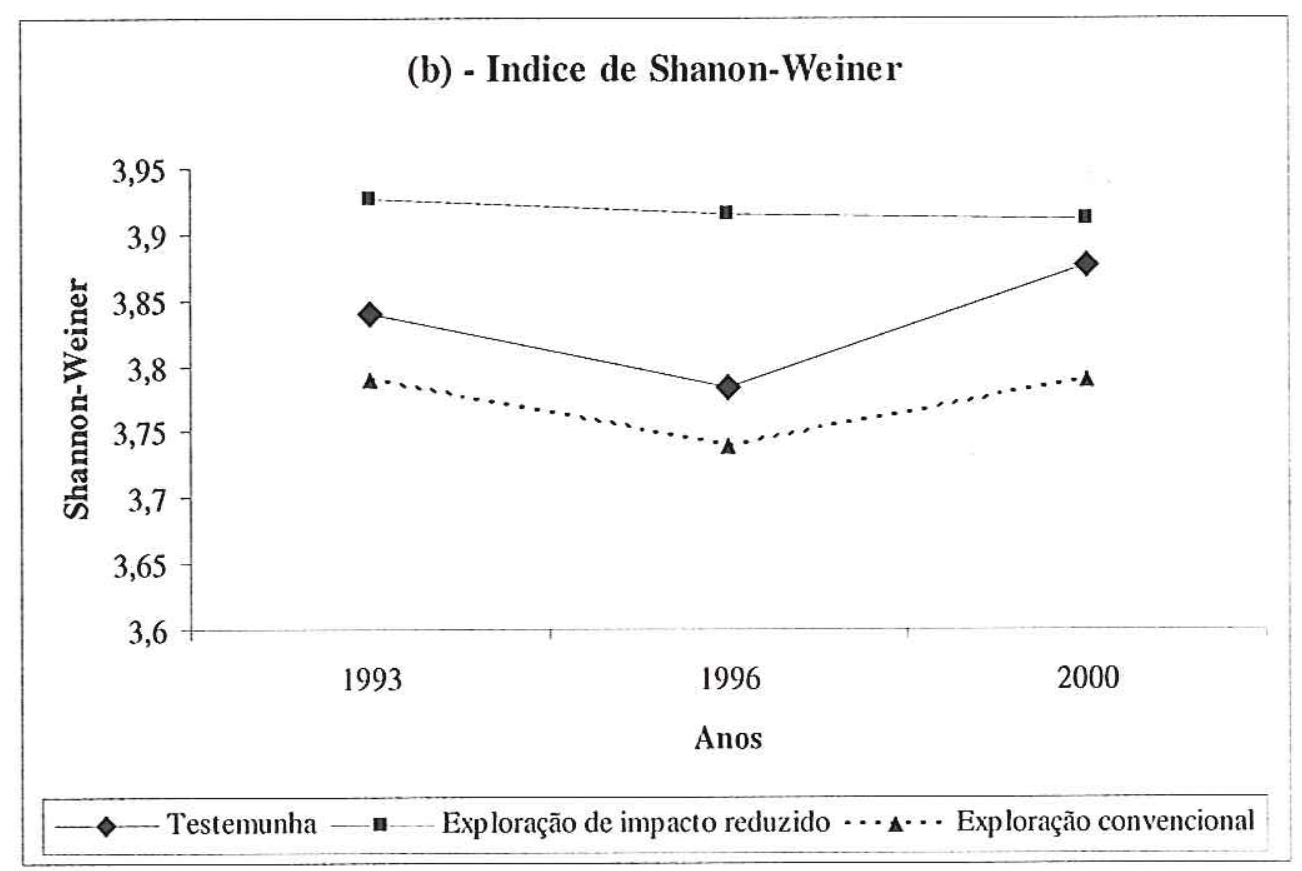

Tabela 12: Número de espécies, número de indivíduos, índice $\alpha$ de Fisher e índice de Shannon em três tratamentos (Testemunha-T, Exploração de impacto reduzido-EIR e Exploração Convencional-EC) numa área de 5,25 ha em Paragominas, Pará.

\begin{tabular}{|c|c|c|c|c|c|c|c|c|c|c|c|c|}
\hline \multirow[t]{2}{*}{ Trat. } & \multicolumn{3}{|c|}{$\mathrm{N}$} & \multicolumn{3}{|c|}{$\mathrm{N}$} & \multicolumn{3}{|c|}{$\alpha$ de Fisher } & \multicolumn{3}{|c|}{ Shannon H' } \\
\hline & 1993 & 1996 & 2000 & 1993 & 1996 & 2000 & 1993 & 1996 & 2000 & 1993 & 1996 & 2000 \\
\hline $\mathrm{T}$ & 138 & 135 & 140 & 2228 & 2114 & 2152 & 31 & 30 & 32 & 3,8 & 3,8 & 3,8 \\
\hline EIR & 157 & 146 & 153 & 2691 & 2119 & 2162 & 35 & 35 & 39 & 3,9 & 3,9 & 3,9 \\
\hline $\mathrm{EC}$ & 117 & 108 & 119 & 2414 & 1818 & 1891 & 21 & 22 & 25 & 3,8 & 3,7 & 3,8 \\
\hline
\end{tabular}

Notas: $N \rightarrow$ número de espécies; $n \rightarrow$ número de indivíduos

\subsubsection{Comparação estatística da diversidade de espécies através do índice de Shannon por período em cada tratamento}

Os resultados das análises estatísticas do índice de diversidade de Shannon para dois períodos (antes (1993) e três anos após (1996) a exploração e antes e sete anos após (2000)) indicaram que não houve diferença estatística para os tratamentos exploração de impacto reduzido e exploração convencional, como também para a área testemunha, ou seja, não houve mudanças significativas na diversidade de espécies com DAP $\geq 10 \mathrm{~cm}$ (Tabela 13). 
Tabela 13: Comparação estatística entre tratamentos através do índice de diversidade de Shannon em Paragominas-Pará.

\begin{tabular}{l|cc|cc|cc}
\hline & \multicolumn{2}{|c|}{$\begin{array}{c}\text { Exploração de } \\
\text { Impacto Reduzido }\end{array}$} & \multicolumn{2}{c|}{$\begin{array}{c}\text { Exploração } \\
\text { Convencional }\end{array}$} & Testemunha \\
\cline { 2 - 7 } & $(93-96)$ & $(93-00)$ & $(93-96)$ & $(93-00)$ & $(93-96)$ & $(93-00)$ \\
\hline Graus de liberdade & 4556 & 4623 & 3965 & 4037 & 4333 & 4379 \\
$\mathrm{t}$ & 0,36 & 0,59 & 1,09 & $-0,23$ & 0,28 & $-1,31$ \\
$\mathrm{p}$ & $0,715^{\mathrm{ns}}$ & $0,552^{\mathrm{ns}}$ & $0,277^{\mathrm{ns}}$ & $0,817^{\mathrm{ns}}$ & $0,776^{\mathrm{ns}}$ & $0,189^{\text {ns }}$ \\
\hline
\end{tabular}

Notas: $t=$ Teste $t$ de Student $;=$ Probabilidade; $n s=$ não significativo

\subsubsection{Densidade de indivíduos por tratamento}

Em 1993, a densidade média de indivíduos era de 442 indivíduos/ha na área testemunha, 526 indivíduos/ha na área com exploração de impacto reduzido e 474 indivíduos/ha na área com exploração convencional. Na área natural (testemunha), em 3 anos, ocorreu uma redução de $5 \%$ na densidade de indivíduos que, em sete anos, foi reduzida para $3 \%$. Na área com exploração de impacto reduzido houve uma redução de $21 \%$, devida principalmente à intervenção. Em 7 anos, esta redução diminuiu para $21 \%$. Já na exploração convencional, a redução foi de $25 \%$, reduzindo para $21 \% \mathrm{em} 7$ anos. $\mathrm{Na}$ área onde não foi realizada exploração foram encontrados $98 \%$ dos indivíduos presentes sete anos antes. $\mathrm{Na}$ área com exploração de impacto reduzido, encontraram-se $80 \%$ e na área com exploração convencional, 79\% desses indivíduos (Anexo 1).

\subsubsection{Densidade de indivíduos por espécie e por tratamento}

Testemunha: Apenas 12\% das espécies apresentaram mais de 10 indivíduos/ha, e cerca de $72 \%$ espécies tinham densidade abaixo de 1 indivíduo/ha. As espécies mais abundantes foram: Ingá cf. cylindrica (Vell.) Mart. (41 indivíduos/ha), Pouteria caimito (Ruiz \& Pav.) Radlk. (36,2 indivíduos/ha) e Lecythis idatimon Aubl. (33,1 indivíduos/ha). A espécie com maior grau de redução populacional era a Ocotea longifolia Kunth. (67\%) (Anexo 1).

Exploração de impacto reduzido: Cerca de $87 \%$ das espécies tinham menos de 1 indivíduo/ha e 15\% tinham mais de 10 indivíduos/ha. As espécies mais abundantes 
foram: Pouteria caimito (Ruiz \& Pav.) Radlk. (34,9\%), Neea sp. (33,7\%), Ingá cylindrica $(33,7 \%)$ e Lecythis idatimon Aubl. (31,2\%). As espécies com alto grau de redução populacional eram Vismia sp. (87\%), Copaifera duckei Dwyer (75\%), Caniceiro (NI) (59\%) e Pourouma guianensis Aubl. (52\%) (Anexo 1).

Exploração convencional: Quarenta e quatro por cento das espécies tinham menos de 1 indivíduo/ha e 12\% tinham mais de 10 indivíduos/ha. As espécies mais abundantes eram: Lecythis idatimon Aubl. (45,7\%) e Ingá cylindrica (Vell.) Mart. $(31,4 \%)$. As espécies com mais alto grau de redução populacional eram Tabebuia serratifolia (Vahl.) Nichols e Hymenaea courbaril L. ambas com 65\% de redução (Anexo 1).

\subsection{Discussão}

\subsubsection{Composição florística da área}

O número de espécies arbóreas encontrado na região de Paragominas parece ser menor do que o encontrado em outras regiões da Amazônia. O número de espécies encontrado neste estudo (171 espécies) foi semelhante aos de outros estudos realizados na região de Paragominas. Vidal et al. (1998) na mesma área de estudo, encontrou entre 121 e 151 espécies acima de $10 \mathrm{~cm}$ de DAP, e Nepstad (1989), próximo à área de estudo, também encontrou 171 espécies acima de $20 \mathrm{~cm}$. Em outras regiões da Amazônia o número de espécies são superiores aos encontrados em Paragominas. Oliveira \& Nelson (2001) encontraram entre 280 e 285 espécies em sítios em Rondônia e Manaus; Vieira (2003) encontrou 265 espécies em Santarém, 232 em Manaus e 164 em Rio Branco, sempre acima de $10 \mathrm{~cm}$ de DAP.

\subsubsection{Efeito da exploração madeireira sobre o número de espécies e número de indivíduos}

Neste estudo, o número de espécies na área explorada convencionalmente foi reduzido em $8 \%$ logo após a exploração. E, sete anos após a exploração, este número aumentou em $1,7 \%$. Na área explorada com técnicas de redução de impacto, o número 
de espécies foi reduzido em $6 \%$. E, sete anos após a intervenção, este número ainda se mantinha 2,5\% menor do que o encontrado antes da exploração. Na área testemunha também houve um aumento no número de espécies em sete anos. Isto por causa do recrutamento de espécies que já estavam estabelecidas no início do estudo, que aproveitaram as aberturas para se desenvolver. Em relação ao número de indivíduos, a dinâmica foi semelhante entre a exploração com impacto reduzido e exploração convencional. No entanto, na exploração com impacto reduzido, a recuperação no número de indivíduos tem sido um pouco superior à da exploração convencional.

Esses resultados coincidem com os de Laurance \& Laurance (1996), em Queensland, Austrália, que observaram um aumento de espécies pioneiras; os de Magnussom et al. (1999) que encontraram um aumento na densidade de espécies comerciais após seis anos da exploração; os de Costa e Magnussom (2003), que observaram um aumento da floração e frutificação de espécies do sub-bosque na Amazônia Central; e os de Pinard et al. (2000), que observaram uma riqueza e densidade de espécies lenhosas maiores nas trilhas de arraste na área com exploração de impacto reduzido do que as da exploração convencional, na Bolívia. No entanto, os resultados deste estudo contrastam com os de Skorupa (1988), que encontrou uma redução na riqueza de espécies na Uganda; e os de Cannon et al. (1994 e 1998), que mostraram uma redução na densidade e no número de espécies tanto para árvores grandes como para árvores intermediárias. Nicholson (1979), citado por Cannon et al. (1998), na Austrália, demonstraram não haver mudanças na riqueza de espécies.

Trinta e nove por cento das espécies na área com exploração de impacto rduzido não sofreram nenhuma redução em suas populações, contra apenas $16 \%$ na área explorada convencionalmente. Cerca de $57 \%$ das espécies na área com exploração de impacto reduzido sofreram reduções em suas populações, enquanto que na área explorada convencionalmente essa redução foi de $66 \%$. (Tabela 11 ). 


\subsubsection{Comparação da diversidade de espécies através de índices}

A diversidade de espécies encontrada neste estudo através do índice $\alpha$ de Fisher são comparáveis às encontradas por outros autores na Amazônia: Thompson et al. (1992), em Maracá/Roraima, 23,6; Uhl \& Murphy (1981), em São Carlos/Venezuela, 23,9; e Gentry (1988a), em Neblina Base Camp (Brasil/Venezuela), 31,7. Em relação ao índice de Shannon, os índices encontrados neste estudo (3,76 na exploração convencional, 3,92 na exploração de impacto reduzido e 3,78 na área testemunha) equivalem ao intervalo encontrado em outras áreas da Amazônia. Estudos anteriores registraram um índice de Shannon variando entre 2,63 e 5,4 (Martins, 1999; Uhl \& Murphy, 1981; Vidal et al., 1998; Vieira, 2003).

Não houve uma redução considerável na diversidade de espécies logo após e sete anos após a exploração, em todos os tratamentos. Isto demonstra que mesmo realizando uma exploração danosa ao ambiente florestal, como é o caso da exploração predatória, a diversidade de espécies quase não é afetada. No entanto, é importante mencionar que a exploração predatória utilizada neste estudo não seguiu o mesmo modelo de exploração predatória típica da região. Geralmente, as áreas de exploração convencional são reexploradas várias vezes. Em muitos casos, é comum também a ocorrência de incêndios, o que torna a floresta ainda mais degradada. Gerwing (2000) registrou os impactos das reexplorações nas florestas exploradas nos arredores da área deste estudo e comprovou que a cada reentrada, os danos estruturais aumentam gradativamente e o número de espécies florestais diminui.

Os resultados deste estudo concordam com os de um estudo de Cannon et al. (1996 e 1998) em florestas de Dipterocarpaceae em Bornéo, no qual não foi observado nenhum decréscimo na diversidade de espécies arbóreas oito anos após a exploração. Todavia, Vidal et al. (1998), na mesma área do presente estudo, usando o mesmo índice (Shannon), mas outra metodologia, verificaram que a diversidade de espécies foi alterada logo após a exploração, e que esta alteração ainda persistia três anos após a exploração convencional. Além disso, nas áreas exploradas com técnicas de exploração de impacto reduzido, Vidal et al. (1998) não observaram diferenças entre a diversidade de espécies encontrada antes e após a exploração. 


\subsection{Conclusões}

A riqueza de espécies e o número de indivíduos reduzem logo após a exploração tanto na exploração de impacto reduzido como na exploração convencional. Após sete anos de monitoramento, a exploração convencional aumentou o número de espécies em comparação ao número existente antes da exploração. Vale ressaltar que a exploração predatória aplicada na área deste estudo não foi o modelo de exploração predatória típico da região, pois não se realizaram entradas sucessivas na floresta (reentradas), como comumente é o caso na Amazônia. Estudos têm demonstrado evidências de que explorações madeireiras sucessivas afetam a riqueza de espécies (para mais detalhes ver Gerwing, 2002).

Considerando a diversidade de espécies através dos índices de Shannon e de Fisher, a área explorada com técnicas de impacto reduzido têm se mantido com a diversidade superior às encontradas nas áreas de exploração convencional e na testemunha.

Este estudo mostra que a composição florística das espécies arbóreas comerciais e das arbóreas não-comerciais não sofrem mudanças profundas por causa da exploração, pelo menos para a amostragem tratada nesta pesquisa; espécies do segundo $(>30 \mathrm{~cm}$ DAP) e do terceiro corte (10 $\mathrm{cm}-30 \mathrm{~cm}$ DAP).

Comparando a exploração predatória com a exploração com técnicas de impacto reduzido, observou-se que, na primeira: i) mais espécies desapareceram, ii) um número maior de espécies teve suas populações reduzidas; iii) mais espécies aumentaram suas populações; e iv) somente um pequeno número de espécies teve suas populações alteradas.

Estudos recentes têm enfocado a sustentabilidade do crescimento da floresta após a exploração (Alder \& Silva, 2001 e Capítulo 6 desta tese), todavia, a sustentabilidade das espécies tem sido pouco estudada na atualidade. É necessário que se realizem estudos de longo prazo, com enfoque na sustentabilidade ecológica das espécies, para que se possam fazer prognósticos sobre a biodiversidade da flora futura, inclusive as espécies arbóreas. Informações desta natureza são importantes para melhorar a sustentabilidade ecológica do manejo florestal. 
Anexo 1: Espécies, famílias e densidade por espécie em cada tratamento, em Paragominas,Pará.

\begin{tabular}{|c|c|c|c|c|c|c|c|c|c|c|}
\hline \multirow{3}{*}{ NOME CIENTÍFICO Autor } & \multirow{3}{*}{ FAMÍLIA } & \multicolumn{9}{|c|}{ Densidade (indivíduos/ha) } \\
\hline & & \multicolumn{6}{|c|}{$\begin{array}{c}\text { Exploração de } \\
\text { impacto reduzido }\end{array}$} & \multicolumn{3}{|c|}{$\begin{array}{c}\text { Exploração } \\
\text { Convencional } \\
\end{array}$} \\
\hline & & 1993 & 1996 & 2000 & 1993 & 1996 & 2000 & 1993 & 1996 & 2000 \\
\hline Aioea laevis (Mart.) Kosterm. & Lauraceae & & & & 0,4 & 0,4 & 0,4 & & & \\
\hline Aiouea sp & Lauraceae & & & & 0,2 & 0,2 & 0,0 & & & \\
\hline Allophylus robustus Radlk & Sapindaceae & & & & 0,4 & 0,4 & 0,2 & & & \\
\hline Annona sp & Annonaceae & 1,7 & 1,7 & 1,9 & 2,1 & 1,1 & 1,1 & 2,5 & 1,9 & 1,7 \\
\hline Apeiba echinata Gaertn. & Tiliaceae & 1,9 & 1,9 & 2,1 & 0,4 & 0,4 & 0,4 & & & \\
\hline Apeiba glabra Aubl. & Tiliaceae & 1,5 & 1,3 & 1,1 & 3,2 & 2,5 & 2,3 & 2,7 & 2,3 & 2,3 \\
\hline Apeiba sp & Tiliaceae & 0,0 & 0,0 & 0,6 & 0,0 & 0,0 & 0,2 & 0,0 & 0,0 & 0,2 \\
\hline Aspidosperma album (Vahl) Benth. ex Pichon & Apocynaceae & 4,0 & 3,6 & 3,0 & 3,6 & 2,9 & 2,3 & 5,3 & 4,4 & 3,8 \\
\hline Aspidosperma nitidum Benth. Ex. Nüell. Arg. & Apocynaceae & & & & 0,4 & 0,2 & 0,2 & 0,2 & 0,2 & 0,2 \\
\hline Astronium lecointei Ducke & Anacardiaceae & 0,2 & 0,2 & 0,2 & 1,0 & 0,8 & 0,8 & 0,6 & 0,4 & 0,4 \\
\hline Auxemma oncocalyx (Allemão) Taub. & Euphorbiaceae & 16,0 & 15,0 & 15,0 & 14,5 & 11,6 & 11,0 & 15,6 & 12,2 & 12,6 \\
\hline Bagassa guianensis Aubl. & Moraceae & 0,2 & 0,2 & 0,2 & 0,8 & 0,4 & 0,6 & 0,0 & 0,0 & 0,2 \\
\hline Balizia pedicellaris (A.Rich.) Barneby & \& & & & & & & & & & \\
\hline J.W.Grimes & Leg: Mimosoideae & 0,2 & 0,2 & 0,2 & 0,2 & 0,2 & 0,2 & & & \\
\hline Bellucia grossularioides (L.) Triana. & Melastomataceae & 0,2 & 0,2 & 0,2 & 0,6 & 0,6 & 0,4 & & & \\
\hline Bombax longipedicellatum (Ducke) A. Robyns & Bombacaceae & 1,0 & 1,0 & 1,1 & 0,0 & 0,0 & 0,2 & 0,6 & 0,4 & 0,4 \\
\hline Bombax paraensis Ducke & Bombacaceae & & & & 0,2 & 0,2 & 0,2 & & & \\
\hline Bowdichia nitida Spruce ex Benth & Leg: Papilionoideae & 0,2 & 0,0 & 0,0 & 0,4 & 0,2 & 0,0 & 0,4 & 0,4 & 0,4 \\
\hline Brosimum sp. & Moraceae & 0,4 & 0,4 & 0,4 & & & & 1,5 & 0,4 & 0,4 \\
\hline Byrsonima aerugo Sagot. & Malpiguiaceae & 0,4 & 0,4 & 0,4 & 0,2 & 0,0 & 0,2 & 0,2 & 0,2 & 0,4 \\
\hline Calophyllum brasiliense Cambess. & Clusiaceae & & & & & & & 0,2 & 0,0 & 0,0 \\
\hline Caraipa grandifolia Mart. & Clusiaceae & 1,5 & 1,5 & 2,5 & 1,0 & 0,8 & 0,8 & 0,4 & 0,2 & 0,8 \\
\hline Carapa guianensis Aubl. & Meliaceae & & & & 1,9 & 1,5 & 1,7 & 0,4 & 0,0 & 0,0 \\
\hline Caryocar glabum (Aubl.) Pers. spp. glabrum & Caryocaraceae & 0,8 & 0,8 & 0,8 & 1,7 & 1,1 & 1,1 & 1,1 & 1,1 & 1,1 \\
\hline Caryocar villosum (Aubl.) Pers & Caryocaraceae & 0,2 & 0,2 & 0,2 & 0,8 & 0,8 & 0,8 & 0,2 & 0,0 & 0,0 \\
\hline Casearia arborea (L.C. Rich.) Urban. & Flacourtiaceae & & & & 0,2 & 0,2 & 0,2 & & & \\
\hline Cecropia sciadophylla Mart. & Cecropiaceae & 10,5 & 9,5 & 8,8 & 5,5 & 3,0 & 11,2 & 5,7 & 5,0 & 17,1 \\
\hline
\end{tabular}


Cedrela odorata L.

Meliaceae

Chamaecrista xinguensis (Ducke) H.S. Irwin \& Leg: Caesalpinioideae Barneby

Chaunochiton kappleri (Sagot. ex Engl.) Ducke Olacaceae

Chrysophyllum lucentifollium Cronquist ssp

pachycarpum

Sapotaceae

Clarisia ilicifolia (Spreng.) Lanj. \& G. Rossberg Moraceae

Clarisia racemosa Ruíz e Pav.

Sapotaceae

Copaifera duckei Dwyer

Cordia bicolor DC.

Cordia goeldiana Huber

Cordia scabrifolia A.DC.

Couratari guianensis Aubl.

Couratari oblongfolia Ducke \& Knuth

Cupania hirsuta Radlk.

Cupania scrobiculata L.C. Rich

Dendrobangia boliviana Rusby

Dialium guianense (Aubl.) Sandwith

Dinizia excelsa Ducke

Diospyros dukei Sandwith

Diospyros melinonii (Hiern) A.C. Sm.

Diospyros praetermissa Sandwith

Diospyros sp

Diospyros tectranda Hiern

Diploon cuspidatum (Hoehne) Cronquist.

Dipteryx odorata (Aubl.) Willd

Drypetes variabilis Uittien

Duguetia echynophora R.E. Fr.

Eperua schonburgkiana Benth.

Eriotheca globosa (Aubl.) Robyns

Leg: Caesalpinioideae

Boraginaceae

Boraginaceae

Boraginaceae

Lecythidaceae

Lecythidaceae

Sapindaceae

Sapindaceae

Icacinaceae

Leg: Caesalpinioideae

Leg: Mimosoideae

Ebenaceae

Ebenaceae

Ebenaceae

Ebenaceae

Ebenaceae

Sapotaceae

Leg: Papilionoideae

Euphorbiaceae

Annonaceae

Leg: Caesalpinioideae

Bombacaceae

Eschweilera apiculata (Miers) A.C.Sm.

Eschweilera coriaceae (DC.) S.A. Mori

Lecythidaceae

Lecythidaceae

Eschweilera grandeflora (Aubl.) Sandwith

Lecythidaceae

Eschweilera ovata (Cambess.) Miers

Lecythidaceae

$\begin{array}{ccccccccc}0,2 & 0,2 & 0,2 & 0,2 & 0,2 & 0,2 & & & \\ & & & & & & & & \\ 0,6 & 0,6 & 0,6 & 0,4 & 0,4 & 0,4 & & & \\ & & & 0,2 & 0,2 & 0,2 & & & \\ 5,7 & 5,7 & 6,1 & 7,6 & 6,1 & 6,3 & 9,0 & 7,2 & 7,0 \\ 0,2 & 0,2 & 0,4 & 0,2 & 0,2 & 0,2 & & & \\ 1,0 & 1,0 & 0,8 & 2,5 & 1,7 & 1,5 & 3,2 & 2,7 & 2,7 \\ & & & 0,8 & 0,2 & 0,2 & 0,4 & 0,0 & 0,0 \\ 6,3 & 5,9 & 8,8 & 12,8 & 11,2 & 10,5 & 7,0 & 4,8 & 5,1 \\ 2,1 & 1,9 & 2,1 & 5,7 & 4,8 & 4,6 & 1,9 & 1,1 & 1,1 \\ 1,7 & 1,7 & 1,5 & 3,4 & 3,0 & 3,0 & 0,2 & 0,2 & 0,6 \\ 0,2 & 0,2 & 0,2 & 0,2 & 0,2 & 0,2 & & & \\ 0,4 & 0,4 & 0,4 & 0,4 & 0,4 & 0,4 & & & \\ & & & 0,4 & 0,4 & 0,2 & & & \\ 1,9 & 1,7 & 2,7 & 1,1 & 0,6 & 1,0 & 1,9 & 1,3 & 2,1 \\ 0,2 & 0,2 & 0,2 & & & & & & \\ & & & & & & 0,2 & 0,2 & 0,2 \\ & & & & & & 0,6 & 0,6 & 0,4 \\ 13,5 & 12,6 & 12,6 & 26,1 & 19,4 & 18,9 & 15,0 & 11,6 & 11,2 \\ & & & 0,2 & 0,2 & 0,2 & & & \\ 0,2 & 0,2 & 0,2 & 1,1 & 1,0 & 0,8 & 0,2 & 0,2 & 0,4 \\ 0,2 & 0,2 & 0,2 & & & & & & \\ 0,4 & 0,4 & 0,4 & & & & & & \\ 0,0 & 0,0 & 0,2 & 0,2 & 0,2 & 0,2 & 0,0 & 0,0 & 0,2 \\ 0,2 & 0,2 & 0,2 & 0,4 & 0,2 & 0,2 & 0,2 & 0,0 & 0,0 \\ 0,2 & 0,0 & 0,6 & 0,8 & 0,8 & 0,8 & 0,0 & 0,0 & 0,2 \\ 0,0 & 0,0 & 0,2 & & & & & & \\ & & & 0,2 & 0,2 & 0,2 & & & \\ 0,2 & 0,2 & 0,2 & 0,4 & 0,4 & 0,4 & & & \\ 0,8 & 0,8 & 0,8 & 11,2 & 8,2 & 7,8 & 4,8 & 4,2 & 4,0 \\ & & & 0,4 & 0,4 & 0,4 & & & \\ 11,8 & 11,2 & 11,4 & 20,0 & 17,1 & 18,7 & 21,3 & 17,5 & 18,1 \\ & & & & & & & & \end{array}$


Eschweilera pedicellata (Rich.) S.A.Mori

Eugenia heterochroa Urb.

Guarea kunthiana A.Juss.

Guatteria olivacea R.E.Fr.

Guatteria poppigiana Mart.

Guatteria schomburgkiana Mart.

Guatteria sp

Helicostyles tomentosa (Poepp. \& Endl.) Rusby

Himatanthus sucuuba (Spruce ex Müll.Arg.)

Woodson

Hymenaea courbaril L.

Hymenaea oblongifolia Huber

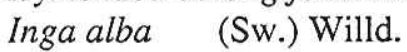

Inga capitata Desv.

Inga cylindrica (Vell.) Mart

Inga dumosa Benth

Inga edulis Mart

Inga eplendens Willd.

Inga gracilifolia Ducke

Inga ingoides (Rich.) Willd.

Inga macrophylla Humb. \&. Bonpl. ex Willd.

Inga melinones Sagot

Inga microcalix Spruce

Inga pezizifera Benth

inga rubiginosa (Rich) DC

Inga thibaldiana DC.

Jacaranda copaia (Aubl.) D. Don

Jacaratia espinosa (Aubl) A. DC.

Laetia procera (Poepp.) Eich.

Lecythis idatimon Aubl.

Lecythis lurida (Miers) S.A. Mori

Lecythis pisonis Cambess.

Licania heteromorpha Benth.

Licania kunthiana Hook F.
Lecythidaceae

Mirtaceae

Meliaceae

Annonaceae

Annonaceae

Annonaceae

Annonaceae

Moraceae

Apocynaceae

Leg: Caesalpinioideae

Leg: Caesalpinioideae

Leg: Mimosoideae

Leg: Mimosoideae

Leg: Mimosoideae

Leg: Mimosoideae

Leg: Mimosoideae

Leg: Mimosoideae

Leg: Mimosoideae

Leg: Mimosoideae

Leg: Mimosoideae

Leg: Mimosoideae

Leg: Mimosoideae

Leg: Mimosoideae

Leg: Mimosoideae

Leg: Mimosoideae

Bignoniaceae

Caricaceae

Flacourtiaceae

Lecythidaceae

Lecythidaceae

Lecythidaceae

Chrysobalanaceae

Chrysobalanaceae

$\begin{array}{ccccccccc}1,1 & 1,1 & 1,3 & 0,4 & 0,4 & 0,2 & 0,6 & 0,6 & 0,6 \\ 1,3 & 1,3 & 1,1 & & & & 1,3 & 1,0 & 0,8 \\ & & & 0,2 & 0,2 & 0,2 & & & \\ 1,3 & 1,3 & 1,3 & 0,2 & 0,2 & 0,0 & & & \\ 0,2 & 0,2 & 0,2 & & & & & & \\ 5,0 & 4,8 & 5,6 & 5,7 & 4,4 & 4,4 & 6,5 & 4,8 & 5,1 \\ 18,9 & 17,7 & 16,8 & 3,8 & 2,5 & 2,5 & 18,3 & 14,1 & 13,0 \\ 0,2 & 0,2 & 0,2 & & & & & & \\ & & & & & & & & \\ 1,1 & 1,1 & 1,1 & 0,2 & 0,2 & 0,2 & 1,5 & 1,5 & 1,5 \\ 1,0 & 1,0 & 1,9 & 1,5 & 1,1 & 1,1 & 0,6 & 0,2 & 0,2 \\ 0,6 & 0,6 & 0,4 & 1,1 & 1,1 & 1,0 & 1,1 & 1,1 & 1,1 \\ 3,8 & 3,8 & 2,5 & 17,1 & 13,3 & 12,0 & 6,1 & 3,8 & 3,0 \\ 1,5 & 1,5 & 2,9 & 1,0 & 0,6 & 0,6 & 0,0 & 0,0 & 0,2 \\ 41,0 & 38,3 & 33,7 & 33,7 & 24,6 & 28,8 & 31,4 & 23,6 & 24,0 \\ & & & 0,2 & 0,2 & 0,2 & & & \\ 2,1 & 2,1 & 1,3 & 0,2 & 0,2 & 0,2 & & & \\ & & & 0,4 & 0,4 & 0,4 & & & \\ & & & 0,2 & 0,2 & 0,2 & & & \\ 1,0 & 1,0 & 1,1 & 3,4 & 3,2 & 2,9 & & & \\ & & & 0,2 & 0,2 & 0,2 & & & \\ 0,4 & 0,2 & 0,2 & 1,1 & 1,1 & 1,1 & & & \\ & & & 0,2 & 0,2 & 0,2 & & & \\ & & & 0,2 & 0,0 & 0,0 & & & \\ 0,8 & 0,8 & 0,8 & 0,2 & 0,2 & 0,2 & 7,8 & 6,7 & 4,8 \\ 0,4 & 0,4 & 0,4 & 3,0 & 2,9 & 2,3 & & & \\ 1,7 & 1,7 & 2,1 & 1,5 & 1,3 & 1,3 & 0,4 & 0,2 & 0,2 \\ 0,2 & 0,2 & 0,2 & 0,4 & 0,4 & 0,6 & 0,4 & 0,4 & 0,6 \\ 3,6 & 3,6 & 3,6 & 6,5 & 5,5 & 5,1 & 4,6 & 3,8 & 3,4 \\ 33,1 & 31,6 & 30,7 & 31,2 & 27,0 & 26,3 & 45,7 & 34,7 & 35,6 \\ 1,5 & 1,5 & 1,7 & 2,5 & 1,9 & 1,9 & 3,0 & 2,9 & 2,5 \\ 0,0 & 0,0 & 0,2 & 0,6 & 0,6 & 0,6 & 1,7 & 1,5 & 1,5 \\ 0,4 & 0,4 & 0,4 & 0,4 & 0,4 & 0,4 & & & \\ 0,2 & 0,2 & 0,2 & 0,2 & 0,2 & 0,2 & 0,4 & 0,4 & 0,4\end{array}$


Licaria rigida (Kosterm.) Kosterm.

Lindackeria paraensis Kuhlm.

Macrolobium campestre Huber

Manilkara bidentada (DC.) A. Chev.

Manilkara huberi (Ducke) A. Chev.

Manilkara paraensis (Huber) Standl.

Matayba guianensis Aubl.

Maytenos guyanensis Klotzsch

Micropholis melinoniana Pierre

Minquartia guianensis Aubl.

Nectandra cuspidata Nees

Nectandra pichurim (H.B.K.) Mez.

Neea sp.

ni a

ni b

nic

ni d

nie

ni

nig

ni h

ni i

ni j

nik

ni 1

nim

Ocotea cernua (Ness) Mez.

Ocotea fragantissima Ducke

Ocotea glomerata (Nees) Mez

Ocotea guianensis Aubl.

Ocotea longifolia Kunth.

Ocotea rubra Mez.

Ormosia coutinhoi Ducke

Parahancornia falciculata (Poir.) Benoist
Lauraceae

Flacourtiaceae

Leg: Caesalpinioideae

Sapotaceae

Sapotaceae

Sapotaceae

Sapindaceae

Celastraceae

Sapotaceae

Olacaceae

Lauraceae

Lauraceae

Nyctaginaceae

$\mathrm{ni}$

ni

ni

ni

Lauraceae

Lauraceae

Lauraceae

Lauraceae

Lauraceae

Lauraceae

Leg: Papilionoideae

Moraceae

$\begin{array}{ccccccccc}0,2 & 0,2 & 0,2 & & 0,2 & 0,2 & & & \\ 25,1 & 24,0 & 25,1 & 18,5 & 14,7 & 15,4 & 17,3 & 14,3 & 14,5 \\ 0,6 & 0,6 & 0,8 & 1,1 & 1,0 & 1,1 & 0,6 & 0,2 & 0,4 \\ 2,3 & 2,1 & 1,9 & 3,2 & 2,7 & 2,5 & 4,4 & 2,1 & 2,3 \\ 0,4 & 0,4 & 0,4 & 0,2 & 0,2 & 0,2 & & & \\ & & & 0,2 & 0,2 & 0,2 & & & \\ 1,0 & 1,0 & 0,8 & 0,2 & 0,0 & 0,0 & 0,2 & 0,0 & 0,0\end{array}$

$0,2 \quad 0,2 \quad 0,2$

$0,2 \quad 0,2 \quad 0,2$

$\begin{array}{lllllllll}0,6 & 0,6 & 0,6 & 0,0 & 0,0 & 0,2 & 0,0 & 0,0 & 0,4\end{array}$

$\begin{array}{lllllllll}25,5 & 24,4 & 24,6 & 33,7 & 26,5 & 27,8 & 25,0 & 21,0 & 21,3\end{array}$

$\begin{array}{lllllllll}18,5 & 18,1 & 19,0 & 26,9 & 22,1 & 20,6 & 27,2 & 19,6 & 18,1\end{array}$

$\begin{array}{lllllllll}1,0 & 1,0 & 1,0 & 1,0 & 0,6 & 0,4 & 1,1 & 0,8 & 0,8\end{array}$

$\begin{array}{rllllll}1,9 & 1,3 & 1,3 & 0,6 & 0,6 & 0,6 \\ 0,2 & 0,2 & 0,2 & & & \end{array}$

$\begin{array}{lllllllll}0,2 & 0,2 & 0,2 & 0,2 & 0,2 & 0,2 & 1,0 & 0,6 & 0,6\end{array}$

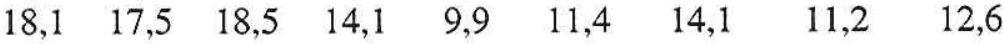

$\begin{array}{lllllllll}1,7 & 1,7 & 1,7 & 0,6 & 0,4 & 0,4 & 1,5 & 1,0 & 1,0\end{array}$

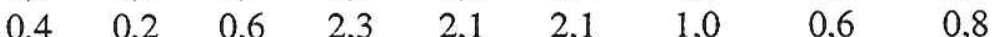

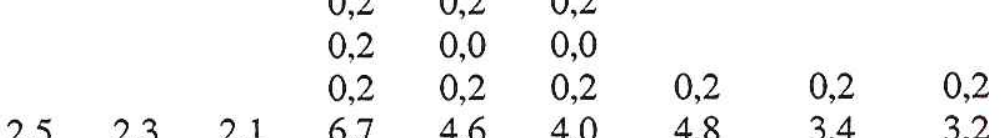

$\begin{array}{lllllllll}2,9 & 2,5 & 2,7 & 0,6 & 0,6 & 0,6 & 0,0 & 0,0 & 0,2\end{array}$

$\begin{array}{lllllllll}0,6 & 0,6 & 0,6 & 1,7 & 1,0 & 1,0 & 0,6 & 0,6 & 0,8\end{array}$

$0,6 \quad 0,4 \quad 0,2$

$\begin{array}{lllllllll}2,9 & 2,1 & 3,0 & 5,5 & 5,0 & 4,6 & 7,8 & 5,7 & 5,1\end{array}$

$\begin{array}{lllllllll}0,6 & 0,6 & 0,6 & 1,0 & 0,6 & 0,6 & 0,4 & 0,2 & 0,2\end{array}$

$\begin{array}{llllll}0,2 & 0,2 & 0,2 & 0,4 & 0,0 & 0,0\end{array}$


Parkia multijuga Benth.

Parkia nitida Miq.

Perebea guianensis Aubl.

Platymiscium filipes Benth

Poecilanthe effusa (Huber) Ducke

Pouroma guianensis Aubl.

Pourouma minor Benoist

Pouteria caimito (Ruiz \& Pav.) Radlk.

Pouteria cladantha Sandwith

Pouteria cuspidata (DC.) Baehni

Pouteria egregia Sandwith

Pouteria eugenifolia (Pierre) Baehni

Pouteria krukovii (A. C. Smith) Baehni

Pouteria macrophylla (Lam.) Eyma

Pouteria manaosensis (Aubrév. \& Pellegr.)

T.D.Penn.

Pouteria oppositifolia (Ducke) Baehni

Pouteria reticulata (Engl.) Eyma

Pouteria sangotiana (Baill.) Eyma

Pouteria sp

Protium altsonii Sandwith

Protium decandrum (Aubl.) March.

Protium tenuifolium (Engl.) Engl.

Pseudopiptadenia suaveolens (Miq.) J.W.Grimes Pterocarpus rohrii Vahl

Qualea sp

Rhodostemonodaphne grandis (Mez.) Rohwer

Rinorea guianensis (Aubl.)

Sacoglottis amazonica Mart.

Sapium lanciolatum

Scheffera morototoni (Aubl.) Maguire

Sclerobium goeldianum Huber

Sclerobium melanocarpum Ducke

Shichozolobium parahyba (Vell.) Blake
Leg: Mimosoideae

Leg: Mimosoideae

Moraceae

Leguminosae-pap.

Leg: Mimosoideae

Cecropiaceae

Cecropiaceae

Sapotaceae

Sapotaceae

Sapotaceae

Sapotaceae

Sapotaceae

Sapotaceae

Sapotaceae

Sapotaceae

Sapotaceae

Sapotaceae

Sapotaceae

Sapotaceae

Burseraceae

Burseraceae

Burseraceae

Leg: Mimosoideae

Leguminosae-pap.

Vochysiaceae

Lauraceae

Violaceae

Humiriaceae

Euphorbiaceae

Araliaceae

Leg: Caesalpinioideae

Leg: Caesalpinioideae

Leg: Caesalpinioideae

$\begin{array}{ccccccccc}0,2 & 0,2 & 0,2 & 1,1 & 0,8 & 0,8 & 0,8 & 0,8 & 1,1 \\ 2,3 & 2,1 & 2,1 & 5,9 & 4,6 & 4,4 & 3,4 & 2,9 & 4,4 \\ 5,3 & 5,3 & 5,3 & 4,4 & 3,8 & 3,0 & 8,8 & 6,9 & 6,7 \\ & & & 0,2 & 0,2 & 0,2 & & & \\ 5,3 & 5,0 & 4,8 & 4,0 & 2,9 & 2,1 & 5,7 & 3,4 & 3,4 \\ 2,9 & 2,3 & 2,7 & 3,2 & 1,7 & 1,5 & 3,6 & 3,2 & 2,7 \\ & & & 0,2 & 0,2 & 0,2 & & & \\ 36,2 & 35,0 & 34,9 & 34,9 & 26,9 & 26,5 & 27,0 & 17,0 & 16,6 \\ 7,4 & 7,2 & 8,6 & 8,2 & 7,0 & 7,0 & 3,0 & 1,3 & 1,5 \\ 0,2 & 0,2 & 0,2 & 0,2 & 0,0 & 0,0 & & & \\ 0,8 & 0,6 & 0,6 & & & & & & \\ & & & 0,2 & 0,2 & 0,2 & & & \\ 1,5 & 1,5 & 1,1 & 0,6 & 0,6 & 0,6 & 3,8 & 2,9 & 3,0 \\ & & & & & & & & \\ 3,2 & 3,0 & 3,2 & 5,3 & 4,0 & 4,4 & 2,1 & 1,7 & 2,5 \\ & & & 0,2 & 0,0 & 0,0 & 1,1 & 0,6 & 0,6 \\ 1,0 & 1,0 & 1,0 & 0,6 & 0,6 & 0,6 & 2,5 & 1,5 & 1,3 \\ & & & 0,6 & 0,6 & 0,6 & & & \\ 1,5 & 1,5 & 1,3 & 4,0 & 3,3 & 3,5 & 6,5 & 3,3 & 3,2 \\ 0,4 & 0,4 & 0,4 & & & & 0,2 & 0,2 & 0,2 \\ & & & & & & 0,4 & 0,4 & 0,4 \\ 8,6 & 8,6 & 8,6 & 6,7 & 5,1 & 5,0 & 4,6 & 3,2 & 3,0 \\ 3,6 & 3,4 & 3,8 & 2,9 & 2,3 & 2,5 & 2,1 & 1,7 & 1,9 \\ 0,8 & 0,8 & 0,8 & 1,0 & 1,0 & 1,0 & 2,7 & 2,1 & 2,1 \\ 0,2 & 0,2 & 0,2 & 0,2 & 0,2 & 0,2 & 0,2 & 0,2 & 0,2 \\ & & & 0,2 & 0,2 & 0,2 & & & \\ 1,9 & 1,9 & 2,3 & 0,8 & 0,8 & 1,0 & 2,3 & 1,7 & 2,1 \\ 1,1 & 1,1 & 1,1 & 0,8 & 0,8 & 0,8 & 1,5 & 1,0 & 0,8 \\ & & & 1,0 & 0,6 & 0,6 & 0,4 & 0,4 & 0,4 \\ 0,6 & 0,6 & 1,0 & 1,5 & 1,0 & 1,0 & 1,0 & 0,6 & 0,6 \\ 0,2 & 0,2 & 0,2 & & & & & & \\ 3,4 & 2,9 & 4,8 & 0,0 & 0,0 & 0,4 & 0,0 & 0,0 & 0,8 \\ 0,2 & 0,0 & 0,0 & & & & & & \end{array}$


Simarouba amara Aubl.

Sloanea obtusa Split.

Sterculia pruriens (Aubl) K. Schum

Simaroubaceae

Elaeocarpaceae

Sterculiaceae

Sterculiaceae

Sterculia speciosa K. Schum

Symphonia globulifera F.f.

Tabebuia impetiginosa (Mart. ex DC.) Standl.

Tabebuia serratifolia (Vahl.) Nichols.

Clusiaceae

Bignoniaceae

Bignoniaceae

Tachigali paniculata Aubl.

Leg: Caesalpinioideae

Combretaceae

Clusiaceae

Combretacea

Terminalia guyanensis Eichler

Tetragastris altissima (Aubl.) Swart

Burseraceae

Theobroma speciosa Willd. Ex Spreng.

Sterculiaceae

Trattinnikia burseraefolia Mart

Burseraceae

Meliaceae

Trichilia micrantha Benth

Virola michelii Heckel

Clusiaceae

Vismia guianensis (Aubl.) Choisy

Annonaceae

Zanthoxylum rhoifolium Lam.

Rutaceae

Rhamnaceae

Zizyphus itacaiunensis Fróes

Leg: Caesalpinioideae

Zygia racema (Ducke) Barneby \& J.W.Grimes

Leg: Mimosoideae

\begin{tabular}{ccccccccc}
0,2 & 0,2 & 0,2 & 0,2 & 0,2 & 0,2 & 1,0 & 1,0 & 1,0 \\
1,0 & 1,0 & 1,0 & 0,6 & 0,4 & 0,4 & 0,4 & 0,2 & 0,2 \\
0,4 & 0,2 & 0,4 & 10,1 & 8,6 & 9,3 & 0,6 & 0,4 & 0,4 \\
0,6 & 0,6 & 1,7 & 0,0 & 0,0 & 0,4 & 0,0 & 0,0 & 0,4 \\
0,8 & 0,8 & 0,8 & 0,2 & 0,2 & 0,2 & 0,2 & 0,2 & 0,2 \\
0,6 & 0,6 & 0,6 & 0,2 & 0,2 & 0,2 & 0,0 & 0,0 & 0,2 \\
0,8 & 0,8 & 0,8 & 0,2 & 0,2 & 0,2 & 0,6 & 0,2 & 0,2 \\
5,7 & 4,8 & 5,0 & 16,2 & 10,4 & 10,8 & 8,9 & 6,5 & 5,4 \\
1,3 & 1,3 & 1,3 & 2,3 & 1,9 & 1,9 & 0,2 & 0,2 & 0,2 \\
0,0 & 0,0 & 0,2 & & & & & & \\
0,6 & 0,6 & 0,6 & 0,6 & 0,4 & 0,4 & 0,4 & 0,0 & 0,0 \\
9,3 & 9,1 & 9,0 & 9,7 & 9,0 & 9,1 & 13,1 & 11,6 & 11,8 \\
2,3 & 2,3 & 2,5 & 2,3 & 2,1 & 2,1 & 2,5 & 2,3 & 2,3 \\
1,0 & 0,8 & 0,8 & 2,5 & 1,9 & 1,9 & 3,2 & 2,5 & 2,1 \\
0,6 & 0,6 & 0,4 & & & & & & \\
1,5 & 1,3 & 2,5 & 3,0 & 2,5 & 3,0 & 4,2 & 3,4 & 3,8 \\
1,1 & 1,0 & 1,0 & 1,5 & 0,6 & 0,2 & 0,4 & 0,2 & 0,4 \\
4,0 & 4,0 & 4,2 & 8,8 & 6,7 & 7,0 & 6,3 & 4,6 & 3,8 \\
2,3 & 1,9 & 2,1 & 2,1 & 1,3 & 1,5 & 3,4 & 2,9 & 2,9 \\
0,2 & 0,2 & 0,4 & & & & & & \\
2,5 & 2,5 & 2,7 & 1,5 & 1,1 & 1,1 & 1,3 & 0,8 & 1,0 \\
0,2 & 0,0 & 0,0 & 0,6 & 0,4 & 0,6 & 0,0 & 0,0 & 0,2 \\
\hline
\end{tabular}




\section{Capítulo VI: Dinâmica da Floresta Tropical Explorada com e sem Exploração de Impacto Reduzido sete anos após Intervenção Silvicultural em Paragominas, Pará.}

\subsection{Introdução}

Atualmente, a exploração madeireira é a principal atividade econômica da região amazônica. Ela responde por 15\% do PIB dos estados do Pará, Rondônia e Mato Grosso (Schneider et al., 2000). Essa importância econômica, entretanto, contrasta com os impactos severos que esta atividade provoca na floresta. O modelo de exploração madeireira geralmente utilizado na região deixa as florestas exploradas propensas a incêndios e à invasão de cipós e pioneiras, que podem dificultar a regeneração das espécies madeireiras (Uhl \& Vieira, 1989; Hegarty \& Caballé, 1991; Veríssimo et al., 1992 e Uhl et al., 1997).

A exploração madeireira na Amazônia e na maioria das florestas tropicais é feita sem planejamento e a floresta é re-explorada diversas vezes antes mesmo de conseguir recuperar sua estrutura (Barreto et al., 1998). Apesar de seletivo, este tipo de exploração predatória causa danos consideráveis à estrutura e à composição da floresta (Uhl \& Vieira 1989; Veríssimo et al., 1992; Pinard \& Putz 1996; Johns et al., 1996; Bertault \& Sist 1997; Uhl et al., 1997; Sist et al., 1998; Sist et al., 2003 ${ }^{\mathrm{b}}$ ), tornando mais lento o crescimento das árvores (Putz, 1984; Clark \& Clark, 1990). Isto tem duas implicações importantes: (i) o acúmulo menor de biomassa (carbono) (Pinard \& Putz, 1996; Gerwing \& Farias, 2000) e (ii) a redução do potencial madeireiro da floresta (Silva, 1998). A exploração madeireira cria clareiras de diversos tamanhos no dossel florestal e, quanto maiores forem elas, maior será a incidência de luz. Dessa maneira, espera-se que o 
crescimento das árvores nas clareiras grandes seja superior ao das clareiras pequenas. No entanto, nessas clareiras, principalmente nas criadas pela exploração convencional o crescimento é lento devido principalmente à presença de cipós e de um grande número de árvores com fustes e copas danificados (Putz, 1984; Clark \& Clark, 1990; Whigham, 1984; Stevens, 1987; Dillenburg et al., 1993; Barreto et al., 1993; Vidal et al., 1997).

A taxa de mortalidade de árvores em decorrência da exploração madeireira é muito alta (Lopes, 1993), e é causada principalmente pela derrubada e pelos danos resultantes das operações. Em geral, essa taxa é muito mais alta nas áreas onde a exploração não foi planejada, principalmente porque os danos provocados nessas operações são maiores (Barreto et al., 1998; Johns et al., 1996; Sist \& Nguyen-Thé, 2002). Todavia, a tendência é que a mortalidade seja reduzida nos anos seguintes à exploração, (Sist \& Nguyen-Thé, 2002), declinando para taxas normais após 10 anos (Jonkers, 1982; de Graaf, 1986). Em condições naturais de distúrbio, a taxa anual de mortalidade de árvores tem variado entre 1\% e 2\% (Swaine et al., 1987; Hartshorn, 1980; Hartshorn, 1990). Têm sido relatadas taxas médias anuais de mortalidade após exploração de cerca de 2,6\% na Indonésia (Sist \& Nguyen-Thé, 2002), de 2,5\% na Amazônia Oriental (Silva et al., 1995), e de 1,6\% a 2,2\% na Amazônia Central (Higuchi et al., 1997).

Apesar da maior parte da madeira produzida na região provir de áreas não manejadas, nos últimos cinco anos, tem havido um crescimento expressivo de experiências de bom manejo florestal na região. As razões para este crescimento incluem: a obrigatoriedade legal do plano de manejo, o rigor maior na fiscalização de campo, a pressão crescente dos consumidores por madeira oriunda de florestas bem manejadas, e alguns benefícios indiretos para o produtor como a possibilidade de certificação, marketing, benefícios econômicos e ganhos sociais (Sobral et al., 2002).

Neste cenário em que a adoção de boas práticas de manejo florestal é crescente, existe a necessidade de se aperfeiçoarem técnicas de exploração que conciliem os interesses produtivos com a conservação dos recursos florestais. Nas florestas tropicais, um dos componentes-chave do manejo florestal é o monitoramento do desenvolvimento da floresta pós-exploração, que raramente é realizado. Informações desta natureza são 
importantes para prever colheitas futuras de madeira. Com o objetivo de contribuir na geração de informações sobre o desenvolvimento da floresta após exploração de madeira, realizou-se esta pesquisa em áreas exploradas há sete anos com técnicas de impacto reduzido e de maneira convencional em Paragominas,Pará.

\subsection{Hipóteses}

$\mathbf{h}_{1}$ : O crescimento (diâmetro, área basal e volume) das árvores na floresta com exploração de impacto reduzido é maior do que na floresta explorada convencionalmente porque na primeira há:

- Maior proporção de árvores sãs (isto é, sem danos na copa e no tronco).

- Menor presença de cipós nas árvores.

- Maior recrutamento de indivíduos.

- Menor mortalidade de árvores.

$\mathbf{h}_{2}$ : A mortalidade das árvores nas florestas exploradas com técnicas de impacto reduzido é menor do que nas florestas exploradas de maneira convencional porque os danos nas árvores remanescentes são menores.

$\mathbf{h}_{3}$ : O recrutamento das árvores nas florestas exploradas com técnicas de impacto reduzido é maior do que nas florestas exploradas convencionalmente porque a primeira deixa um número maior de árvores remanescentes.

\subsection{Material e métodos}

\subsubsection{Procedimentos amostrais e estatísticos}

Em 1993, nas áreas designadas para exploração com e sem de impacto reduzido, e numa área não perturbada (testemunha) demarcaram-se três blocos aleatorizados com parcelas subdivididas, sendo um bloco em cada tratamento (exploração de impacto reduzido, exploração convencional e floresta não explorada - testemunha). Em cada 
bloco de 24,5 ha $(350 \mathrm{~m} \times 700 \mathrm{~m})$ foram estabelecidas 49 parcelas de 0,5 ha $(50 \mathrm{~m} \times 100$ m) (Figura 2 do Capítulo 1).

\subsubsection{Coleta dos dados}

Mediram-se os DAPs das árvores inicialmente em 1993 e, posteriormente, em 1994, 1995, 1996, 1998 e 2000. Coletaram-se os dados sobre recrutamento somente em 1998 e 2000. Identificou-se o nome vulgar e o nome científico de todas as espécies de valor madeireiro com DAP a partir de $10 \mathrm{~cm}$. Em seguida, mapearam-se as árvores através de um sistema de coordenadas e marcaram-se cada árvore com uma placa de alumínio. Os DAPs foram remedidos logo abaixo da placa de identificação das árvores, à uma altura de cerca de $1,30 \mathrm{~m}$ do solo.

Para medir os efeitos dos danos sobre o crescimento das árvores, coletaram-se dados sobre as condições físicas da copa e do fuste em todas as árvores amostradas. Estes dados foram coletados de acordo com a severidade do dano: classe 1, sem danos; classe 2, danos moderados; e classe 3, danos severos (Figura 21 A e B).

Para medir os efeitos da incidência de cipós nas copas das árvores sobre o seu crescimento, coletaram-se informações sobre a quantidade de cipós presente em cada indivíduo amostrado. De acordo com esses dados, determinaram-se três classes de incidência de cipó na copa: classe 1, sem cipós na copa; classe 2, poucos cipós; e classe 3, muitos cipós na copa (Figura 21C).

Finalmente, para medir os efeitos da iluminação sobre o crescimento das árvores, coletaram-se dados sobre a incidência de luz nas copas das árvores amostradas e, a partir dessas informações, estabeleceram-se três classes de iluminação da copa: classe 1, iluminação superior total; classe 2, alguma iluminação superior e principalmente luz lateral; e classe 3, recebimento de somente luz difusa (adaptado de Dawkins, 1958; Silva (1989) reduziu de cinco para quatro classes de incidência de luz (Figura 21 D). 
Figura 21: A - Classes de dano de acordo com as condições físicas do fuste e da copa das árvores; B - Classes de incidência de cipó de acordo com a quantidade de cipó encontrada nas copas das árvores; e C - Classes de iluminação de acordo com as características de iluminação das copas das árvores.

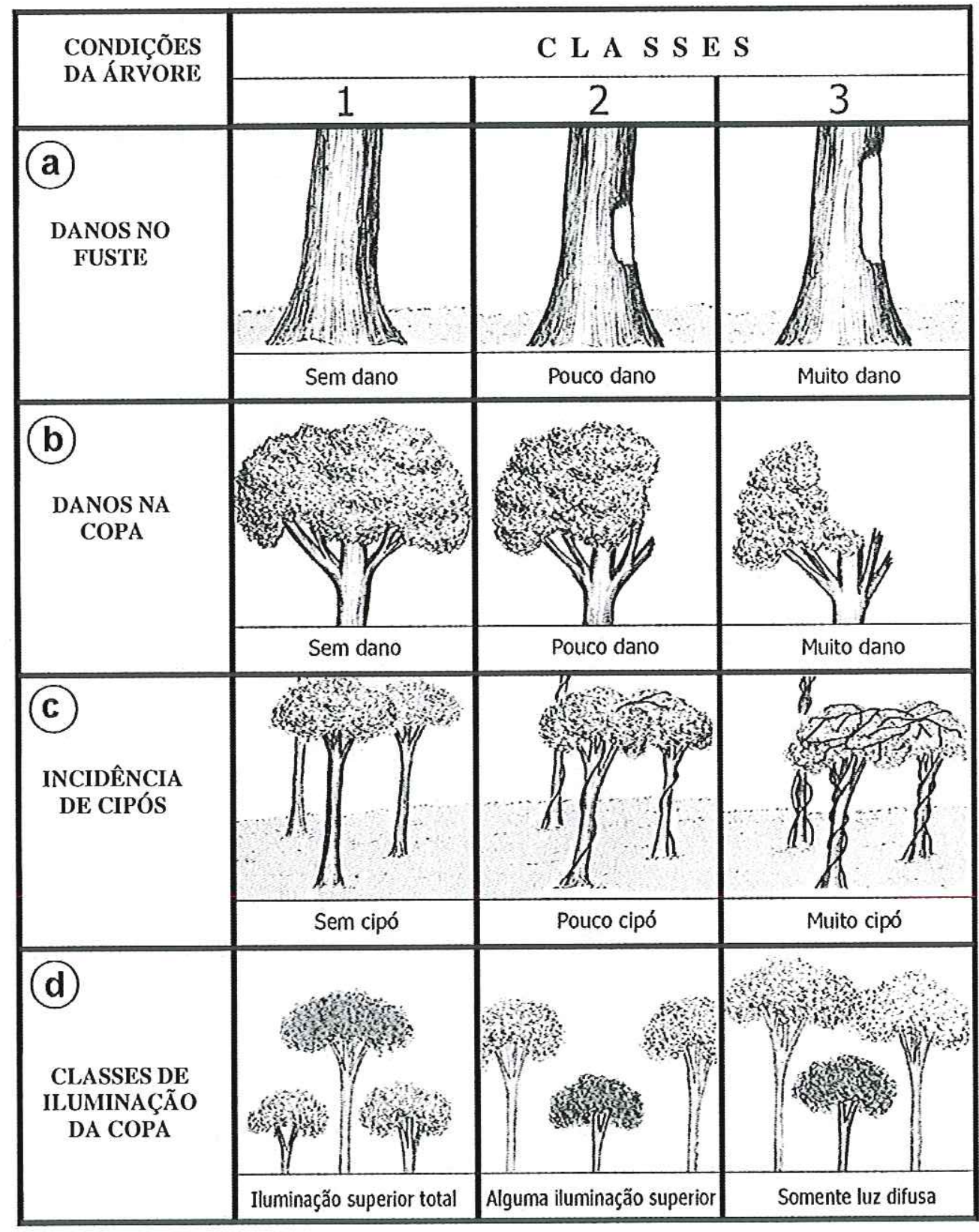

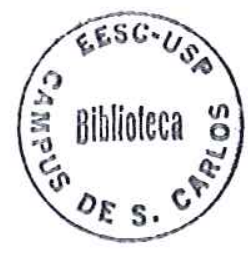




\subsubsection{Análise dos dados - considerando as árvores individuais}

6.3.3.1 Efeitos dos danos no fuste e na copa, da incidência de cipós e da iluminação da copa e tratamento (exploração de impacto reduzido, convencional e testemunha) sobre 0 crescimento das árvores.

Para analisar o efeito de características peculiares das árvores sobre o crescimento fez-se uma análise de variância para cada variável estudada.

\subsubsection{Crescimento - Comparação entre tratamentos}

Nos três blocos aleatorizados (49 parcelas de 0,5 ha em cada tratamento), se avaliaram as diferenças estatísticas entre os tratamentos através da análise de variância de um fator e teste $t$ de student para comparar diferenças entre as classes de DAP dentro de cada tratamento. As variáveis testadas foram: incremento em diâmetro, área basal e volume. Realizou-se teste de Bartlett para verificar a homocedasticidade dos resíduos para a variável original (média de Incremento Periódico Anual, G ou V), usando transformação logarítmica quando necessário. O incremento foi calculado subtraindo a última informação coletada da primeira e dividindo pelo número de anos de monitoramento. O Incremento Corrente Anual (ICA) foi calculado subtraindo-se sempre o ano posterior do anterior. Para calcular o volume correspondente para cada espécie, utilizaram-se equações de volume desenvolvidas para uma região com composição florística semelhante à área de estudo, dada à ausência de equação para a área. A equação usada para calcular o volume de indivíduos com DAP acima de $10 \mathrm{~cm}$ foi $\ln V$ $=-7,62812+2,18090(\ln )(D A P)($ Silva et al., 1984).

\subsubsection{Mortalidade e recrutamento}

Cálculo da mortalidade: A taxa de mortalidade média anual foi calculada de acordo com modelo abaixo (Primack et al. 1985):

$\mathrm{m}=1-\left(\mathrm{N}_{1} / \mathrm{N}_{0}\right)^{1 / /}$,

onde: $\mathrm{m}$ é a taxa anual de mortalidade; $\mathrm{N}_{0}$ é o número de indivíduos na amostra inicial (1994); $\mathrm{N}_{1}$ é o número de indivíduos na amostra final (2000) e t é o tempo de observações em ano (6) 
Comparação entre tratamentos. Primeiramente comparou-se a mortalidade entre tratamentos através da análise de variância para todo o período (1994-2000). Em seguida, comparou-se a mortalidade entre os períodos através da análise de variância em um desenho de blocos aleatorizados, na qual cada parcela foi considerada como um bloco. O fator testado foi o período de monitoramento, com três níveis, a saber: de 1994 a 1996, de 1996 a 1998 e de 1998 a 2000. Para cada tratamento, inicialmente fez-se uma análise de variância para comparar a significância das médias, quando pelo menos uma média diferia das demais, fazia-se o teste de Tukey (5\% de significância) das médias individualmente. Para comparar o recrutamento, fez-se uma análise de variância de um fator e comparou-se o recrutamento médio anual para os três tratamentos para todo o período, já que dados de recrutamento foram coletados somente em 2000.

Comparação entre classes diamétricas. A mortalidade entre classes diamétricas dentro de cada tratamento foi comparada através do teste qui-quadrado e, quando existiam diferenças estatísticas entre as classes, foi usado o procedimento de Marascuillo. Neste procedimento avaliou-se a existência de diferenças entre as proporções de mortalidade em cada classe diamétrica. Para realizar as análises, preparou-se uma tabela de contigência para cada tratamento, considerando indivíduos vivos numa coluna e indivíduos mortos em outra coluna. Em seguida, calcularam-se e posteriormente testaram-se as proporções observadas com as proporções esperadas através do teste qui-quadrado.

\subsubsection{Análise de sobrevivência}

A sobrevivência das árvores entre os três tratamentos foi analisada através do modelo não-paramétrico de Kaplan-Meier (Norman \& Streiner, 1994). A análise de sobrevivência de Kaplan-Meier estima a probabilidade de sobrevivência das árvores em cada tratamento como uma função do tempo. Um pré-requisito básico para o modelo seguido neste trabalho foi uma amostra aleatória da população de interesse, de modo que sejam independentes entre si. 


\subsection{Resultados}

\subsubsection{Efeito das variáveis (danos no fuste, danos na copa, incidência de cipós,} incidência de luz) sobre o crescimento (cm/ano).

Para avaliar separadamente o efeito de cada variável no crescimento, se utilizou análise de variância. Das variáveis estudadas separadamente, somente dano no fuste (Figura 22d) não apresentou diferenças significativas em nenhum nível. Isto é, árvores com danos no fuste cresceram igual às árvores sem danos no fuste $(F=1,28 ; p=0,163)$. As árvores sem cipós cresceram mais rápido que as árvores com poucos e muitos cipós (Figura 22a). As árvores que recebiam muita luz na copa cresceram mais do que as que só recebem luz lateral ou difusa (Figura 22b). As árvores sem danos na copa cresceram mais que as árvores que apresentavam algum dano na copa (Figura 22c). As espécies tolerantes à sombra cresceram menos que as espécies pioneiras e demandantes de luz e, por sua vez, as demandantes de luz cresceram igual às pioneiras (Figura 22e). As árvores do tratamento exploração de impacto reduzido cresceram mais do que as árvores dos tratamentos exploração convencional e testemunha. (Figura 22f). 
Figura 22: Efeito do gradiente de cipós (a) e luz (b), danos físicos (copa (c) e fuste (d)), grupo ecológico (e) e tratamentos (f) sobre o crescimento das árvores individuais. A barra vertical representa o desvio-padrão.
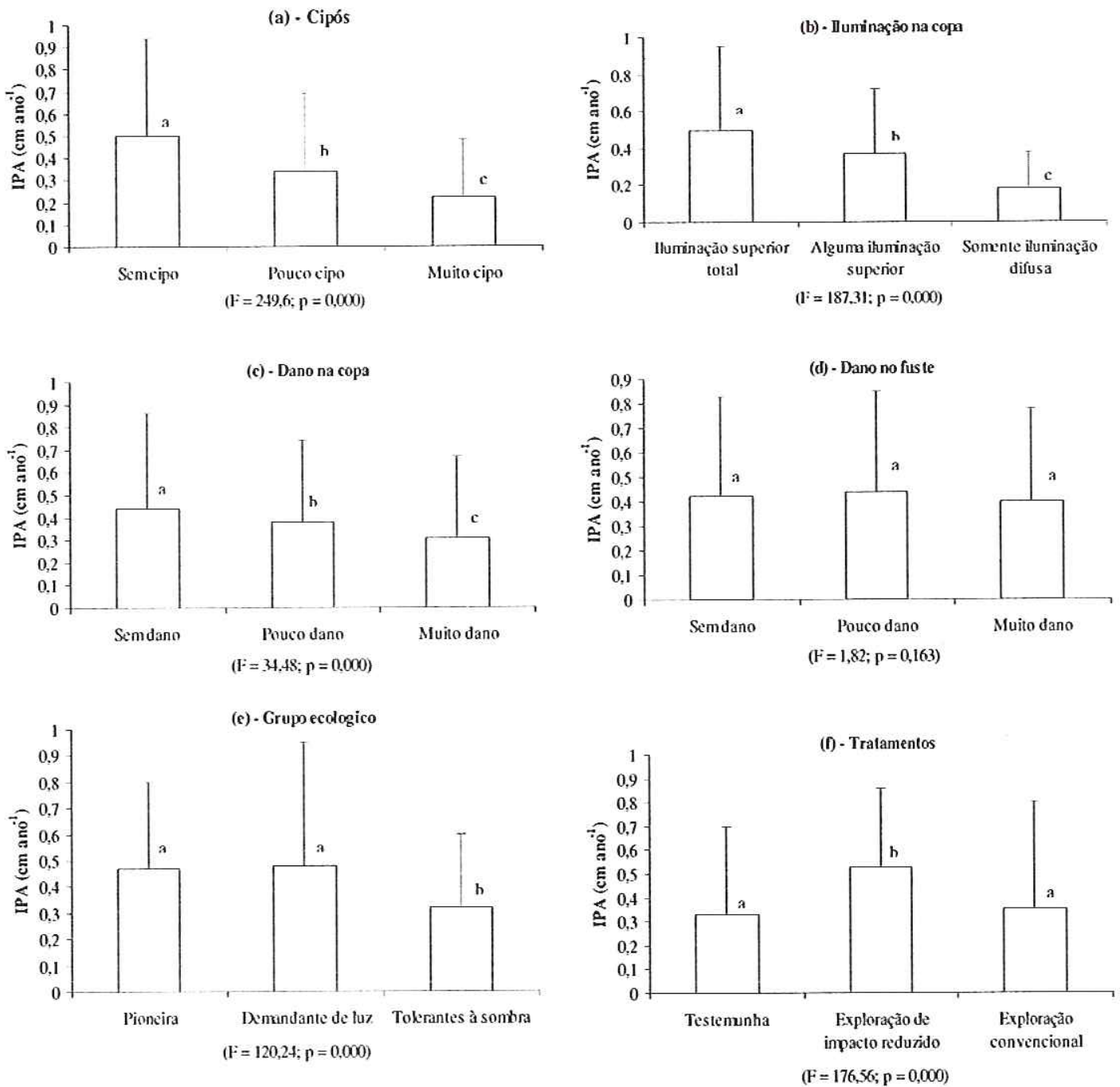

Médias que repartem letras iguais não diferem estatisticamente através do teste de Tukey $(\mathrm{p}=$ 0,05 ). Entre parênteses na parte inferior central apresentam-se resultados da análise de variância. 


\subsubsection{Incremento em DAP}

O teste de Bartlett indicou variância inconstante para a variável original, média de incremento diamétrico. Foi aplicada então a transformação $\mathrm{Y}=\ln$ incremento para estabilização da variância. O teste de Bartlett indicou variância constante para a transformada $Y$ e a não existência de correlação espacial.

Os resultados das análises de variância indicaram que para ln do incremento na classe $10 \geq$ DAP $\leq 30 \mathrm{~cm}$, as médias da exploração de impacto reduzido foram significativamente maiores do que as médias da convencional e testemunha. A testemunha foi significativamente maior que a convencional $(F=114,96 ; p=0,000)$ (Tabela 12). Na classe diamétrica $>30 \mathrm{~cm}$, o incremento $(\mathrm{cm} / \mathrm{ano})$ da exploração de impacto reduzido foi significativamente maior do que o da exploração convencional. Todavia, a convencional foi significativamente igual à testemunha $(F=15,96 ; p=0,000)$ (Tabela 12).

Comparando-se o incremento em DAP entre as classes diamétricas $(10 \geq \mathrm{DAP} \leq$ $30 \mathrm{~cm}$ e $>30 \mathrm{~cm}$ de DAP) por tratamento através de teste $t$, notam-se diferenças entre classes na área testemunha $(\mathrm{t}=-3,19 ; \mathrm{p}=0,002)$. No entanto, não foram observadas diferenças entre classes na exploração de impacto reduzido $(t=0,53 ; p=0,60)$ e na exploração convencional $(\mathrm{t}=0,56 ; \mathrm{p}=0,58)$ (Tabela 12$)$.

\subsubsection{Incremento em área basal}

Os incrementos em área basal na classe $10 \geq$ DAP $\leq 30 \mathrm{~cm}$ foram significativamente maiores na exploração de impacto reduzido $\left(0,128 \mathrm{~m}^{2} / \mathrm{ha} / \mathrm{ano} ; \mathrm{dp}=\right.$ $0,055)$ em comparação com os outros tratamentos, não sendo significativo entre a testemunha $\left(0,03 \mathrm{~m}^{2} / \mathrm{ha} / \mathrm{ano} ; \mathrm{dp}=0,029\right)$ e a exploração convencional $\left(0,03 \mathrm{~m}^{2} / \mathrm{ha} / \mathrm{ano}\right.$; $\mathrm{dp}=0,042)(\mathrm{F}=82,37 ; \mathrm{p}=0,000)$. Os incrementos em área basal na classe de DAP $>30$ $\mathrm{cm}$ foi significativamente maior na exploração de impacto reduzido em relação aos outros tratamentos e estatisticamente iguais entre a testemunha e a convencional $(\mathrm{F}=$ $5,79 ; \mathrm{p}=0,004)$ (Tabela 12). 
As médias de incremento em área basal entre as classes diamétricas $(10 \geq \mathrm{DAP} \leq$ $30 \mathrm{~cm}$ e $>30 \mathrm{~cm}$ de DAP) na exploração convencional $(\mathrm{t}=-2,07 ; \mathrm{p}=0,043)$ e testemunha $(t=-2,56 ; p=0,012)$ foram iguais. Na exploração de impacto reduzido, as árvores menores cresceram mais do que as maiores $(t=-5,63 ; p=0,0001)$ (Tabela 12).

\subsubsection{Incremento em Volume}

Para as árvores menores (entre $10 \mathrm{~cm}$ a $30 \mathrm{~cm}$ de DAP), as quais assumiu-se como árvores do terceiro/quarto cortes, o incremento tem sido superior no tratamento exploração de impacto reduzido $\left(1,57 \mathrm{~m}^{3} \mathrm{ha}^{-1} \mathrm{ano}^{-1}\right.$; desvio-padrão $\left.=0,65\right) \mathrm{em}$ comparação com o tratamento exploração convencional $\left(0,38 \mathrm{~m}^{3} \mathrm{ha}^{-1} \mathrm{ano}^{-1} ; \mathrm{dp}=0,50\right) \mathrm{e}$ testemunha $\left(0,38 \mathrm{~m}^{3} \mathrm{ha}^{-1} \mathrm{ano}^{-1}\right.$; $\left.\mathrm{dp}=0,34\right)$ Não houve diferença estatística entre o tratamento exploração convencional e testemunha $(F=87,51 ; p=0,000)$ (Tabela 12). Os resultados do incremento, sete anos após a exploração, indicam um ótimo crescimento das árvores acima de $30 \mathrm{~cm}$ de DAP na floresta com tratamento exploração de impacto reduzido $\left(0,92 \mathrm{~m}^{3} \mathrm{ha}^{-1} \mathrm{ano}^{-1} ; \mathrm{dp}=1,16\right)$ em comparação com o tratamento exploração convencional, no qual as árvores têm apresentado crescimento muito baixo $\left(0,13 \mathrm{~m}^{3}\right.$ ha $\left.{ }^{1} \mathrm{ano}^{-1} ; \mathrm{dp}=0,49\right)$. Na comparação estatística entre exploração convencional e testemunha não houve diferenças de incremento entre as médias $(F=6,25 ; \mathrm{p}=0,002)$ (Tabela 12). 
Tabela 14: Valores das médias e desvio-padrão (em parênteses) e teste $t$ entre classes dentro de cada tratamento de incrementos em DAP, área basal e volume.

\begin{tabular}{|c|c|c|c|}
\hline \multicolumn{4}{|l|}{ Incremento em DAP (cm/ano) } \\
\hline Tratamento Classe & $10 \geq \mathrm{DAP} \leq 30 \mathrm{~cm}$ & $>30 \mathrm{~cm} \mathrm{DAP}$ & Teste t \\
\hline Testemunha & $0,3(0,09)^{\mathrm{a}}$ & $0,38(0,15)^{\mathrm{a}}$ & $\mathrm{t}=-3,19 ; \mathrm{P}=0,002$ \\
\hline Exploração de impacto reduzido & $0,55(0,09)^{b}$ & $0,53(0,21)^{b}$ & $\mathrm{t}=0,53 ; \mathrm{P}=0,60$ \\
\hline Exploração convencional & $0,36(0,09)^{c}$ & $0,35(0,15)^{\mathrm{a}}$ & $\mathrm{t}=0,56 ; \mathrm{P}=0,58$ \\
\hline Anava & $\mathrm{F}=114,96 ; \mathrm{p}=0,000$ & $F=15,96 ; p=0,000$ & \\
\hline \multicolumn{4}{|c|}{ Incremento em área basal $\left(\mathrm{m}^{2} / \mathrm{ha} / \mathrm{ano}\right)$} \\
\hline Tratamento Classe & $10 \geq \mathrm{DAP} \leq 30 \mathrm{~cm}$ & $>30 \mathrm{~cm} \mathrm{DAP}$ & Teste $\mathbf{t}$ \\
\hline Testemunha & $0,030(0,029)^{\mathrm{a}}$ & $0,004(0,085)^{\mathrm{a}}$ & $t=-2,07 ; p=0,043$ \\
\hline Exploração de impacto reduzido & $0,128(0,055)^{\mathrm{b}}$ & $0,049(0,082)^{\mathrm{b}}$ & $t=-5,63 ; p=0,0001$ \\
\hline Exploração convencional & $0,030(0,042)^{\mathrm{a}}$ & $-0,003(0,081)^{\mathrm{a}}$ & $\mathrm{t}=-2,56 ; \mathrm{p}=0,012$ \\
\hline Anava & $\mathrm{F}=82,37 ; \mathrm{p}=0,000$ & $F=5,79 ; p=0,004$ & \\
\hline \multicolumn{4}{|c|}{ Incremento em volume $\left(\mathrm{m}^{3} \mathrm{ha}^{-1} \mathrm{ano}^{-1}\right)$} \\
\hline $\begin{array}{ll}\text { Tratamento Classe } \\
\end{array}$ & $10 \geq \mathrm{DAP} \leq 30 \mathrm{~cm}$ & $>30 \mathrm{~cm} \mathrm{DAP}$ & Teste t \\
\hline Testemunha & $0,38(0,34)^{\mathrm{a}}$ & $0,27(1,2)^{\mathrm{a}}$ & $\mathrm{t}=-0,55 ; \mathrm{p}=0,58$ \\
\hline Exploração de impacto reduzido & $1,57(0,65)^{b}$ & $0,92(1,16)^{b}$ & $\mathrm{t}=-3,43 ; \mathrm{p}=0,001$ \\
\hline Exploração convencional & $0,38(0,50)^{\mathrm{a}}$ & $0,13(1,16)^{\mathrm{a}}$ & $\mathrm{t}=-1,36 ; \mathrm{p}=0,18$ \\
\hline Anava & $\mathrm{F}=87,51 ; \mathrm{p}=0,000$ & $F=6,25 ; p=0,002$ & \\
\hline \multicolumn{4}{|c|}{$\begin{array}{l}\text { Médias que repartem letras iguais não diferem estatisticamente através do teste de Tukey }(p=0,05) \text {. } \\
\text { Análise de variância em anexo. }\end{array}$} \\
\hline
\end{tabular}

Em síntese, os incrementos médios anuais em DAP, área basal e volume foram estatisticamente diferentes entre todos os tratamentos e faixas diamétricas somente entre a exploração de impacto reduzido e os demais tratamentos (convencional e testemunha). E a única comparação onde houve diferenças estatísticas entre todos os tratamentos foi no incremento em DAP, na faixa de $10 \geq \mathrm{DAP} \leq 30 \mathrm{~cm}$ (Tabela 12). 


\subsubsection{Incremento Corrente Anual - ICA $\left(\mathrm{cm} \mathrm{ano}^{-1}\right)$}

O ICA do DAP, em $\mathrm{cm}$, no período do monitoramento, foi sempre superior no tratamento com exploração de impacto reduzido ao dos outros tratamentos, sendo que em todos os tratamentos houve um leve aumento do crescimento nos períodos logo após a exploração. Isso ocorreu também no tratamento testemunha, no qual, três anos após a exploração, houve uma redução no ICA. O ICA do tratamento testemunha foi maior do que o do tratamento exploração convencional no último período de medição (19982000). Esse padrão se manteve em duas classes diamétricas, entre $10 \geq \mathrm{DAP} \leq 30 \mathrm{~cm}$ (Figura 23a) e $>30 \mathrm{~cm}$ de DAP (Figura 23b), sendo que na classe menor, os incrementos foram praticamente iguais nos primeiros períodos após a exploração (1994-1996) (Figura 23). 
Figura 23: Incremento corrente anual $\left(\mathrm{cm} \mathrm{ano}^{-1}\right)$ de espécies madeireiras em duas classes de DAP: a) $10 \mathrm{~cm} \geq$ DAP $<30 \mathrm{~cm} \mathrm{e} \mathrm{b)} \geq 30 \mathrm{~cm}$ de DAP, em 3 tratamentos (testemunha, exploração convencional e exploração de impacto reduzido) em Paragominas,Pará.
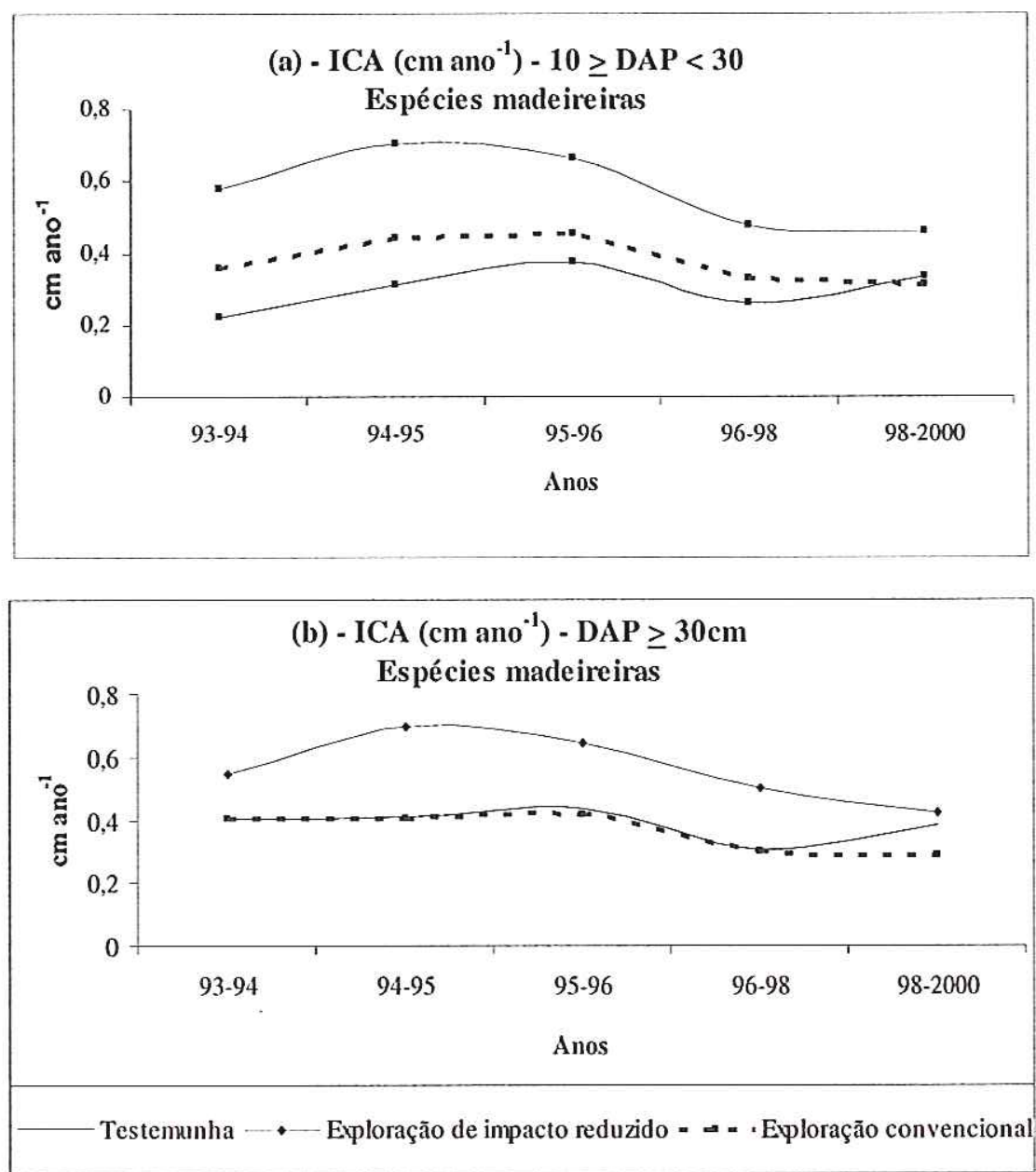

\subsubsection{Incremento Corrente Anual em Volume (ICA $\left.A_{V}\right)$}

$\mathrm{O} \mathrm{ICA}_{\mathrm{V}}$ das espécies comerciais para as áreas variou de acordo com os tratamentos aplicados. A área com exploração de impacto reduzido apresentou um estoque maior em todo o período nas duas classes de DAP consideradas: a) $10 \mathrm{~cm} \geq$ DAP $<30 \mathrm{~cm} \mathrm{e} \mathrm{b)} \geq 30 \mathrm{~cm}$ de DAP, ocorrendo de 1998 a 2000 uma queda em ambas as classes. As áreas testemunha e explorada de forma convencional apresentaram o mesmo padrão, todavia, com acúmulo em metros cúbicos menor do que as áreas exploradas. 
Ambas tiveram um crescimento acentuado na classe de tamanho superior a $30 \mathrm{~cm}$ de DAP no último período (Figura 24). Essas quedas leves no crescimento em volume observadas indiscriminadamente em todos os tratamentos em 1998 podem ser explicadas pela ocorrência do fenômeno El Niño naquele ano, pois as quedas foram semelhantes em todos os tratamentos.

Os resultados mostram um crescimento superior na área com exploração de impacto reduzido, nas duas classes diamétricas consideradas (Figura 24). 
Figura 24: Incremento Corrente Anual - ICA para árvores comerciais em 3 tratamentos (testemunha, exploração de impacto reduzido e exploração convencional), em duas classes de DAP: a) $\geq 10<30 \mathrm{~cm} \mathrm{e} \mathrm{b)}>30 \mathrm{~cm}$ ), sete anos após exploração madeireira em Paragominas,Pará.
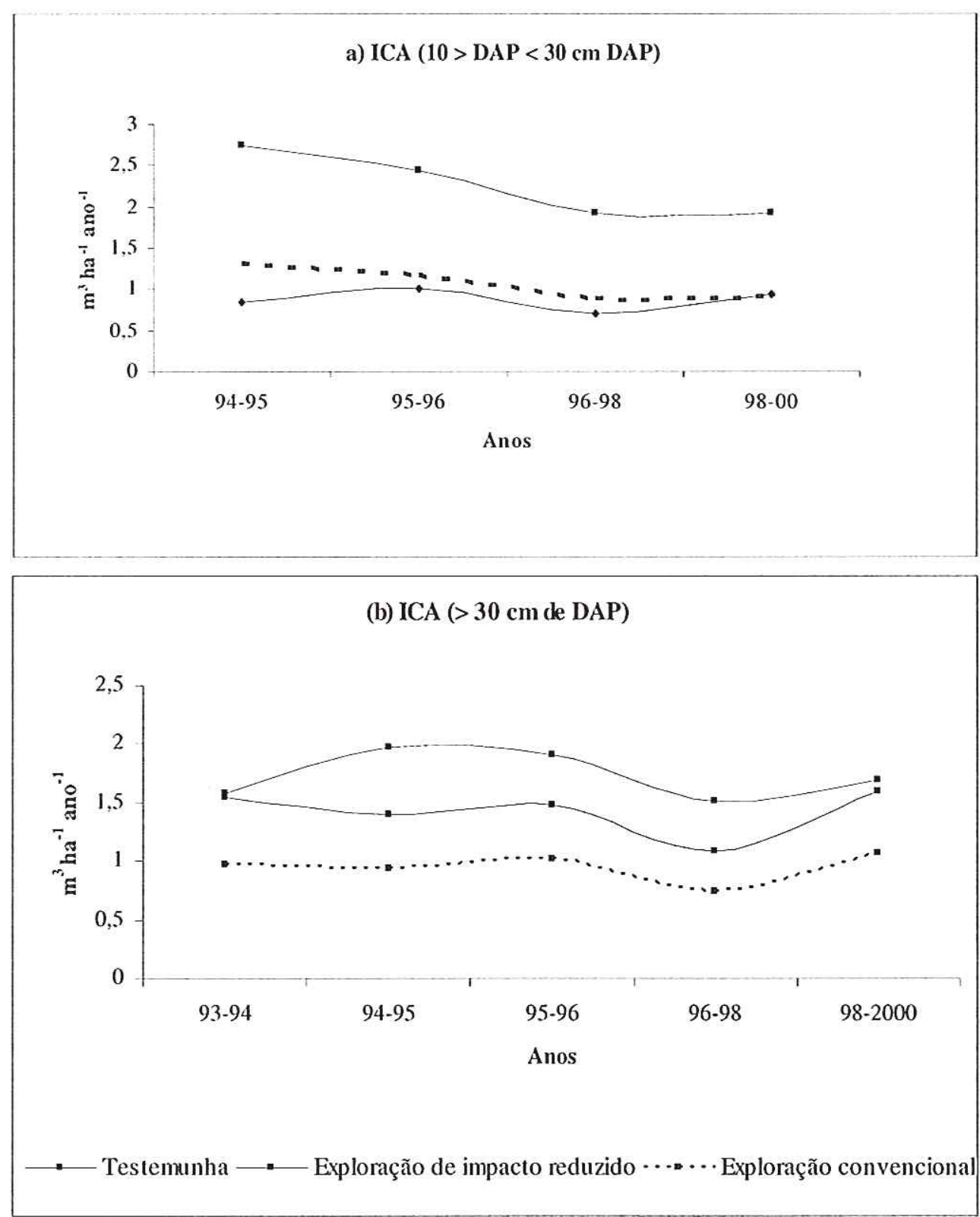


\subsubsection{Crescimento por classe diamétrica}

Com exceção do crescimento diamétrico em cm (Figura 25a), o crescimento nas classes menores em comparação com as maiores em todos os tratamentos foi bem acentuado. No tratamento exploração de impacto reduzido, observa-se um excelente crescimento das árvores com DAP inferior a $50 \mathrm{~cm}$, principalmente em área basal (Figura 25b) e metro cúbico (Figura 25c).

Figura 25: Incremento Períodico Anual (1993-2000) em (a) diâmetro (cm ano-1), (b) área basal $\left(\mathrm{m}^{2} \mathrm{ha}^{-1}\right.$ ano $\left.^{-1}\right)$ e (c) volume $\left(\mathrm{m}^{3} \mathrm{ha}^{-1}\right.$ ano $\left.^{-1}\right)$ por faixa diamétrica em cada tratamento, para o período de sete anos.

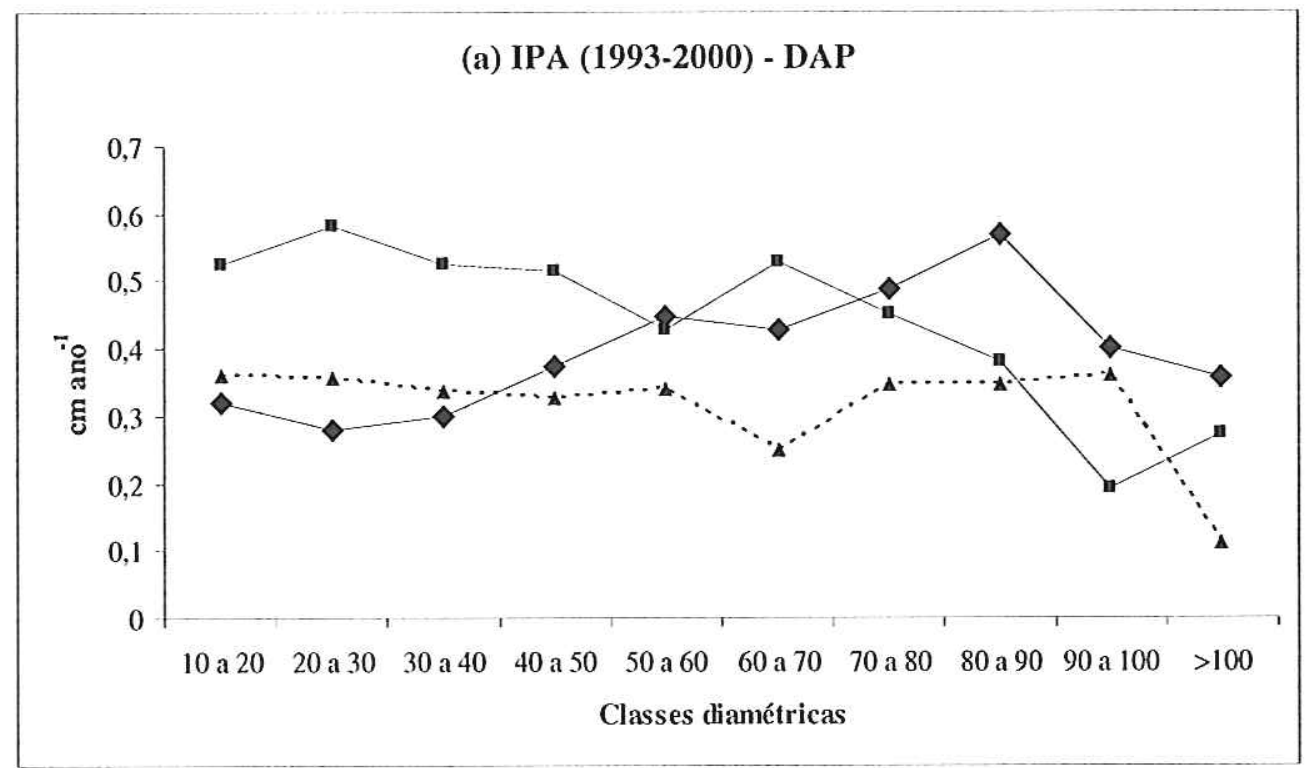



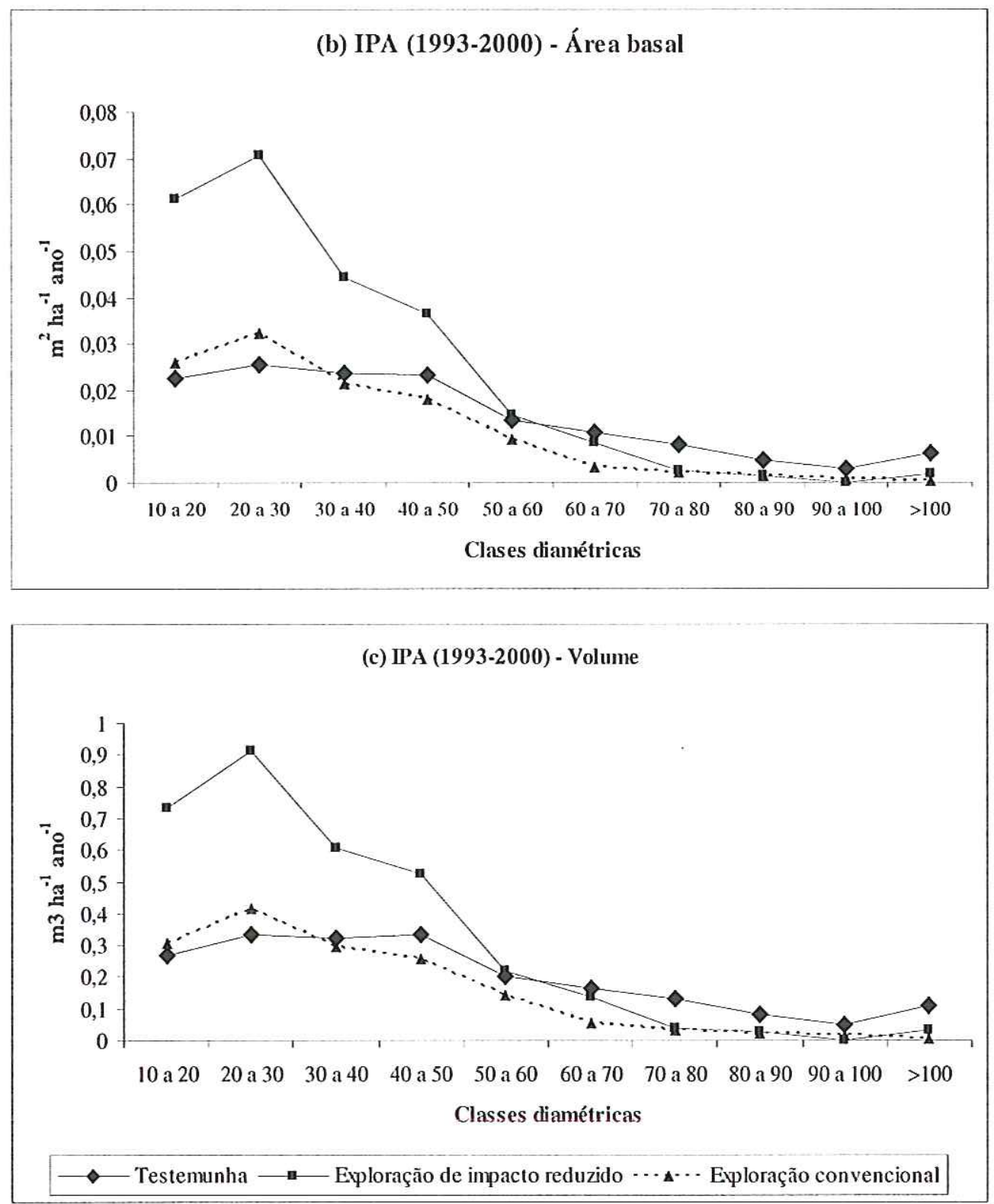

Comparando estatisticamente o incremento médio em volume por classes diamétricas, observou-se que a exploração de impacto reduzido teve suas médias em volume superiores em todas as classes diamétricas, exceto na das árvores maiores ( $>50$ cm de DAP). Não houve diferenças estatísticas entre exploração convencional e testemunha nas classes diamétricas $10 \mathrm{~cm}-20 \mathrm{~cm}, 30 \mathrm{~cm}-40 \mathrm{~cm}$ e $40 \mathrm{~cm}-50 \mathrm{~cm}$. Somente na classe $20 \mathrm{~cm}-30 \mathrm{~cm}$ houve diferença estatística em todos os tratamentos (Tabela 13). 
Tabela 15: Incrementos volumétricos em cinco faixas diamétricas em cada tratamento e respectivos resultados da Análise de variância.

\begin{tabular}{|c|c|c|c|c|c|}
\hline \multirow{2}{*}{$\begin{array}{c}\text { Classes } \\
\text { diamétricas }\end{array}$} & \multicolumn{5}{|c|}{ IPA em Volume } \\
\cline { 2 - 6 } & $\begin{array}{c}\text { Exploração } \\
\text { de impacto } \\
\text { reduzido }\end{array}$ & $\begin{array}{c}\text { Exploração } \\
\text { convencional }\end{array}$ & Testemunha & $\mathrm{F}$ & $p$ \\
\hline $10 \leq \mathrm{DAP}<20$ & $0,73^{\mathrm{a}}$ & $0,31^{\mathrm{b}}$ & $0,27^{\mathrm{b}}$ & 59,58 & 0,000 \\
\hline $20 \leq \mathrm{DAP}<30$ & $0,91^{\mathrm{a}}$ & $0,42^{\mathrm{b}}$ & $0,33^{\mathrm{c}}$ & 113,50 & 0,000 \\
\hline $30 \leq \mathrm{DAP}<40$ & $0,61^{\mathrm{a}}$ & $0,29^{\mathrm{b}}$ & $0,32^{\mathrm{b}}$ & 34,00 & 0,000 \\
\hline $40 \leq \mathrm{DAP}<50$ & $0,53^{\mathrm{a}}$ & $0,26^{\mathrm{b}}$ & $0,33^{\mathrm{b}}$ & 9,83 & 0,000 \\
\hline$>50$ & $0,46^{\mathrm{a}}$ & $0,27^{\mathrm{b}}$ & $0,73^{\mathrm{a}}$ & 8,25 & 0,000 \\
\hline
\end{tabular}

\subsubsection{Mortalidade}

A mortalidade média anual, sete anos após a exploração, foi de 1,82\% no tratamento testemunha, $1,40 \%$ na exploração de impacto reduzido e $2,38 \%$ no tratamento exploração convencional (Tabela 14). Não houve diferenças estatísticas significativas de mortalidade média anual para o período de sete anos entre a exploração de impacto reduzido e a testemunha, no entanto, houve diferença entre a exploração convencional e os demais tratamentos $(\mathrm{F}=12,83 ; \mathrm{p}=0,000)$. 
Tabela 16: Médias anuais de mortalidade e recrutamento sete anos após a exploração em três tratamentos (testemunha, exploração de impacto reduzido e exploração convencional).

\begin{tabular}{|c|c|c|}
\hline Tratamentos & $\begin{array}{c}\text { Mortalidade (1994-2000) } \\
\%\end{array}$ & $\begin{array}{c}\text { Recrutamento (1994-2000) } \\
\%\end{array}$ \\
\hline Testemunha & $1,82^{\mathrm{a}}(0,13)$ & $1,72^{\mathrm{a}}(0,19)$ \\
\hline $\begin{array}{l}\text { Exploração de impacto } \\
\text { reduzido }\end{array}$ & $1,40^{\mathrm{a}}(0,10)$ & $2,51^{b}(0,26)$ \\
\hline Exploração convencional & $2,38^{\mathrm{b}}(0,17)$ & $2,48^{\mathrm{b}}(0,21)$ \\
\hline
\end{tabular}

A mortalidade na área explorada convencionalmente foi superior à da área com exploração de impacto reduzido e da testemunha nos três períodos de medição. A área com exploração de impacto reduzido teve uma mortalidade menor do que a testemunha nos períodos analisados. Na exploração de impacto reduzido e na área testemunha ocorreu redução significativa no segundo período de medição, enquanto que na área com exploração convencional não houve diferenças estatísticas nos três períodos observados (Tabela 15).

Tabela 17: Comparação de mortalidade dentro de cada tratamento por período de medição.

\begin{tabular}{lccccc}
\hline Tratamentos & $94-96$ & $96-98$ & $98-00$ & $\mathrm{~F}$ & $\mathrm{p}$ \\
\hline Testemunha & $2,29^{\mathrm{a}}(0,26)$ & $1,36^{\mathrm{b}}(0,19)$ & $2,02^{\mathrm{a}}(0,24)$ & 4,56 & 0,013 \\
Exploração de impacto reduzido & $1,95^{\mathrm{a}}(0,21)$ & $1,02^{\mathrm{b}}(0,15)$ & $1,34^{\mathrm{a}}(0,19)$ & 6,59 & 0,002 \\
Exploração convencional & $2,59^{\mathrm{a}}(0,32)$ & $1,91^{\mathrm{a}}(0,25)$ & $2,72^{\mathrm{a}}(0,33)$ & 1,99 & 0,143
\end{tabular}

Notas: Valores em parênteses significam erro-padrão da média.

\subsubsection{Mortalidade por classe diamétrica}

A mortalidade média anual por classe diamétrica apresenta-se maior nas classes diamétricas menores em todos os tratamentos, sendo mais acentuada na exploração convencional. Nas classes seguintes, entre $30 \mathrm{~cm}-50 \mathrm{~cm}$, parece haver um equilíbrio na 
mortalidade entre os tratamentos testemunha e exploração convencional. A mortalidade na área de exploração de impacto reduzido foi inferior à da testemunha e da exploração convencional em quase todas as classes diamétricas. Apenas nas árvores com DAP superior a $50 \mathrm{~cm}$, a exploração convencional teve mortalidade menor que os outros tratamentos (Figura 26). Comparando estatisticamente as diferenças de mortalidade entre classes diamétricas dentro de cada tratamento, notaram-se diferenças entre classes somente na exploração convencional (Qui-quadrado $=26.523, \mathrm{gl}=4, \mathrm{p}=0,000$ )

Figura 26: Taxa anual de mortalidade por tratamento e classe diamétrica.

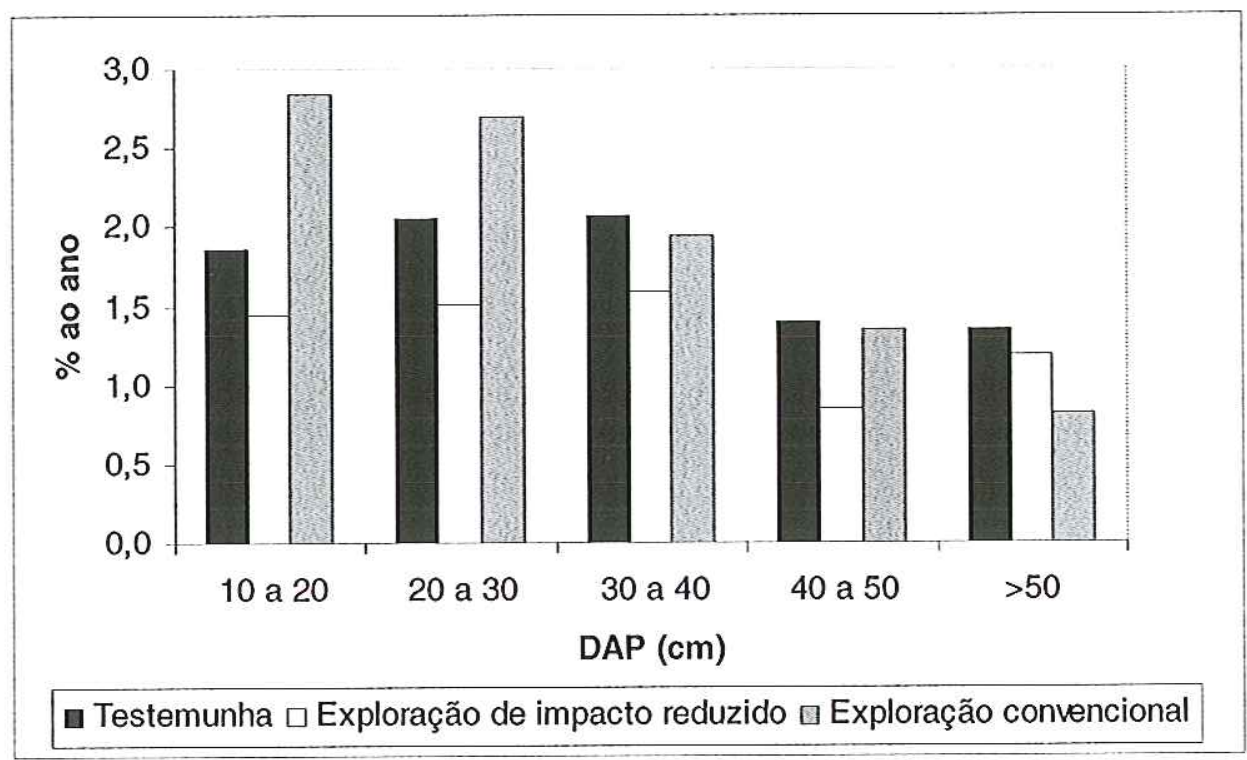

\subsubsection{Recrutamento}

O recrutamento foi semelhante entre a área submetida à exploração de impacto reduzido (2,5\%/ano) e a que sofreu exploração convencional (2,3\%/ano), e em ambos os tratamentos, ele foi significativamente maior que na área testemunha (1,7\%/ano) $(\mathrm{F}=4,11 ; \mathrm{p}=0,018)$. O recrutamento foi de 7,9 árv/ha/ano no tratamento testemunha, 14,6 árv/ha/ano na exploração de impacto reduzido e 11,5 árv/ha/ano na exploração convencional. Nas comparações entre recrutamento e mortalidade nos tratamentos 
observou-se que: o recrutamento foi $61 \%$ superior na exploração de impacto reduzido, $17 \%$ inferior na floresta testemunha, e praticamente iguais na exploração convencional.

\subsubsection{Sobrevivência}

O resultado da estimativa não-paramétrica (Kaplan-Meier) de sobrevivência indica naturalmente uma queda mais acentuada nas áreas exploradas. No entanto, na área explorada convencionalmente, essa porcentagem foi a mais acentuada, principalmente devido à ausência de planejamento da exploração. Em geral, a sobrevivência de indivíduos foi sempre menor na exploração convencional em relação à exploração de impacto reduzido no período monitorado. No entanto, no terceiro e quarto períodos de medição, a sobrevivência na exploração de impacto reduzido foi menor do que na exploração convencional. Em síntese, sete anos após a exploração, a área testemunha tinha cerca de $83 \%$ dos indivíduos encontrados antes da exploração; a área com exploração de impacto reduzido tinha cerca de $78 \%$; e a área explorada convencionalmente, cerca de $66 \%$ (Figura 27). 
Figura 27: Sobrevivência de árvores com valor madeireiro em sete anos de monitoramento pós-exploração em três tratamentos (testemunha, exploração de impacto reduzido e exploração convencional).

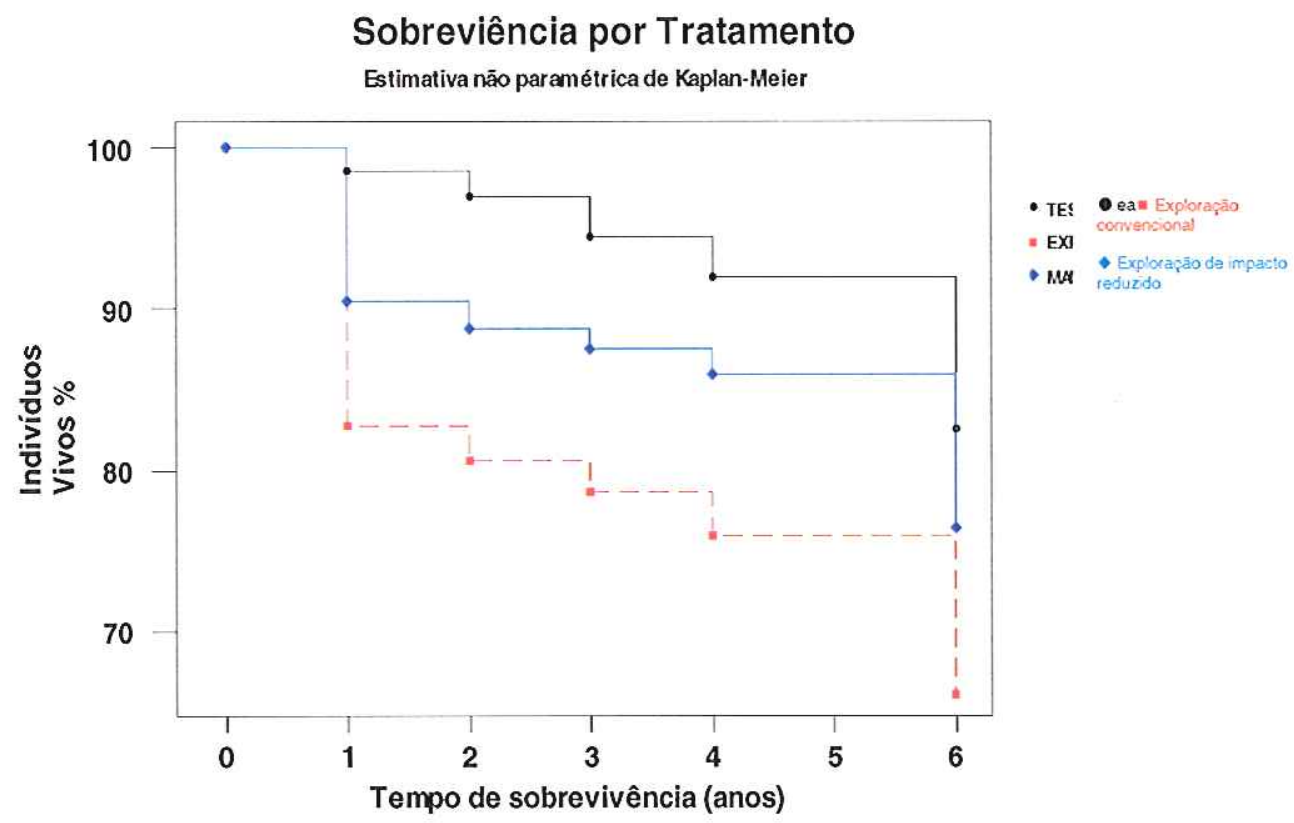

\subsubsection{Volume total por hectare}

Considerando o crescimento das árvores de valor comercial entre duas classes de diâmetro $(10 \mathrm{~cm}>$ DAP $<30 \mathrm{~cm}$ e $>30 \mathrm{~cm}$ de DAP), é notável a recuperação volumétrica da floresta remanescente explorada com técnicas de impacto reduzido. O crescimento foi extremamente superior na classe diamétrica entre $10 \mathrm{~cm}$ a $30 \mathrm{~cm}$ na área com exploração de impacto reduzido em relação aos demais tratamentos (Figura 28a). O volume total por hectare das árvores com DAP > $30 \mathrm{~cm}$ no tratamento de exploração de impacto reduzido também apresentou resultado superior ao tratamento de exploração convencional, indicando que a recuperação volumétrica será maior na exploração de impacto reduzido (Figura 28b). 
Figura 28: Volume total por hectare em duas classes diamétricas: a) para árvores entre $10 \mathrm{~cm} \geq$ DAP $<30 \mathrm{~cm} \mathrm{e} \mathrm{b)} \geq 30 \mathrm{~cm}$ de DAP em três tratamentos (testemunha, exploração de impacto reduzido e exploração convencional).
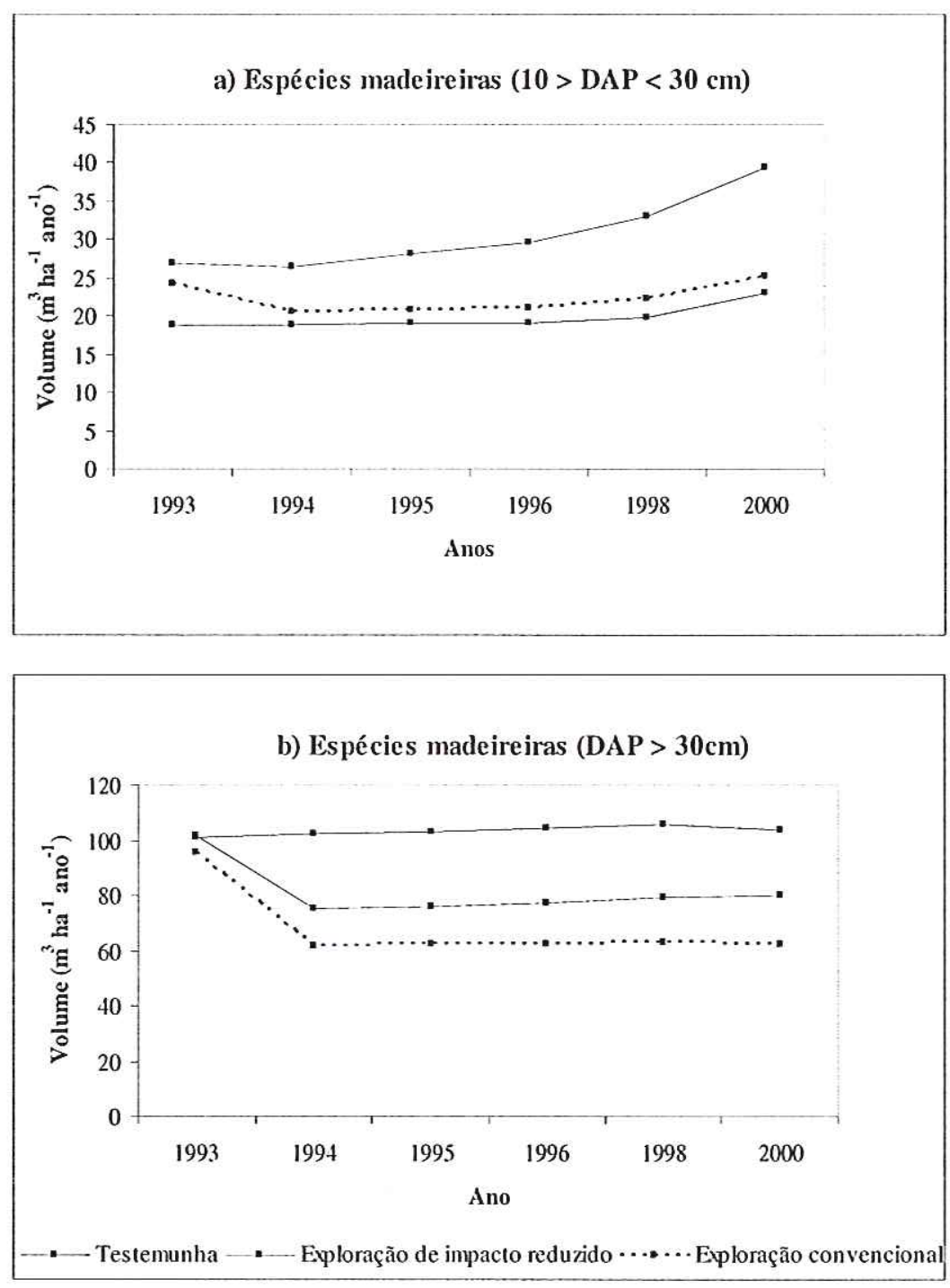

\subsection{Discussão}

\subsubsection{Incremento em DAP}

A taxa média de incremento diamétrico das árvores nas florestas tropicais varia por vários fatores, porém, raramente é superior a $1 \mathrm{~cm} / \mathrm{ano}$ (Schmidt, 1987). Geralmente, 
a taxa de crescimento diamétrico de espécies com valor comercial nas florestas tropicais varia entre 0,1 e 0,5 cm/ano (Silva, 1989; Silva, 1998). As florestas de Dipterocarpáceae na Indonésia são descritas na literatura mundial como florestas que apresentam uma taxa de crescimento relativamente alta. Nessas florestas, tem sido relatado um incremento de até 0,5 cm/ano em florestas naturais (Johnson \& Dyckstra, 1978; Miller, 1981) e de 1,0 $\mathrm{cm} /$ ano em florestas exploradas (Abdul Rashid, 1983). Contudo, em um estudo realizado em Kalimantan, na Indonésia, Sist \& Nguyen-Thé (2002) relatam uma taxa de incremento diamétrico inferior à encontrada neste trabalho para florestas não exploradas. Na parcela testemunha (floresta primária) do presente trabalho, essa taxa de crescimento foi $27 \%$ superior à encontrada por Sist \& Nguyen-Thé (2002) na Indonésia $(0,29$ cm/ano), 55\% superior à encontrada por Higuchi et al., (1997) na Amazônia Central $(0,17 \mathrm{~cm} / \mathrm{ano})$, e $47 \%$ superior à encontrada por Carvalho (1992) no baixo Amazonas $(0,2 \mathrm{~cm} / \mathrm{ano})$.

Após a exploração, encontrou-se uma taxa de incremento diamétrico entre 0,53 $\mathrm{cm} / \mathrm{ano}$ e $0,55 \mathrm{~cm} / \mathrm{ano}$ para árvores com valor madeireiro, enquanto que Silva et al. (1995) e Higuchi et al. (1997) encontraram respectivamente $0,4 \mathrm{~cm} /$ ano e $0,31 \mathrm{~cm} / \mathrm{ano}$ em outras regiões da Amazônia. No entanto, a taxa de incremento diamétrico encontrada para espécies de Dipterocarpáceas é semelhante à encontrada por Sist \& Nguyen-Thé (2002) na Indonésia $(0,54 \mathrm{~cm} / \mathrm{ano})$ e inferior à encontrada por Elias (1996) em Kiani Lestari (Kalimantan), onde o incremento anual em DAP após a exploração variou de 0,8 $\mathrm{cm} / \mathrm{ano}$ a $0,95 \mathrm{~cm} / \mathrm{ano}$ nos dois primeiros anos, e de $0,47 \mathrm{~cm} / \mathrm{ano}$ e $0,69 \mathrm{~cm} /$ ano entre $4 \mathrm{e}$ 17 anos.

De Graaf (1986), em áreas com tratamentos silviculturais, encontrou um incremento variando de 0,6 a $1,0 \mathrm{~cm} /$ ano no Suriname. Tanto De Graaf (1986) como Jonkers (1987) relatam que nas florestas do Suriname a aplicação de tratamentos silviculturais elevou a taxa de incremento em DAP entre $4 \%$ a $42 \%$. Em síntese, o sucesso dos sistemas silviculturais seletivos depende muito da quantidade e da qualidade das árvores da colheita futura (Rapera, 1978). A idade e a taxa de crescimento são determinantes, tanto nas florestas tropicais como nas florestas temperadas, porque é 
através dessas informações que se determina o ciclo de corte, o regime de desbaste e o corte permissível ou volume explorável (Bormann e Berlyn, 1981).

\subsubsection{Incrementos volumétricos}

Existem diversos trabalhos enfocando crescimento volumétrico em florestas tropicais no mundo. A variação de produtividade é muito alta. Baseado em considerações gerais de diferentes florestas, o crescimento anual potencial pode ser estimado em: (i) África 1-2 $\mathrm{m} \mathrm{m}^{3} \mathrm{ha}^{-1} \mathrm{ano}^{-1}$; (ii) América Latina 1-3 $\mathrm{m}^{3} \mathrm{ha}^{-1} \mathrm{ano}^{-1}$, (iii) Ásia 2-4 $\mathrm{m}^{3} \mathrm{ha}^{-1} \mathrm{ano}^{-1}$ e (iv) Amazônia brasileira 1-5 $\mathrm{m}^{3} \mathrm{ha}^{-1} \mathrm{ano}^{-1}$ (Sommer, 1976; Wadsworth, 1987; Leslie, 1987; Silva et al.,1994; Silva et al.,1995; Higuchi et al.,1997). O incremento médio pós-exploração no estudo atual para todas as espécies de valor comercial com DAP igual ou superior $10 \mathrm{~cm}$ foi de $2,49 \mathrm{~m}^{3} \mathrm{ha}^{-1} \mathrm{ano}^{-1}$. Os resultados do estudo atual não diferem muito de outros já encontrados na Amazônia. Um estudo realizado por Silva et al. (1995) relata um incremento médio para indivíduos com DAP acima de $45 \mathrm{~cm}$ de cerca de $1,8 \mathrm{~m}^{3} \mathrm{ha}^{-1} \mathrm{ano}^{-1}$, somente para espécies com valor comercial em uma floresta explorada. Em outro estudo, Silva et al. (1994) observaram um crescimento para floresta natural de cerca de $1,6 \mathrm{~m}^{3} \mathrm{ha}^{-1} \mathrm{ano}^{-1}$. Os resultados do estudo atual diferem dos encontrados por Silva et al. (1995), pois na floresta que se estudou, as árvores com DAP superior a $30 \mathrm{~cm}$ estão crescendo cerca de $0,92 \mathrm{~m}^{3} \mathrm{ha}^{-1} \mathrm{ano}^{-1}$, e a floresta natural está crescendo cerca de $0,27 \mathrm{~m}^{3} \mathrm{ha}^{-1} \mathrm{ano}^{-1}$. Higuchi et al. (1997) encontraram uma taxa de crescimento de $2,12 \mathrm{~m}^{3} \mathrm{ha}^{-1} \mathrm{ano}^{-1}$ para espécies com valor comercial e de 2,82 $\mathrm{m}^{3} \mathrm{ha}^{-1} \mathrm{ano}^{-1}$ para floresta natural na região Central da Amazônia.

\subsubsection{Ciclo de corte}

As estimativas de ciclo de corte para florestas tropicais variam de acordo com o sistema de manejo empregado e a intensidade de exploração. Essas estimativas para as florestas tropicais variam de 30 a 40 anos (Silva, 1992; Sayer et al., 1995; Bach, 1999). Para áreas exploradas com alta intensidade e exploradas predatóriamente, as estimativas de ciclo de corte variam entre 70 e 100 anos (Barreto et al., 1993; Sayer et al., 1995; 
Higuchi et al., 1997) e de 30 a 40 anos para exploração com técnicas de impacto reduzido (Barreto et al., 1993). Na Amazônia brasileira, as recomendações mínimas para ciclo de corte são de 20 anos (Silva, 1992), todavia, ciclos entre 30 e 40 anos podem ser mais realísticos (Silva et al., 1996; Alder \& Silva, 2000), isto para uma intensidade de corte de $40 \mathrm{~m}^{3} / \mathrm{ha}$ (volume em pé; ou $20 \mathrm{~m}^{3} / \mathrm{ha}$, para volume em tora). A produtividade após a exploração nas florestas da Amazônia é baixa e isso deve ser levado em consideração na estimativa de ciclo de corte (Silva et al., 1996). Um estudo recente de Alder \& Silva (2002) na Amazônia brasileira mostra que uma intensidade de corte de 2 $\mathrm{m}^{2} / \mathrm{ha}\left( \pm 27-28 \mathrm{~m}^{3} / \mathrm{ha}\right)$ pode ser sustentável em ciclos de 30 anos por um cenário de até 200 anos. No entanto, a partir do terceiro ciclo, as espécies potenciais passam a contribuir significativamente na colheita. Sayer et al. (1995) acham preferível um ciclo de corte entre 20 e 40 anos, com poucas árvores extraídas, do que uma alta intensidade de corte com ciclo de corte de 70 a 80 anos. Esta é uma recomendação não aplicável para todas as florestas tropicais do mundo, pois estudos demonstram que existem grandes variações em crescimento nessas florestas. Para Sayer et al., (1995), a intensidade baixa apresenta outros ganhos importantes em termos de conservação florestal, como a sensível proteção de espécies de plantas, animais e pássaros.

No estudo atual, mesmo sem realizar tratamentos silviculturais, todos os tratamentos tiveram crescimentos diamétrico, volumétrico e em área basal positivos. A expectativa é que se fossem aplicados tratamentos silviculturais, as taxas de crescimento aumentariam consideravelmente. Pelo menos é o que mostram alguns estudos que tratam deste tema (De Graaf et al., 1986; Jonkers, 1987; de Graaf et al., 1999, de Graaf et al., 2000).

O padrão de produtividade apresentado neste trabalho assemelha-se ao de outros estudos realizados na Amazônia, como os de Silva (1989), Silva et al., (1995) e Higuchi et al., (1997), os quais relatam uma redução de crescimento em aproximadamente 3 a 5 anos após a exploração. A recomendação desses autores é aplicar tratamentos silviculturais neste período com o intuito de melhorar a produtividade da floresta. Ainda há poucos estudos com enfoque em tratamentos silviculturais na região, pois não existem pesquisas científicas de longo prazo que realmente apresentem resultados 
econômicos e ambientais confiáveis da aplicação desta técnica. A maioria das pesquisas sobre tratamentos silviculturais na América latina tem enfocado a eficiência em eliminar a árvore competidora (Louman et al., 2001). Poucos são os estudos que analisam os custos e benefícios da aplicação dos tratamentos silviculturais. Pesquisas com tratamentos silviculturais em florestas tropicais mostram que estes aumentam o crescimento das árvores (Lamprecht, 1990; Lamprecht, 1993). Porém, a exploração com intensidade alta também pode funcionar como um tratamento silvicultural; como aconteceu na Floresta Nacional do Tapajós (Silva et al.,1995). Todavia, há uma tendência para uma taxa de crescimento mais baixa dez anos após o tratamento silvicultural inicial (Silva et al., 1995; Primack, 1987). Portanto, para executar tratamento silvicultural, deve-se ter em mente a necessidade de ter que repeti-lo algumas vezes antes do próximo corte. Neste caso, é necessário realizar análise de viabilidade econômica para decidir sobre a realização de tal atividade.

Usando uma análise similar à utilizada por Higuchi et al., (1997) para estimar o ciclo de corte e, assumindo que as árvores da classe maior com trinta centímetros de DAP estariam aptas para serem derrubadas e que a dinâmica da floresta (crescimento, mortalidade e recrutamento) se manteria ao longo do tempo, seriam necessários 42 anos para a floresta recuperar a quantidade de metros cúbicos retirados no primeiro ciclo na área com exploração de impacto reduzido e 226 anos na área com exploração convencional; isto é, um período 5,5 vezes maior. Muitos estudos têm relatado um ciclo de corte em torno de 30 a 40 anos (Silva, 1992; Barreto et al., 1993; Sayer et al., 1995; Bach, 1999), e mais recentemente, outros têm recomendado um ciclo de 60 a 100 anos (Huth \& Ditzer, 2001; Kammesheidt et al., 2001). O que se deve levar principalmente em conta é a intensidade de corte. Neste estudo, para um volume extraído de $38 \mathrm{~m}^{3} / \mathrm{ha}$, serão necessários cerca de 40 anos para recuperar o que foi retirado no primeiro corte. Já Alder e Silva (2000) recomendam um ciclo de corte de 30 anos para uma intensidade de exploração de $20 \mathrm{~m}^{3} / \mathrm{ha}$ (em toras). Portanto, o ciclo de corte vai variar de acordo com a intensidade de corte e outros fatores também importantes como a composição da floresta, tipo de intervenção na floresta e técnica silvicultural empregada. 


\subsubsection{Mortalidade e recrutamento}

A taxa anual de mortalidade nas áreas testemunha (1,82\%/ano) e com exploração de impacto reduzido (1,40\%/ano) estão dentro da taxa esperada para floresta natural; 1\%-2\% (de Graaf, 1986; Jonkers, 1987; Swaine \& Lieberman, 1987; Hartshorn, 1980; Hartshorn, 1990).

A taxa de mortalidade média geral anual na área testemunha para todo o período monitorado (1994-2000) foi levemente superior à taxa de recrutamento. Enquanto que na área de exploração de impacto reduzido e na de exploração convencional a mortalidade foi inferior ao recrutamento. Na exploração de impacto reduzido, a relação entre mortalidade e recrutamento foi muito alta. O recrutamento foi $44 \%$ superior à mortalidade. Já na exploração convencional, o recrutamento foi apenas $4 \%$ superior à mortalidade. A relação entre mortalidade e recrutamento é semelhante à encontrada por outros autores (Silva et al., 1995; Higuchi et al., 1997; Sist \& Nguyen-Thé, 2002).

A mortalidade na área de exploração de impacto reduzido foi inferior à encontrada na área de exploração convencional. Obviamente que a mortalidade inferior na exploração de impacto reduzido em relação à exploração convencional e testemunha indica que houve danos menores às árvores remanescentes. $\mathrm{O}$ fato de a mortalidade estar relacionada à quantidade de árvores danificadas foi comprovado por Sist \& Nguyen-Thé, 2002, na Indonésia. A mortalidade na área com EIR durante os últimos sete anos após exploração tem se apresentado similar à da área não explorada (natural); fato já comprovado por outros autores que realizaram estudos na floresta tropical Amazônica (Silva et al., 1995; Higuchi et al., 1997)

Existem evidências de que a mortalidade alta na área testemunha $(1,82 \%)$ é conseqüência da presença maciça de cipós nas copas sufocando as árvores, pois nesta área, a porcentagem de árvores com cipós é de $60 \%$.

Alguns estudos mostram que a mortalidade pode diferir entre as classes diamétricas (Uhl, et al., 1988; Silva, 1989; Taylor et al., 1996; Pélissier et al., 1998), contrastando com os resultados de outros estudos que dizem não haver evidências dessa 
diferença (Lieberman et al., 1985; Swaine et al., 1987; Manokoran \& Kochumen, 1987; de Graaf, 1986; Sist \& Nguyen-Thé 2002). No estudo atual, constatou-se que existem diferenças nas taxas de mortalidade entre as classes diamétricas apenas nas áreas exploradas sem o uso de técnicas de EIR. No entanto, nas áreas em que se adota a exploração de impacto reduzido e nas áreas naturais não existem evidências dessa diferença.

\subsection{Conclusões}

Estudos anteriores sobre exploração de impacto reduzido na Amazônia têm demonstrado que quando se utiliza essas técnicas, há mais benefícios em termos gerais do que quando se faz exploração sem manejo. Em síntese, os estudos anteriores demonstram que o emprego de exploração de impacto reduzido contribuiu para a redução dos impactos biológicos, aumento da produtividade do trabalho, diminuição dos riscos de acidente, viabilidade econômica, maior fixação de carbono da atmosfera, etc. Neste estudo, demonstrou-se que quando as atividades são planejadas (uso de técnicas de exploração de impacto reduzido), as árvores beneficiadas crescem mais em todos os tipos de medidas avaliadas (cm de DAP, área basal e volume). A mortalidade de árvores foi menor e o recrutamento foi maior na área com EIR em comparação com as áreas de exploração predatória e testemunha.

Apesar do extraordinário sucesso das técnicas de manejo, o desenvolvimento da floresta após a colheita é uma questão que ainda não foi bem pesquisada. Estudos com monitoramento de florestas após exploração na Amazônia são escassos. Quando realizados, são feitos sem muito critério científico e, como não houve planejamento inicial, os dados dessas pesquisas não podem ser comparados com os do estudo atual. Há uma grande demanda por este tipo de informação na Amazônia; desde agências governamentais até o setor privado. É importante estabelecer uma rede de parcelas permanentes na Amazônia brasileira que possa fornecer informações confiáveis sobre o que acontece com a floresta após a exploração madeireira, considerando a diversidade de tipologias florestais na Amazônia. Os resultados deste estudo indicam que a floresta 
manejada com EIR vai recuperar o volume original colhido na primeira extração num prazo 5,5 menor ao da área explorada de forma convencional. 
Anexo 2: Análise de Variância do incremento periódico anual (IPA) para DAP, área basal e volume em três classes de tamanho. Para o caso de incremento em DAP, como os dados não apresentaram distribuição normal foi realizada a transformação logarítma (Sokal e Rohlf, 1981).

$10 \mathrm{~cm} \geq \mathrm{DAP}<30 \mathrm{~cm}$

\begin{tabular}{lccccc}
\hline \multicolumn{7}{c}{ In de IMA } \\
\hline Fonte de variação & Gl & SQ & QM & F & p \\
\hline Tratamento & 2 & 1.64389 & 0,82195 & 114,96 & 0,000 \\
\hline Resíduo & 144 & 1,02961 & 0,00715 & & \\
\hline \multicolumn{7}{c}{ Área Basal } \\
\hline Tratamento & 2 & 0,31454 & 0,15727 & 82,37 & 0,000 \\
\hline Resíduo & 144 & 0,27494 & 0,00191 & & \\
\hline Tratamento & 2 & 46,487 & 23,243 & 87,51 & 0,000 \\
\hline Resíduos & 144 & 38,246 & 0,266 & & \\
\hline
\end{tabular}

$>30 \mathrm{~cm}$ de DAP

\begin{tabular}{lccccc}
\hline \multicolumn{7}{c}{ In de IMA } \\
\hline Fonte de variação & Gl & SQ & QM & F & p \\
\hline Tratamento & 2 & 0,9539 & 0,4769 & 15,96 & 0,000 \\
\hline Resíduo & 144 & 4,3043 & 0,0299 & & \\
\hline Tratamento & 2 & 0,07914 & 0,03957 & 5,79 & 0,004 \\
\hline Resíduo & 144 & 0,98418 & 0,00683 & & \\
\hline Aratamento & 2 & 17,12 & 8,56 & 6,25 & 0,002 \\
\hline Resíduos & 144 & 197,25 & 1,37 & & \\
\hline
\end{tabular}




\section{Capítulo VII - Conclusões e Recomendações}

Abaixo apresentam-se as principais conclusões desta tese:

1 - Não houve diferenças significativas em termos de crescimento da regeneração ( $>1 \mathrm{~m}$ de altura e $<10 \mathrm{~cm}$ de DAP) entre clareiras testemunhas, clareiras de exploração de impacto reduzido e clareiras da exploração convencional.

2 - Com relação à mortalidade, não ocorreram diferenças entre clareiras de áreas exploradas e entre clareiras de áreas exploradas e clareiras testemunha.

3 - Não houve diferença na taxa de recrutamento entre clareiras naturais e clareiras de áreas exploradas.

4 - Clareiras de florestas exploradas de forma convencional apresentam diversidade semelhante às clareiras de exploração de impacto reduzido quando não ocorrem reentradas naquelas áreas. Esse resultado é um importante estímulo para o aproveitamento dessas florestas exploradas predatoriamente, que atualmente sofrem forte pressão para serem transformadas em outros usos do solo. Políticas de incentivo governamental para aproveitar essas áreas poderiam ser importantes para torná-las uma fonte futura de madeira de floresta nativa. No entanto, é necessário que se realizem mais pesquisas nestes ambientes para descobrir não somente seu potencial ecológico mais também o potencial econômico. 
5 - Os desbastes realizados em clareiras podem aumentar em até $115 \%$ o crescimento das plantas beneficiadas em relação às não beneficiadas, sem que isso cause alteração significativa na diversidade de espécies madeireiras.

6 - A diversidade de espécies arbóreas (> $10 \mathrm{~cm}$ de DAP) após a exploração tem aumentado ao longo do tempo, inclusive na área de exploração convencional. Estes resultados demonstram que a exploração madeireira seja com técnicas de impacto reduzido ou de forma convencional não causam impactos significativos na diversidade de espécies arbóreas.

7 - Árvores beneficiadas com o uso de técnicas de exploração de impacto reduzido crescem mais em todos os parâmetros avaliados (DAP, área basal e volume).

8 - A mortalidade de árvores foi menor e o recrutamento foi maior na área com exploração de impacto reduzido em comparação com as áreas de exploração convencional e testemunha.

9 - Usando uma análise simples para estimar a próxima colheita, assumindo que as árvores da classe maior que $30 \mathrm{~cm}$ centímetros de DAP seriam as que estariam aptas para serem colhidas e que a dinâmica da floresta (crescimento, mortalidade e recrutamento) se manteria ao longo do tempo, seriam necessários cerca de 42 anos para a floresta recuperar a quantidade de metros cúbicos retirados na primeira colheita na área com exploração de impacto reduzido e 226 anos na área com exploração convencional; isto é, um período 5,5 vezes maior na área com exploração convencional.

10 - Pesquisas anteriores a esta, realizadas na mesma área de estudo deste projeto, demonstraram que a exploração de impacto reduzido reduziu os impactos estruturais à floresta, os desperdícios e os riscos de acidente de trabalho e aumentou a eficiência e a produtividade do trabalho. Com todos esses ganhos, a colheita de madeira tornou-se mais barata. Essas são algumas das inúmeras vantagens que o emprego de 
boas práticas de manejo florestal pode oferecer. Neste estudo descobriu-se que o uso de técnicas de exploração de impacto reduzido também promove um maior crescimento das árvores e causa um menor efeito sobre a diversidade de espécies quando comparada à exploração convencional. Essas informações são muito importantes, pois indicam que com um melhor desenvolvimento, essas florestas exploradas com técnicas de impacto reduzido se recuperarão num período relativamente menor do que as florestas exploradas convencionalmente ou mesmo as florestas com outros usos do solo como pecuária e plantio de grãos, que são, hoje, grandes ameaças para as florestas da Amazônia. Além disso, essas florestas exploradas utilizando técnicas de redução de impacto estarão conservando a biodiversidade florestal.

Um dos pontos cruciais sobre exploração de impacto reduzido é conhecer o desenvolvimento da floresta após a exploração. Os estudos mais antigos sobre o tema não avaliam a exploração de impacto reduzido incluindo técnicas adequadas de planejamento que visam à diminuição dos impactos estruturais ao ambiente florestal. Devido a isso, esses estudos, quando comparados aos mais recentes, devem demonstrar crescimento diferenciado após a colheita de madeira, principalmente porque o nível de danos é diferente. Mesmo estudos mais antigos de desenvolvimento da floresta na Amazônia são raros. Por isso, será necessário estabelecer uma rede de parcelas permanentes na Amazônia brasileira que possa fornecer informações confiáveis sobre o que acontece com a floresta após a exploração madeireira, considerando a diversidade de tipologias florestais na Amazônia e a diversidade de intensidade de colheita. Muitos dos estudos realizados no mundo sobre este tema relatam que a exploração de impacto reduzido não apresenta sustentabilidade ecológica, outros relatam que não apresenta sustentabilidade econômica e outros questionam que não existem exemplos de áreas que já se chegou ao segundo ciclo na Amazônia. No entanto, alguns estudos têm demonstrado que o manejo pode ser sustentável até 200 anos. Neste caso, estamos falando da sustentabilidade volumétrica, pois é possível que nos ciclos seguintes ocorra uma transformação na composição florística, e algumas espécies como as do grupo ecológico das pioneiras dominem a composição. Portanto, há necessidade urgente de 
prognosticar o futuro da Amazônia através de modelos ecológicos sofisticados, para que se inicie uma ampla discussão sobre como será a floresta futura, baseado nas intervenções a que essas florestas estão sendo submetidas. 


\section{Referências Bibliográficas}

ABDUL RASHID, M.A. The implementation of the selective management system in Peninsular Malaysia. Oxford, 1983. Dissertação (MS) - University of Oxford.

AGYEMAN, V.K., TURNBULL, C., \& SWAINE, M.D. Maintenance of biodiversity in the tropical high forest: current research iniciatives in Ghana. In: IUFRO XX World Congress, Procedings, Abstract. 1995. p. 76-77.

ALDER, D \& SILVA, J.N.M. An empirical cohort model for management of Terra Firme forest in the Brazilian Amazon. Forest Ecology and Management. v. 130, p. 141-157. May. 2000.

ALDER, D \& SILVA, J.N.M. Sustentabilidade da produção volumétrica: um estudo de caso na Floresta Nacional do Tapajós com auxílio do modelo de crescimento Cafogrom. In: SILVA, J.N.M.; CARVALHO, J.O.P. \& YARED, J.G. A silvicultura na Amazônia Oriental: Contribuições do Projeto Embrapa/DFID. Belém, Embrapa Amazônia Oriental/DFID. 2001. p. 325-337.

ALDER, D. \& SYNNOTT, T.J.. Permanent simple plot techniques for mixed tropical forest. Tropical Forestry Papers. N. 25. Oxford. 1992. 124p.

ALDER, D. Forest volume estimation and yield prediction. vol. 2: Yield prediction. FAO Forest Paper 22, 1980. 194 p.

ALDER, D. Growth modelling for mixed tropical forests. Oxford: Oxford Forest Institute, 1995. $231 \mathrm{p}$. 
ALMEIDA, S.S. Clareiras naturais na Amazônia Central: abundância, distribuição, estrutura e aspectos de colonização vegetal. Manaus, 1989. Dissertação (Mestrado) - INPA.

AMARAL, P.; VERÍSSIMO, A.; BARRETO, P. \& VIDAL, E. Floresta para sempre: um manual para a produção de madeira na Amazônia. Belém: Imazon, 1998.. $155 \mathrm{p}$.

APPANAH, S \& PUTZ, F.E. Climber abundance in virgin dipterocarp forest and the effects of pre-logging climber cutting on logging damage. Malaysian Forester v. 47 , p. 335-432. 1984.

ARIMA, E. \& VERÍSSIMO, A. Brasil em Ação: ameaças e oportunidades na fronteira Amazônica. Cadernos Konrad Adenauer. Ano II, nº. 04. 2001. p. 79-99.

AUBRÉVILLE, A. La forêt coloniale; les forêt de l'Afrique occidentales française. Annales Académie des Sciences Coloniales. Paris. 1938. 9: 1-245.

$\mathrm{BACH}, \mathrm{C.F}$. Economic incentives for sustainable management: a smal optimal control model for tropical forestry. Ecological economics. v. 30: p. 251-265. 1999.

BARRETO, P.; AMARAL, P.; VIDAL, E.; UHL, C. Costs and benefits of forest management for timber production in eastern Amazonia. Forest Ecology and Management. v. 108, p. 9-26, Aug. 1998.

BARRETO, P.; UHL, C.; YARED, J. Avaliação do Potencial para Manejo florestal em Paragominas, considerando Fatores Ecológicos e Econômicos. In: ANAIS DO VII CONGRESSO FLORESTAL BRASILEIRO E I CONGRESSO FLORESTAL PANAMERICANO, SBS-SBEF. Set. 1993. p. 387-392. 
BARROS, A.; UHL, C. Logging along the Amazon River and Estuary: patterns, problens and potential. Forest Ecology and Management. v.77, p.87-105, Sep. 1995.

BATISTA, J.L.F. Spatial dynamics of trees in a Brazilian Atlantic tropical forest under natural and managed conditions. Seattle, 1984. Thesis (Ph.D.) - University of Washington.

BAUR, B.N. The ecological basis of rainforest management. Forest Comission, Sydney, New South Wales, Australia. 1964.

BERRY, P.E. Diversidad y endemismo em los bosques neotropicales de bajura. In M. R. Guariguata \& G. H. Kattan. Ecologia y Conservación de Bosques Neotropicales. LUR, 2002.. p. 83-96.

BERTHAULT, J.G. \& SIST, P. An experimental comparison of different harvesting intensities with reduced impact and conventional logging in East Kalimantan, Indonesia. Forest ecology and management. v. 94, p. 209-218, Jun. 1997.

BIOT, Y., BRILHANTE, V., VELOSO, J., FERRAZ, J.B.S., LEAL, N., HIGUCHI, N., FERREIRA, S., DESJARDINS, T., INFORM: o modelo florestal do INPA. In: N. HIGUCHI, J.B.S.FERRAZ, L. ANTONY, F. LUIZÃO, R. LUIZÃO, Y. BIOT, I. HUNTER, J. PROCTOR \& S. ROSS (eds.). Biomassa e nutrientes florestais: Relatório Final. Manaus, INPA/DFID. 1997, p. 273-318.

BOLTZ, F., CARTER, D.R., HOLMES, T.P. e PEREIRA Jr., R. Financial returns under uncertainty for conventional and reduced-impact logging in permanent production forests of the Brazilian Amazon. Ecological Economics. 39, 2001. p. 387-398. 
BONGERS, F. \& POPMA, J. Trees and gaps in a Mexican tropical rain forest. The Netherlands, Utresht, 1988. Thesis (Ph.D), Utrecht University..

BORMANN, F.H. \& BERLYN, G. Age and growth rate of tropical trees: new directions for research. New Haven. Yale University School of Forestry and Environmental Studies. 1981.120p.

BRANDANI, A., HARTSHORN, G.S. \& ORIANS, G.H. 1988. Internal heterogeneity in gaps and species richness in Costa Rican tropical wet forest. Journal of Tropical. Ecology. 4: 99-119.

BROKAW, N.V.L. The definition of treefall gap and its effect on measures of forest dynamics. Biotropica. 1982. 11: 158-160.

BROKAW. N.V.L. Gap-phase regeneration in a tropical forest. Ecology 66 (3), 1985. p. 682-687.

BRYAN, M.B. Studies of timber growth and mortality in the mixed dipterocarp forest in Sarawak. FAO Report, no. FO: MAL/76/008. Field Document 11. 1981. 56 p.

BULLOCK, S. H. Demography of and undergrow the palm in litoral Cameroon. Biotropica 12. 1980. p.247-255.

BUSCHBACHER, R.J. Natural forest management in the humid tropics: ecological, social, and economics considerations. Ambio, v. 19 (5), p. 253-258, 1990.

CAMPBELL, D.G., DALY, D.C., PRANCE, G.T., MACIEL, V.N. Quantitative ecological inventory of terra firme and várzea tropical forest on the Rio Xingu, Brazilian Amazon. Brittonia. 38, 1986. p. 369-393. 
CANNON, C.H.; PEART, D.R.; LEIGHTON, M. Tree species diversity in commercially logged Bornean rainforest. Science. V. 281, p. 1366-1368, 1998.

CANNON, C.H.; PEART, D.R.; LEIGHTON, M.; KARTAWINATA, K. The structure of lowland rainforest after selective logging in West Kalimantam, Indonesia. Forest ecology and management. v. 67, p. 49-68, Aug 1994.

CARVALHO, J.O.P. Structure and dynamics of a logged over Brazilian Amazonian rain forest. Oxford. 1992. Thesis (Ph.D.) - University of Oxford.

CATTÂNIO, J.H. Efeito da exclusão da chuva no fluxo dos gases traçadores em solo de floresta primária de terra firme no leste amazônico. Belém, 1996, 102p. Dissertação (mestrado) - Faculdade de Ciências Agrárias do Pará.

CLARK, D.B. \& CLARK, D.A. Distribution and effects on tree growth of lianas and woody hemiepiphytes in a Costa Rican tropical wet forest. Journal of Tropical Ecology. v. 6: 321-331. 1990.

COCHRANE, M. A. \& SCHULZE, M. D. Fire as a recurrent event in tropical forests of the eastern Amazon: effects on forest structure, biomass, and species composition. Biotropica, v. 31, p. 2-16. 1999.

CONDIT, R., FOSTER, R.B., HUBBELL, S.P., SUKUMAR, R., LEIGH, E.G., MANOKARAN, N., LOO DE LAO, S., LAFRANKIE, J.V., ASHTON, P.S. Assessing forest diversity on small plots: calibration using species-individual curves from 50-ha plots. In: DALMEIER, F. \& COMISKEY, J.A. (Ed.). Forest biodiversity research, monitoring and modeling. Man and Biosphere Series Vol. 20. UNESCO \& Parthernon Publishing Group, France. 1998. p. 247-268. 
CONDIT, R., HUBBELL, S.P., LAFRANKIE, J.V., SUKUMAR, R., MANOKARAN, N., FOSTER, R.B., ASHTON, P.S. Species-area and species-individual relationship for tropical tree: a comparison of three 50-ha plots. Journal of Ecology v. 84, p. 549-562. 1996.

COSTA, F.R.C. \& MAGNUSSON, W. Effects of Selective Logging on the Diversity and Abundance of Flowering and Fruiting Understory Plants in a Central Amazonian Forest. Biotropica. v. 35 (1), p. 103-114. 2003.

DAWKINS, H.C. \& PHILIP, M.S. Tropical moist forest silviculture and management. A history of success and failure. $\mathrm{CAB}$ International, Wallingford, RU. 1998. 359p.

DAWKINS, H.C. The management of natural tropical forest with special reference to Uganda. Imperial Forest Institute Paper 34. 1958.

De GRAAF, N.R. Reduced impact logging as part of the domestication of neotropical rainforest. International forestry review. v. 2 (1): 40-44. 2000.

De GRAAF, N.R. A silvicultural system for natural regeneration of tropical rainforest in Suriname. Wageningem, The Netherlands: University of Wageningem. 1986, 250p.

DE GRAAF, N.R., FILIUS, A.M. HUESCA SANTOS, A.R. Financial analysis of sustained forest management for timber Perspectives for application of the CELOS management system in Brazilian Amazonia. Forest Ecology and Management. v. 177, p. 287-299, Apr. 2003. 
De GRAAF, N.R.; POELS, R.L.H.; van ROMPAEY, R.S.A.R. Effect of silvicultural treatments on growth and mortality of rainforest in Surinam over long periods. Forest ecology and management. v. 124, p. 123-135, Dec. 1999.

DENSLOW, J. S. Tropical rainforest gaps and tree species diversity. An. Review of Ecology and System, v.18, p. 431-451. 1987.

DENSLOW, J. S. Disturbance and diversity in tropical rain forest the density effect. Ecological Applications, v. 5 (4), p. 962-968. 1995.

DENSLOW, J.S. Patterns of plant species diversity during sucession under defferent disturbance regimes. Oecologia v. 46, p. 18-21. 1980.

DILLENBURG, L.R.; WHIGHAM, D.F.; TERAMUA, A.H.; FORSETH, I.N. Effects of below and aboveground competition from the vines Lonicera japonica and Parthenocissus quinquefolia on the growth of the tree host Liquidambar styraciflua. Oecologia, v. 93: 48-54. 1993.

DUBOIS, J.C.L. En el desarrollo integral de las comunidades rurales del tropical Americano. In: REICHE C.C. Leituras selecionadas: seminário sobre planejamento de projetos auto-sustentáveis de lenha para América latina e Caribe, Anal. Turrialba: FAO, 1991. v.2, 1991. p. 136-151.

DUNN, 0.J. Multiple contrast using rank sums. Technometrics v. 6, p. 241-252. 1964.

ELIAS, I.R. A case study on forest harvesting, damage, structure and composition: dynamics changes of the residual stand for dipterocarps Forest in East Kalimatan, Indonésia. In: Proceedings of Forest operations for Sustainable Forestry, XX IUFRO, World Congress, August 6-12, 1995. IUFRO S3.05-00 and CIFOR Publication. 1996. p. 13-27. 
LEAL FILHO, N. Dinâmica inicial de regeneração natural de florestas exploradas na Amazônia brasileira. São Paulo, 2000. 157p. Tese (Doutorado) - Instituto de Biociências/Universidade de São Paulo.

FOX, J.E.D. Logging damage and the influence of climber cutting prior to logging in the lowland dipterocarp forest of Sabah. Malaysian Forester, v. 31, p. 326-347. 1968.

FOX, J.E.D. Contraints on the natural regeneration of tropical moist forest. Forest Ecology and Management. v. 1, p. 37-65. 1976.

GENTRY, A.H. Patterns of neotropical plant species diversity. Evolution Biological v. 15, p. 1-84. 1982.

GENTRY, A.H. Changes in plant community diversityand floristic composition on environmental and geographical gradients. Annals of the Missouri Botanical Garden $1988^{\mathrm{a}} .75:$ 1-34.

GENTRY, A.H. $1988^{\mathrm{b}}$. Tree species richness of upper Amazonian Forest. Procedings of the National Academy of Sciences 85, p. 156-159.

GERWING, J. Degradation of forests through logging and fire in the eastern Brazilian Amazon. Forest Ecology and Management v. 157 (1), p. 131-141, Mar. 2002.

GERWING, J. J. \& FARIAS, D. L., Integrating liana abundance and forest stature into an estimate of aboveground biomass for an eastern Amazonian forest. Journal of Tropical Ecology v. 16, 327-336, 2000.

GRUBB, P.J. The maintenance of species-richness in plant communities: the importance of the regeneration niche. Biological Reviews. v. 52: 107-145. 1977. 
HARTSHORN, G.S. An overview of neotropical forest dynamics. In: Four neotropical rainforest. New haven: Yale University Press, 1990. p.585-599.

HARTSHORN, G.S. Neotropical Forest dynamics. Biotropic v.12, 23-33, 1980.

HEGARTY, E. E.; CABALlÉ, G., Distribution and abundance of vines in forest communities. In: Putz, F. E., Mooney, H. A. (Eds.), The Biology of Vines. Cambridge University Press, Cambridge, United Kingdom, 1991. p. 313-335.

HIGUCHI, N. Short-term growth of an undisturbed tropical moist forest in the Brazilian Amazon. Michigan, 1987. Tese (Ph.D.) - Michigan State University.

HIGUCHI, N., SANTOS, J., RIBEIRO, R.J., FREITAS, J.V., VIEIRA, G., COIC, A. \& MINETTE, L.J. Crescimento e incremento de uma floresta amazônica de terrafirme manejada experimentalmente. In: N. HIGUCHI, J.B.S.FERRAZ, L. ANTONY, F. LUIZÃO, R. LUIZÃO, Y. BIOT, I. HUNTER, J. PROCTOR \& S. ROSS (eds.). Biomassa e nutrientes florestais: Relatório Final. Manaus, INPA/DFID. 1997, p. 88-132.

HOLDSWORTH, A. R.; UHL, C. Fire in Amazonian selectively logged rain forest and the potential for fire reduction. Ecological Applications, v.7, p.173-725. 1997.

HOLMES, T.; BLATE, G.; ZWEEDE, J.; PEREIRA JR., R.; BARRETO, P. ; BOLTZ, F.; BAUCH, R. Financial and ecological indicators of reduced impact logging performance in the eastern Amazon. Forest Ecology and Management. v. 163, p. 93-110, Jun. 2002.

HUANG, W.; POHJONEM, V.; JOHANSSON, S.; NASHANDA, M. Species diversity, forest structure and species composition in Tanzanian tropical forest. Forest Ecology and Management. v. 173, p. 11-24, Feb. 2003. 
HUTCHINSON, I.D. The management of humid tropical forest to produce wood. In: Management of the forest of tropical america: prospects and tecnologies. Proceedings of a conference. Institute of Tropical Forestry. Puerto Rico. p.121-156, 1986.

HUTH, A. \& DITZER, T. Long-term impacts of logging in a tropical rain forest - a simulation study. Forest Ecology and Management. v. 142: 33-51, Mar. 2001.

Instituto Brasilerio de Geografia e Estatística. Censo Agropecuário. 1995-1996. Rio de Janeiro: IBGE, 1996.

Instituto Nacional de Pesquisas Espaciais. Monitoramento de floresta amazônica por satélite. São José dos Campos/SP: IBGE. 2000.

JENNINGS, S.B. BROWN, N.D., BOSHIER, T.C., WHITMORE, T.C., LOPES, J. do C.A. Ecology provides a pragmatic solution to the maintenance of genetic diversity in sustainably in sustainable managed tropical rain forest. Forest Ecology and Management. v. 154, p. 1-10, Nov. 2000.

JESUS, R.M. \& SOUZA, A.L. Produção sustentável em mata secundária de transição - oito anos de monitoramento. Documentos SIF, n.014, dez. 1995. p.1-99.

JOHN, L. Amazônia represente 53\% das florestas tropicais em pé. O Estado de São Paulo. São Paulo, 05/12/2003. http://www.estado.estadao.com.br/editorias/2002/12/05/ger015.html.

JOHNS, J.S., BARRETO, P., UHL, C., Logging damage during planned and unplanned logging operations in the eastern Amazon. Forest Ecology and Management v. 89, p. 59-77, Dec. 1996. 
JOHNSON, N.E. \& DYCKSTRA, G.F. Maintanig forest production in east Kalimantan. Indonesia. In: Eight World Forest Congress. Jakarta, Indonesia, 1978. Anais. 1978. $11 \mathrm{p}$.

JONKERS, W. B. J. Vegetation structure logging damade and silviculture in a tropical rain forest in Suriname. Agricultural University, Wageningen, $1987 .$. $172 \mathrm{p}$.

JONKERS, W.B.J. Options for silviculture and management of the mixed dipterocarp forest Sarawak. FAO. Working Paper 11. 1982.

KAMMESHEIDT, L.; KOHLER, P.; HUTH, A. Sustainable timber harvest in Venezuela: a modeling approach. Journal of Applied Ecology. v. 38: 756-770, 2001 .

KYEREH, B., SWAINE, M.D. \& THOMPSON, J. Effect of light on the germination of forest trees in Ghana. Journal of Ecology v. 87, p. 772-783, 1999.

LAMPRECHT, H. Silviculture in the tropical natural forest: In: Tropical Forestry Handbook. Springer-Verlag, Germany. . 1993, p.728-810.

LAMPRECHT, H. Silvicultura en los trópicos. Rossdorf, Alemania, Deustsche Gesellschaft fur Technische Zusammenarbeit (GTZ). 1990. 335 p.

LAURANCE, W.F. \& LAURANCE, S.G.W. Response of five arboreal marsupials to selective logging in tropical Australian. Biotropica v. 28 (3), p. 310-332, 1996. 
LESLIE, A.J. The economic feasibility of natural management of tropical forest. In: Natural Management of tropical moist forest: silvicultural and management prospects of sustained utilization. Yale University Press. 1987. p.178-198.

LIEBERMAN, D.; LIEBERMAN, M.; PERALTA, R.; HASTHORN, G.S. Mortality pattern and stand turnover rates in a wet tropical forest in Costa Rica. Journal Ecology. v. 73: 915-924, 1985.

LOPES, J.C.A. Demografia e flutuações temporais da regeneração natural após uma exploração florestal: Flona Tapajós/PA. Piracicaba, 1993, 133p. Dissertação (Mestrado) - Escola Superior de Agricultura Luiz de Queiroz, Universidade de São Paulo.

LOUMAN, B., QUIRÓS, D.; NILSSON, M... Silvicultura de bosques latifoliados con énfase en América Central. CATIE, Turrialba, Costa Rica, 2000. 265p.

LOWE, R. G. Experience with the tropical shelterwood system of regeneration in natural forest in Nigeria. Forest Ecology and Management, v.1, p. 129-136, 1978.

MACEDO, D.S. Estrutura e manejo de uma floresta de várzea no estuário amazônico. Piracicaba, 1996, 143p. Dissertação (Mestrado) - Escola Superior de Agricultura "Luiz de Queiroz". Universidade de São Paulo.

MAGNUSSOM, W.E., LIMA, O.P., REIS, F.Q., HIGUCHI, N., RAMOS, J.F. Logging activity and tree regeneration in an Amazonian forest. Forest Ecology and Management. v. 113, p. 67-74, Jan. 1999.

MAGURRAN, E. A Ecological diversity and its measurement. Princeton University Press. 1987. 179p. 
MARGULIS, S. Causas do desmatamento da Amazônia brasileira. Banco Mundial. Brasília. 2003. 80p.

MARTINEZ-RAMOS, M. Claros, ciclos vitales de los arboles tropicales y regeneración natural de las selvas altas perenifolias. In: GOMEZ-POMPA, A. \& DEL AMO, $\mathrm{S}$. Investigaciones sobre la regeneración de selvas altas en Veracruz. México, 1985. v. 2, 1985. p. 191-239.

MARTINI, A.; ROSA, N. \& UHL, C. An attempt to predict which Amazonian tree species may be threatened by logging activities. Environmental Conservation, v. 21 (2), p. 152-162, 1994.

MARTINS, F.R. \& SANTOS, F.A.M. Técnicas usuais de estimativa da biodiversidade. Revista Holos, 1999. p. 236-267.

MEVART, J. Appendix to the paper on growth and mortality rates in the natural high forest of western Nigeria. Nigerian Forest Information Bulletin, n. 28. 1974. $30 \mathrm{p}$.

MILLER, T.B. Growth and yield of a logged-over mixed dipterocarp forest in East Kalimantan. Malaysian Forest 44: 1981. 419-424.

MYERS, P.G., NEWTON, A.C. \& MELGAREJO, O. The influence of canopy gap on natural regeneration of Brazil nut (Bertholletia excelsa) in Bolivia. Forest Ecology and Management, v. 127: 119-128, Mar. 2000.

NEPSTAD, D., VERÍSSIMO, A., ALENCAR, A., NOBRE, C., LIMA, E., LEFEBVRE, P., SCHLESINGER, P., POTTER, C., COCHRANE, M.A., BROOKS, V. Largescale improverishment of Amazoniam forest by logging and fire. Nature, v. 398, p. 505-508, 1999. 
NEPSTAD, D.C. CARVALHO, C.R., DAVIDSON, E.A., JIPP, P.H., LEFEBVRE, P.A., NEGREIROS, G.H., SILVA, E.D., STONE, T.A., TRUMBORE, S.E. \& VIEIRA, S. The deep-soil link between water and carbon cycles of Amazonian forests and pastures. Nature, v. 372, p. 666-669, 1994.

NEPSTAD, D.C., UHL, C. \& SERRÃO, E.A.S. Surmouting barriers to forest regeneration in abandoned, highly degraded pastures: a case study from Paragominas, Pará, Brasil. Pp. 215-229. In: Alternativas to deforestation, steps towards sustainable use of the Amazon rain forest. A. Anderson (ed.) Columbia University Press, New York. 1990.

NEPSTAD, D.C. Forest regrowth in abandoned pastures of Eastern Amazonian: limitations to tree seeling survival and growth. New Haven, CT. 1989, 233p. Thesis (Ph.D.) - University of Yale.

NICHOLSON, D.I. The effects of logging and treatment on the mixed dipterocarp forests of Southeast Ásia. Food and Agricultura Organization of the United Nations, Rome, Rep. FO: MISC/79/8. 1979. 65p.

NORMAN G.R.; STREINER D.L. Biostatistics. The Bare Essentials. Mosby-Year Book. 1994. 260p.

O LIBERAL. Ibama apóia monitoramento em áreas de manejo: Esta é a saída para o Brasil dominar o mercado mundial - Belém, Pará. Brasil, 07/06/2003.

OLIVEIRA, A.A. Diversidade, estrutura e dinâmica do componente arbóreo de uma floresta de terra firme de Manaus, Amazonas. São Paulo, 1997, 187p. Tese (Doutorado) - Universidade de São Paulo. 
OLIVEIRA, A.A. \& MORY, S.A. A central Amazonian terra firme Forest. I. High tree species richness on poor soils. Biodiversity and Conservation v. 8, p. 12191244. 1999.

OLIVEIRA, A.A. \& NELSON, B.W. Floristic relationships of terra firme forests in the Brazilian Amazon. Forest Ecology and Management. v. 146, p. 169-179, Jun. 2001.

OSAFO, E.D. The development of silvicultura techniques applied to natural forest in gana. Technical Note Forest Products Research Institute Ghana, v.13, p.18, 1970.

PANAYOTOU, T. \& ASHTON, P.S. Not by timber alone: economics and ecology for sustaining tropical forest. Island Press. 1992. 282p.

PARIONA, W. \& FREDERICKSEN, T.S. Regeneración de especies comerciales en claros de corta de bosques manejados en Bolivia. Boletín BOLFOR, Edición n. 21, 2000. p. 9-11.

PEÑA-CLAROS, M. Secondary forest sucession: processes affecting the regeneration of Bolivian tree species. PROMAB Scientific Series 3. 2001. 170p.

PHILliPS, O.L., HALl, P., GENTRY, A.H., SAWYER, S.A., VÁSQUEZ, R. Dynamics and species richness of tropical rain forests. Proceedings of the Mational Academy of Sciences, 91, 1994. p. 2805-2809.

PICKETT, S.T.A. \& WHITE, P.S. Patch dynamics: A syntesis. p. 371-383. In: S.T.A. PICKETT AND P.S. WHITE (Eds.). The ecology of natural disturbance and patch dynamics. Academic Press, New York. 1985. 
PINARD, M.A. \& PUTZ, F.E. Retaining forest biomass by reducing logging damage. Biotropica v. 28 (3), p. 278-295, 1996.

PINARD, M.A., BARKER, M.G., TAY, J. Soil disturbance and post-logging forest recovery on bulldozer paths in Sabah, Malaysia. Forest Ecology and Management v. 130, p. 213-225, May. 2000.

PITT, J. Relatório ao Governo do Brasil sobre aplicação de métodos silviculturais a algumas florestas da Amazônia. Belém. Superintendência do Desenvolvimento da Amazônia (SUDAM). 1969. 245p.

POORTER, L. Seeling growth of Bolivian rain Forest tree species in relation to light water availability, PROMAB, S. C. Sierra, Bolivia, 1998.195p.

POSEY, D.A. Conhecimento indígena sobre ecologia: um novo caminho para o futuro? Ciência e Cultura, vol. 35, n. 7, julho de 1983.

POSEY, D.A. O conhecimento entomológico kayapó: etnometodologia e sistema cultural. Anuário Antropológico. Brasília, Universidade de Brasília, 1982.

PRANCE, G.T. American tropical forests. In: LIETH, H. \& WERGER, M.J.A. (Ed.). Tropical rain forest ecosystems. Elsevier, The Netherlands. 1989. p. 99-132.

PRIMACK, R.B., ASHTON, P.S., CHAI, P. \& LEE, H.S. Growth rates and population structure of Moraceae trees in Sarawak, East Malaysia. Ecology v. 66 (2), p. 577-588, 1985.

PULKKI, R., BULL, G.Q., SCHWAB, O. Literature review on logging impacts in moist tropical forest. Working Paper Series FAO. 2001. 
PUTZ, F. E., The natural history of lianas on Barro Colorado Island, Panama. Ecology, v. $65,1713-1724,1984$.

RADAMBRASIL, Projeto RADAMBRASIL. Levantamento de Recursos Naturais, vol. 5, Folha AS 22 Belém: geologia, geomorfologia, solos, vegetação e uso potencial da terra. Ministério das Minas e Energia. Departamento Nacional de Produção Mineral (DNPM). Rio de Janeiro. 1974.

RAPERA, R. B. Effects of logging on residual stands. Biotropic Special Publication 1978.3: 119-125.

RICE et ai, 2001. Sustainable forest management: a review of conventional wisdom. Center for Applied Biodiversity Science/Conservation Intemational. No. 3. 2001. $29 \mathrm{p}$.

RICHARDS, P.W. The tropical rain forest. Cambridge University Press, Cambridge, UK. 1952.

SA YER, J.A.; ZUIDEMA, P.A.; RIJKS, M.A. Managing for biodiversity in humid tropical forest. Commonwealth Forestry Review. v. 71 (4): 282-287, 1995.

SCHMIDT, B.; VOLPATO, E. Aspectos silviculturais de algumas espécies nativas da Amazônia. Acta Amazônica, 2, 1972. p. 99-122.

SCHMIDT, R.C. Tropical rain forest management: a status report. Unasylva. v. 39 (2), p. $2-17,1987$.

SCHNEIDER, R. R.; ARIMA, E.; VERÍSSIMO, A.; BARRETO, P.; SOUZA JR., C. Amazônia sustentável: limitantes e oportunidades para o desenvolvimento rural. Brasília: Banco Mundial e Imazon. 2000. 58 p. 
SILVA, E.J.V. Impactos da exploração madeireira predatória e com manejo florestal sobre o crescimento e diversidade de espécies arbóreas na Amazônia Oriental. Piracicaba, 1998, 83p. Dissertação (Mestrado) - Escola Superior de Agricultura "Luiz de Queiroz", Universidade de São Paulo.

SILVA, J. N. M. Manejo de florestas tropicais: o caso da Amazônia brasileira .. In: $1^{0}$ SIMPÓSIO LATINO-AMERICANO SOBRE MANEJO FLORESTAL. Santa Maria/RS, CCRJUFSM, 09-10 Nov. 2000, ANAIS. p. 15-28.

SILVA, J.N.M. 1989. The behaviour of the tropical rain Forest of the brazilian Amazon after logging. Oxford, 1989. Thesis (Ph.D.) - University of Oxford.

SILVA, J.N.M. A note on Brazils tropical rain forests under new Forest management regulations. Journal oftropical Science. v. 4(4), p. 355-356,1992.

SILVA, J.N.M; CARVALHO, J.O.P.; LOPES, J. DO C.X., OLIVEIRA, R.P.K.; OLIVEIRA, L.c. Growth and yield studies in the Tapajós region, Central Brazilian Amazon. Commonwealth Forestry Review, v. 75 (4), p.325-329, 1996.

SILVA, J.N.M; CARVALHO, J.O.P.; LOPES, r.C., CARVALHO, M.S.P. Equação de volume para a Floresta Nacional do Tapajós. Boletim de Pesquisa Florestal, n. 89.1984.p.50-63.

SILVA, J.N.M; DE CARVALHO, J.O.P.; LOPES, J. DO C.X., ALMEIDA, B.F.; COSTA, D.H.M.; OLIVEIRA, t.c., VANCLAY, J.K.; SKOVSGAARD, J. P. Growth and yield of a tropical rain forest in the brazilian Amazon 13 years after logging. Forest Ecology and management, v.71, n.3, p.267-274, Feb. 1995. 
SIST, P. \& NGUYEN-THÉ. Logging damage and the subsequent dynamics of a dipterocarp forest in East Kalimantan (1990-1996). Forest ecology and management. v. 165, p. 85-103, lu\. 2002.

SIST, P. Why RIL won't work by minimum-diameter cutting alone. Tropical Forest Update, 2001.11 (20): 5.

SIST, P. FIMBEL, R., SHEIL, D., NASI, R., CHEV ALLIER, M. Towards sustainable management of mixed dipetrocarp forest of South-east Asia: moving beyong minimum diameter cutting limits. Environmental Conservation, v. 30 (4), p. $364-374,2003^{\mathrm{a}}$.

SIST, P.; SHEIL, D.; KARTAWINATA, K.; PRIYADI, H. Reduced-impact logging in Indonesian Borneo: some results confirming the need for new silvicultural prescriptions. Forest ecology and management. v. 179, p. 415-427, Jul. $2003^{\text {b }}$.

SKORUPA, l.P. The effects of selective timber harvesting on rain forest primates in KibaIe Forest. U ganda. 1988. Thesis (Ph.D.). University of California.

SMERALDI, R. \& VERÍSSIMO, A. Acertando o alvo: consumo de madeira no mercado interno brasileiro e promoção da certificação florestal. Amigos da Terra, Imaflora e Imazon. São Paulo. 1999.4 t p.

SOBRAL, L., VERÍSSIMO, A., LIMA, E., AZEVEDO, T. \& SMERALDI, R. Acertando o Alvo 2: Consumo de madeira amazônica e certificação florestal no Estado de São Paulo. Belém: Imazon. 2002. 72p. 
SOKPON, N. \& BIAOU, S.H. The use diameter distributions in sustained-use management of remnant forests in Benin: case of Bassila forest reserve in North Benin. Forest ecology and management. v. 161, p. 13-25, May. 2002.

SOKAL, R.R. and ROHLF, F.I. Biometry: The principIes and practice os statistics in biological research. W.H. Freeman and Company, New York. 1981. 850p.

SOMMER, A. Attempt at assessment of the world's tropical moist forest. Unasylva v. 28 (112-113), 5-24, 1976.

SPIES, T.A \& FRANKLIN, I.F. Gap characteristics and vegetation response m coniferous forests ofthe Pacific Northwest. Ecology. v. 70, p. $543-545,1989$.

STEVENS, G. C. Lianas as structural parasites: the Bursera simaruba example. Ecology, v. 68: 77-81, 1987.

STOKES, BJ.; HIGUCHI, N.; HUMMEL, A.C.; DE FREITAS, r.V. \& MALINVOSKI, I.R. Harvesting in the Várzea forests of the Brazilian Amazon. In: Proceedings of the FAO/IUFRO Satellite Meeting held in conjunction with the IUFRO XX

World Congress, Tampere, Finland, 4-5 August, 1995, Research on Environmentally Sound Forest Practices to Sustain Tropical 
Forest. Food and

Agricultural Organization of the United Nations. 1997. p.47-56.

SW AINE, M.D. \& LIEBERMAN, D. Note on the caIculation of mortality rates. Journal of tropical ecology, v.83, p. 331-333, 1987.

SWAINE, M.D; HALL, l.B.; ALEXANDER, I.J. Tree population dynamics at kade, Ghana (1968-1982). Journal Tropical Ecology. v. 3, 33] -345, 1987. 
SYNNOTT, T.J. Tropical rainforest silvicultura: a research Project report. C.F.I.

Occasional Papers, Commonwealth Forestry Institute, University of Oxford. 1976. No. 10.45 pp.

T ABARELLI, M. \& MANTOV ANI, W. Gap-phase regeneration i n tropical montane forest: the effects of gap structure and bamboo species. Plant Ecology v. 148, p. 149-155, 2000.

TANG, H. T. Problens and strategies for regenerating dipterocarp forest in Malaysia. ln:

i F. Mergen and J. Vincent (eds.), Natural Management of Tropical Moist Forest: Silvicultural and Management Prospects of Sustained Utilization. New Haven, CT, USA, Yale University School of Forestry and Environmental Studies. 1987.

TAYLOR, D.M.; HAMILTON, X.C., WHYATT, J.D.; MUCUNGUZI, P.; BUKENYAZIRABA, R. Stand dynamics in Mpanga Research forest reserve, Uganda, 19681993. Journal Tropical Ecology. v. 12,583-597,1996.

TER STEEG, H.; et al. Ecology and logging in a Tropical Rain Forest in Guyana: with recommendations for forest management. The Tropenbos Foundation, Wagenigen, The Netherlands, Tropenbos Series 14. 1996. 123p.

THE ECONOMIST. How to save the rainforest. New York, p 11-13, may 2001.

THOMPSON, J., PROCTOR, J., VIANA, V. MILIKEN, W, RATTER, J.A. E SCOTT, D.A. Ecological studies on a lowland evergreen rain Forest on Maracá Island, Roraima, Brazil. Journal ofEcology. v. 80,689-703,1992.

UHL, C. \& MURPHY, P.G. Composition, structure, e regeneration of a tierra-firme in the Amazon basin of Venezuela. Tropical Ecology. v.22 n. 2 p. 219-237, ] 981. 
UHL, C. \& VIEIRA, LC.G. Ecological impacts of selective logging in the Brazilian Amazon: a case study from the Paragominas region of the State of Para. Biotropica v. 21 (2), p. 98-106, 1989.

UHL, C., BARRETO, P.; VERÍSSIMO, A; BARROS, A C.. AMARAL, P.; VIDAL, E.; SOUZA Jr., C. Natural resource management in the brazilian Amazon: an integrated research approach. BioScience, v.47, n.3, p.160-199, 1997.

UHL, C.; CLARK, K.; MAQUIRINO, P. Vegetation dynamics in Amazonian treefall / gaps. Ecology. v. 69, 751-763,1988.

UHL, C., VERÍSSIMO, A; MATTOS, M.; BRANDINO, Z.; VIEIRA, L Social economic, and ecological consequences of logging in an Amazon frontier: the case of Tailândia. Forest Ecology and Management v. 46, p.243-273, Dec. 1991.

VALENCIA, R. BALSLEV, H. \& PAZ Y MINO, G.c. High tree alpha-diversity in Amazonian Ecuador. Biodiversity and Conservation. v. 3, p. 21-28, 1994.

Van STEENIS, C.C.G.J. De biologische nomaden theorie. Vakblad voor biologen. 1956. 36: $165-172$.

VANCLAY, J. Growth models for tropical forest: a synthesis of models and methods. Forest Science. v. 41, n. 1, p. 7-42,1995.

VANCLAY, J. Modelling Forest growth and yield: application to mixed tropical forests. Wallinford: CAB International, 1994. 312p.

VERÍSSIMO, A \& AMARAL, P. A exploração madeireira na Amazônia: situação atual e perspectivas, Fase: Cadernos de Propostas, ano 3, 1996. p. 9-16. 
VERÍSSIMO, A. \& AMARAL, P. Forestry in the Amazon: current situation and prospects. In: LEIHNER, D.E.; MITSCHEIN, T.A. (Ed.) A third millennium for humanity? The search for paths of sustainable development. Frankfurt: Peter Lang, 1998. p.265-276.

VERÍSSIMO, A.; BARRETO, P.; MATIOS, M.; TARIFA, R.; UHL, C. Logging impacts and prospects for sustainable forest management in an old Amazonian frontier: the case of Paragominas. Forest Ecology and Management, v. 55, p. 169-199, Dec. 1992.

VIANA, V. As florestas brasileiras e os desafios do desenvolvimento sustentável: manejo, certificação e políticas públicas associadas. Piracicaba, 2002, 163p. Tese (Livre Docência) - Escola Superior de Agricultura "Luiz de Queiroz", Universidade de São Paulo.

VIANA, V. M. Seed dispersal and gap regeneration: the case of three Amazonian tree species. Tese de Doutorado, Harvard University. Cambridge, 1989.270 p.

VIANA, V. M. Seed dispersal and gap regeneration: the case of three Amazonian tree species. Cambridge, 1989.270 p. Tese (Ph.D.) - Harvard University.

VIANA, V.M. et alo Instrumentos para o manejo florestal sustentável do setor florestal privado no Brasil: uma análise das oportunidades para o manejo de florestas naturais e plantações florestais de pequenas escala. Série Instrumentos para um Setor Florestal Privado Sustentável, International Institute for Environment and Development, Londres. 2002. 90p.

VIDAL, E.; BARRETO, P.; JOHNS, J.; GERWING, J.; UHL, C. Vine management for reduced-impacts logging m Eastern Amazon. Forest Ecology and Management, v. 98, p.105-114, Nov. 1997. 
VIDAL, E.; VIANA, V.; BATISTA, J.L.F. Efeitos da exploração madeireira predatória e manejada sobre a diversidade de espécies na Amazônia Oriental. Árvore v. 4 (22), p. 503-520, 1998.

VIDAL, E.; VIANA, V.; J. F. L. BATISTA. Crescimento de floresta tropical três anos após colheita de madeira com e sem manejo florestal na Amazônia oriental. Scientia Forestales. v. 6, p. 133-143, Jun. 2002.

VIEIRA, G. \& HIGUCHI, N. Efeito do tamanho da clareira na regeneração natural em floresta mecanicamente explorada na Amazônia brasileira. In: $6^{\circ}$ Congresso Florestal Brasileiro, Campos do Jordão, São Paulo, 22 a 27 de setembro, 1990, Anais. Campos do Jordão, Brasil.

VIEIRA, G. Gaps dynamics in managed Amazonian forest: structural and ecophysiological aspectos. Oxford, 1996. Thesis (PhD), University of Oxford.

VIEIRA, S.A. Mudanças globais e taxa de crescimento arbóreo na Amazônia. Piracicaba. 2003. 133 p. Tese (Doutorado). Centro de Energia Nuclear na Agricultura - Universidade de São Paulo.

VOLPATO, E. et al. The condition of experimental plantings in the Ducke Forest Reserve. Twelve native species of Amazonian in enrichment plantings. Acta Amazônica, v. 3, p. 71-82, 1973.

WADSWORTH, F.H. Natural forest in the development of the humid American tropics. Paper n. 8 in: Proccedings of the Conference on the Use of Ecological Guidelines for Development in the Humid American Tropics, Caracas. IUCN, Morges. 1974. 
WADSWORTH, F.H. Applicability of Asian and African silviculture systems to naturally forest of the neotropics. In: F. MEGEN \& J.F.VINCENT (eds.). Natural management of tropical moist forests: Silvicultural an management prospects of sustained utilization. Yale University Press. New Haven. 1987. p. 94-111.

WADSWORTH, F.H. Forest production for tropical America. USDA Forest Service, Agriculture Handbook 710. Washington DC, E.U. 1997. 563 p.

WATT, A.S. On the ecology of the Britissh beechwoods with special reference to their regeneration. Part I and II. Journal of ecology. v. 11, 1-48, 1923.

WHIGHAM, D. The influence of vines on the growth of Liquiambar straciflua L. (sweetgum). Canadian Journal of Forest Researsh. v. 14, 37-39, 1984.

WHITMORE, T.C. Tropical forest disturbance, disappearance, and species loss. In: Tropical forest remnants: ecology, management and conservation of fragmented communities, W.F Laurance \& R.O. Bierregaard (Eds). Chicago Press, 1997. p. 3-12.

WHITMORE, T.C. Tropical rain forest of the Far East. Clarendon. Oxford. 1984.

WHITMORE, T.C. Canopy gaps and two major groups of forest trees. Ecology, Durham, v. 70 (3), 356-358, 1989. 